\title{
The integration of CSR-related strategies into firms' decision making
}

Citation for published version (APA):

Yang, L. (2018). The integration of CSR-related strategies into firms' decision making. [Doctoral Thesis, Maastricht University]. Datawyse / Universitaire Pers Maastricht. https://doi.org/10.26481/dis.20181114ly

Document status and date:

Published: 01/01/2018

DOI:

10.26481/dis.20181114ly

Document Version:

Publisher's PDF, also known as Version of record

\section{Please check the document version of this publication:}

- A submitted manuscript is the version of the article upon submission and before peer-review. There can be important differences between the submitted version and the official published version of record.

People interested in the research are advised to contact the author for the final version of the publication, or visit the DOI to the publisher's website.

- The final author version and the galley proof are versions of the publication after peer review.

- The final published version features the final layout of the paper including the volume, issue and page numbers.

Link to publication

\footnotetext{
General rights rights.

- You may freely distribute the URL identifying the publication in the public portal. please follow below link for the End User Agreement:

www.umlib.nl/taverne-license

Take down policy

If you believe that this document breaches copyright please contact us at:

repository@maastrichtuniversity.nl

providing details and we will investigate your claim.
}

Copyright and moral rights for the publications made accessible in the public portal are retained by the authors and/or other copyright owners and it is a condition of accessing publications that users recognise and abide by the legal requirements associated with these

- Users may download and print one copy of any publication from the public portal for the purpose of private study or research.

- You may not further distribute the material or use it for any profit-making activity or commercial gain

If the publication is distributed under the terms of Article $25 \mathrm{fa}$ of the Dutch Copyright Act, indicated by the "Taverne" license above, 
The Integration of CSR-related Strategies into Firms'

Decision Making

Lu Yang 
(C) copyright Lu Yang, Maastricht 2018

Printing: Datawyse | Universitaire Pers Maastricht

ISBN 978-94-6380-060-0 


\title{
The Integration of CSR-related Strategies into Firms'
}

\section{Decision Making}

\author{
DISSERTATION
}

to obtain the degree of Doctor at the Maastricht University, on the authority of the Rector Magnificus, Prof.dr. Rianne M. Letschert in accordance with the decision of the Board of Deans, to be defended in public on Wednesday, 14th November, 2018, at 12 p.m. hours

by

Lu Yang 


\section{Supervisor:}

Prof. Dr. Frank Moers

\section{Co-supervisor(s):}

Prof. Dr. Isabella Grabner (WU Vienna, Austria)

Dr. Annelies Renders

\section{Assessment Committee:}

Prof. Dr. Stefanie Kleimeier (Chair)

Prof. Dr. Eddy Cardinaels (Tilburg University)

Prof. Dr. Peter Sampers

Prof. Dr. Naomi Soderstrom (University of Melbourne, Australia) 


\section{Acknowledgements}

Pursuing a Ph.D. has been one of the most important decisions I have ever made. This journey, or virtually an adventure, turned out to be a challenging, exciting, and fruitful experience. While the experience is full of ups and downs, sometimes frustrating and stressful, those great people around me make me feel confident about my choice in the end. I am very delighted to take this opportunity to express my gratitude to them.

First and foremost, I would like to express my deep gratefulness to my supervision team - Prof. Frank Moers, Prof. Isabella Grabner, and Dr. Annelies Renders - for their critical feedback on my dissertation and invaluable supports throughout my Ph.D. program. Frank, thank you for giving me the opportunity to pursue a Ph.D. at Maastricht University. I feel very lucky to have you as my promoter as you were always willing to guide me whenever I encountered difficulties. Your questions were often challenging, but they inspired me to think broadly when I came up with research ideas. Your viewpoints were often sharp, but they inspired me to think deeper from the perspectives of economic reasoning. Your motivating feedback and your extreme research enthusiasm not only encouraged me to be persistent on my own research, but also taught me to enjoy the process of doing research. After work, you were always happy to join our parties, drinks, and telling jokes with us, making me realize the equal importance of enjoying life. Frank, you pushed me much further on my way as a researcher than I can be on my own. Isabella, it is so wonderful to have you as my supervisor! Although you are very busy, you were always willing to spend a lot of time not only on our joint project but also on helping me with my other papers. I never felt alone as you always came to me. You understood my feelings and you shared your own experience with me. All these made me encouraged and brave to meet challenges. I am deeply indebted to your critical insights and have been greatly infected by your passion for research. Annelies, you are always so patient whenever I came to your office with a question to ask. After our discussion, I felt inspired and full of energy to continue with next steps. I was deeply impressed by your insightful feedbacks! Your excellent guidance made a substantial influence on my professional development. Frank, Isabella, and Annelies, I am so happy to have you all as my supervision team! Your guidance and your company undoubtfully became the most precious treasure all along my way. Without your involvement and support, my dissertation cannot be in its final stage. I would also like to express my great gratitude to all of you for spending so much time in helping me on the job market-reviewing my package, attending my mock seminars, and getting me prepared for interviews. I cannot be that confident without your enormous supports and encouragements!

My deep gratitude also goes to the assessment committee members of my dissertation - Prof. Stephanie Kleimeier (Chair), Prof. Eddy Cardinaels, Prof. Peter Sampers, and Prof. Naomi Soderstrom - for their crystal comments and feedback. They raised many insightful comments about my dissertation. Although challenging to address, they prompted me to think much in depth about my research. Stephanie not only gave comments on my individual chapters, but her thought regarding the overall picture of my research inspired me a lot. Peter has also given me constructive comments not only on my chapters but also during my 
seminars. Eddy, it was your interesting research that attracted and inspired me initially to pursue a Ph.D. in management accounting. You not only gave me feedback on my dissertation but were also willing to provide your thoughts on my other projects and supported me during my job market. Naomi, I actually spent one entire year with you at the same place during my four-year Ph.D. study. I have learned a lot from your CSR-related studies and finally became confident about my research in this area. Thank you for your valuable feedback on my research, your support for my job market, and taking care of me when I was visiting Melbourne.

My deep thankfulness also goes to Prof. Margaret Abernethy, who invited me to visit the Department of Accounting at the University of Melbourne as a visiting Ph.D. student. Maggie, thank you for sharing your wisdom on research with me, giving me feedbacks on my papers, and providing me the great opportunity to present my work in the department. It was your passion to impact the society with high-quality accounting research that changed my understanding of the field and encouraged me to push my research forward. In addition, the visiting experience in Melbourne turned out to be very fruitful that Dr. Bo Qin and I developed a joint project during that period. Bo, I was deeply impressed by your quick responses and insightful opinions! Also, I would like to thank Flora, Chung-Yu, Xue, Like, Gladyse, Hrishikesh, Sabutay, James, Chris, Kerui, Ajanee, Yan, and Ruidi for their warm welcome and hospitality. I also would like to thank Prof. Tom Groot for providing me the Limperg scholarship to support my visit overseas. The research in this dissertation was funded in part by the National Natural Science Foundation of China (Grant No. 71702094).

Further, I want to thank my colleagues at the Department of Accounting and Information Management at Maastricht for the homey and supportive environment. Christoph, thank you for providing me detailed feedbacks on my papers, job market preparation, and sharing your experience with me. Caren, thank you for bringing delicious snacks from Japan, sharing your humour with us and telling interesting travel stories. Mathijs and Kathijn, thank you for always encouraging me and getting me prepared for interviews. Ann, thank you for all your support along my $\mathrm{PhD}$ years and my job market. Oscar, thank you for being my paranymph. All of them, and also many others like Alex, Anant, Banu, Judith, Lars and Lars, and Patrick, made my four years in Maastricht an unforgettable experience. My dearest Maastricht colleagues, I enjoyed all the wonderful moments we spent together during and after work. All these made Maastricht almost my second hometown in my life. Tanja, thank you very much for helping me deal with all the administrative issues. Your patience and great support made my life in Maastricht efficient and smooth!

My office girls, it was wonderful to have you as my officemates. Although I am not a coffee person, I always enjoyed our time at the coffee-lovers. Lei, thank you for inviting me to your place to celebrate our traditional Chinese festivals, to enjoy your great Chinses cuisine, and to share all the happiness and stress of our studies in our mother tongue. All these made me feel at home. Britt, thank you for preparing the delicious Indonesian food and the fun parties! Also, thank you for translating the letters written in Dutch for me, which made my life much easier. Olga, how can I forget the Boom-Shakalaka moments in our office! 
Ulrike, your enthusiasm for research encouraged me when I have downs in my Ph.D. study. Raginee, I cannot tell how much your optimistic attitude influenced me, but every time I came to you with a problem, you gave me very good suggestions. I enjoyed the time with you when we were in Puerto Rico, surprised by your swimming talent! Also, thank you for being my paranymph! Girls, thank you for your wedding gifts, thank you for your good-bye gifts, thank you for encouraging me during my job market. It was your smile, your humour, and your warmest encouragements supported me during my stressful time.

I would also like to thank Prof. Jan Bowens, Dr. Bart Dierynck, Prof. Laurence van Lent, Prof. Jeroen Suijs, Dr. Huaxiang Yin, and Dr. Yachang Zeng for their invaluable help and guidance when I was doing the master programs at Tilburg University. Without the experience in Tilburg, I would not have the opportunity and passion to pursue a Ph.D. in accounting. Also, Jingwen, Jizhang, Ming, Nan, Runliang, Shusen, and Wenjiao, we have more or less overlap years during PhD time. Thank you for sharing your experience with me. I enjoyed those great moments we spent when we were studying, celebrating Chinese festivals or we were participating in conferences together.

Last but not the least, I would like to express my love and the deepest thanks to my family. I am extremely grateful for my parents' enormous support and endless love! Although they may not understand my research, they always stand on my side and encourage me to pursue my dream. Despite I am their only child, they never complained about my absence of the traditional Chinese family-reunion days. Mom and Dad, you gave me immense courage and strength. I am so proud to be your daughter! To my husband, Zhengyu. It is hard to find a starting word to express my gratefulness to you. When we were married, we had already spent two years in a long-distance relationship. Even so, you conquered many hurdles to come to visit me, no matter Maastricht or Melbourne. Your understanding of my choices, and your sense of humour to cheer me up, made my life full of colours! I wouldn't be able to achieve what I have achieved so far without you.

Life is a journey full of ups and downs. But those people around you make your journey a beautiful scenery. Thank you all!

Lu Yang

Melbourne, 07 October 2018 



\section{Table of content}

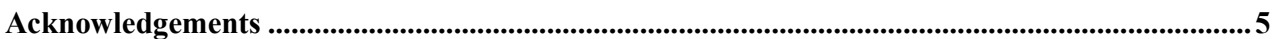

Chapter 1 Introduction................................................................................................................................... 13

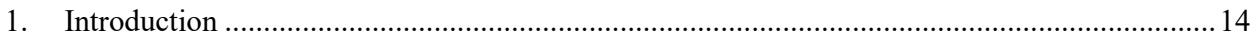

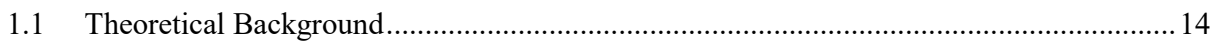

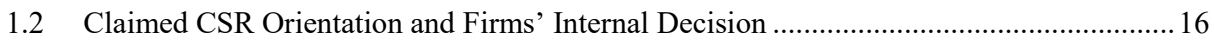

1.3 Interplay of CSR Incentives and CSR Disclosure Decisions.............................................. 16

1.4 CSR Performance Measures and Director Experience ........................................................ 17

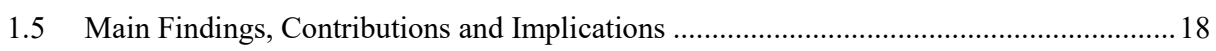

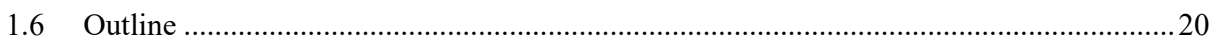

Chapter 2 Do CSR firms "walk their talk"? An analysis of firing decisions of US firms .............21

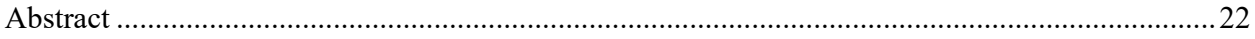

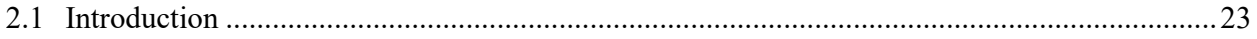

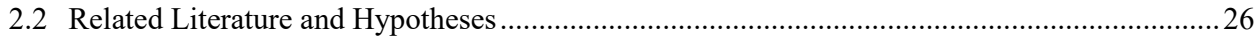

2.2.1 Corporate Social Responsibility and Word-Deed Alignment .............................................26

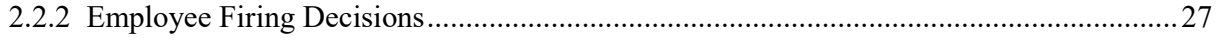

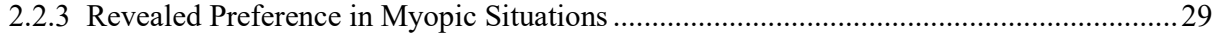

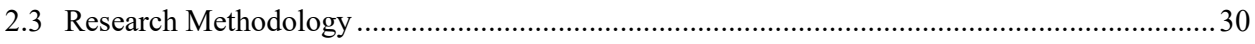

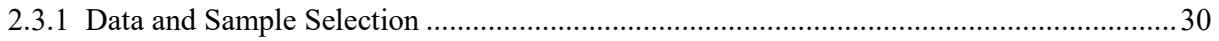

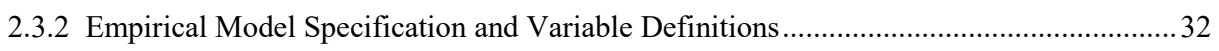

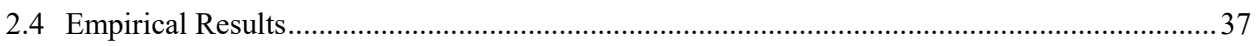

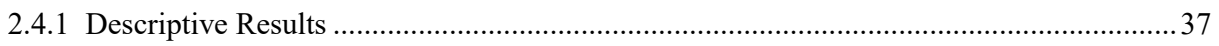

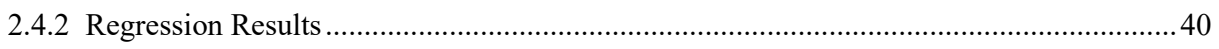

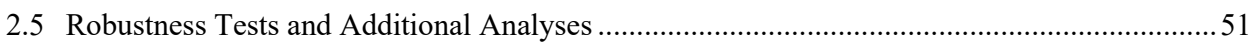

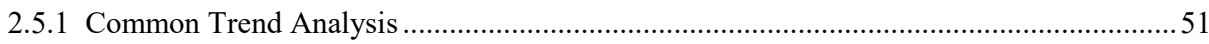

2.5.2 Firms with non-Negative and Negative KLD Ratings ..................................................... 51

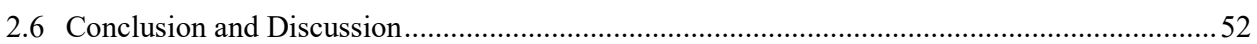


Chapter 3 The Complementarity between CSR Disclosures and the Use of CSR-based Performance Measures in CEO Annual Contracts..........................................................................55

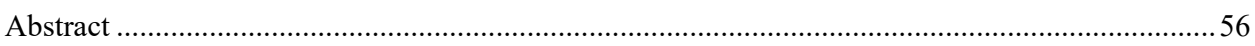

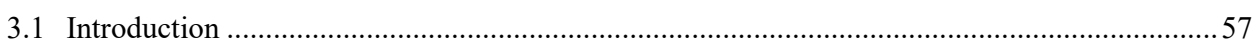

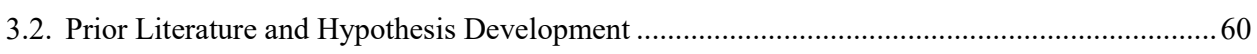

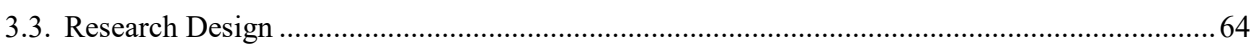

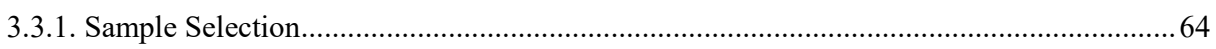

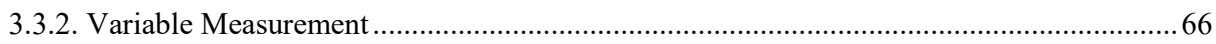



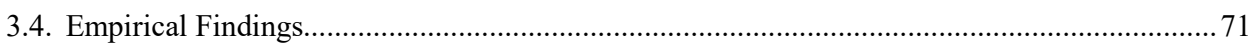

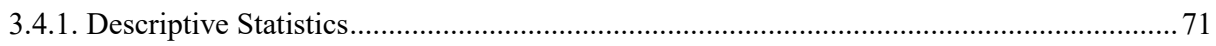

3.4.2. Complementarity between CSR Disclosures and CSR Contracting (H1).......................... 74

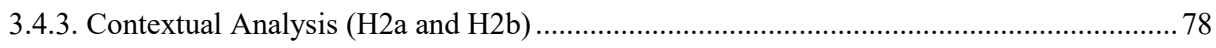



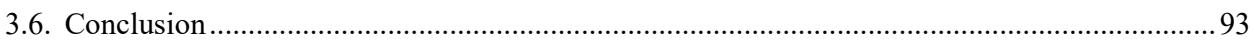

Chapter 4 Adopting CSR Performance Measures into Executives' Compensation Contracts:

Does Board Experience Matter?.................................................................................................................95

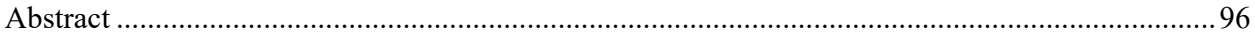

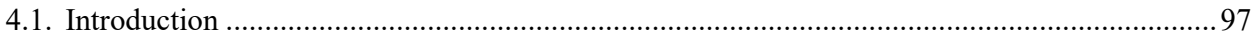

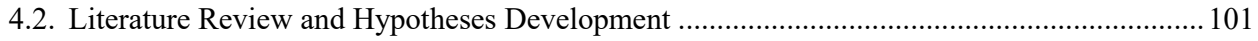

4.2.1. Prior Literature on Tying CSR to Executive Compensation Contracts ............................ 101

4.2.2. Uncertainties of CSR Performance Measures in Executives' Contracts............................. 102

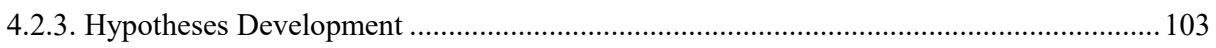

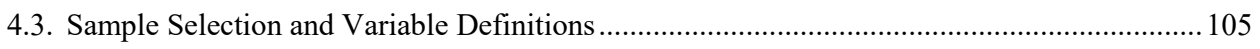

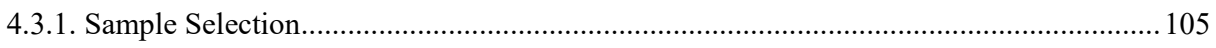

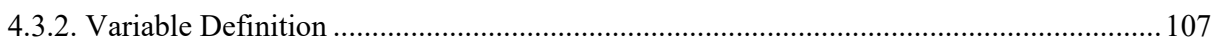

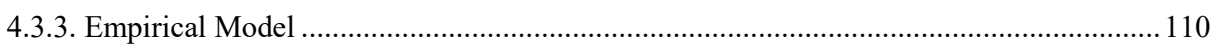

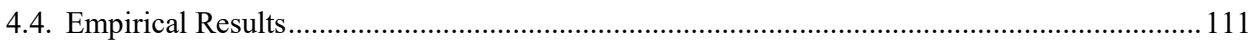

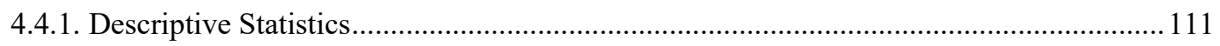

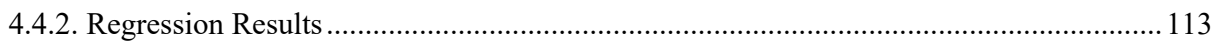



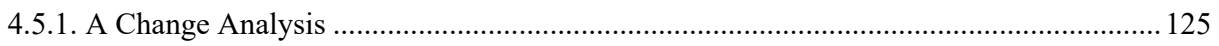





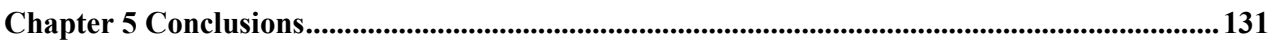




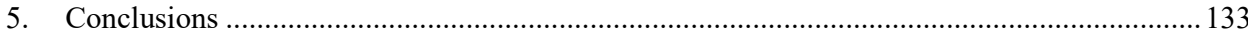

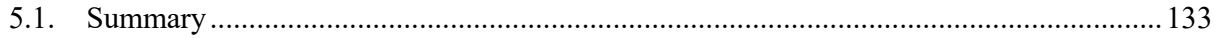

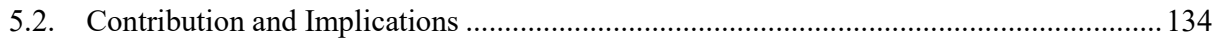

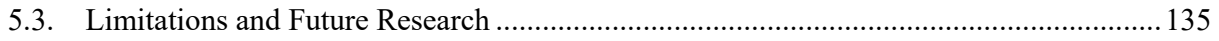

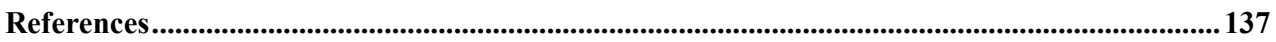

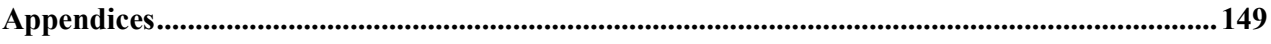

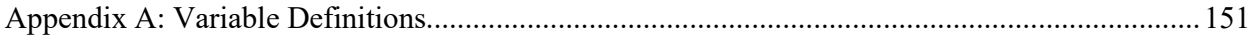

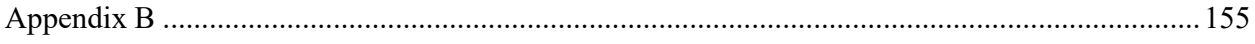

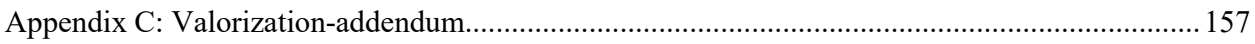



Chapter 1

Introduction 


\section{Introduction}

Since the release of the Brundtland Commission report in 1987, sustainable business has become an important issue that is associated with various initiatives, such as environmental disposal of wastes, restriction of the use of child labor, and the emphasis on welfare creation for wide stakeholders (Simnett et al. 2009). Investors also have started to realize the important connections between firms' implementation of responsible conducts, the wellbeing of the community and the development of the whole society. As a consequence, in contrast to exclusively focusing on shareholder value maximization, firms are stimulated to incorporate concerns about environmental and social issues when making decisions, and investors are willing to pay a premium for firms' corporate social responsibility (CSR) engagement (Anderson and Frankel 1980; Dhaliwal et al. 2011; KPMG 2013; Cheng et al. 2014). In line with the increasing emphasis on CSR issues around the world, firms have become more active in communicating their sustainable strategy through media, announcements on firm websites, and public reports. In 2008 alone, nearly 80 percent of the largest 250 firms worldwide issued sustainability reports (KPMG 2011).

Despite the substantial time and effort that firms exert to show their CSR orientation, stakeholders outside a firm often have difficulties in understanding CSR-related strategies. One frequently raised critique by investors is that CSR-strategies are symbolic. Due to the lack of generally accepted CSR reporting rules and the absence of adequate monitoring and verification mechanisms of CSR disclosures, CSR cheap talk is not unlikely (Gray et al. 1995; Laufer 2003; Simnett et al. 2009; Eccles and Krzus 2010; KPMG 2011; Casey and Grenier 2014). CSR is therefore frequently criticized for being a marketing tool rather than deeply rooted in firms' internal decision-making practices.

In this dissertation, I aim to contribute to our understanding of firms' CSR initiatives by addressing two main issues: First, whether CSR is integrated into firms' decisions; and second, how firms increase the credibility of CSR-related strategies. I execute three studies, in which I empirically investigate (1) the consistency of firms' words-deeds alignment by analysing the relation between CSR disclosures and firms' dismissal decisions; (2) the interdependence between CSR disclosures and the use of CSR-based performance measures in CEO annual incentive contracts; and (3) how firms incorporate CSR-based performance measures into CEO annual incentive contracts.

\subsection{Theoretical Background}

Despite the debate of how to conceptualize CSR in the literature, there is consensus about the distinctive characteristics of CSR. Specifically, CSR can be characterized as (1) voluntary behavior of the firm that is (2) focused on maximizing long-run shareholder wealth by (3) refraining from activities that increase short-run shareholder wealth at the expense of the long-run interests of one or more stakeholder groups (Kitzmueller and Shimshack 2012). In line with this definition, Van Marrewijk (2003) suggests that CSR refers to firms' voluntary activities demonstrating the inclusion of social and environmental concerns in business and in the interaction of stakeholders. 
As the importance of issues related to CSR is growing, an increasing number of firms are considering different ways to communicate their CSR-related strategies, for instance, the issuance of CSR reports or the incorporation of CSR-related factors in their performance measurement systems. Through the implementation of CSR strategies, firms are expected to create a good social reputation, increase institutional legitimacy, gain acceptance from different stakeholder groups, and achieve better performance in the long run (Husted and Allen 2000). However, due to the inadequacy of monitoring as well as the lack of uniform criteria to verify CSR actions, firms' disclosed CSR activities are often accused as symbolic. As Gray (2001) writes, "the quality of attestation to social and environmental reports is poor". Similarly, Lydenberg (2002) finds that few firms that publish CSR reports address the full range of relevant CSR issues.

In contrast to CSR being simply viewed as a marketing strategy, firms are encouraged by various stakeholders to improve the internal coherence of CSR practices. Here the term "internal coherence" means that firms are expected to (1) incorporate the announced CSR strategies into their internal business operations, and (2) achieve an alignment with respect to different levels of CSR-related decisions (Yuan, Bao and Verbeke 2011). In line with the concept of internal coherence regarding CSR strategies, Basu and Palazzo (2008) propose that CSR initiatives appear to be dependent on two aspects of consistency, one of which is the consistency between an organization's overall strategy and CSR. It addresses what constitutes appropriate CSR, given the organization's goals and strategic direction. For instance, an organization could act consistently by embedding CSR both in its external conversations and internal processes. Alternatively, CSR disclosures might be prepared simply to respond to pressures from stakeholders while not being aligned with internal CSR decisions. The other aspect of consistency is the consistency within the variety of CSR choices implemented in a firm during a given period of time. It addresses the willingness among managers to regard proposed CSR choices as a whole package to achieve specific aims. Internal inconsistency, in contrast, demonstrates a propensity to treat CSR-related decisions arbitrarily without a coherent framework, which can lead to conflicts and ultimately weakens the credibility and the effectiveness of CSR initiative outcomes (Sethi 1975; Weaver et al. 1999). Despite the discussions in literature, many firms still view CSR strategies as being isolated from daily business practices.

For CSR to be efficiently promoted, scholars argue that it is necessary to have an incentive system to reward executives' efforts on CSR dimensions (Berrone and GomezMejia 2009b). According to the principal-agent theory, a principal hires an agent to work in the best interest of the principal. As the agent is effort-averse, the principal often needs some mechanisms to guarantee that the agent works in the direction desired by the principal (e.g. Hölmstrom 1979; Hölmstrom and Milgrom 1991; Fama and Jensen 1983; Feltham and Xie 1994; Banker and Datar 1989). As good CSR performance may take long time to materialize, which increases uncertainty about the outcomes of doing CSR, the agent may allocate resources to more conservative investments to avoid these uncertainties. Incorporating appropriate CSR-related performance measures in executives' incentive contracts can not only motivate the executives to work on CSR dimensions, but can also lower the risks imposed on executives when the executives undertake CSR activities. 


\subsection{Claimed CSR Orientation and Firms' Internal Decision}

As mentioned above, although an increasing number of firms are claiming to act socially responsible, due to the lack of uniform criteria and insufficient monitoring mechanisms, their claimed CSR orientation is often questioned by investors and scholars. In addition, there is a considerable variation in claimed commitment to CSR across firms (Cho and Patten 2007; Clarkson et al. 2008; KPMG International 2013). For outsiders, it is very difficult to understand whether firms practice what they preach regarding their claimed CSR orientation.

In my first study, I investigate whether the variation in firms' claimed CSR orientation is associated with variation in internal business decisions. Specifically, I examine whether firms with a stronger claimed CSR orientation fire fewer employees in response to short-term activity decreases. I use a firm's decision to fire employees when sales decrease as a proxy for internal CSR practices. As employees are often considered as the most important stakeholder of the firm, the way in which the firm treats its employees is thus an important signal of the firm's internal CSR practices (Pfeffer 2010; Shen and Benson 2016). To proxy for the claimed CSR commitment of the firm, I take advantage of the KLD database. The main argument is that the KLD ratings are based on observable CSR disclosures such as CSR reports, CSR-related surveys and interviews that can be easily manipulated by firms at low cost (Edmans 2011). Thus, the KLD ratings are viewed more as a reflection of the claimed CSR orientation of the principals of firms rather than the true CSR practices (Sharfman 1996).

Further, I investigate situations in which firms are more likely to reveal their true underlying preferences with regard to CSR. Prior literature suggests that when facing incentives to meet earnings benchmarks, managers are more eager for economic benefits compared to a normal sales change (Kama and Weiss 2013). Failure to meet earnings targets can lead to negative consequences such as violating debt covenants, or breaking a smooth earnings growth pattern (Baber et al. 1991; Dechow and Sloan 1991; Burgstahler and Dichew 1997; Degeorge et al. 1999; Roychowdhury 2006; Rees and Sivaramakrishnan 2007). Therefore, firms' preferences for economic benefits or for CSR orientation are better revealed by observing their firing decisions when firms are under pressure to meet earnings targets. Accordingly, my second research question in this study is whether the differences of employee dismissal between firms with higher and lower claimed CSR orientation are amplified when firms are pressured to meet or beat earnings benchmarks.

\section{I.3 Interplay of CSR Incentives and CSR Disclosure Decisions}

My second study empirically investigates the relationship between the use of CSR-based performance measures in CEO annual incentive contracts (henceforth, CSR contracting) and CSR disclosures. CSR has become increasingly popular in recent decades. In addition to maximizing shareholder wealth, firms are expected to take the needs of various stakeholders into account in their business decisions. In response to this, firms are using different ways to communicate their CSR engagement (KPMG 2013). One way of doing so is by issuing CSR reports. Through the issuance of CSR reports, firms can explain their CSR strategy to outside stakeholders and thus meet their information demands (Dhaliwal et al. 2011). Alternatively, 
firms can also show their CSR commitment by integrating CSR-based performance measures in senior executives' incentive contracts. Despite that the two practices have attracted growing attention from investors and stakeholders, the interplay between CSR disclosures and CSR contracting is not yet fully understood as prior research mainly examines the two choices separately. As suggested by Baso and Palazza (2008), failure to recognize patterns of interrelationships of CSR-related choices might lead to an incomplete understanding of a firms' CSR impact.

In my second study, I draw on complementarity theory and argue that the use of CSR contracting complements CSR disclosures. I not only examine the relationship between the presence and absence of these two mechanisms, but also the intensity of CSR disclosure and CSR contracting. Specifically, I manually collect the number of dimensions of performance measures used in CEO contracts as well as the disclosure intensity of CSR reports, and investigate whether more intensive use of CSR contracting complements more intensive disclosures. I further argue that the relationship might not be uniform, but dependent on specific firm-contexts. Therefore, in a second step, I examine how the association between the two choices varies with specific firm-contexts.

\subsection{CSR Performance Measures and Director Experience}

My third study explores firms' motivations to adopt CSR-based performance measures by investigating whether they incorporate decision-relevant information when making this choice. In the most recent decade, an increasing number of firms start to adopt CSR-based performance measures in their executive contracts. While this practice becomes prevalent, whether the adoption reflects a substantial commitment or merely a symbolic attempt remains unanswered by the literature (Berrone and Gomez-Mejia 2009b). For instance, a symbolic adopter may attach very low weights to CSR-based performance measures, set easilyachievable CSR targets, or not induce significant changes in core CSR-related practices. While such symbolic policies are decoupled from core business practices, firms send a "positive" signal to stakeholders by announcing that they are linking executive pay to CSR criteria and might be able to mislead public perceptions regarding their social legitimacy.

In the third chapter, I argue that deciding on CSR-based performance measures imposes a different sort of challenge and specifically requires decision-relevant information (e.g. Rickard 2014). First, the challenge may come from the inconclusive relationship between CSR and financial performance (Margolis and Walsh 2003). This ambiguity imposes difficulties on firms to trade-off economic benefits and social benefits when designing CSRbased performance measures. Second, deciding on CSR-based performance measure dimensions is a process that incorporates the needs of different stakeholders. However, the CSR interests of different stakeholder groups may conflict with each other (Van Marrewijk 2003). An important challenge of adoption is thus the balance of different stakeholder groups' interests. Third, as the practice of adopting CSR-based performance measures only arose recently and executives' CSR performance often requires discretionary judgments, firms may not have sufficient guidance from outside parties such as business schools or compensation consultants. 
I argue that director experience of using CSR-based performance measures in other firms is an important information source to cope with uncertainties associated with the adoption of CSR contracting. However, this experience is only valuable to true adopters that care about the effectiveness of CSR contracting. In contrast, symbolic adopters are neither concerned about the underlying rationale of designing CSR performance measures, nor care about the evaluation of executives' CSR performance. Thus, they may not further allocate efforts to collect and analyze information relevant for the design and implementation of CSR contracting. Therefore, a positive association between director experience and firms' adoption choice is only expected if the adopters are true adopters.

In this study, I investigate whether directors with experience of using CSR contracting in other firms increase the likelihood of focal firms' adoption of CSR-based performance measures. Further, I test whether adopters with experienced directors show higher substantiveness in CSR contracting adoptions than adopters without an experienced director. In a third step, I argue that the relevance of director experience is not uniform to all firms but dependent on specific firm-contexts. I thus further investigate under which circumstances focal firms are more likely to rely on this experience.

\subsection{Main Findings, Contributions and Implications}

As mentioned previously, my dissertation explores the relationships between firms' internal and external CSR decisions and investigates firms' motivation of adopting CSR-based performance measures in executives' compensation contracts. The results of my first study indicate that compared to firms with a weaker claimed CSR orientation, firms with a higher claimed CSR orientation fire fewer employees for a decrease in sales. The difference in firing decisions between firms with a stronger claimed CSR orientation and firms with a weaker claimed CSR orientation is amplified in myopic situations where firms are pressured to meet or beat earnings benchmarks. This study shows that firms are practicing what they preach in term of their internal CSR decisions, for instance, employee dismissal. This study unravels the relationship between firms' claimed CSR orientation and firing decisions and identifies a mechanism through which the claimed CSR orientation influences firms' internal practices. Further, it shows that KLD ratings can reflect firms' internal CSR practices.

The results of my second study show that the intensity of CSR disclosures and CSR contracting intensity are not independent strategies addressing different control problems, but a set of complementary choices that reinforce each other in achieving higher credibility. I also show that this complementarity is not uniform, but especially observed in firms that face particular incentives to convince their stakeholders of their CSR commitment, i.e., firms facing higher credibility issues. Overall, my findings provide important insights into the cost and benefits of alternative CSR strategies and highlight the importance of aligning decisions with respect to external disclosure policies and internal contract design choices. I provide evidence that firms use strategies as complements to deal with internal and external stakeholders, which has important implications for practitioners as well.

Despite that a vast majority of existing research has demonstrated the antecedence of CSR disclosures, little is known about firms' motivation of incorporating CSR performance 
measures in executives' compensation contracts. The findings of my third study show that director experience is one important factor that facilitates focal firms' adoption decisions. The reliance on this experience suggests that firms are incorporating relevant information when adopting CSR-based performance measures. This reliance indicates that firms are on average serious adopters. In addition, I complement the literature by exploring the moderating role of uncertainties in the relationship between information sharing and performance measurement design in a CSR setting (Hwang, Erkens and Evan 2009). I show that the reliance on director experience is stronger for firms with more dispersed CSR interests among stakeholder groups and for firms in more unpredictable environments. This suggests that director experience is an important way to address uncertainties associated with CSR contracting adoption. Finally, this study contributes to the management accounting literature in suggesting that director experience is an important factor that influences the diffusion of performance measurement systems across firms and industries.

Taken together these studies give insights into firms' internal and external CSR choices, and information used in adopting CSR-based performance measures. Overall, the studies in my dissertation contribute to literature in several ways: First, my dissertation contributes to the literature in CSR credibility issues. While an increasing number of firms are claiming to be CSR oriented, their CSR-related strategies are often accused of being symbolic or greenwashing. As there are no uniform or mandatory criteria to evaluate firms' CSR-related activities, outsiders often have difficulties in understanding firms' authentic motivation of CSR strategies. By investigating how firms' external CSR strategies (e.g. disclosure) are related with internal CSR practices, my dissertation shows that firms' CSR disclosures are consistent with their internal CSR-related decisions, which suggests that CSR practices are not symbolic. Second, my study contributes to the literature streams in CSR disclosures and CSR-related strategies in firms' internal decisions. In contrast to most studies that treat internal and external CSR choices separately (Dhaliwal et al., 2011), my study investigates whether and how firms' internal and external CSR-related decisions are correlated with each other. I find that firms not only communicate their CSR orientation to outside stakeholders, but also factor these orientations into their internal decisions. In addition to that, I show that firms CSR disclosure choice complements their CSR contracting choice. Third, my dissertation contributes to literature in innovative performance measurement systems. My study shows that when firms are to adopt innovative performance measures, individual experience and knowledge play an important role in reducing uncertainties associated with the new performance measures.

In addition to academic contribution, my study also has important implications to shareholders, auditors and practitioner. First, while CSR credibility issues have been intensively discussed by auditors and practitioners, whether a firm's CSR disclosure is symbolic or not remains unclear. My dissertation suggests that one way to understand this issue is to investigate the alignment between firms' external CSR disclosures and internal CSR-related choices. Next, my study highlights the role of CSR contracting in communicating firms' CSR strategies to outsiders. 


\subsection{Outline}

Each of the following three chapters describes one the three aforementioned studies of this dissertation. Chapter two presents the first study about firms' claimed CSR orientation and firing decision in response to sales decreases. Chapter three describes the second study about the complementarity between CSR disclosure and CSR contracting. Chapter four investigates director experience and the adoption of CSR-based performance measures. Chapter five summarizes the main findings of all three studies, discusses their limitations and contributions, and also provides directions for future research. 


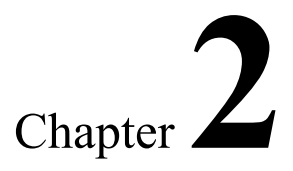

Do CSR firms "walk their talk"? An analysis of firing decisions of US firms 


\begin{abstract}
$^{1}$
Over the past fifteen years, more and more firms are claiming that they act socially responsible. At the same time, there is variation in the extent to which firms claim to incorporate corporate social responsibility (CSR) issues. As a result, investors remain skeptical about these claims due to the lack of credible CSR disclosures and inadequate assurance of firms' CSR disclosures. As outsiders, investors often have difficulties in understanding the variation in claimed CSR-orientation and whether and how this variation translates into firms' internal decision-making. To test whether variation in claimed CSRorientation is reflected in firms' internal decision making, this study investigates how firms with a stronger or weaker CSR orientation deal with their employees in response to shortterm activity decreases. Using 11,613 firm-year observations, we find that, compared to firms with a weaker CSR-orientation, firms with a stronger CSR-orientation fire fewer employees. This effect is stronger in situations where managerial myopia is more likely to be present. This study advances our insights into the role of a claimed CSR-orientation for internal managerial decisions.
\end{abstract}

${ }^{1}$ This chapter is based on a working paper together with Dr. Bart Dierynck and Dr. Annelies Renders. 


\subsection{Introduction}

Due to an increasing attention for the scarcity of natural resources, global warming, and human rights development, an increasing number of firms claim to be committed to Corporate Social Responsibility (CSR) issues, which we define as firms' voluntarily refraining themselves from activities that increase short-run shareholder wealth at the expense of the long-run interests of one or more stakeholder groups (Kitzmueller and Shimshack 2012). Although the claimed commitment of firms to CSR has increased over time, there is still a considerable variation across firms (Cho and Patten 2007; Clarkson et al. 2008; KPMG International 2013). For instance, firms such as Abbott and Excel Energy extensively state that their businesses are embedded with a comprehensive CSR strategy, but some other firms only describe their engagement in one or two CSR aspects. For outsiders, it is important to know whether firms practice what they preach regarding CSR. Our first research question is thus whether the variation in claimed commitment to CSR is associated with variation in internal business practices. Next, we investigate instances where firms are more likely to reveal their true underlying preferences with regard to CSR. We look into situations where firms have stronger incentives to meet earnings benchmarks and test whether firms with stronger claimed CSR orientation fire fewer employees when economic benefits of not doing so become more attractive.

To examine our research questions, we need a proxy for the claimed CSR commitment of the firm and an internal business practice that reflects how the firm deals with one or more of its stakeholders. We use the KLD database to proxy for the claimed CSR commitment of a firm. As one of the largest CSR rating agencies, the KLD database collects their data in various ways including analysing information from firms' corporate social responsibility reports, administering voluntary CSR-related surveys, studying reports disclosed by media, and actively communicating with management teams of firms (Scalet and Kelly 2010). Despite wide information sources where the KLD ratings seek information, most of the information is controlled by how firms describe their CSR strategies, how managers respond to survey questions, what firms are stating on their websites, and how firms communicate their CSR-related issues to the public. Therefore, KLD ratings are more likely to capture what firms are trying to claim regarding their CSR orientation.

The internal CSR practice that we use in this study is a firm's decision to fire employees in response to short-term activity decreases. Traditional cost literature suggests that firms tend to cut resources when sales decrease (Anderson et al. 2003; Noreen 1991). Obviously, firms' dismissal decision is a deliberate adjustment that not only affects firms' future performance, but also affects the employees themselves. As employees are often considered as the most important stakeholder of the firm, the way in which the firm treats its employees is thus an important signal of the firm's internal CSR practices (Pfeffer 2010; Shen and Benson 2016). To the extent that variations in KLD ratings are associated with variations in internal CSR practices, we expect that firms with higher KLD ratings will fire fewer employees in response to short-term activity decreases compared to firms with lower KLD ratings.

Besides investigating whether firms with a stronger claimed CSR orientation fire fewer employees following a decrease in sales, we further look into situations where the 
trade-off between keeping the employee base and improving earnings performance becomes more explicit. According to the revealed preference theory, a decision maker's preference is better disclosed through observing his/her resource allocation decisions over multiple choices under constrained budget (Varian 1992). Intuitively, when the budget is constrained, a decision maker may not be able to afford all available choices and as a consequence, the choices $\mathrm{s} /$ he makes will reveal his/her true preferences.

One situation where firms' preferences are better revealed is when firms are under pressure to meet or beat earnings benchmarks. Facing incentives to meet earnings benchmarks, managers are more eager for economic benefits compared to a normal sales change (Kama and Weiss 2013). This is because failure to meet earnings targets can have negative consequences such as violating debt covenants, or breaking a smooth earnings growth pattern (Baber et al. 1991; Dechow and Sloan 1991; Burgstahler and Dichew 1997; Degeorge et al. 1999; Roychowdhury 2006; Rees and Sivaramakrishnan 2007). Firms may thus act myopically by firing employees that are beneficial for firm future value creation, to meet these targets (Kama and Weiss 2013; Dierynck et al. 2012).

The above statement has been evidenced by BuzzFeed's laying off 100 employees from its business and sales team when its sales missed 2017 revenue targets. Also, Starbucks is planning to fire its employees in order to revive company sales in the US when its revenue has been declining over past quarters. In the US, legal protection against lay-offs is generally characterized by relatively low expected costs for firms (Eger 2003). Under the at-will employment term in US labor law, an employee can be fired for any legal reasons without warning. When an employee is acknowledged as being fired due to this term, the court can deny the employee's claim for loss resulting from the dismissal (Harcourt and Hannay 2013).

When firms are under pressure to meet earnings targets, the relative attractiveness of economic benefits increases while the relative benefits of keeping employees decrease. In other words, the budget for keeping the employee base is relatively more constrained in such situations. If a firm still prefers protecting the interest of its internal stakeholder employees - it can be viewed as a stronger indicator that the firm is truly CSR-oriented. Therefore, managers' incentive to meet earnings targets provides us an ideal and more powerful setting to test firms' real preference between social benefits and economic profits. Hence in a second step, we investigate whether firms with a stronger claimed CSR orientation still fire fewer employees when they are under the pressure of meeting or beating earnings targets.

Using 11,613 firm-year observations from US listed firms over the period 1993 to 2012, we first document that firms with a stronger claimed CSR orientation are less likely to fire employees following a short-term activity decrease. We find marginal evidence that for firms with stronger claimed CSR orientation, firms on average fire 0.19 percent fewer employees for one percent decrease in sales. To further unravel the role of a claimed CSR orientation on firing decisions, we partition our sample into subsamples where myopic behavior is more likely. That is, we examine firing decisions when firms are facing earnings benchmarks such as zero profit earnings, last year earnings, and analyst forecasts. As previous research has shown that firms that just meet or beat these benchmarks face stronger incentives to manage earnings by cutting resources, the subsample analysis can help us better understand whether short-term earnings pressure crowds out the effect of the claimed CSR 
orientation on firing decisions. Our results show that in situations where firms are to meet or beat earnings benchmarks, firms with a stronger claimed CSR orientation still fire fewer employees in response to short-term activity decreases than firms with a weaker claimed CSR orientation. In addition to that, compared to situations where firms do not have earnings benchmark pressure, the differences regarding firing decision between firms with a stronger and weaker claimed CSR orientation become more obvious when firms are to meet the benchmarks.

Our study extends current research in different ways. First, this study contributes to the stream of research aiming to extend our understanding of how managerial incentives affect resources adjustment when sales decreases (e.g. Dierynck et al. 2012; Kama and Weiss 2012). When managers face incentives to meet earnings targets, they are likely to accelerate cuts of resources in response to a sales decrease even when the drop is expected temporary (Kama and Weiss 2012). Our study investigates how firms' claimed CSR orientation influences employee dismissal following a sales drop. In contrast to prior literature that indicates a higher likelihood of myopic behavior when firms are to meet or beat earnings benchmarks, our results show those firms with stronger claimed CSR orientation do not behave myopically to meet earnings targets. Our findings suggest that while managerial incentive is an important factor that determines firms' resources adjustment decisions, firms' CSR-related orientation is consistently reflected in firms' infernal management practices, even when firms are under pressure of earnings benchmarks.

Second, we contribute to the literature on the consequences of the variation in claimed CSR orientation. By unravelling the relationship between the claimed CSR orientation and firing decisions, this study takes one step back and tries to clarify a mechanism through which the claimed CSR orientation influences internal firm practices. One disadvantage of this approach is that one needs to choose a particular action such as firing employees in response to a short-term activity decrease. As it can be argued that the action we have chosen is an important one to proxy for firms' internal decisions, this study enriches our knowledge about the internal consequences of a claimed CSR orientation.

Third, this study contributes to the debate about the consistency between the claims and actions of CSR firms. Contemporaneous research in economics and psychology has already indicated the importance of consistency between words and deeds (Leroy et al. 2012). However, the difficulty in collecting large sample data about managerial actions has refrained researchers from empirically testing the word-deed alignment. By using the KLD database to proxy for the claimed CSR commitment of a firm and by borrowing an empirical methodology from the cost behavior literature, this study is one of the first attempts to examine word-deed alignment at the firm level using an extensive sample. Our findings suggest that firms are practicing what they preach in terms of their internal decisions. Our study contributes to the current debate about the usefulness of the KLD database as a valid proxy for internal firm decisions. 


\subsection{Related Literature and Hypotheses}

\subsubsection{Corporate Social Responsibility and Word-Deed Alignment}

Over the past decades, CSR has gradually become a prominent issue in firm management. For instance, a survey by the Boston Consulting Group (BCG) reveals that $62 \%$ of the CEOs indicate that having a sustainability-oriented strategy is necessary for being competitive. Similarly, the latest UN Global Compact-Accenture CEO study reports that $93 \%$ of the CEOs declared CSR as 'important' or 'very important' for the future success of the firm. The BCGsurvey also reveals that CSR is permanently on the agenda of top management in more than $40 \%$ of the firms. Although the conceptualization of CSR remains a topic of debate, there is a consensus about the distinctive characteristics of CSR. That is, CSR can be conceptualized as (1) voluntary behavior of the firm that is (2) focused on maximizing long-run shareholder wealth by (3) refraining from activities that increase short-run shareholder wealth at the expense of the long-run interests of one or more stakeholder groups (Kitzmueller \& Shimshack 2012).

Previous research mainly focuses on the implications of CSR for firm value and firm profitability. Although extant literature found mixed evidence, it seems that there is at least some evidence that CSR has positive implications for firms. Cheng et al. (2014), for instance, find that superior performance on CSR leads to better access to finance because of reduced agency costs and information asymmetry. Lee and Faff (2009) document that firms with a high CSR score experience lower idiosyncratic risk. Finally, Servaes and Tamayo (2013) find that CSR is positively related with firm value, but only for firms with high customer awareness.

The potential economic benefits that are linked to CSR also instigate firms to claim that they act in a socially responsible way without truly embracing CSR when important decisions have to be made. Such behavior can be labeled as 'CSR cheap talk'. Although there are variations in firms' claimed orientation towards CSR, monitoring whether the firm also adheres to its claims concerning CSR is difficult for outsiders because of the lack of generally accepted reporting rules concerning CSR and the absence of adequate verification mechanisms (Laufer 2003; Gray et al. 1995; Simnett et al. 2009; Eccles and Krzus 2010; KPMG 2011; Casey and Grenier 2014). Recent surveys among investors indeed show that investors remain skeptical about the realization of the claims concerning CSR because CSR disclosures do not touch upon the material issues (KPMG, 2015). Also, investors complain that the CSR disclosures typically lack clear links between CSR and the firm's long-term financial performance and that firms fail to communicate how their CSR efforts fit in the overall strategy (Eccles and Krzus 2010). Taken together, it seems that word-deed alignment with respect to CSR is a salient issue. The primary purpose of this study is to empirically examine CSR-related word-deed alignment by analyzing whether variations in claims about CSR orientation are related to variations in employee dismissals when firms are confronted with short-term activity decreases. 
Do CSR firms "walk their talk"? An analysis of firing decisions of US firms

\subsubsection{Employee Firing Decisions}

The underlying assumption of this study is that firms behave more responsibly when they fire fewer employees in response to a short-term activity decrease. Thus, in case firms practice what they preach, we expect that firms with a higher claimed CSR orientation will fire fewer employees than firms with a lower claimed CSR orientation in response to the same shortterm activity decrease.

Despite that employees represent an important asset for firms, in the US, legal protection against dismissal is in general characterized by relatively low expected dismissal costs with a high variance (Eger 2003). For instance, according to the at-will employment term in US labor law, an employee can be dismissed by an employer for any legal reasons without warning. When an employee is acknowledged as being fired due to this term, the court can deny the employee's claim for loss resulting from the dismissal. Under the employment-at-will, employees have very limited protection from dismissal and remedies are restricted to just a few exceptions (Harcourt and Hannay 2013). Importantly, labor costs represent a significant cost to the firm. ${ }^{2}$ Managers who try to meet earnings benchmark may thus deliberately focus on employees that are easier and cheaper to fire. For instance, Dierynck et al. (2012) document that firms that try to meet an important earnings benchmark fire more employees in response to a short-term activity decrease compared to firms that are not under pressure to meet an earnings benchmark. As employees are the most important internal stakeholders within the firm, the way of treating employees has been identified as a very representative marker to measure the extent to which internal CSR practices are observed (Greenwood 2002; Welford 2005; Cornelius et al. 2008).

Reasons why we expect a difference regarding firing decisions in firms with a high and low claimed CSR orientation can be summarized into the following perspectives. First, employees are very concerned about dismissal risk. Losing a job not only affects employees' psychological (Clark and Oswald 1994; Winkelmann and Winkelmann 1998) and physical well-being (Gibbons and Katz 1991; Ruhm 1991), but it has also a negative impact on society in general (Kalil and Ziol-Guest 2008; Rege et al. 2011). Fired employees may not be able to keep up with their mortgage repayment and support their children's education. Psychological problems such as depression and stress arise when people find it difficult to search for another job. Unemployment is also linked to social deprivation. Regions that suffer from long-term unemployment issues are more likely to witness falling income, instability and higher divorce rates (Pfeffer 2010; McKee-Ryan et al. 2005). Socially responsible firms are expected to possess moral status and therefore perform in a morally responsible manner that is consistent with ethical and philanthropic expectations of society. Fundamentally, socially responsible firms are expected to minimize or avoid harm to stakeholders and to actively promote human welfare and enhance a community's quality of life. However, firing employees in response to a short-term activity decrease is not consistent with these social responsibilities. Hence, it can be expected that firms with a high claimed CSR orientation are

\footnotetext{
${ }^{2}$ Exception situations involve for example, discrimination, tort, public policy violation, breach of contract or bad faith (Harcourt and Hannay 2013).
} 
less likely to fire employees since they should take stakeholders' interests into consideration.

Second, from an economic perspective, firms engage in socially responsible behavior mainly because doing so will generate long-term benefits by improving relationships with various stakeholders such as employees, customers, government and community, and therefore, CSR firms are often considered to be long-term oriented. Accordingly, one may not expect CSR firms to fire their employees easily because human capital is often claimed to be the most important asset for the long-run development of the firm (Pfeffer 2010). On the one hand, firms' policies towards their employees directly influence employees' work attitude, behavior and occupational safety. Motivation-enhancing policies increase employees' organization identification, which makes them more willing to take risks in helping their colleagues and share resources with others (Jiang et al. 2012; Carmeli et al. 2007; Shen and Benson 2016). Edmans (2011) finds that employee satisfaction is positively correlated with long-run stock returns. These aspects can foster long-run benefits for a firm, which is valued more by CSR firms. On the other hand, accumulated experience, specific knowledge and a climate of mutual trust between employers and employees are all non-substitutable resources that promote effectiveness, loyalty and stable operations, which further provide strong safeguards for the sustainable development of a firm (Lado and Wilson 1994; Wright et al. 1995; Schuler and Jackson 1987). As firms with a higher claimed CSR orientation are expected to value these long(er)-term benefits, it can be expected that they will factor in these benefits when faced with short-term activity decreases.

Third, previous research has already documented that consistency between words and deeds can foster positive outcomes. In psychology, for instance, alignment between words and deeds is termed as "behavioral integrity". Based on observations over time, behavioral integrity represents the extent to which a firm is conceived as "walking its talk" and is expected to affect trust through the mechanisms of perceived reliability and conceived value congruity (Simons 2002). The perception of word-deed alignment has a direct influence on credibility as well. While word-deed alignment is backward-looking since it focuses on past performance, credibility on the other hand is forward-looking and influences the extent to which the speakers' statements can be relied on to guide future attitudes and cooperation (Simons 2002; O'Keefe 1990). Within an organization, strong word-deed alignment reinforces personal reputation, mutual trust, the efficiency of corporate governance and longterm cooperation both within and from outside the firm, which finally has a positive effect on employee retention and corporate performance (Rousseau and McLean Parks 1993). As firms with a high claimed CSR orientation are likely more future oriented, we expect they are more likely to practice what they preach.

In the paragraphs above we have documented that employees are an important stakeholder and an important asset for the long-run development of the firm. Also, firing employees imposes negative consequence on the dismissed employees, the remaining employees and society in general. If the claimed CSR orientation is aligned with firms' internal decision making, one may expect that firms factor in these issues when deciding about employee dismissals in response to a short-term activity decrease. However, as previously discussed, the absence of clear monitoring and verification mechanisms to assess the claimed CSR orientation can instigate firms to claim a CSR orientation but not truly embracing that commitment when making important decisions. Given the above arguments, we put forward the first hypothesis: 
H1: Firms with a stronger claimed CSR orientation fire fewer employees following a short-term activity decrease.

\subsubsection{Revealed Preference in Myopic Situations}

Revealed preference theory suggests a method of unrevealing individuals' true preferences by analysing the choices or decisions made by individuals (Samuelson 1938). It has been widely used for comparing the choice between bundles of goods by consumers. Specifically, a consumer's preference is disclosed through the priority of choices among bundles of goods under budget constraints. For instance, if a consumer buys bundle of goods $A$ over bundle of goods $B$, it is revealed that he/she directly prefers $A$ over $B$. It is assumed that the consumer's preferences are stable over the observed time period, i.e. the consumer will not reverse its relative preferences regarding $A$ and $B$ (Varian, 1992). Consistent with revealed preference theory, Murphy and Ackermann (2014) document that a decision maker's social preference can be revealed through observing his choice of distributing resources over "social dimension" and "narrowly self-interest dimension" under a constrained budget. In their experiment, each participant is asked to make a binary choice between two options of allocating resources to herself and to another person: Option 1 allocates an equal 85 dollars to the participant and to the other person; Option 2 allocates 100 dollars to the participant, and 50 dollars to the other person. A pay-off maximizing decision maker will select Option 2 because this results in a larger individual payoff, while a decision maker with social preferences will take the other person's benefit into consideration and select Option 1.

We argue that examining firms' firing decision in response to a sales decrease in situations where firms are under pressure to meet earnings targets provides us an ideal and powerful setting to test firms' true preferences over social benefits and economic profits. Prior studies document that managers have strong incentives to manage revenues and expenses to avoid reporting negative earnings, earnings decreases and missing earnings' forecast (Burgstahler and Dichew 1997; Degeorge et al., 1999; Dechow and Sloan 1991; Baber et al. 1991; Roychowdhury 2006). For instance, Rees and Sivaramakrishnan (2007) find that the market penalty for not meeting earnings benchmarks is higher than that of a normal sales decrease. Their findings suggest that market views firms' ability to meet earnings targets as a strong signal of firms' future profitability. Other incentives of meeting earnings targets include avoiding violation of debt covenants, meeting the criteria to distribute dividends, and showing a continuous earnings growth pattern. Barth et al. (1999) document that firms with a consistent pattern of earnings increases have higher price-toearnings multipliers. Similarly, DeAngelo et al. (1996) document that firms that break the pattern of consistent earnings growth experience on average $14 \%$ negative abnormal returns in the year the pattern is broken. Accordingly, combined with a decrease in sales, incentives to meet earnings targets impose more pressure on firms (Kama and Weiss 2014).

Facing incentives to meet earnings benchmarks, firms may accelerate firing employees when sales decrease even if the decrease is temporary (Dierynck et al. 2012; Kama and Weiss 2014). As suggested by Anderson and Lanen (2007), labor costs are subject to managerial discretions and represent a significant part of total costs. To further examine 
whether firms with a stronger claimed CSR orientation behave more consistently with respect to their internal decisions when myopic behavior is more likely to occur, we investigate firms' firing decision when they are exposed to the pressure of meeting/beating earnings benchmarks. In this case, firms trade-off "meeting the benchmark" against "keeping the employee base". As the attractiveness of economic benefits increases, the relative benefits of keeping employees decrease. Given that firms' resources are limited, if a firm still prefers protecting the interest of its internal stakeholder - employees - it can be viewed as a stronger indicator that the firm is truly CSR-oriented. Managers' incentives to meet earnings targets thus provides us with an ideal and powerful setting to test firms' real preferences between social benefits and economic profits. However, it is likely that firms' CSR orientation is crowded out by the explicit incentives to meet earnings benchmarks. Based on above argumentation, we propose our second hypothesis:

H2: Firms with a stronger claimed CSR orientation fire fewer employees following a short-term activity decrease when they are under the pressure of meeting/beating earnings targets.

\subsection{Research Methodology}

\subsubsection{Data and Sample Selection}

To examine our hypotheses, we use publicly available data of US listed firms. Our sample is obtained from merging KLD, Compustat and Execucomp databases. The KLD database consists of 38,098 firm-year observations from 1991 to 2013. After merging KLD with Compustat, we obtain 28,744 firm-year observations. Our full sample is reduced to 11,613 firm-year observations from 1993 to 2012 after we further merge with Execucomp and exclude observations with missing variables. Table 1, Panel A provides an overview of the sample selection procedure. 
Table 1: Sample Selection and Distribution

\begin{tabular}{|c|c|c|c|c|c|c|c|}
\hline \multicolumn{6}{|c|}{ Panel A: Sample Selection } & \multicolumn{2}{|c|}{ No. of Firm-Year Obs. } \\
\hline \multicolumn{2}{|c|}{ Original Sample } & \multicolumn{5}{|c|}{ Firm-year observations from KLD } & 38,098 \\
\hline \multicolumn{2}{|l|}{ Less: } & \multicolumn{5}{|c|}{$\begin{array}{l}\text { Firm-year observations from Compustat that fail to } \\
\text { merge with KLD }\end{array}$} & $-9,354$ \\
\hline \multicolumn{2}{|l|}{ Less: } & \multicolumn{5}{|c|}{$\begin{array}{l}\text { Firm-year observations from Execucomp that fail to } \\
\text { merge with KLD and Compustat }\end{array}$} & $-9,264$ \\
\hline \multicolumn{2}{|l|}{ Less: } & \multicolumn{5}{|c|}{ Missing control variables of Compustat and KLD } & $-7,867$ \\
\hline \multicolumn{7}{|c|}{ Final Sample } & 11,613 \\
\hline \multicolumn{8}{|c|}{ Panel B: Year Distribution } \\
\hline Year & Full & $S P^{a}$ & $\boldsymbol{L} \boldsymbol{P}^{b}$ & MB_L.Earn ${ }^{c}$ & $E X \_L . E a r n^{d}$ & MB_Forecast $t^{e}$ & EX_Forecast ${ }^{f}$ \\
\hline 1993 & 15 & 0 & 13 & 0 & 15 & 2 & 8 \\
\hline 1994 & 222 & 4 & 209 & 5 & 214 & 59 & 85 \\
\hline 1995 & 232 & 10 & 202 & 40 & 119 & 66 & 68 \\
\hline 1996 & 228 & 7 & 209 & 49 & 111 & 52 & 82 \\
\hline 1997 & 233 & 0 & 213 & 45 & 107 & 49 & 82 \\
\hline 1998 & 245 & 10 & 212 & 38 & 112 & 52 & 70 \\
\hline 1999 & 266 & 12 & 243 & 55 & 134 & 76 & 75 \\
\hline 2000 & 269 & 9 & 228 & 52 & 119 & 63 & 84 \\
\hline 2001 & 280 & 14 & 205 & 41 & 85 & 62 & 59 \\
\hline 2002 & 314 & 13 & 229 & 43 & 164 & 86 & 87 \\
\hline 2003 & 476 & 18 & 382 & 64 & 324 & 141 & 154 \\
\hline 2004 & 517 & 18 & 446 & 91 & 332 & 132 & 205 \\
\hline 2005 & 867 & 31 & 748 & 109 & 613 & 200 & 327 \\
\hline 2006 & 917 & 24 & 808 & 164 & 490 & 266 & 288 \\
\hline 2007 & 995 & 15 & 880 & 187 & 497 & 294 & 298 \\
\hline 2008 & 1,098 & 27 & 818 & 166 & 427 & 249 & 274 \\
\hline 2009 & 1,097 & 46 & 800 & 122 & 452 & 224 & 490 \\
\hline 2010 & 1,070 & 36 & 918 & 181 & 653 & 278 & 482 \\
\hline 2011 & 1,114 & 37 & 959 & 190 & 532 & 316 & 357 \\
\hline 2012 & 1,158 & 41 & 966 & 230 & 440 & 333 & 301 \\
\hline Total & 11,613 & 372 & 9,688 & 1,872 & 5,940 & 3,000 & 3,876 \\
\hline
\end{tabular}

a. The $S P$ subsample is composed of firm-year observations with scaled net earnings larger than (or equal to) 0 , but smaller than or equal to 0.01 .

b. The $L P$ subsample is composed of firm-year observations with scaled net earnings larger than 0.01 .

c. The MB_L.Eearn subsample is composed of firm-year observations with scaled changes of net income larger than or equal to 0 , but smaller than or equal to 0.01 .

d. The EX_L.Eearn subsample is composed of firm-year observations with scaled changes of net income larger than 0.01 .

e. The MB_Forecast subsample is composed of firm-year observations with the scaled difference between actual and forecasted EPS larger than or equal to 0, but smaller than or equal to 0.05 .

f. The EX_Forecast subsample is composed of firm-year observations with the scaled difference between actual forecasted EPS larger than 0.05 . 
Next to analysing firms' firing decisions in response to sales decreases in our full sample, we further analyse these decisions in subsamples when firms are to meet or beat earnings benchmarks. The main goal of the subsample analyses is to examine whether short-term earnings pressures crowd out the effect of the claimed CSR orientation on firing decisions. Following prior literature, we identify three situations where managerial myopia is more likely: Meet/beat zero-earnings benchmark, meet/beat last-year earnings benchmark, and meet/beat analyst forecast benchmark (Gunny 2010; Brown and Higgins 2001). To identify zero-earnings benchmark, firm-year observations are grouped into intervals according to net income scaled by total assets. Next, we construct categories of scaled earnings with widths of 0.01 . We classify firm-year observations with scaled earnings just to the right of zero ([0, $0.01]$ ) into the small-profit subsample (the $S P$ subsample). For comparison, firm-year observations are classified into the large-profit subsample (the $L P$ subsample) if their scaled earnings are higher than 0.01 . Next, we construct categories of scaled changes in earnings for widths of $0.01 .{ }^{3}$ Firms that are to the immediate right of zero have scaled changes in earnings greater than or equal to zero, but smaller than (or equal to) 0.01 . Firms in the first zone to the right of zero are identified as just meeting or beating last year earnings (the MB_L.Earn subsample). Firms with scaled changes in earnings larger than 0.01 are classified into the exceed-last-year-earnings subsample (the EX_L.Earn subsample). Previous literature also indicates that firms have incentives to meet or beat analyst forecasts (Burgstahler and Eames 2006; Kama 2009). Accordingly, we further split our full sample into firms that just meet or beat analyst forecasts and firms with earnings largely exceeding analyst forecasts. Specifically, we first identify the median of the analyst forecasts and compare it with the actual earnings. When actual earnings per share exceed the median of the analyst forecasts by no more than five percent, we classify the firm into the meet/beat-analyst-forecast subsample (the MB_Forecast subsample) (Bartov et al. 2002; Brown and Higgins 2001; Hope 2003). ${ }^{4}$ When actual earnings beat analyst forecasts by more than five percent, we classify it into the exceed-forecast subsample (the EX_Forecast subsample). Table 1 Panel A and Panel B give an overview of how the sample and subsamples are constructed and the detailed distribution of the samples.

\subsubsection{Empirical Model Specification and Variable Definitions}

To examine our hypotheses, we use an approach that previously has been used in the cost asymmetry literature (Dierynck et al. 2012; Anderson et al. 2003). The basic model is as follows:

\footnotetext{
${ }^{3}$ Scaled changes in earnings is calculated as (Net income $\left.\mathrm{t}-\mathrm{Net}_{\mathrm{income}} \mathrm{t-1}\right) /$ total assets $_{\mathrm{t}}$.

${ }^{4}$ The market typically expects that firms beat analyst forecasts in the range of 3-5\% (Anonymous, 1998, p.13). Alternative to the five percent, our results hold if we use three percent as the cutoff for small positive surprise.
} 


$$
\begin{aligned}
\left.\log _{\left(\frac{\text { Employe }_{i t}}{\text { Employe }_{i t-1}}\right.}\right) & \\
& =\beta_{0}+\beta_{1} \times \log \left(\frac{\text { Sales }_{i t}}{\text { Sales }_{i t-1}}\right)+\beta_{2} \times \text { Log }\left(\frac{\text { Sales }_{i t}}{\text { Sales }_{i t-1}}\right) \times \text { Decrease }_{i t} \\
& +\beta_{3} \times \log \left(\frac{\text { Sales }_{i t}}{\text { Sales }_{i t-1}}\right) \times \text { Decrease }_{i t} \times \text { CSR }_{i t-1} \\
& +\beta_{4} \times \log \left(\frac{\text { Sales }_{i t}}{\text { Sales }_{i t-1}}\right) \times \text { CSR }_{i t-1}+\beta_{5} \times \text { CSR }_{i t-1}+\beta_{6} \times \text { Decrease }_{i t} \\
& +\varepsilon_{i t}
\end{aligned}
$$

Employee represents the actual number of people employed by the company and its consolidated subsidiaries; and $\frac{\text { Employe }_{i t}}{\text { Employe }_{i t-1}}$ is the annual change in employee numbers for firm $i$.

This model enables us to measure employee dismissal response to contemporaneous changes in sales revenue and distinguishes between periods when sales revenue increases or decreases (Anderson et al. 2003). We use $\log \left(\frac{\text { Employee }_{i t}}{\text { Employee }_{i t-1}}\right)$ as our main dependent variable. The log specification accommodates economic interpretation of the estimated coefficients. Decrease $_{i t}$ is equal to one when the sales in year $t$ are lower than those in year $t-1$, and zero otherwise. Because we are interested in whether firms with higher claimed CSR orientation fire more employee when sales decrease, we further interact lagged CSR with changes in sales and sales decrease dummy $\left(\log \left(\frac{\text { Sales }_{i t}}{\text { Sales }_{i t-1}}\right) \times\right.$ Decrease $_{i t} \times$ CSR $\left._{i t-1}\right)$. The coefficient $\beta_{1}$ indicates the percentage increase in employee numbers for every one percent increase in sales for firms with zero value of $C S R_{i t-1}$. As the value of Decrease $i t$ is 1 when sales drop, the sum of $\beta_{1}$ and $\beta_{2}$ reflects the percentage decrease in employees for a one percent decrease in sales for firms with zero $C S R_{i t-1}$. In line with prior research, $\beta_{1}$ should be positive, $\beta_{2}$ should be negative and in absolute value smaller than $\beta_{1}$. The coefficient $\beta_{3}$ represents the change with respect to firing decisions in response to a one percent activity decrease for $C S R_{i t-1}$ equal to one. If firms with a stronger claimed CSR orientation fire fewer employees in response to sales decreases, we expect $\beta_{3}$ to be significantly negative. The coefficient $\beta_{4}$ represents the change in employee numbers in response to an activity increase for $C S R_{i t-1}$ of one. We do not have specific expectations with regard to the sign of $\beta_{4}$.

As it is possible that firms' firing decisions and CSR ratings are endogenously determined (i.e., firms get higher CSR ratings because they fire fewer employees), we lag our variable of interest by one year. To control for error dependence of firm observations, we use robust standard errors clustered at firm level in all regression models. Besides, year, industry and state fixed effects are included.

To capture variations in firms' claimed CSR orientation, we use ratings from the KLD database. One of the potential problems of using the KLD database is that KLD ratings are based on communications with managers, surveys, media, and other public information disclosed by the firm. Although the KLD database provides third-party analysis of firms' social behavior, it does not analyze the actions of the firm itself but determines the scores 
based on survey responses of the firm and publicly available information. How participants answer survey questions, how managers introduce the firm to the public (through websites or conferences, etc.), what kind of information is disclosed to the media and what corporate culture is declared by the firm can influence the final CSR score of the firm. Therefore, one of the concerns of using the KLD ratings is that the assessments are, as pointed out by Edmans (2011), largely based on "observables" and that these "observables" are subject to "check the box behavior of companies". The ratings therefore measure what firms are declaring to be rather than how firms are actually behaving. Although this is generally viewed as a shortcoming of the KLD ratings, in our study this is an advantage since we need a measure of the "words" of firms.

The variations in KLD ratings, as our main independent variable, are captured by $C S R_{i t-1}$. This variable is constructed in two steps: First, we follow prior literature (Kim et al. 2012; Chatterji et al. 2009) to calculate the KLD scores. The KLD database provides ratings for different CSR dimensions, including corporate governance, community, diversity, employees, environment, product, alcohol, gambling, military contracting, nuclear power, and tobacco. Among all the eleven dimensions described above, the last five are exclusionary categories. Thus, we do not consider them when constructing the CSR scores. Among the remaining six dimensions, corporate governance is considered as a dimension that is different from social responsibility (Kim et al. 2012; Chatterji et al. 2009). We therefore exclude corporate governance when calculating the KLD score. The KLD score is measured as the number of total strengths minus the number of total concerns in the KLD's five social rating categories: Community, diversity, employees, environment, and product. The KLD scores are integral numbers with a minimum of -7 and a maximum of 19 . As the KLD scores are discrete numbers, it is difficult to interpret the meanings of coefficients in regression equations. In a next step, we therefore transform the discrete KLD score into a continuous variable $\left(C S R_{i t-1}\right)$. The distribution of $C S R_{i t-1}$ follows a Cumulative Distribution Function (CDF) with the minimum, median, maximum equal to $0,0.5$, and 1 , respectively. ${ }^{5}$ We use the KLD ratings (KLD_Rating) to capture the overall claimed CSR commitment of a firm instead of only looking into the "employees" dimension because we aim to capture the overall CSR commitment.

In the extended model, we include control variables according to literature on firing and hiring decisions (Banker et al. 2013; Dierynck et al. 2012; Roychowdhury 2006). Detailed variable definitions are provided in Appendix A. The extended model is as follows: ${ }^{6}$

\footnotetext{
${ }^{5}$ Our results do not change materially if we use discrete KLD ratings.

${ }^{6}$ Our main parameters of interest are based on interactions CSR and sales decreases $\left(\log \left(\frac{\text { Sales }_{i t}}{\text { Sales }_{i t-1}}\right) \times\right.$ Decrease $_{i t}$ ). Therefore, we control for the main effects of CSR and interactions with sales increases to avoid distorted coefficients of variable of interests. However, including all two-way interactions can lead to multicollinearity and spurious regression results. Therefore, we do not include all the two-way interactions. This design choice is consistent with prior research (e.g. Dierynck et al. 2012).
} 


$$
\begin{aligned}
& \log \left(\frac{\text { Employe }_{i t}}{\text { Employe }_{i t-1}}\right) \\
& =\beta_{0}+\beta_{1} \times \log \left(\frac{\text { Sales }_{i t}}{\text { Sales }_{i t-1}}\right)+\beta_{2} \times \log \left(\frac{\text { Sales }_{i t}}{\text { Sales }_{i t-1}}\right) \times \text { Decrease }_{i t} \\
& +\beta_{3} \times \log \left(\frac{\text { Sales }_{i t}}{\text { Sales }_{i t-1}}\right) \times \text { Decrease }_{i t} \times \text { CSR }_{i t-1} \\
& +\beta_{4} \times \log \left(\frac{\text { Sales }_{i t}}{\text { Sales }_{i t-1}}\right) \times \operatorname{CSR}_{i t-1}+\beta_{5} \times \text { CSR }_{i t-1}+\beta_{6} \times \text { Decrease }_{i t} \\
& +\beta_{7} \times \log \left(\frac{\text { Sales }_{i t}}{\text { Sales }_{i t-1}}\right) \times \text { Decrease }_{i t} \times \text { Average_Sales_Growt }_{i t} \\
& +\beta_{8} \times \log \left(\frac{\text { Sales }_{i t}}{\text { Sales }_{i t-1}}\right) \times \text { Decrease }_{i t} \times \text { Success_ }_{-} D_{i t} \\
& +\beta_{9} \times \log \left(\frac{\text { Sales }_{i t}}{\text { Sales }_{i t-1}}\right) \times \text { Decrease }_{i t} \times R O A_{i t} \\
& +\beta_{10} \times \log \left(\frac{\text { Sales }_{i t}}{\text { Sales }_{i t-1}}\right) \times \text { Decrease }_{i t} \times \Delta \text { RECT }_{i t} \\
& +\beta_{11} \times \log \left(\frac{\text { Sales }_{i t}}{\text { Sales }_{i t-1}}\right) \times \text { Decrease }_{i t} \times \text { Asset_Intensity }_{i t} \\
& +\beta_{12} \times \log \left(\frac{\text { Sales }_{i t}}{\text { Sales }_{i t-1}}\right) \times \text { Decrease }_{i t} \times \text { Employee_Intensity }_{i t} \\
& +\beta_{13} \times \log \left(\frac{\text { Sales }_{i t}}{\text { Sales }_{i t-1}}\right) \times \text { Decrease }_{i t} \times R D_{i t} \\
& +\beta_{14} \times \log \left(\frac{\text { Sales }_{i t}}{\text { Sales }_{\text {it }-1}}\right) \times \text { Decrease }_{i t} \times F C F_{i t} \\
& +\beta_{15} \times \log \left(\frac{\text { Sales }_{i t}}{\text { Sales }_{i t-1}}\right) \times \text { Decrease }_{i t} \times A B N_{-} \text {ACC }_{i t} \\
& +\beta_{16} \times \log \left(\frac{\text { Sales }_{i t}}{\text { Sales }_{i t-1}}\right) \times \text { Decrease }_{i t} \times \text { Change_CEO }_{i t} \\
& +\beta_{17} \times \log \left(\frac{\text { Sales }_{i t}}{\text { Sales }_{\text {it }-1}}\right) \times \text { Decrease }_{i t} \times \Delta G N P_{i t} \\
& +\beta_{18} \times \log \left(\frac{\text { Sales }_{i t}}{\text { Sales }_{i t-1}}\right) \times \text { Average_Sales_Growth } \text { }_{i t} \\
& +\beta_{19} \times \text { Average_Sales_Growth } h_{i t}+\beta_{20} \times \text { Success_D } D_{i t}+\beta_{21} \times R O A_{i t} \\
& +\beta_{22} \times \Delta R E C T_{i t}+\beta_{23} \times \text { Asset_Intensity }_{i t} \\
& +\beta_{24} \times \text { Employee_Intensity } i t+\beta_{25} \times R D_{i t}+\beta_{26} \times F C F_{i t} \\
& +\beta_{27} \times A B N \_A C C_{i t}+\beta_{28} \times \text { Change_CEO }_{i t}+\beta_{29} \times \Delta G N P_{i t}+\varepsilon_{i t}
\end{aligned}
$$

As argued by Banker et al. (2014), previous increases or decreases in sales influence managers' future expectations regarding sales revenues. We therefore include Success_D and Average_Sales_Growth to control for firms' past sales performance, which may potentially affect managers' expectation towards future sales revenues. Success_D measures whether a firm experiences a loss in sales in continuous two years while Average_Sales_Growth captures sales growth rate in continuous three years. We include two-way and three-way interactions $\log \left(\frac{\text { Sales }_{i t}}{\text { Sales }_{i t-1}}\right) \times$ Average_Sales_Growth $_{i t} \quad$ and $\quad \log \left(\frac{\text { Sales }_{i t}}{\text { Sales }_{i t-1}}\right) \times$ Decrease $_{i t} \times$ Average_Sales_Growth $h_{i t}$ in our regression model. We first calculate the average sales growth 
rates in the previous three years for each firm-year observation. Average_Sales_Growth is defined as the logarithm of the average growth rate over these three years. Following Chen et al. (2012), Success_D is equal to one when there is a decrease in sales over the previous two years, and is zero otherwise.

We control for firms' financial performance by including the return on assets $(R O A)$. As previous research suggested that an increase in receivables is viewed as a negative signal about future sales, we incorporate changes in accounts receivables over two subsequent years scaled by total sales $(\triangle R E C T)$. We further include Asset_Intensity and Employee_Intensity to control for cost asymmetry identified by previous research (Dierynck et al. 2012; Anderson et al. 2003). The development of innovation and new technology may have either a positive or negative effect on employment. Technology improvements may lead to decrease in employment since firms can rely on machines, emerging technological methods, and engineering rather than human resource inputs. On the other hand, as indicated by Fagerberh et al. (1997), encouraging R\&D development in backward regions is crucial for those poor regions to exploit the potential of learning from advanced areas and leads to higher growth for the poor region. Therefore, it helps to create more job opportunities. To capture the influence of technology and innovation inputs, we include $\mathrm{R} \& \mathrm{D}$ expenses scaled by total sales $(R D)$ as an additional control variable.

Zang (2011) indicates that firing employees can be considered as 'real earnings management' and that real and accrual-based earnings management are substitutes. We thus control for earnings management behavior by including free cash flows and abnormal accruals. Free cash flows $(F C F)$ are defined as cash flow from operating activities minus common and preferred dividends divided by total assets (Chen et al. 2012). We use performance-adjusted abnormal accruals as a proxy for abnormal accruals $\left(A B N_{-} A C C\right)$ (Kothari et al. 2005). Since new CEOs may bring new governance experience or take new actions that are not fully consistent with the culture of the firm, and such new measures may affect employee dismissals, we include changes in CEO as another control variable (Change_CEO). Economic growth is calculated as the logarithm of GNP annual increase ratio $(\triangle G N P)$.

In all the regressions, we control for year, industry, and state-fixed effects. Although the federal laws override most state and local laws, the state and local laws usually have different rights for workers. For example, some states presume that workers who are not covered by a collective bargaining agreement or an individual employment agreement have the so-called "at-will employment". This "at-will employment" is a policy which states that employees can be dismissed without notice and for no stated reasons. Some other states have modified the "at-will employment" rule by stating that employees may have implied contractual rights to fair treatment by their employers. The state-fixed effect is incorporated in all regressions to control for variations in firing policies across states. Standard errors are clustered at firm level. 
Do CSR firms "walk their talk"? An analysis of firing decisions of US firms

\subsection{Empirical Results}

\subsubsection{Descriptive Results}

Table 2 presents descriptive statistics for the different samples. ${ }^{7}$ On average, the employee number of our full sample is 27.12 thousand and total assets is $8,123.68$ million dollars. The number of employees for the $L P, M B_{-}$L.Earn and MB_Forecast subsample is higher, with 28.85 thousand, 42.42 thousand and 35.89 thousand, respectively. With respect to financial performance, we find that on average firms in the $S P$ subsample are more likely to experience a decrease in sales and report lower ROA than the other subsamples.

The mean of the KLD ratings of the full sample is 0.13. For the SP, MB_L.Earn and the $M B$ Forecast subsample, the rating scores are $-0.37,0.24$ and 0.40 , respectively. As to the $L P \bar{E} X \_$LEarn and the EX_Forecast subsample, we find that the average KLD ratings are $0.20,0.09$, and 0.03 , respectively. Change_CEO, ABN_ACC, $\triangle R E C T$, and Employee_Intensity do not differ much across the different subsamples.

\footnotetext{
${ }^{7}$ Following Cornett et al. (2008) and Kothari et al. (2005), we winsorize changes in employee numbers and changes in sales at $0.5 \%$ and $99.5 \%$ levels.
} 


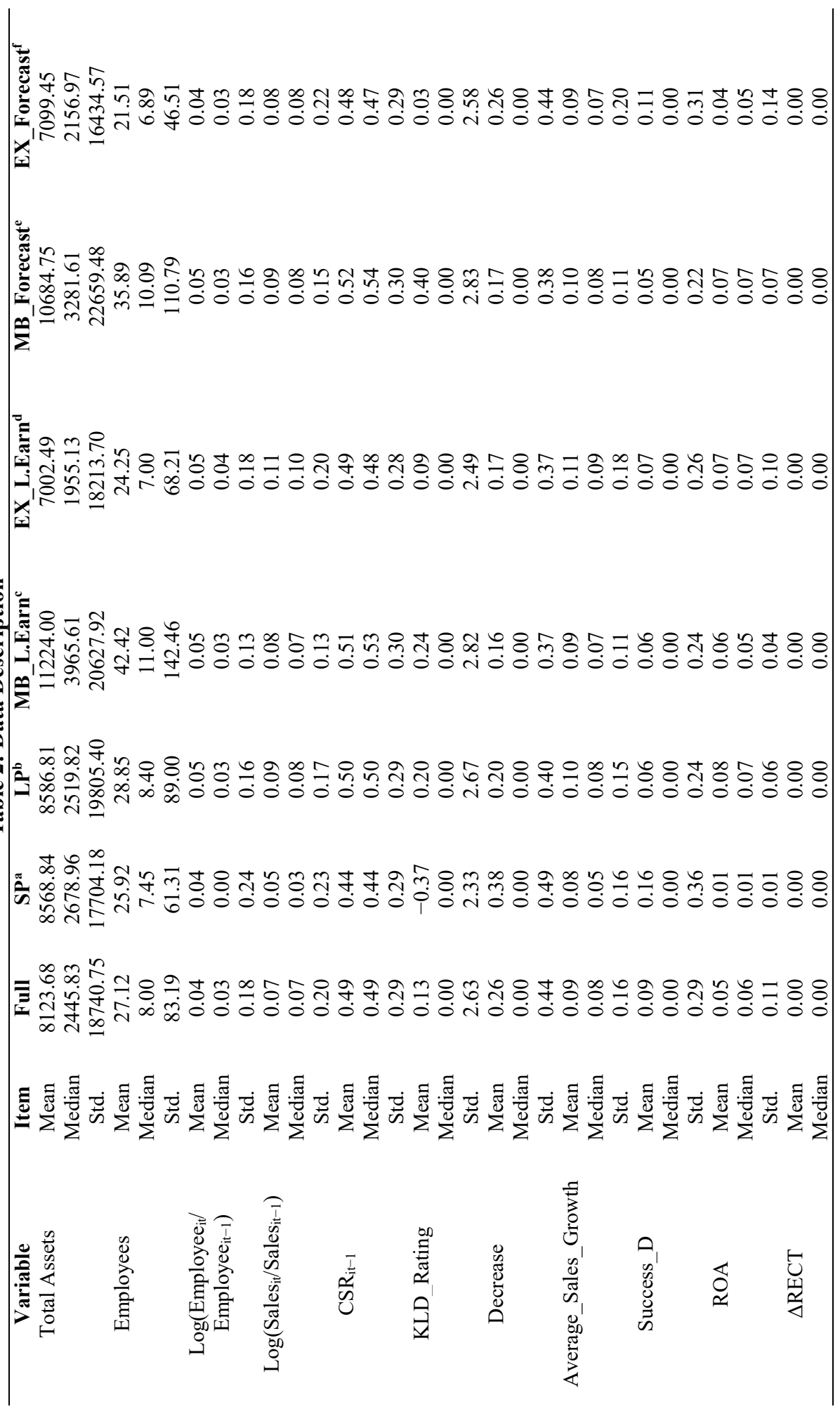


Do CSR firms "walk their talk"? An analysis of firing decisions of US firms

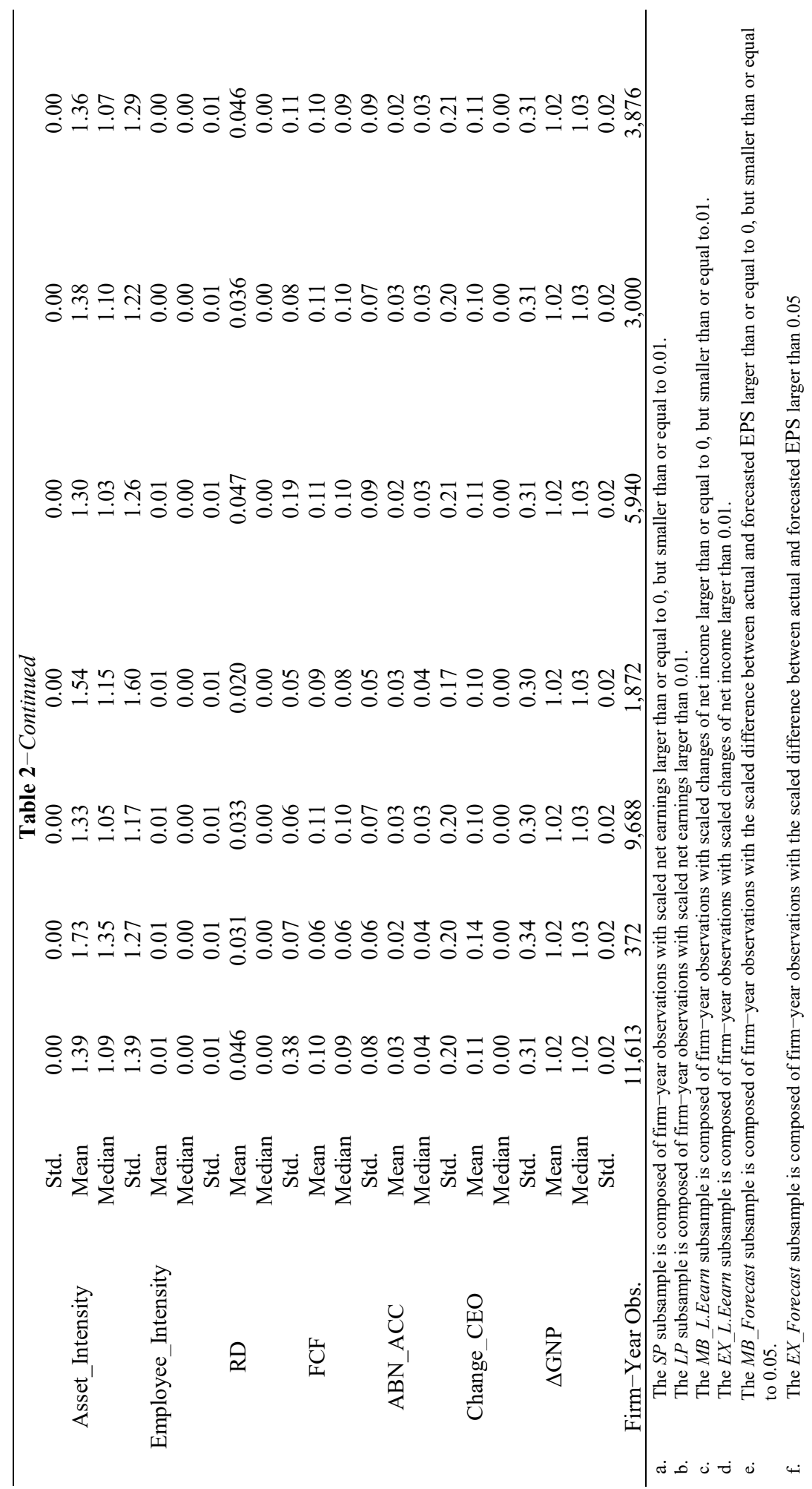




\subsubsection{Regression Results}

\section{Main Results}

The first column of Table 3 shows the estimation of Equation (2) for the full sample. In line with our expectations, we find a significantly positive coefficient of $\beta_{1}$, suggesting that for a one percent increase in sales, firms with zero $C S R_{i t-1}$ hire 0.405 percent more employees $\left(\beta_{1}\right.$ $=0.407, \mathrm{t}=9.60)$. The sign of $\beta_{2}$, which is the interaction between sales and the decrease dummy, is negative but not significant for the extended model $\left(\beta_{2}=-0.048, \mathrm{t}=-0.57\right)$. Regarding the three-way interaction variable $\log \left(\frac{\text { Sales }_{i t}}{\text { Sales }_{i t-1}}\right) \times$ Decrease $_{i t} \times$ CSR $_{i t-1}$, we find that $\beta_{3}$ is significantly negative in the extended model using a one-tailed test $\left(\beta_{3}=\right.$ $-0.193, \mathrm{t}=-1.32$ ). It provides marginal evidence that for a one percent decrease in sales, firms with a stronger claimed CSR orientation fire fewer employees than firms with a weaker claimed CSR orientation. The coefficient of the two-way interaction term $\log \left(\frac{\text { Sales }_{\text {it }}}{\text { Sales }_{i t-1}}\right) \times$ $C S R_{i t-1}$ is positively significant $\left(\beta_{4}=0.240, \mathrm{t}=2.88\right)$, suggesting that firms with the highest $C S R_{i t-1}$ hire 0.243 percent more employees for a one percent increase in sales than firms with the lowest $C S R_{i t-1}$.

With respect to the control variables, we find a significantly negative coefficient for the three-way interaction of $\log \left(\frac{\text { Sales }_{i t}}{\text { Sales }_{i t-1}}\right) \times$ Decrease $_{i t} \times$ Average_Sales_Growth $\left(\beta_{7}=\right.$ $-0.218, \mathrm{t}=-1.84)$, indicating that firms fire fewer employees in response to a sales decrease when the average sales growth rate in three continuous years is higher. Compared to firms without changes in CEO, firms that hire a new CEO on average fire 0.137 percent more employees when there is a one percent decrease in sales $\left(\beta_{16}=-0.136, t=-1.79\right)$. In addition, when GNP increases one percent, firms fire 5.97 percent fewer employees in response to one percent decrease in sales $\left(\beta_{17}=5.766, t=5.62\right)$. 
Table 3: Firing Decision Analysis for the Full Sample

\begin{tabular}{|c|c|c|}
\hline Variable & Pre. Sign & $\begin{array}{c}\text { Full } \\
\text { (I) }\end{array}$ \\
\hline$\beta_{0}:$ Constant & & $\begin{array}{l}81.37 \\
(1.42)\end{array}$ \\
\hline$\beta_{1}: \log \left(\right.$ Sales $_{\mathrm{it}} /$ Sales $\left._{\mathrm{it}-1}\right)$ & + & $\begin{array}{l}0.407 * * * \\
(9.60)\end{array}$ \\
\hline$\beta_{2}: \log \left(\right.$ Sales $_{\mathrm{it}} /$ Sales $\left._{\mathrm{it}-1}\right) *$ Decrease $_{\mathrm{it}}$ & - & $\begin{array}{l}-0.048 \\
(-0.57)\end{array}$ \\
\hline$\beta_{3}: \log \left(\right.$ Sales $_{\mathrm{it}} /$ Sales $\left._{\mathrm{it}-1}\right) *$ Decrease $_{\mathrm{it}} * \mathrm{CSR}_{\mathrm{it}-1}$ & - & $\begin{array}{l}-0.193 \\
(-1.32)\end{array}$ \\
\hline$\beta_{4}: \log \left(\operatorname{Sales}_{\mathrm{it}} / \text { Sales }_{\mathrm{it}-1}\right)^{*} \mathrm{CSR}_{\mathrm{it}-1}$ & & $\begin{array}{l}0.240^{* * *} \\
(2.88)\end{array}$ \\
\hline$\beta_{5}: \mathrm{CSR}_{\mathrm{it}-1}$ & & $\begin{array}{c}-0.022 * * \\
(-2.41)\end{array}$ \\
\hline$\beta_{6}:$ Decrease $\mathrm{it}_{\mathrm{it}-1}$ & & $\begin{array}{l}-0.004 \\
(-0.74)\end{array}$ \\
\hline$\beta_{7}: \log \left(\right.$ Sales $_{\mathrm{it}} /$ Sales $\left._{\mathrm{it}-1}\right) *$ Decrease $_{\mathrm{it}} *$ Average_Sales_Growth ${ }_{\mathrm{it}}$ & & $\begin{array}{l}-0.218^{*} \\
(-1.84)\end{array}$ \\
\hline$\beta_{8}: \log \left(\right.$ Sales $_{\mathrm{it}} /$ Sales $\left._{\mathrm{it}-1}\right) *$ Decrease $_{\mathrm{it}}{ }^{*}$ Success_D $_{\mathrm{it}}$ & & $\begin{array}{l}0.127 \\
(1.57)\end{array}$ \\
\hline$\beta_{9}: \log \left(\right.$ Sales $_{\mathrm{it}} /$ Sales $\left._{\mathrm{it}-1}\right) *$ Decrease $_{\mathrm{it}} * \mathrm{ROA}_{\mathrm{it}}$ & & $\begin{array}{l}-0.108 \\
(-0.77)\end{array}$ \\
\hline$\beta_{10}: \log \left(\right.$ Sales $_{\mathrm{it}} /$ Sales $\left._{\mathrm{it}-1}\right) *$ Decrease $_{\mathrm{it}} * \Delta \mathrm{RECT}_{\mathrm{it}}$ & & $\begin{array}{l}-8.986 \\
(-0.67)\end{array}$ \\
\hline$\beta_{11}: \log \left(\right.$ Sales $_{\mathrm{it}} /$ Sales $\left._{\mathrm{it}-1}\right) *$ Decrease $_{\mathrm{it}} *$ Asset_Intensity $_{\mathrm{it}}$ & & $\begin{array}{l}-0.005 \\
(-0.30)\end{array}$ \\
\hline$\beta_{12}: \log \left(\right.$ Sales $_{\mathrm{it}} /$ Sales $\left._{\mathrm{it}-1}\right) *$ Decrease $_{\mathrm{it}} *$ Employee_Intensity $_{\mathrm{it}}$ & & $\begin{array}{l}-1.294 \\
(-0.22)\end{array}$ \\
\hline$\beta_{13}: \log \left(\right.$ Sales $_{\mathrm{it}} /$ Sales $\left._{\mathrm{it}-1}\right) *$ Decrease $_{\mathrm{it}} * \mathrm{RD}_{\mathrm{it}}$ & & $\begin{array}{l}-0.018 \\
(-0.52)\end{array}$ \\
\hline$\beta_{14}: \log \left(\right.$ Sales $_{\mathrm{it}} /$ Sales $\left._{\mathrm{it}-1}\right) *$ Decrease $_{\mathrm{it}}{ }^{*} \mathrm{FCF}_{\mathrm{it}}$ & & $\begin{array}{l}0.172 \\
(0.64)\end{array}$ \\
\hline$\beta_{15}: \log \left(\right.$ Sales $_{\mathrm{it}} /$ Sales $\left._{\mathrm{it}-1}\right) *$ Decrease $_{\mathrm{it}} * \mathrm{ABN}_{-} \mathrm{ACC}_{\mathrm{it}}$ & & $\begin{array}{l}-0.05 \\
(-0.53)\end{array}$ \\
\hline$\beta_{16}: \log \left(\right.$ Sales $_{\mathrm{it}} /$ Sales $\left._{\mathrm{it}-1}\right) *$ Decrease $_{\mathrm{it}} *{ }^{*}$ Change_CEO $\mathrm{CEO}_{\mathrm{it}}$ & & $\begin{array}{c}-0.136^{*} \\
(-1.79)\end{array}$ \\
\hline$\beta_{17}: \log \left(\right.$ Sales $_{\mathrm{it}} /$ Sales $\left._{\mathrm{it}-1}\right) *$ Decrease $_{\mathrm{it}} * \Delta \mathrm{GNP}_{\mathrm{it}}$ & & $\begin{array}{l}5.766 * * * \\
(5.62)\end{array}$ \\
\hline$\beta_{18}: \log \left(\right.$ Sales $_{\mathrm{it}} /$ Sales $\left._{\mathrm{it}-1}\right) *$ Average_Sales_Growth ${ }_{\mathrm{it}}$ & & $\begin{array}{l}-0.253 * * * \\
(-5.31)\end{array}$ \\
\hline$\beta_{19}$ :Average_Sales_Growth & & $\begin{array}{l}0.129 * * * \\
(5.84)\end{array}$ \\
\hline$\beta_{20}:$ Success_D $D_{\text {it }}$ & & $\begin{array}{c}0.0126 \\
(1.31)\end{array}$ \\
\hline$\beta_{21}: \mathrm{ROA}_{\text {it }}$ & & $\begin{array}{l}-0.009 \\
(-0.19)\end{array}$ \\
\hline$\beta_{22}: \Delta \mathrm{RECT}_{\mathrm{it}}$ & & $\begin{array}{l}-0.523 \\
(-0.21)\end{array}$ \\
\hline$\beta_{23}$ :Asset_Intensity ${ }_{\mathrm{it}}$ & & $\begin{array}{l}0.018 * * * \\
(3.56)\end{array}$ \\
\hline$\beta_{24}:$ Employee_Intensity ${ }_{i t}$ & & $\begin{array}{l}0.965 \\
(1.03)\end{array}$ \\
\hline$\beta_{25}: \mathrm{RD}_{\text {it }}$ & & -0.004 \\
\hline
\end{tabular}




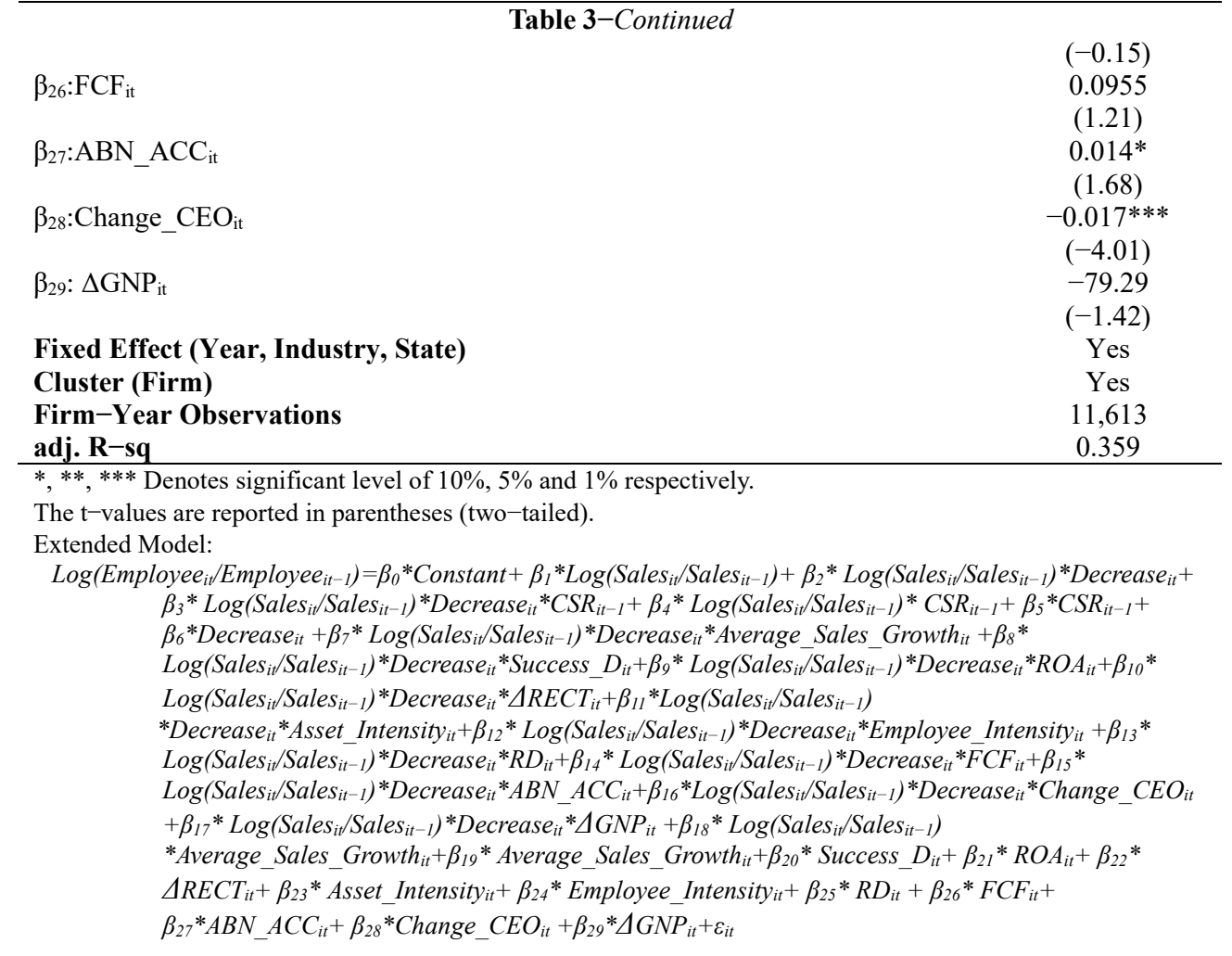

\section{Myopic Situations}

Next we examine the behavior of firms that report a small profit (the $S P$ subsample), that just meet or beat last year earnings (the $M B \_L$.Earn subsample), and that just meet or beat analyst forecasts (the $M B_{-}$Forecast subsample). We present our estimated results for the myopic subsamples in Table 4. For comparison, we provide the regression results for related subsamples where myopic decisions are less expected, for example, when firms report a large profit (the $L P$ subsample), exceed last year earnings (the EX_L.Earn subsample) and exceed analyst forecasts (the EX_Forecast subsample).

The first and second columns of Table 4 report regression results for the $S P$ and $L P$ subsamples. We find a significantly positive $\beta_{1}$ for the extended model for the $S P$ subsample $\left(\beta_{1}=0.344, t=2.28\right)$, suggesting that firms will hire more employees when sales go up for firms with zero $C S R_{i t-1}$. The estimated coefficient of the two-way interaction between sales ratio and the decrease dummy is negative, but not significant $\left(\beta_{2}=-0.186, \mathrm{t}=-0.38\right)$. The predicted value of $\beta_{3}$ of $-1.306(t=-2.39)$ suggests that for a one percent decrease in sales, firms with the strongest claimed CSR orientation fire 1.306 percent fewer employees than firms with the lowest claimed CSR orientation. In contrast, firms in the $L P$ subsample have weaker incentives to fire employees to report positive earnings. We find that that $\beta_{3}$ of the extended model is insignificant $\left(\beta_{3}=0.020, \mathrm{t}=0.12\right)$. The estimated $\chi^{2}$ is $7.64(\mathrm{p}-$ value $=$ 0.006 ), suggesting that the estimated $\beta_{3}$ of the $S P$ subsample is significantly different from 
that of the $L P$ subsample. These results are aligned with our second hypothesis that firms with a stronger claimed CSR orientation fire fewer employees in response to sales decreases when they are under pressure to report a positive profit.

The third and fourth columns of Table 4 report the regression results for the $M B \_L . E a r n$ and EX_L.Earn subsample. In line with our expectations, the coefficient of $\beta_{3}$ is significantly negative at $5 \%$ level $\left(\beta_{3}=-0.867, \mathrm{t}=-2.28\right)$ for the MB_L.Earn subsample. This suggests that when firms are to meet last-year earnings, firms with $C S R_{i t-1}$ of one fire 0.895 percent fewer employees than firms with $C S R_{i t-1}$ of zero for a one percent decrease in sales. In contrast, we do not find significant differences between firms with a stronger and weaker claimed CSR orientation regarding their firing decisions when firms largely excess last year earnings $\left(\beta_{3}=-0.245, \mathrm{t}=-1.17\right)$. Chi-square test shows that the two coefficients differ from each other using one-tailed test $\left(\chi^{2}=2.23, p=0.136\right)$.

Next, we report the results of the meet/beat-analyst-forecast-earnings subsample and the subsample of firm-year observations that largely beat analyst forecasts in the last two columns of Table 4. Similar to the $S P$ subsample, the estimated value of $\beta_{3}$ for the $M B \_$Forecast subsample is significantly negative for the extended model $\left(\beta_{3}=-0.849, \mathrm{t}=\right.$ -3.64). This indicates that firms with a higher claimed CSR orientation fire fewer employees for every one percent decrease in sales when faced with incentives to meet or beat analyst forecast. For comparison purpose, we present the results of the EX_Forecast subsample. The estimated coefficient of the three-way interaction is insignificantly negative $\left(\beta_{3}=-0.064, \mathrm{t}=\right.$ -0.28 ). To further compare the difference in the estimated coefficients across these two subsamples, we conduct a Chi-square test. The estimated $\chi^{2}$ is 6.25 with a p-value of 0.012 , which suggests that there is significant difference in the coefficients in the two subsamples.

In addition to dividing our sample into the SP subsample, the $M B_{-}$L.Earn subsample and the $M B_{-}$Forecast subsample, we combine the three subsamples and look at whether firm-year observations with stronger claimed CSR orientation in myopic subsample behave differently in terms of laying off employees following an activity decrease. In line with our expectation, untabulated result shows that $\beta_{3}$ is -0.812 with a $\mathrm{p}$-value of 0.000 for the myopic subsample. In contrast, the coefficient of variable of interest is not significant for the non-myopic subsample $\left(\beta_{3}=-0.055, \mathrm{t}=-0.32\right)$. The estimated $\chi^{2}$ is 8.43 with a $\mathrm{p}-$ value of 0.004 , which suggests that there is significant difference in the coefficients in the two subsamples. ${ }^{8}$

Taken together, the regression results reported in Tables 3 and 4 provide evidence that firms with a high claimed CSR orientation are less likely to fire employees following an activity decrease than low claimed CSR orientation firms. This effect is stronger in situations where managerial myopia is more likely by showing that the estimated coefficients of the $S P$ subsample, the MB_L.Earn subsample and the MB_Forecast subsample are significantly more negative than that of their comparison subsamples.

\footnotetext{
${ }^{8}$ Also, we look at observations who are "close to benchmarks" (e.g. observations with scaled earnings larger than or equal to -0.01 , but smaller than or equal to 0.01 ; or scaled changes in earnings larger than or equal to -0.01 , but smaller than or equal to 0.01 ; or scaled difference between actual and forecasted EPS larger than or equal to -0.05 , but smaller than or equal to 0.05 ) and those who are not close to the benchmarks. We only find significantly negative $\beta_{3}$ in the "close to benchmarks" subsample (untabulated). However, we are very careful in interpreting such result as close to benchmarks observations could include observations relating to firms that fail to meet benchmarks or relating to firms that do not have incentives to meet benchmarks (Dierynck et al. 2012).
} 


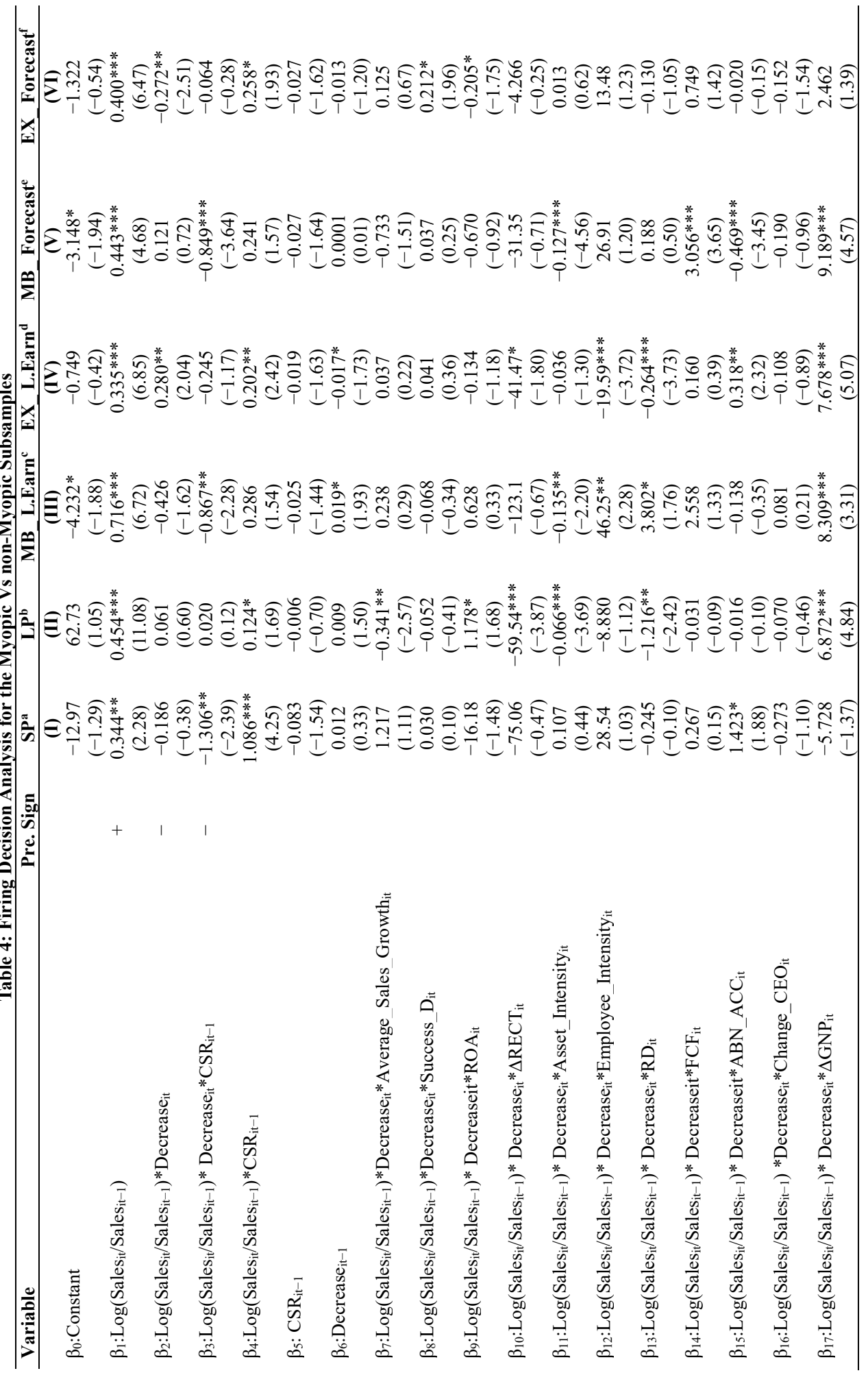




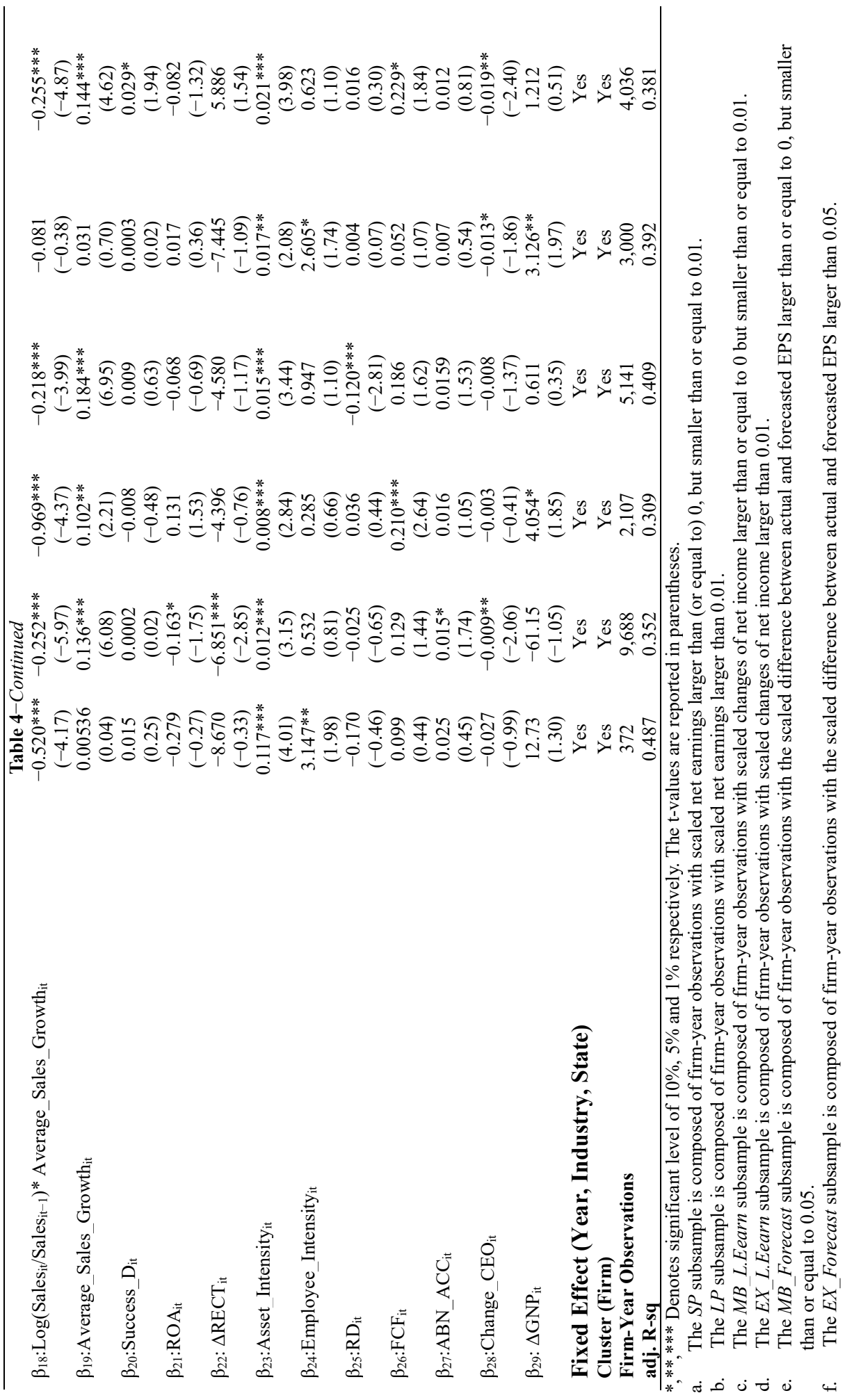




\section{Do firms with a higher claimed CSR orientation over employee dimensions fire fewer employees?}

In our main analysis, we measure the overall profile of firms' social responsibility instead of only looking into the "employee relationship" dimension because we aim to capture the overall CSR orientation. However, it might be relevant to further test whether firms with stronger claimed CSR orientation over employee dimensions fire fewer employees as a response to sales decreases. Therefore, we conduct analyses by capturing firms' claimed CSR orientation over the employee dimension only. The total employee score in the KLD database is calculated as the total strengths minus total concerns over employee dimension of the previous year. To better interpret the meanings of the coefficient, we transfer the discrete variable of employee score into a variable $\left(E M P_{i t-1}\right)$ whose distribution follows a Cumulative Distribution Function (CDF).

Table 5 shows the results of the full sample regression. As can be seen from the first column, the coefficient of the three-way interaction of $\log \left(\frac{\text { Sales }_{i t}}{\text { Sales }_{i t-1}}\right) \times$ Decrease $_{i t} \times$ $E M P_{i t-1}$ is negative, but insignificant $\left(\beta_{3}=-0.143, \mathrm{t}=-1.06\right)$. This suggests that firms with $E M P_{i t-1}$ of one do not fire fewer employees than firms with $E M P_{i t-1}$ of zero for a one percent decrease in sales. One reason for the insignificant coefficient could be that the variations in $E M P_{i t-1}$ is too small. Thus, it fails to capture enough the variations in firms' declared CSR orientation over employee dimensions. 
Table 5: Firing Decision Analysis for Firms with Different Employee Scores

\begin{tabular}{|c|c|c|}
\hline Variable & Pre. Sign & $\begin{array}{c}\text { Full } \\
\text { (I) }\end{array}$ \\
\hline$\beta_{0}:$ Constant & & $\begin{array}{l}81.62 \\
(1.44)\end{array}$ \\
\hline$\beta_{1}: \log \left(\right.$ Sales $_{\mathrm{it}} /$ Sales $\left._{\mathrm{it}-1}\right)$ & + & $\begin{array}{c}0.507 * * * \\
(11.76)\end{array}$ \\
\hline$\beta_{2}: \log \left(\right.$ Sales $_{\mathrm{it}} /$ Sales $\left._{\mathrm{it}-1}\right) *$ Decrease $_{\mathrm{it}}$ & - & $\begin{array}{l}-0.066 \\
(-0.75)\end{array}$ \\
\hline$\beta_{3}: \log \left(\right.$ Sales $_{\mathrm{it}} /$ Sales $\left._{\mathrm{it}-1}\right) *$ Decrease $_{\mathrm{it}} * \mathrm{EMP}_{\mathrm{it}-1}$ & - & $\begin{array}{l}-0.143 \\
(-1.06)\end{array}$ \\
\hline$\beta_{4}: \log \left(\text { Sales }_{\mathrm{it}} / \text { Sales }_{\mathrm{it}-1}\right)^{*} \mathrm{EMP}_{\mathrm{it}-1}$ & & $\begin{array}{l}0.020 \\
(0.27)\end{array}$ \\
\hline$\beta_{5}: \mathrm{EMP}_{\mathrm{it}-1}$ & & $\begin{array}{l}0.003 \\
(0.30)\end{array}$ \\
\hline$\beta_{6}:$ Decrease $\mathrm{e}_{\mathrm{it}-1}$ & & $\begin{array}{l}-0.004 \\
(-0.64)\end{array}$ \\
\hline$\beta_{7}: \log \left(\right.$ Sales $_{\mathrm{it}} /$ Sales $\left._{\mathrm{it}-1}\right) *$ Decrease $_{\mathrm{it}} *$ Average_Sales_Growth ${ }_{\mathrm{it}}$ & & $\begin{array}{l}-0.243^{*} \\
(-1.87)\end{array}$ \\
\hline$\beta_{8}: \log \left(\right.$ Sales $_{\mathrm{it}} /$ Sales $\left._{\mathrm{it}-1}\right) *$ Decrease $_{\mathrm{it}} *$ Success_D $_{\mathrm{it}}$ & & $\begin{array}{l}0.124 \\
(1.54)\end{array}$ \\
\hline$\beta_{9}: \log \left(\right.$ Sales $_{\mathrm{it}} /$ Sales $\left._{\mathrm{it}-1}\right) *$ Decrease $_{\mathrm{it}} * \mathrm{ROA}_{\mathrm{it}}$ & & $\begin{array}{l}-0.103 \\
(-0.78)\end{array}$ \\
\hline$\beta_{10}: \log \left(\right.$ Sales $_{\mathrm{it}} /$ Sales $\left._{\mathrm{it}-1}\right) *$ Decrease $_{\mathrm{it}} * \Delta \mathrm{RECT}_{\mathrm{it}}$ & & $\begin{array}{l}-6.456 \\
(-0.48)\end{array}$ \\
\hline$\beta_{11}: \log \left(\right.$ Sales $_{\mathrm{it}} /$ Sales $\left._{\mathrm{it}-1}\right) *$ Decrease $_{\mathrm{it}} *$ Asset_Intensity $_{\mathrm{it}}$ & & $\begin{array}{l}-0.004 \\
(-0.23)\end{array}$ \\
\hline$\beta_{12}: \log \left(\right.$ Sales $_{\mathrm{it}} /$ Sales $\left._{\mathrm{it}-1}\right) *$ Decrease $_{\mathrm{it}} *$ Employee_Intensity $_{\mathrm{it}}$ & & $\begin{array}{l}-1.398 \\
(-0.25)\end{array}$ \\
\hline$\beta_{13}: \log \left(\right.$ Sales $_{\mathrm{it}} /$ Sales $\left._{\mathrm{it}-1}\right) *$ Decrease $_{\mathrm{it}} * \mathrm{RD}_{\mathrm{it}}$ & & $\begin{array}{l}-0.011 \\
(-0.32)\end{array}$ \\
\hline$\beta_{14}: \log \left(\right.$ Sales $_{\mathrm{it}} /$ Sales $\left._{\mathrm{it}-1}\right) *$ Decrease $_{\mathrm{it}} * \mathrm{FCF}_{\mathrm{it}}$ & & $\begin{array}{l}0.204 \\
(0.79)\end{array}$ \\
\hline$\beta_{15}: \log \left(\right.$ Sales $_{\mathrm{it}} /$ Sales $\left._{\mathrm{it}-1}\right) *$ Decrease $_{\mathrm{it}}{ }^{*} \mathrm{ABN} \_\mathrm{ACC}_{\mathrm{it}}$ & & $\begin{array}{l}-0.050 \\
(-0.55)\end{array}$ \\
\hline$\beta_{16}: \log \left(\right.$ Sales $_{\mathrm{it}} /$ Sales $\left._{\mathrm{it}-1}\right) *$ Decrease $_{\mathrm{it}}{ }^{*}$ Change_CEO $\mathrm{CE}_{\mathrm{it}}$ & & $\begin{array}{l}-0.137^{*} \\
(-1.79)\end{array}$ \\
\hline$\beta_{17}: \log \left(\right.$ Sales $_{\mathrm{it}} /$ Sales $\left._{\mathrm{it}-1}\right) *$ Decrease $_{\mathrm{it}} * \Delta \mathrm{GNP}_{\mathrm{it}}$ & & $\begin{array}{l}6.169^{* * *} \\
(6.05)\end{array}$ \\
\hline$\beta_{18}: \log \left(\right.$ Sales $_{\mathrm{it}} /$ Sales $\left._{\mathrm{it}-1}\right) *$ Average_Sales_Growth ${ }_{\mathrm{it}}$ & & $\begin{array}{c}-0.235^{* * *} \\
(-4.34)\end{array}$ \\
\hline$\beta_{19}$ :Average_Sales_Growth ${ }_{\text {it }}$ & & $\begin{array}{c}0.128 * * * \\
(5.34)\end{array}$ \\
\hline$\beta_{20}:$ Success_D $D_{\text {it }}$ & & $\begin{array}{l}0.012 \\
(1.21)\end{array}$ \\
\hline$\beta_{21}: \mathrm{ROA}_{\mathrm{it}}$ & & $\begin{array}{l}-0.010 \\
(-0.21)\end{array}$ \\
\hline$\beta_{22}: \triangle \mathrm{RECT}_{\text {it }}$ & & $\begin{array}{l}-0.265 \\
(-0.11)\end{array}$ \\
\hline$\beta_{23}$ :Asset_Intensity ${ }_{i t}$ & & $\begin{array}{c}0.018 * * * \\
(3.58)\end{array}$ \\
\hline$\beta_{24}:$ Employee_Intensity ${ }_{i t}$ & & $\begin{array}{l}0.971 \\
(1.04)\end{array}$ \\
\hline$\beta_{25}: \mathrm{RD}_{\text {it }}$ & & -0.005 \\
\hline
\end{tabular}




\section{Table 5-Continued}

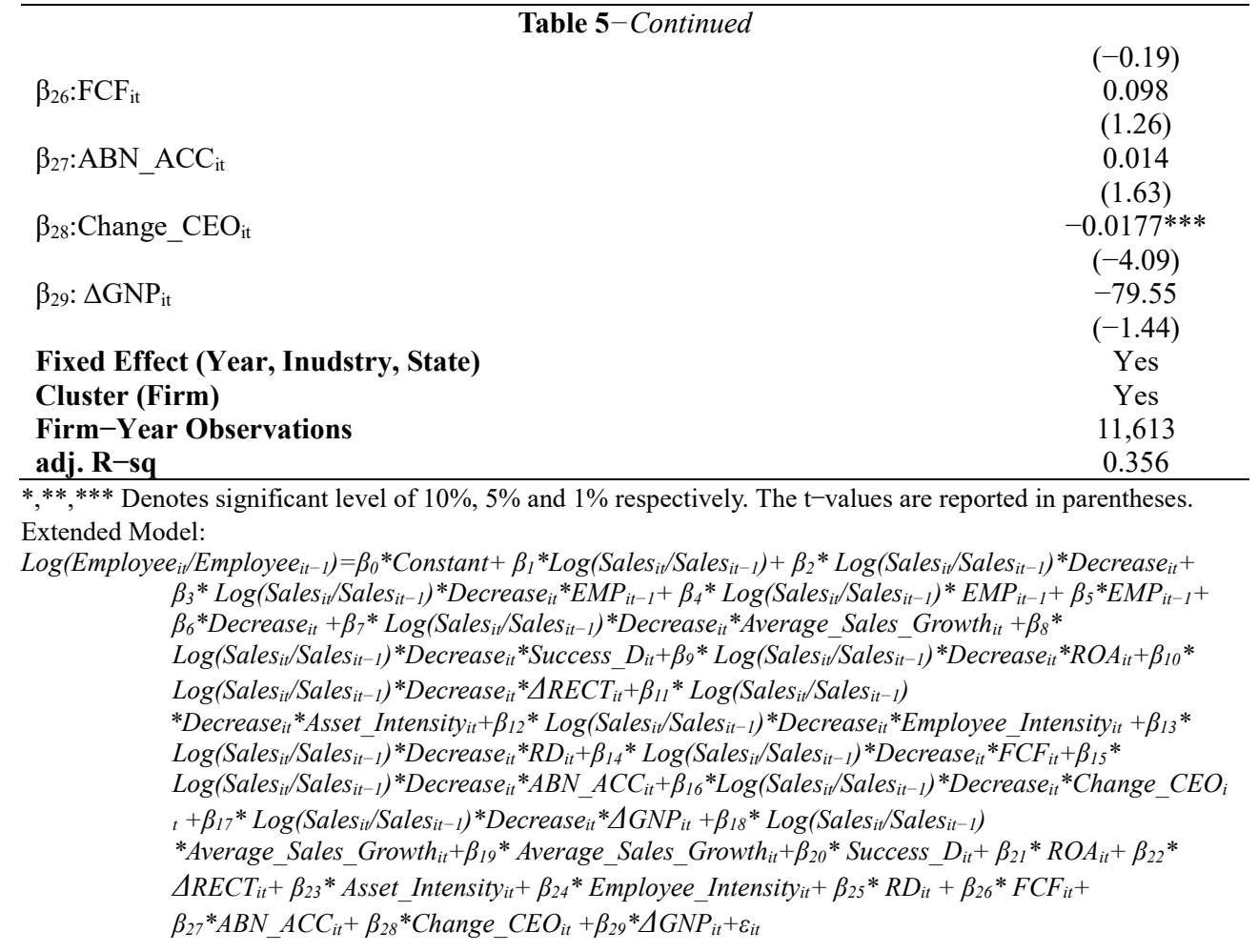

Next, we investigate whether the difference regarding employee dismissal is more pronounced between firms with a stronger and weaker claimed employee orientation focusing on the myopic subsamples. The results are shown in Table 6. The first and second columns show the results of the $S P$ and $L P$ subsample, respectively. The estimated value of $\beta_{3}$ for the $S P$ subsample is significantly negative for the extended model using a one-tailed test $\left(\beta_{3}=\right.$ $-1.107, \mathrm{t}=-1.37)$. Similarly, we also do not find a significant coefficient of the $L P$ subsample $\left(\beta_{3}=0.105, \mathrm{t}=0.62\right)$. Chi-square test suggests that the two coefficients are significantly different using one-tailed test $\left(\chi^{2}=3.09, \mathrm{p}=0.0789\right)$. We do not observe significant coefficients in the MB_L.Earn subsample $\left(\beta_{3}=-0.355, \mathrm{t}=-0.94\right)$ and the EX_L.Earn subsample $\left(\beta_{3}=-0.050, \mathrm{t}=-0.72\right)$ either. For the subsample analysis of firms just meeting or beating analyst forecasts versus firms largely exceeding analyst forecasts, we only observe a significantly negative coefficient of $\beta_{3}$ in the MB_Forecast subsample $\left(\beta_{3}=\right.$ $-0.719, \mathrm{t}=-2.65)$. For the EX_Forecast subsample, the coefficient of $\beta_{3}$ is insignificant $\left(\beta_{3}=\right.$ $0.052, \mathrm{t}=0.24)$. The Chi-square test shows that the coefficients significantly differ between the two subsamples $\left(\chi^{2}=5.16, \mathrm{p}=0.023\right)$. It indicates that firms with $E M P_{i t-1}$ of one results in 0.719 percent fewer employees being fired in response to a sales decrease than firms with $E M P_{i t-1}$ of zero when under the pressure to meet or beat analyst forecasts. In addition, compared to firms that do not have the pressure to meet or beat analyst forecasts, the difference of firms with a higher and lower claimed employee orientation regarding firing decision is more pronounced for firms that have such pressure. 


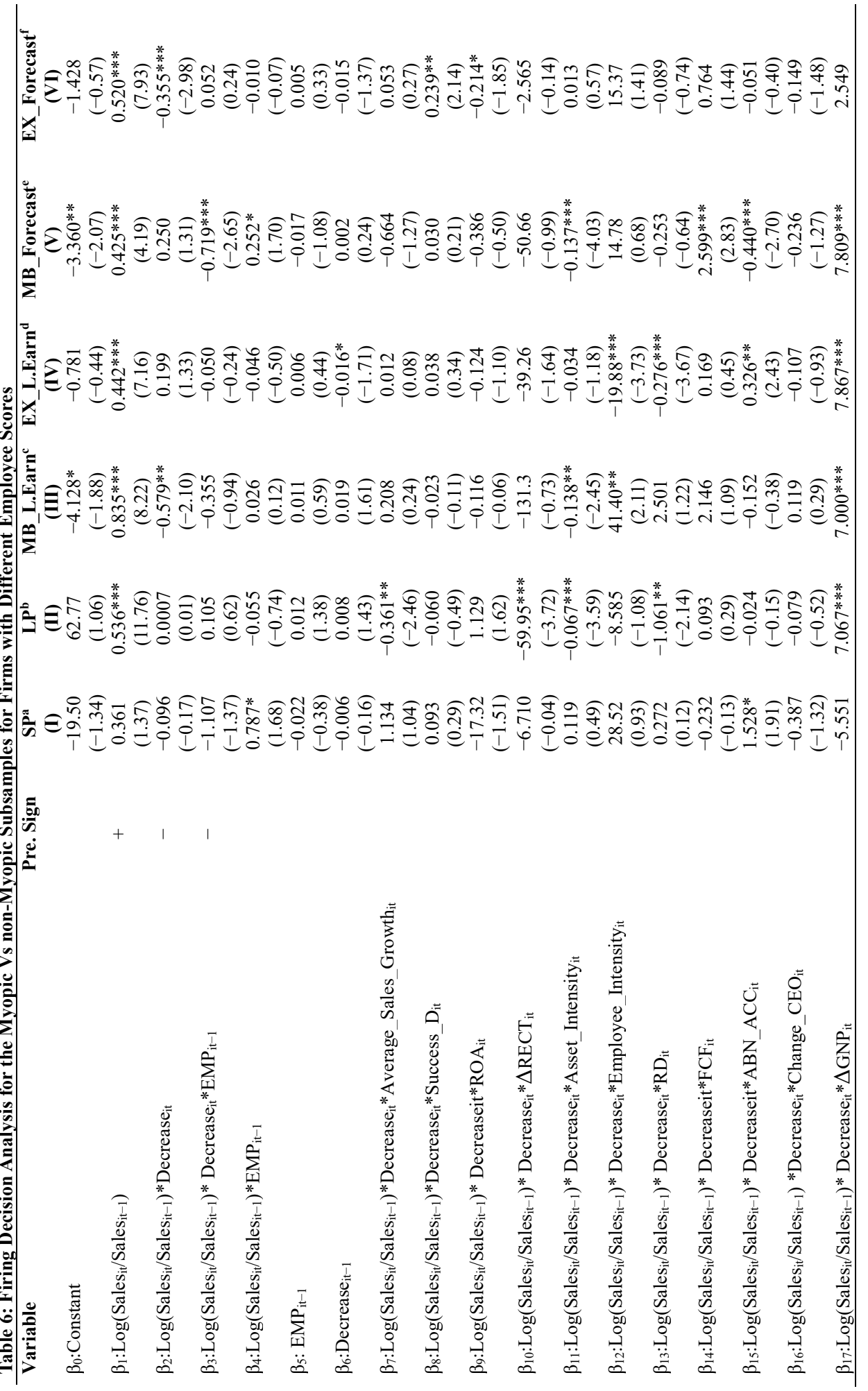




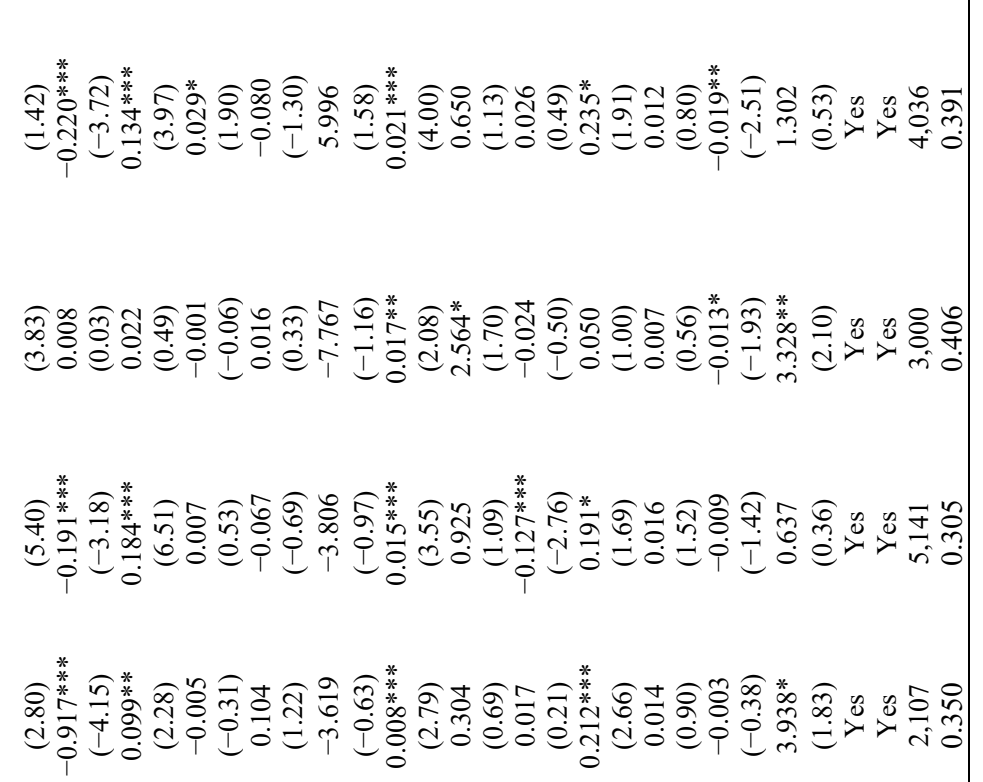

๙



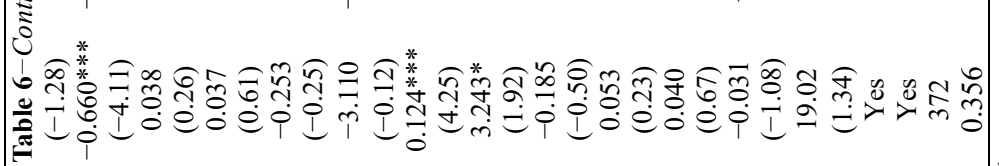




\subsection{Robustness Tests and Additional Analyses}

In this section, we conduct several additional tests to examine the sensitivity of our findings with respect to firing decisions of firms with varying claimed CSR orientation when activities decrease.

\subsubsection{Common Trend Analysis}

One possibility why we find differences regarding firing decisions is that firms that claim a stronger or weaker CSR orientation may have different characteristics. For example, some have argued that compared with small- or median-sized firms, large companies are more likely to identify relevant stakeholders and meet their demands through formal CSR practices (Perrini et al, 2007; Russo and Perrini, 2010). Although we have controlled for variables that may drive the differences in CSR strategy, the choice of CSR-related strategies might not be random as there are significant differences in business model variables. As an additional test to control for firms' observable characteristics, we conduct a common trend analysis. Specifically, we require that the total assets, market value, research and development expenses, advertisement expenses, and employee number of firm-year observations with above-median claimed CSR orientation to be within the same ranges with firm-year observations whose claimed CSR orientation is equal to or below the median value.

Untabulated results show that our conclusion does not change materially. After dropping firm-year observations whose total assets, market value, research and development expenses, advertisement expenses, and employee number are out of the common ranges, we find the coefficient of $\beta_{3}$ significantly negative using one-tailed test $\left(\beta_{3}=-0.202, \mathrm{t}=-1.55\right)$, suggesting that compared to firms with a lower claimed CSR orientation, firms with a higher claimed CSR orientation fire fewer employees for a one percent decrease in sales. Next, split sample analysis shows that when firms are to meet earnings benchmarks, the differences between firms with a stronger and firms with lower claimed CSR orientation regarding firing decision become more obvious. ${ }^{9}$

\subsubsection{Firms with non-Negative and Negative KLD Ratings}

In sections above, we transfer the KLD ratings to a continuous variable whose distribution follows a CDF. To further analyse whether firms with a non-negative claimed CSR orientation fire fewer employees in a response to sales decreases, we categorize KLD scores

\footnotetext{
${ }^{9}$ The coefficient of $\beta_{3}$ for the $S P(L P)$ subsample is $-1.490(0.029)$ with a $t-$ value of $-2.68(-0.18)$. The $\chi^{2}$ is equal to $9.80(\mathrm{p}=0.0017)$, suggesting that the coefficient of $\beta_{3}$ differs significantly between the two subsamples. For the MB_L.Earn (EX_L.Earn) subsample, the coefficient of $\beta_{3}$ is $-0.834(-0.27)$ with a $\mathrm{t}-\mathrm{value}$ of -2.17 $(-1.35)$. The $\chi^{2}$ is equal to $1.84(\mathrm{p}=0.1745)$, suggesting that the coefficient of $\beta_{3}$ differs marginally between the two subsamples. The coefficient of $\beta_{3}$ for the MB_Forecast (EX_Forecast) subsample is $-0.825(-0.132)$ with a $\mathrm{t}-$ value of $-3.48(-0.59)$. The $\chi^{2}$ is equal to $4.94(\mathrm{p}=0.0262)$, suggesting that the coefficient of $\beta_{3}$ differs significantly between the two subsamples.
} 
into non-negative scores and negative scores. Specifically, we create an indicator variable $D C S R$ that is equal to one if the KLD score is equal to or higher than zero. If the KLD score is negative, DCSR is equal to zero. Next, we interact the lagged value of DCSR with

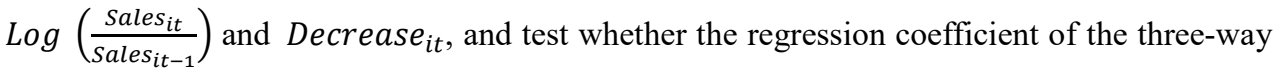
interaction of $\log \left(\frac{\text { Sales }_{i t}}{\text { Sales }_{i t-1}}\right) \times$ Decrease $_{i t} \times D C S R_{i t-1}$ is significant.

Untabulated results show that $\beta_{3}$ is negative, but insignificant for the three-way interaction of $\log \left(\frac{\text { Sales }_{i t}}{\text { Sales }_{i t-1}}\right) \times$ Decrease $_{i t} \times D$ CSR $_{i t-1}$ in the model $\left(\beta_{3}=-0.056, \mathrm{t}=-0.65\right)$. It suggests that there is no difference between firms with a negative or non-negative claimed CSR orientation with respect to their firing decisions following a sales decrease.

We further investigate whether there is a difference when firms are to meet or beat earnings benchmarks. Untabulated results show that we do find significantly negative coefficients in the $S P$ subsamples using a one-tailed test $\left(\beta_{3}=-0.533, \mathrm{t}=-1.38\right)$. In the $L P$ subsamples, we do not find significant coefficient either $\left(\beta_{3}=-0.015, \mathrm{t}=-0.15\right)$. The Chisquare test shows that the two coefficients are significantly different from each other using one-tailed test $\left(\chi^{2}=2.39, \mathrm{p}=0.1222\right)$. It provides marginal evidence that firms with nonnegative claimed CSR fire fewer employees following a short-term activity decrease when they are under the pressure to meet/beat zero earnings benchmarks.

In the $M B_{-}$L.Earn subsample, we find the coefficient of $\beta_{3}$ significantly negative using one-tailed test $\left(\beta_{3}=-0.289, \mathrm{t}=-1.22\right)$, suggesting that firms with non-negative claimed CSR orientation fire 0.289 percent fewer employees than firms with negative claimed CSR orientation for one percent decrease in sales. We further compare this coefficient with the coefficient from the EX_L.Earn subsample $\left(\beta_{3}=-0.099, \mathrm{t}=-0.81\right)$. However, we did not find the coefficients significantly differ from each other in these two subsamples.

With respect to firms that are under the pressure to meet or beat analyst forecast, we find significantly negative coefficient in the $M B_{-}$Forecast subsample $\left(\beta_{3}=-0.50, \mathrm{t}=-3.42\right)$. In contrast, the coefficient of $\beta_{3}$ is insignificant in the $E X$ Forecast subsample $\left(\left(\beta_{3}=0.066, \mathrm{t}\right.\right.$ $=0.54)$. The Chi-square test shows that the two coefficients are significantly different from each other using one-tailed test $\left(\chi^{2}=9.07, p=0.0026\right)$. It provides evidence that firms with non-negative claimed CSR fire fewer employees following a short-term activity decrease when they are under the pressure to meet/beat analyst forecast.

\subsection{Conclusion and Discussion}

This study examines whether variations in claimed CSR orientation are reflected in firms' decisions regarding human capital when faced with short-term activity decreases. We further investigate whether incentives to meet earnings benchmarks influences firms' firing decision differently for firms with stronger or weaker claimed CSR orientation. Our findings show that firms with a high claimed CSR orientation fire fewer employees than firms with a low claimed CSR orientation following a short-term sales decrease. Analysing subsamples where managerial myopia is more likely, we find that the differences between high claimed and low claimed CSR firms regarding firing decisions are accentuated when firms face pressure to report positive earnings, to meet or beat prior year earnings or analyst forecasts. This suggests 
that the negative relationship between claimed CSR orientation and firms' firing decision is not crowded out by incentives to meet earnings benchmarks. Overall, our findings suggest that firms indeed practice what they preach in terms of employee dismissal decisions. Our findings reveal that firms with a higher claimed CSR orientation value human capital more and will incorporate these benefits when making dismissal decisions. In short, our findings show that firms with a higher claimed CSR orientation indeed walk their talk.

One alternative interpretation is that pessimistic future expectations can be a good reason to fire employees. To the extent that CSR orientation is systematically associated with these future expectations, our findings might be driven by firms' pessimistic expectation. However, Lys et al. (2016) find that although firms' CSR orientation is not positively associated with positive future financial benefits, such orientation signals firms' optimistic expectations to the future. We further rule out this alternative explanation by including multiple proxies as indicators for managers' future prospects. Our inferences are robust to various controls for future sales expectations.

This study is related to, but different from the line of research that investigates CSR and cost stickiness (e.g. Liu et al. 2017; Habib and Hasan 2016). While Liu et al. (2017) and Habib and Hasan (2016) shows that firms with stronger CSR orientation are less likely to cut SG\&A cost when sales drops, we examine the influence of managerial incentives on firing decision in firms with stronger and weaker claimed CSR orientation. We do not find significant difference in reducing the number of employees in firms that report a healthy profit. The difference of firing employees following an activity decrease in firms with stronger and weaker claimed CSR orientation is only observed when firms have strong incentive to meet earnings benchmarks. In this sense, our study differs from Liu et al. (2017) and Habib and Hasan (2016) by providing evidence that managerial incentive as an important factor to consider when analysing firms' CSR orientation and cost-adjustment behaviors.

Our study contributes to the contemporaneous literature in three ways. First, by addressing the influence of CSR on firms' firing decision under different managerial incentives, our study contributes to the stream of literature on how managerial incentives to meet earnings benchmarks influence resource adjustment decisions (e.g. Kama and Weiss, 2010; Dierynck et al. 2012). For instance, Dierynck et al (2012) show that managers of firms reporting a small profit focus on firing low-cost employees. Our study suggests that when firms have a strong claimed CSR orientation, they are less likely to do so to meet earnings benchmarks. While meeting earnings' benchmark pressure is often associated with firms' myopic decision such as firing employees, our finding suggests that firms' CSR related orientation may relieve the negative impact of earnings' benchmarks. Second, our results reveal that the difference between firms with a high claimed and low claimed CSR orientation is most pronounced in situations where managerial myopia is more likely. This suggests that investors can gather valuable information about the true CSR-commitment of a firm by carefully analysing managerial decisions in myopic situations. Another contribution of the paper is regarding the validity of KLD ratings. Quite some researchers have criticized these ratings for not being reliable and not reflecting how CSR is dealt with inside the firm. This study provides some evidence about the word-deed alignment of claimed CSR orientation with respect to human capital, indicating that KLD ratings are good predictors of corporate behaviour. 
Chapter 2

One of the main limitations is that we only investigate decisions regarding human capital and firing decisions in particular. CSR encompasses much more decisions than the ones we investigate in our paper. Future research may test whether our findings holds for other types of managerial such as compensation design and promotion decisions. 


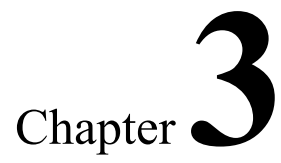

The Complementarity between CSR Disclosures and the Use of CSR-based Performance Measures in CEO Annual Contracts 


\begin{abstract}
$^{10}$
Corporate Social Responsibility (CSR) has become an integral part of conducting business around the world. However, firms differ in the extent to which they communicate their CSRrelated efforts to their stakeholders (henceforth, "CSR disclosures") and in the extent to which they incorporate CSR-based performance measures in executives' incentive contracts (henceforth, "CSR contracting"). In this study, we examine the relationship between these two strategies and argue that CSR disclosures and CSR contracting are complements, as they both demonstrate a strong CSR orientation of the firm to the market. We further argue that this complementarity is not uniform but varies with the context. In particular, we hypothesize that firms that have a strong CSR orientation but face higher credibility concerns show stronger complementarity between the two strategies and are more likely to use both strategies intensively. Using hand-collected data to capture disclosure intensity of CSR reports and intensity of CSR contracting, we find evidence that is largely consistent with our predictions.
\end{abstract}

${ }^{10}$ This chapter is based on a working paper together with Prof. Isabella Grabner and Dr. Annelies Renders. 


\subsection{Introduction}

Corporate social responsibility (CSR) has become increasingly popular over the past 20 years. Besides maximizing shareholders' wealth, firms are also expected to contribute to a more harmonious society and a better environment by integrating the needs of various stakeholders into their internal business decisions (McWilliams and Siegel 2001; Hopkins 2003; Kitzmueller and Shimshack 2012). In response to this, firms are using different ways to communicate their CSR engagement (KPMG 2013). This is typically done by issuing a CSR report. Alternatively, firms can show their CSR commitment by incorporating CSR-based performance measures in senior executives' incentive contracts, a trend commonly referred to by practitioners as "CSR contracting" (Ditillo and Lisli 2016; Flammer et al. 2017).

This study empirically investigates the relationship between CSR contracting and CSR disclosures. Up-to-date, very few papers have investigated the interplay between external and internal CSR strategies, although Basu and Palazza (2008) note that "recognizing patterns of interrelationships of CSR-related choices might lead to a better understanding of a firm's CSR impact."

We address this issue by investigating whether and how the use of CSR contracting is related with CSR disclosures. We argue that CSR contracting and CSR disclosures are complements and this for two reasons. First, firms with a strong CSR orientation can use both strategies as alternatives to signal their CSR orientation to their stakeholders, but the combination of the two strategies will most likely increase a firm's credibility with respect to CSR-related activities. On a stand-alone basis, CSR disclosures suffer from credibility concerns. As CSR disclosures are voluntary in nature and usually not assured, CSR disclosures are not viewed as a costly signal to the market about the CSR orientation of the firm. As a consequence, for CSR disclosures to be credible, it is important that CSR is an integral part of a firm's objective function, as reflected by executives' incentive contracts (Armstrong et al. 2010). This leads to a deeper integration of sustainability in the organizational strategy through the use of more formal controls (Gond et al. 2012). This also ties in with the notion that CSR practices should be consistent by actively embedding CSR in the organization's (external) conversations and (internal) processes (Basu and Palazzo 2008). Consequently, firms with a strong CSR orientation are more likely to use CSR contracting too as this in turn renders the CSR disclosures more credible. In other words, it allows them to differentiate themselves from firms that are only "window-dressing" in their CSR reports in response to stakeholder pressures. Vice versa, CSR disclosures also increase the credibility of CSR contracting. Allowing stakeholders to observe, through the disclosures, how changes in CSR performance translate into changes in CEO compensation increases confidence that CSR-based performance measures are not merely window-dressing and that the firm has a strong CSR orientation. In addition, the disclosures allow investors to recognize the internal CSR orientation of the firm which should result in higher firm value (Hawn and Ioannou 2016). In short, firms with a strong CSR orientation are more likely to use the two strategies simultaneously, as this reduces credibility concerns and is a costly signal to the market.

Second, besides these credibility gains, the net benefits of each of these CSR strategies also increase by using the other strategy, as the relative information acquisition costs decrease. The use of CSR contracting requires the collection and management of CSR- 
related measures in the performance management system, which makes the subsequent disclosure of this information less costly. Vice versa, the disclosure of how the firm performs with regard to CSR makes it easier for the board of directors to decide which measures to contract upon.

Overall, we argue that for firms with strong CSR orientation, the net benefits of each CSR strategy increase by their joint use because of higher benefits through credibility gains and lower costs through relatively lower information acquisition costs. We argue that the combination of these two strategies allow firms to demonstrate their true CSR orientation.

There are, however, several reasons why we might not expect a relationship between the two strategies. First, CSR disclosures and CSR contracting could be viewed by companies as two unrelated strategies. The issuance of CSR reports satisfies external investors' information demand (Dhaliwal et al. 2011), while CSR contracting focuses on incentivizing managers' behaviour on CSR dimensions. As the two strategies serve different purposes, firms may not find it necessary to coordinate their adoption and implementation and may not view them as a way to demonstrate the firm's CSR orientation. Second, it is also possible that firms, on average, engage to a greater extent in CSR disclosures than CSR contracting because they are typically "window-dressing" in their CSR reports in response to stakeholder pressures (Meyer and Rowan 1977; Simnett et al. 2009; Adams et al. 2011; Casey and Grenier 2015; Cohen and Simnett 2014), rather than having a true CSR orientation. For example, British Petroleum (BP) has been repeatedly accused by Greenpeace of greenwashing activities, as it external communications try to create an image of a firm that is investing in alternative energy sources, while its internal actions have remained unchanged.

Given that both CSR disclosures and CSR contracting are costly to firms, we further argue that the complementarity between CSR disclosures and CSR contracting is not uniform but depends on the context (Grabner and Moers 2013). In particular, we argue that in firms in industries that are under greater public scrutiny regarding CSR activities, i.e., industries that are often blamed to be greenwashing, credibility concerns play a more important role in the choice of CSR strategies. Thus, we expect that firms with a strong CSR orientation in these industries face higher credibility concerns and are hence more likely to invest in both strategies.

Our research proceeds in two steps. First, we hand-collect detailed information on CSR disclosures and CSR-based performance measures in incentive contracts using standalone CSR reports and the proxy statements for the S\&P500 firms for 2013. The final sample consists of 343 firm observations. We use conditional correlation analysis to examine the relationship between (the intensity of) CSR contracting and (the intensity of) CSR disclosures. We find indeed that CSR disclosures and CSR contracting are complements. We further show that firms in high public scrutiny industries are more likely to use both strategies and to use them more intensively, providing support for our underlying theory that the choice of CSRrelated strategies is indeed driven by credibility concerns.

With the exception of Hawn and Ioannou (2016), existing literature on the relationship between CSR disclosures and CSR contracting is scant, as most literature either focuses on CSR disclosures (Simnett et al. 2009; Dhaliwal et al. 2011) or investigates CSR contracting (Flammer et al. 2017). Hawn and Ioannou (2016) investigate the effect of the interplay between a firm's external and internal CSR actions on market value. They find that 
a gap between external and internal CSR actions results in a lower market value. Rather than examining the effect on outcome variables, we take one step back and investigate whether a relationship between external and internal CSR actions exists and which form this relationship takes.

In doing so, our research answers the call in Basu and Palazzo (2008) to increase our understanding of the interrelationships of CSR-related choices and to generate a rich research agenda that links key organizational features to CSR character. As a consequence, our study has important practical implications for stakeholder groups who care about CSR. We argue that besides looking at CSR disclosures, it is equally important to look at firms' compensation practices to find out which firm has a strong CSR orientation.

We also contribute to the management accounting literature on non-financial performance measures by focusing on CSR-based performance measures. ${ }^{11}$ CSR-based performance measures differ from other non-financial performance measures in several ways. Unlike prior research that generally suggests a positive performance effect of including certain non-financial performance measures (e.g., customer satisfaction), the underlying rationale of using CSR-based performance measures is unknown. On the one hand, firms' motivation of conducting CSR activities is ambiguous as it could be driven by greenwashing incentives or stem from core firm values. On the other hand, prior research is inconclusive regarding the performance effects of CSR contracting. By looking into details of performance measure choices in CEO incentive contracts, we show that despite their complexity, CSRbased performance measures are frequently used as a complementary choice with CSR disclosures.

The findings of this study are not only limited to the CSR context. As CSR-related strategies are often long-term oriented and the outcomes of CSR-related activities are uncertain, which is similar to other long-term investments a firm undertakes, for instance $\mathrm{R} \& \mathrm{D}$ investments, the complementarity between CSR disclosures and CSR contracting can be generalized to other long-term oriented strategies as well.

This study also contributes to the accounting literature by providing evidence of a relationship between firms' external reporting choices and their internal organizational design choices, thereby demonstrating a link between financial and management accounting. The CSR setting is ideal to investigate the complementarity between external disclosures and internal incentives because both CSR disclosures and CSR contracting are voluntary choices. It therefore provides a setting in which we can examine firms' choices of engaging in such activities, which is not applicable to mandatory disclosure requirements. Our insights contribute to what we believe is an upcoming and highly promising stream of research on the interaction between management and financial accounting (see also Hemmer and Labro 2008; Labro 2015).

\footnotetext{
${ }^{11}$ Based on observation of our data, in most cases CSR performance measures are in non-financial dimensions.
} 


\subsection{Prior Literature and Hypothesis Development}

The concept of CSR has triggered a long and controversial discussion. Despite the debate on the conceptualization of CSR in the literature, there is a consensus that businesses can no longer act as isolated economic entities operating in detachment from broader society. Firms are expected to voluntarily contribute to a more harmonious society by integrating social and environmental needs in their internal business decisions (Clarkson 1995; Wood and Jones 1995; Maignan et al. 1999). In line with this view, Kitzmueller and Shimshack (2012) propose that CSR can be characterized as (1) voluntary behaviour of the firm that is (2) focused on maximizing long-run shareholder wealth by (3) refraining from activities that increase short-run shareholder wealth at the expense of the long-run interests of one or more stakeholder groups.

As a consequence, CSR has become more prevalent as investors, customers and other stakeholders demand greater transparency about all aspects of business (Simnett et al. 2009; Kim et al. 2012). Following this trend, firms are looking for different ways to communicate their CSR engagement (Weaver et al. 1999). One way of doing this is by issuing a CSR report. For instance, a typical CSR report contains a large amount of non-financial information, such as expenditures related to environmental protection and climate change, charity donations, and employee welfare (Dhaliwal et al. 2014). Alternatively, some firms show their commitment by incorporating CSR-based performance measures in their senior executives' incentive contracts, i.e., CSR contracting. Bonus plans that are explicitly tied to CSR performance may serve as a signal to outside stakeholders that the firm is monitoring and incentivizing executives' CSR commitment (Armstrong et al. 2010).

Both CSR strategies have been investigated in prior research. For example, one stream of literature focuses on the economic consequences of firms issuing CSR reports. For example, Dhaliwal et al. (2011) analyse first-time issued CSR reports over the years 19932007 and find that firms with a higher cost of capital are more likely to issue a CSR report. A second stream of literature focuses on the incorporation of CSR into performance measurement and incentive systems. Agency theory states that a principal designs an incentive contract to motivate the work-averse agent to put effort in desired directions. In other words, performance measures that provide incremental information on the actions the principal wishes to motivate to promote congruence between the principal's objectives and those of the agent should be included in incentive contracts (Holmstrom 1979; Banker and Datar 1989; Feltham and Xie 1994). If a principal has a desire for CSR, CSR-related incentives should be used to encourage agents' effort on CSR-related issues.

However, both CSR disclosures and CSR contracting are subject to credibility issues. While they may bring some economic advantages to firms, CSR disclosures are often received with much scepticism as they are subject to very few regulations. Although some accounting and consulting firms provide voluntary assurance services, the assurance and verifiability of multi-dimensional CSR disclosures are considered to be poor. In addition, there are no uniform criteria to regulate the assurance, which makes the comparability and verifiability of CSR disclosures very difficult for external parties (Abbott et al. 1979; Simnett et al. 2009; Dhaliwal et al. 2011; Casey and Grenier 2015; Cohen and Simnett 2014). Given the nature of CSR disclosures, it is frequently argued that CSR disclosures are "cheap talk" or 
"greenwashing" (Ingram and Frazier 1980; Hobson and Kachelmeier 2005; Adams et al. 2011).

Similarly, prior research suggests that firms can symbolically use CSR contracting as well. While prior research in general shows a positive association between non-financial performance measures (e.g., customer satisfaction) and firms' financial performance, studies examining the relationship between executives' compensation and CSR performance fail to find consistent results (McGuire et al. 2003; Mahoney and Thorne 2005; Campbell et al. 2007; Berrone and Gomez-Mejia 2009a; Cai and Pan 2011). For example, Berrone and GomezMejia (2009a) find that firms with an explicit environmental pay policy do not reward environmental strategies more than firms without these policies.

Observing that firms are exerting effort on both CSR disclosures and CSR contracting but that both strategies have credibility issues, the question arises whether and how firms can credibly demonstrate that they have a strong CSR orientation. In answering this question, we draw from the complementarity theory.

Complementarity theory states that organizational design choices can be interdependent, i.e., they can be complements or substitutes (Milgrom and Roberts 1995; Grabner and Moers 2013). This implies that the value of one practice depends on the use of another practice, and vice versa. Following this argumentation, different CSR strategies may influence each other as well. Although many firms issue stand-alone CSR reports nowadays, and some of them state they are encouraging their senior management team to contribute to a better society by incorporating CSR-based performance measures into incentive contracts, it still remains an open question how a firm's choice of using CSR contracting is related with CSR disclosures.

We argue that CSR contracting and CSR disclosures are complements for the following reasons. First, we argue that both CSR strategies reinforce each other in signalling a strong CSR orientation to the market, thus increasing a firm's credibility with respect to CSR-related activities. As discussed before, being voluntary in nature and unlikely to be reliably assured, CSR disclosures suffer from credibility concerns (Simnett et al. 2009; Adams et al. 2011; Casey and Grenier 2015; Cohen and Simnett 2014). As a consequence, for CSR disclosures to be credible, it is necessary that CSR becomes an integral part of firms' objective functions, as reflected by executives' incentive contracts. It has long been recognized that agency problems may arise because the agent, who is supposed to make the decisions that would best serve the principal, is motivated by self-interest, and the agent's self-interest may differ from the interests of the principal. Therefore, principals use performance measurement and incentive schemes to direct agents' efforts and attention towards desired goals. In a multiple-task setting, incentive pay also helps to direct the allocation of the agent's attention among his various duties (Holmstrom and Milgrom 1991; Milgrom and Roberts 1992).

Following these arguments, if the board of directors has the intention to stimulate executives to deploy effort and resources towards specific CSR strategies, it is important to identify CSR-related measures in the incentive system. If executives are only evaluated on non-CSR targets, executives are not likely to allocate resources to pursue CSR practices. On the other hand, the outcomes of CSR activities are often uncertain and long-term oriented which imposes higher risks on the executives and can lead to a second-best choice (Lambert 
2001; Deckop et al. 2006). Therefore, it is argued that the board provides incentives if it desires CSR practices, which lowers the risks imposed on executives when undertaking CSR activities. Based on these arguments, CSR contracting may serve as a credible signal that the board is actively promoting CSR commitment. Consequently, firms that have a strong CSR orientation are more likely to use CSR contracting. This makes the CSR disclosures more credible because the two strategies reinforce each other in signalling a true CSR orientation to the market.

In addition, CSR reports also enhance the credibility of CSR contracting. Given that CSR-related compensation is often only a small fraction of overall compensation, it is still unclear whether CSR contracting is indeed effective in directing the CEO's attention and effort to specific CSR dimensions. Stand-alone CSR reports provide firms with an opportunity to communicate how CSR contracting promotes CSR performance. Relatedly, allowing stakeholders to observe how changes in CSR performance translate into changes in CEO compensation increases confidence that the CSR-based performance measures are indeed reliable. In sum, by disclosing how CSR-based performance measures allocate executives' effort and how this leads to improved CSR performance, CSR reports reinforce the credibility of CSR contracting.

We further argue that the net benefits of each of these CSR strategies also increase because of a decrease in the relative information acquisition costs. The use of CSR contracting requires the collection and management of CSR-related measures in the performance management system, which makes the subsequent disclosure of this information less costly. The use of (CSR-related) incentives requires careful setting of targets and subsequent monitoring of target achievement (Merchant and Van der Stede 2012). This in turn requires the collection of quantitative and qualitative data from multiple internal and external sources of information; in essence, the same information required for composing a CSR report. Grabner et al. (2016) show that internal target setting quality is associated with the issuance of (voluntary) management forecasts. The same argument holds vice versa. If the effort is undertaken to systematically collect CSR-related information in order to disclose a CSR report, it is more efficient to also use this information to set targets for the CEO.

Overall, we argue that the net benefits of using each of the CSR strategies increase by their joint use because of higher benefits through credibility gains and lower costs through lower information acquisition costs. Stated formally:

\section{HYPOTHESIS 1: CSR disclosures and CSR contracting are complements.}

We further argue that the strength of the proposed complementarity between CSR disclosures and CSR contracting is not uniform but depends on the context (Grabner and Moers 2013). While the choice of one organizational practice may be influenced by another co-varying practice, it is possible that contextual factors also affect the degree of interdependence among different practices. In other words, some practices may be complements in one context but independent in another (Grabner 2014). This could arise because these contexts trigger different control problems or change the pay-off functions of using the two practices. Therefore, in a second step, we identify an industry-related factor that shapes firms' decisions to adopt specific organizational practices with respect to CSR-related strategies, i.e., 
affiliation to industries that are under high public scrutiny regarding CSR concerns, because they are often blamed to be greenwashing.

Firms in some industries, such as the transportation and utilities industry, face more environmental issues than firms in other industries. To manage their reputation, firms in these industries often claim themselves to be engaged in "green" activities such as tree-planting and the use of clean energy. However, as the regulation of greenwashing in the U.S. is quite limited, and enforcement of such regulation is highly imbalanced between industries, there seems to be quite some evidence of a gap between their stated intentions towards the environment and their actual behaviour (Sharrattet al. 2007; Delmas and Burbano 2011). For example, Green Mountain Power Corporation was targeted by environmental groups for its usage of pollution combustion techniques as its new energy resource, which they announced as "green energy" (Delmas and Burbano 2011). Consequently, firms in industries that are accused of greenwashing may be scrutinized more intensively, and therefore feel a greater need to respond to these outside pressures.

In sum, in these industries with high public scrutiny, firms with a strong CSR orientation face, on average, higher credibility concerns with respect to their CSR strategies, which we expect to be reflected in their choices of CSR strategies in the following ways. First, credibility concerns will be more likely taken into account in the choice of CSR strategies. If the two CSR strategies reinforce each other in signalling a credible commitment to CSR, we expect that such firms are more likely to either incur the cost and adopt both strategies to benefit from credibility gains, or refrain from using any of them. In other words, we expect that such firms are less likely to use one of the mechanisms alone to serve their individual purposes (only). Thus, we argue that the complementarity between CSR disclosures and CSR contracting is stronger in firms in high public scrutiny industries.

Second, we also argue that these firms will benefit more from the intensive use of both CSR strategies compared to firms in other industries. As discussed above, firms in high public scrutiny industries perceive a strong need to engage in CSR strategies to manage their reputation, and thus also to credibly communicate them. We therefore expect that these firms receive relatively higher benefits from increasing their credibility through the joint use of both CSR strategies than firms under less public scrutiny. Given that both CSR disclosures and CSR contracting are costly to firms, we argue that firms in high public scrutiny industries are more likely to commit a higher amount of resources in terms of time and money to their CSR strategies (Grabner 2014). Consequently, we hypothesize that such firms are more likely to intensively use both CSR strategies.

In sum, we hypothesize that in firms in high public scrutiny industries the two strategies are more likely to be complements, and that these firms also have the highest incentives to incur the costs of using both strategies intensively. Stated formally:

HYPOTHESIS 2a: The complementarity between CSR disclosures and CSR contracting is stronger in firms in high public scrutiny industries

HYPOTHESIS 2b: The likelihood of using both CSR disclosures and CSR contracting is higher in firms in high public scrutiny industries. 


\subsection{Research Design}

\subsubsection{Sample Selection}

Our data collection starts with the collection of CEO incentive contract information that is provided in the "Compensation, Discussion and Analysis" section in the SEC proxy statements (DEF 14) during 2013 for the S\&P500 firms. Proxy statements provide detailed information describing how a CEO contract is designed and what kind of performance measures are used to evaluate CEO performance. We hand-collected detailed information on the performance measures used in CEO incentive contracts and classify the measures as CSR-based and non-CSR-based performance measures. Financial institutions are excluded from our sample, leaving 418 observations.

Next, we collect CSR reports that are published for the year 2013. These reports are downloaded from various sources including Corporate Register ${ }^{12}$, the Global Reporting Initiative (GRI) database ${ }^{13}$, firms' websites and a general internet search.

To obtain financial and corporate governance information, we merge the handcollected disclosure and performance measurement database with Compustat, CRSP and Execucomp. To control for firms' claimed CSR orientation, following prior literature (Dhaliwal et al. 2011), we further merge our sample with the KLD database. The KLD database provides ratings on seven dimensions, including environment, society, product, diversity, human rights, corporate governance, and employees. It rates the total strengths and total concerns for firms on each of these seven dimensions. Observations with missing values on control variables are deleted from our sample, which leads to an additional loss of 75 observations, resulting in a final sample of 343 observations. Table 7 Panel A shows our sample selection procedure. Table 7 Panel B provides firm-industry distributions.

\footnotetext{
${ }^{12} \mathrm{http}: / /$ www.corporateregister.com._Corporate Register is the largest worldwide dictionary that provides online corporate responsibility reports.

${ }^{13}$ The GRI database publishes sustainability reporting guidelines. The GRI database provides users access to all types of sustainability reports, GRI-guideline-based or not, and relevant information related to the reporting organizations.
} 


\section{TABLE 7: Sample Selection and Industry Distribution}

PANEL A: Sample selection

S\&P 500 firms

No. Obs. 505

Less:

Financial institutions

Less:

Missing observations

\begin{tabular}{|c|c|c|c|}
\hline Final Sample & & 343 & \\
\hline PANEL B: Industry distribution & & & \\
\hline Industry (two-digit SIC code) & No. & Percent & Cum. Percentage \\
\hline Agriculture, Forest, and Fishing (01-09) & 1 & $0.29 \%$ & $0.29 \%$ \\
\hline Mining (10-14) & 29 & $8.45 \%$ & $8.74 \%$ \\
\hline Construction (15-17) & 3 & $0.87 \%$ & $9.61 \%$ \\
\hline Manufacturing (20-39) & 164 & $47.81 \%$ & $57.42 \%$ \\
\hline Transportation and Public Utilities (40-49) & 58 & $16.91 \%$ & $74.33 \%$ \\
\hline Wholesale Trade (50-51) & 8 & $2.33 \%$ & $76.66 \%$ \\
\hline Retail Trade (52-59) & 37 & $10.79 \%$ & $87.45 \%$ \\
\hline Service $(70-89)$ & 42 & $12.24 \%$ & $100.00 \%$ \\
\hline Public Administration ((90-98) & 0 & $0.00 \%$ & $100.00 \%$ \\
\hline Non-classifiable Establishments (99) & 0 & $0.00 \%$ & $100.00 \%$ \\
\hline Total & 343 & $100.00 \%$ & $100.00 \%$ \\
\hline
\end{tabular}

PANELC: Percentage of firms with and without CSR disclosures and CSR contracting Variable measurement based on hand-collected data (original sample)

\begin{tabular}{lccccc}
\hline & Yes & Percentage & No & Percentage & Total \\
CSR disclosures & 239 & $57.18 \%$ & 179 & $42.82 \%$ & 418 \\
CSR contracting & 125 & $29.90 \%$ & 293 & $70.10 \%$ & 418 \\
CSR contracting and disclosures & 86 & $20.57 \%$ & & & \\
CSR contracting and no disclosures & 39 & $9.33 \%$ & & & \\
No CSR contracting, but disclosures & 153 & $36.60 \%$ & & & \\
No CSR contracting, no disclosures & 140 & $33.49 \%$ & & & \\
\hline
\end{tabular}

Variable measurement based on measures available in ASSET4 database (sample after merge with ASSET4)

\begin{tabular}{lccccc}
\hline & Yes & Percentage & No & Percentage & Total \\
CSR disclosures & 224 & $62.05 \%$ & 137 & $37.95 \%$ & 361 \\
CSR contracting & 166 & $45.98 \%$ & 195 & $54.02 \%$ & 361 \\
CSR contracting and disclosures & 130 & $36.01 \%$ & & & \\
CSR contracting and no disclosures & 36 & $9.97 \%$ & & & \\
No CSR contracting, but disclosures & 94 & $26.04 \%$ & & & \\
No CSR contracting, no disclosures & 101 & $27.98 \%$ & & & \\
\hline
\end{tabular}

This table shows the sample selection procedure and industry distribution. Specifically, Panel A shows how we construct the final sample. Panel B presents industry distributions of the final sample. Panel C shows the distribution and combination of CSR disclosures (Yes/No) and CSR contracting (Yes/No) for the full handcollected sample and after merging with the ASSET4 database. 
Panel $\mathrm{C}$ of Table 7 presents the percentage of firms with CSR disclosures and CSR contracting. Over the hand-collected sample of 418 firms, there are 225 firms that issue stand-alone CSR reports (57.18\%). In contrast, only 125 firms incorporate CSR-based performance measures. About 86 (20.57\%) firms have both CSR disclosures and CSR-based performance measures, while 140 (33.49\%) firms neither disclose CSR reports nor use CSR contracting. There are $153(36.6 \%)$ firms that disclose stand-alone CSR reports but do not have CSR-based performance measures. Only 39 (9.33\%) firms use CSR-based performance measures but do not provide CSR reports at the same time.

To further analyse whether our hand-collected data is reliable, we compare the distribution of our hand-collected sample with data from the Thomson Reuters ASSET4 database. With respect to CSR-based performance measures and CSR disclosures, the ASSET4 database provides two indicator variables that capture "the use of senior executive compensation linked to CSR/Health and Safety/Sustainability targets" and whether or not a "company publishes a separate sustainability report or publishes a section in its annual report on sustainability", respectively.

After merging our hand-collected sample with the data from the ASSET4 database, there are 361 observations left. Of these 361 firms, 62\% discloses CSR information. This number is very similar to the percentage of firms that issue a CSR report in our handcollected sample, suggesting that our hand-collected data on CSR disclosures is reliable. Next, $46 \%$ of the ASSET4 firms incorporate CSR incentives into senior executive incentive contracts, which is higher than our hand-collected sample. We attribute this to the criteria of identifying CSR-based performance measures, for which we take a relatively conservative approach.

\subsubsection{Variable Measurement}

\section{CSR disclosures}

We measure CSR disclosures in three different ways. First, we use a measure for the presence of a stand-alone CSR report. If a firm issues a stand-alone CSR report for 2013, an indicator variable $D \_C S R \_$Reporting is set to one, and is zero otherwise. Second, although many firms publish a stand-alone CSR report, there is large variation in reporting intensity. Compared with shorter CSR reports, longer CSR reports take more time to issue, require more effort and are more likely to cover more comprehensive aspects related to CSR. ${ }^{14}$ Following prior literature (Li 2008; Loughran and McDonald 2014), we also measure the intensity of CSR disclosures (Disclosure_Intensity) by capturing the length of CSR reports as the natural logarithm of the total number of words (LnWords) and total number of pages (LnPages), respectively.

\footnotetext{
${ }^{14} \mathrm{We}$ do not argue that longer CSR reports are more informative to investors. Our point is that the decision whether to disclose a CSR report or not, and how much information to incorporate in these reports is a strategic choice made by firms.
} 


\section{CSR contracting}

We first hand-collect the proxy statements for 2013 for the S\&P500 firms. According to the GRI disclosure guidelines, there are six material categories: Economy, environment, employee/labor practice, human rights, society, and product responsibility. Given that performance measures falling in the economy dimension typically cannot be classified as CSR or non-CSR, we focus on the remaining five dimensions. Performance measures on the environment dimension cover firms' financial incentives that aim to protect the environment, such as "environment protection", "water/energy recycle", "reductions of firms' environmental footprint", etc. We identify "employee safety", "employee health", "diversity", "injury rate", and "equal opportunity" as employee-related performance measures. Societyrelated performance measures cover measures that encourage improvement of community/society welfare, examples including "public safety", "stakeholder transparency", "association engagement", etc. CSR-based performance measures of product dimension specifically consider "product safety" and "customer safety". Here we take a relatively conservative stance to define CSR-based performance measures in order to identify firms that really care and incorporate CSR into their incentive system. The human rights dimension captures performance measures that "prohibit the use of child labor", "association freedom", etc. In Appendix B, we provide some detailed examples from proxy statements that show how CSR-based performance measures are used in CEO incentive contracts.

To capture the presence of CSR contracting, we create an indicator variable that is equal to one if any CSR-based performance measure is used in CEO incentive contracts and is zero otherwise (D_CSRPM). We measure two aspects of CSR contracting intensity, i.e., the scope of CSR performance measures and the relative importance of CSR versus non-CSR performance measures included in the contract. Regarding the first, we measure how many CSR dimensions are covered by CSR-based performance measures in the contract. Based on the GRI dimensions described above, we create five binary variables, namely, environment_pm, labor_pm, product_pm, society_pm and human_rights_pm to measure whether the firm uses CSR-based performance measures over that specific dimension. The binary variable over the specific dimension is equal to one if the firm uses performance measures related to that specific dimension and is zero otherwise. CSRPM_SCOPE is measured as the sum of the five binary variables with a theoretical range between zero and five. For example, if a firm uses environmental protection and employee safety in its CEO incentive contract as performance measures, then CSRPM_SCOPE equals 2. In order to capture a firm's scope of CSR engagement, we measure the number of dimensions covered rather than the number of measures used (which could be concentrated in a single dimension). ${ }^{15}$ However, CSRPM_SCOPE does not capture the relative importance of CSRbased performance measures compared to the other performance measures used in the CEO's incentive contract. ${ }^{16}$ To capture the relative importance of the CSR-based performance measures, we divide the number of CSR-based performance measure dimensions by the total number of performance measures used in the contract (CSRPM_IMP).

\footnotetext{
${ }^{15}$ We provide robustness tests using alternative measures of CSR contracting intensity in section 3.5.

${ }^{16}$ For example, we argue that firms using one non-CSR performance measure and one CSR performance measure relatively attach more importance to CSR-related performance measures than firms using ten non-CSR performance measures and only one CSR performance measure.
} 


\section{High public scrutiny industries}

We classify Mining and Construction (SIC 10-17) and Transportation and Public Utilities (SIC 40-49) industries as under relatively higher public scrutiny regarding their CSR activities, as these industries are more likely to be accused of "greenwashing" (Delmas and Burbano 2011) and as a consequence firms in these industries may face a stricter regulatory and monitoring environment. Firms in these industries form the "high-scrutiny" subsample, while all firms in other industries are classified into the "low-scrutiny" subsample.

\section{Control variables}

We control for firm size as larger firms are more likely to suffer from public pressure and regulations (Lang and Lundholm 1993). Firm size is measured as the logarithm of total assets (LogAssets). LEVERAGE is measured as total debt divided by total common equity. In addition, since firms that raise capital through public markets are more likely to voluntarily communicate information with the public (Frankel et al. 1995), we control for firms' financial activities during the fiscal year (Dhaliwal et al. 2011). Following Dhaliwal et al. (2011) and Richardson et al. (2004), the variable FIN is measured as the sale of common and preferred shares minus the purchase of common and preferred shares, plus long-term debt issuance and minus long-term debt reduction, scaled by total assets at the beginning of the year. We further incorporate the market-to-book ratio to capture firms' growth opportunities $(M B R)$. Return on assets $(R O A)$ is included to control for firms' financial performance. As argued by McWilliams and Siegel (2001), research and development and advertising expenditures play an important role for CSR to be differential. Therefore, we incorporate advertising expenses and $\mathrm{R} \& \mathrm{D}$ expenses scaled by total revenue as additional controls $(A D$ and $R D$, respectively). As firms' disclosure strategies may reflect their overall transparency, CSR disclosures could be driven by firms' general disclosure policies and transparency (Kim et al. 2012). We use abnormal accruals to capture the variation in financial reporting transparency of firms $\left(A B N \_A C C\right)$. Following Kothari et al. (2005) and Dechow et al. (1995), we use the performance-adjusted cross-sectional model to estimate abnormal accruals.

Previous literature has indicated the important role that the board of directors plays in determining and designing CEO contracts (Core et al. 1999). Following prior literature (Hoppe and Moers 2011), we therefore capture monitoring intensity (MONITORING) at the board level. It is measured by a factor score that includes board size, percentage of busy outsiders (i.e., directors with three or more directorships), and percentage of busy insiders (i.e., directors with two or more directorships). We further measure corporate governance by the proportion of independent board members (\%INDEPENDENT) and CEO duality (CEO_DUALITY). CEO_DUALITY is an indicator variable that equals one if the CEO is also chairman of the board of directors, and zero otherwise. In addition, as Hoppe and Moers (2011) indicate that environmental unpredictability (UNPREDICT) and noise in performance measures (NOISE) are determinants of incentive choice, we further incorporate these two variables as controls. To capture UNPREDICT, we first regress stock holding period returns on the CRSP value-weighted index over the prior 12 to 60 months. Next, UNPREDICT is calculated as the standard deviation of the residuals. Noise in accounting numbers (NOISE) is measured as the time-series variability in median 3-digit industry accounting returns over five years prior to the proxy data. Prior literature uses the KLD database to construct CSR ratings 
(Dhaliwal et al. 2011; Kim et al. 2012). The KLD database rates companies on 11 dimensions including corporate governance, employee relation, community, diversity, product, employee relation, alcohol, gambling, tobacco, military contracting and nuclear power, of which the last five dimensions are exclusionary screen categories. Aligned with the previous chapter, we include $K L D \_R A T I N G$ as a proxy for firms' claimed CSR orientation, as it may influence firms' following CSR choices (Scalet and Kelly, 2010). It is calculated by the total strength value over five dimensions, that is, environment, community relation, employee relation, diversity, and product, minus the total concern value over these five dimensions. In line with Kim et al. (2012), we do not include the corporate governance score in the calculation of total CSR performance score. Appendix A provides detailed information of how we measure each variable included in our model.

\subsubsection{Empirical Model}

\section{Complementarity between CSR disclosures and CSR contracting (H1)}

Our aim is to test for complementarity between (the intensity of) CSR disclosures and the (intensity of) CSR contracting (H1). The choice of empirical strategy depends on the assumptions made with respect to the optimality of decision making (Grabner and Moers 2013). In particular, we assume, on average, optimality in CSR decisions, implying that the revealed choices are consistent with the optimal decision. This is a reasonable assumption for the following reasons. First, sustainability issues have become increasingly popular in the boardroom. According to survey data provided by Corporate Register, in 2001 there were 800 of firms that issued a stand-alone CSR report. However, one decade later, the number increased to more than 5,500 firms. Second, surveys and articles in mass media indicate that in recent years there has been a growing interest among shareholders in the inclusion of sustainability performance as a part of the compensation formula (Singer 2012). Finally, since 2006, GRI has issued detailed instructions to guide firms to report their CSR engagement. Following these guidelines, management can take targeted actions to improve the process, observe the results and thereby learn gradually how to improve CSR reporting and CSR contracting over time. Therefore, we argue that by 2013, firms are, on average, capable of making optimal decisions regarding CSR-related strategies.

Assuming that firms seek to optimize their decisions, complementarity implies a positive conditional correlation between the two choices after controlling for other variables. Following prior literature on interdependent control choices (Indjeijkian and Matejka 2011; Grabner and Moers 2013; Grabner 2014), in a first step we estimate the conditional correlations between the presence of a stand-alone CSR report and the use of CSR-based performance measures. ${ }^{17}$ In particular, we correlate the residuals of the following OLS regression models ${ }^{18}$ :

\footnotetext{
${ }^{17}$ Some exogenous variables are not joint determinants and positively affect the marginal returns or use of one control system component, but not the other. If complementarity is present, however, then the increase in use of the one will increase the benefits and thus the use of the other, leading to a positive correlation between the two components. This positive correlation is not due to both components having the same determinants, but due to
} 


$$
\begin{aligned}
& \text { D_CSR_REPORTING } G_{i t}=\beta_{0}+\beta_{1} \log A S S E T S_{i t-1}+\beta_{2} M B R_{i t-1}+\beta_{3} D E B T \_T O \_E Q U I T Y_{i t-1} \\
& +\beta_{4} R D_{i t-1}+\beta_{5} A D_{i t-1}+\beta_{6} \text { UNPREDICT }_{i t-1}+\beta_{7 N O I S E_{i t-1}}+\beta_{8} \text { FIN }_{i t-1}+\beta_{9} R_{\text {ROA }} \text { it }+ \\
& \beta_{10} \text { MONITORING } \text { it }-1+\beta_{11} \% \text { INDEPENDENT } \text { it-l }+\beta_{12} \text { CEO_DUALITY } \text { it }-1^{+} \\
& \beta_{13} K L D_{-} R A T I N G_{i t-1}+\beta_{14} A B N \_A C C_{i t-1}+S I C-F I X E D+\varepsilon_{-} \text {Report } \\
& D_{-} C S R P M_{i t}=\beta_{0}+\beta_{1} \log A S S E T S_{i t-1}+\beta_{2} M_{B R} R_{i t-1}+\beta_{3} D E B T \_T O \_E Q U I T Y_{i t-1}+\beta_{4} R D_{i t-1}+ \\
& \beta_{5} A_{i t-1}+\beta_{6} U_{N P R E D I C T} T_{t-1}+\beta_{7} \text { NOISE }_{i t-1}+\beta_{8} \text { FIN }_{i t-1+}+\beta_{9} \text { ROA }_{i t}+ \\
& \beta_{10} \text { MONITORING }_{i t-1}+\beta_{11} \% \text { INDEPENDENT }_{i t-1}+\beta_{12} \text { CEO_DUALITY }{ }_{i t-1}+ \\
& \beta_{13} K L D \_R A T I N G_{i t-1}+\beta_{14} A B N \_A C C_{i t-1}+S I C-F I X E D+\varepsilon_{-} P M
\end{aligned}
$$

Equation (1) predicts the disclosure of a CSR report, and Equation (2) predicts the use of CSR-based performance measures. Following Dhaliwal et al. (2011), the economic determinants are lagged one year.

In this first model specification, $D \_C S R \_R E P O R T I N G$ and $D \_C S R P M$ are two binary variables. To further examine whether the intensity of CSR contracting complements the disclosure of longer CSR reports, we re-run Equation (1) and Equation (2) using the continuous variables DISCLOSURE_INTENSITY (measured by either Lnpages or Lnwords) and CSRPM_DIMENSIONS (measured by the total number of dimensions covered by the CSR-based performance measures used in CEO incentive contracts) as dependent variables.

\section{Contextual Analysis (H2a and H2b)}

Besides investigating whether the presence and intensity of CSR disclosures and CSR contracting are complements, we are also interested in how affiliation to the "high-scrutiny" industries affects the interdependence of the two choices (H2a). We split our sample into subsamples based on whether firms are in "high-scrutiny" industries or not and compare the conditional correlations for each group. One common approach in testing correlation parameters is to use an "inverse hyperbolic tangent transformation", which is also known as "Fisher's Z transformation” (Fisher 1915). Therefore, we conduct Fisher's Z tests to examine whether there is a difference in the correlation coefficients between the subsamples.

$\mathrm{H} 2 \mathrm{~b}$ predicts that the likelihood of choosing both CSR disclosures and CSR contracting is higher in firms in "high-scrutiny" industries. To test this hypothesis, we estimate the following probit models:

$$
\begin{aligned}
& \operatorname{Pr}(\text { HIHI or Alternatives })=\beta_{0}+\beta_{1} H I G H-S C R U N I T Y+\beta_{2} \log A S S E T S_{i t-1}+\beta_{3} M_{B R R_{i t-1}}+ \\
& \beta_{4} D E B T \_T O \_E Q U I T Y_{i t-1}+\beta_{5} R D_{i t-1}+\beta_{6} A D_{i t-1}+\beta_{7} U_{N P R E D I C T} T_{i t-1}+\beta_{8} N O I S E_{i t}- \\
& { }_{1}+\beta_{9} \text { FIN }_{i t-1}+\beta_{10} \text { ROA }_{i t}+\beta_{11} \text { MONITORING }_{i t-1}+\beta_{12} \% \text { INDEPENDENT }_{i t-1} \\
& +\beta_{13} C E O \_D U A L I T Y_{i t-1}+\beta_{14} K_{L} D_{-} R A T I N G_{i t-1}+\beta_{15} A B N \_A C C_{i t-1}+\varepsilon \text {, }
\end{aligned}
$$

\footnotetext{
both components being complements. The test for conditional correlations attempts to capture this correlation due to complementarity (Grabner 2014).

${ }^{18}$ Given that the conditional correlation analysis requires the correlation of the residuals of OLS regressions, we use OLS estimations, despite the dependent variables being indicator variables.
} 
where $H I H I$ is an indicator variable that equals one if a firm discloses a CSR report and uses CSR contracting, and zero otherwise. To capture high disclosure intensity of CSR reports and intensive use of CSR-based performance measures, we use a set of indicator variables to capture the following alternatives: HIHI25_PAGE_SCOPE equals one if both InPages and CSRPM_SCOPE are in the top quartile of the sample, and zero otherwise; HIHI25_PAGE_IMP equals one if both InPages and CSRPM_IMP are in the top quartile of the sample, and zero otherwise; HIHI25_WORD_SCOPE equals one if both lnWords and CSRPM_SCOPE are in the top quartile of the sample, and zero otherwise; HIHI25_WORD_IMP equals one if both lnWords and CSRPM_IMP are in the top quartile of the sample, and zero otherwise. According to hypothesis $H 2 b$, we expect the coefficient of $H I G H-S C R U T I N Y$ to be significantly positive.

\subsection{Empirical Findings}

\subsubsection{Descriptive Statistics}

Table 8 provides descriptive statistics. Panel A of Table 8 reports descriptive statistics for all variables included in our models. For comparison, we also provide descriptive statistics separately for firms that issue/do not issue a stand-alone CSR report and for firms that use/do not use CSR-based performance measures in Panels B and C of Table 8. As can be seen from Panel A of Table 8, the mean of total assets is 24,699.21 million dollars. On average, a standalone CSR report consists of 32 pages, with an average of 10,850.56 words. ${ }^{19}$

We further conduct several differences-in-means t-tests to examine differences in variables across the subsamples. Panel B shows that compared to firms that do not disclose a CSR report, firms that publish a CSR report are more likely to use CSR-based performance measures. Firms with CSR disclosures have higher total assets, market-to-book ratio, leverage ratio, and more expenditures on $R \& D$ than firms that do not disclose CSR reports. They also exhibit on average higher CEO duality, a higher percentage of independent directors and higher KLD ratings. Moreover, firms that disclose CSR reports have on average a lower noise in accounting measures, environmental unpredictability, advertising expenses and ROA. Panel $\mathrm{C}$ makes a comparison between firms that use CSR contracting and those that do not. It shows that firms that use CSR-based performance measures are on average more likely to disclose CSR reports, have larger total assets, leverage ratio, financing needs and more independent directors than firms that do not use CSR contracting. In addition, CSRcontracting firms have on average a lower noise in accounting measures, external environment unpredictability and ROA.

${ }^{19}$ For firms that do not disclose a CSR report, the words and pages are 0. 
TABLE 8: Descriptive Statistics for the Full Sample and Four Subsamples

\begin{tabular}{|c|c|c|c|c|c|c|}
\hline \multicolumn{7}{|c|}{ PANEL A: Descriptive statistics } \\
\hline Variable & Obs & Mean & Median & Std. Dev. & Min & Max \\
\hline D_CSR_REPORTING & 343 & 0.615 & 1.000 & 0.487 & 0.000 & 1.000 \\
\hline TOTAL WORDS & 343 & $10,850.560$ & $4,210.000$ & $15,565.850$ & 0.000 & $83,637.000$ \\
\hline TOTAL PAGES & 343 & 31.793 & 17.000 & 40.170 & 0.000 & 199.000 \\
\hline lnPages & 343 & 2.216 & 2.833 & 1.898 & 0.000 & 5.293 \\
\hline $\ln W o r d s$ & 343 & 5.687 & 8.340 & 4.633 & 0.000 & 11.334 \\
\hline D_CSRPM & 343 & 0.321 & 0.000 & 0.467 & 0.000 & 1.000 \\
\hline CSRPM_SCOPE & 343 & 0.453 & 0.000 & 0.745 & 0.000 & 3.000 \\
\hline CSRPM_IMP & 343 & 0.078 & 0.000 & 0.135 & 0.000 & 0.75 \\
\hline HIHI & 343 & 0.248 & 0.000 & 0.432 & 0.000 & 1.000 \\
\hline HIHI25_PAGE_SCOPE & 343 & 0.102 & 0.000 & 0.303 & 0.000 & 1.000 \\
\hline HIHI25_WORD_SCOPE & 343 & 0.107 & 0.000 & 0.311 & 0.000 & 1.000 \\
\hline HIHI25_PAGE_IMP & 343 & 0.082 & 0.000 & 0.274 & 0.000 & 1.000 \\
\hline HIHI25_WORD_IMP & 343 & 0.087 & 0.000 & 0.283 & 0.000 & 1.000 \\
\hline TOTAL ASSETS & 343 & $24,699.210$ & $12,356.000$ & $37,677.190$ & $1,043.325$ & $33,3795.000$ \\
\hline LogASSETS & 343 & 9.473 & 9.423 & 1.083 & 7.494 & 12.359 \\
\hline$M B R$ & 343 & 3.136 & 2.713 & 5.718 & -39.789 & 22.344 \\
\hline LEVERAGE & 343 & 1.181 & 1.051 & 3.418 & -26.688 & 16.410 \\
\hline$R D$ & 343 & 0.037 & 0.001 & 0.069 & 0 & 0.454 \\
\hline$A D$ & 343 & 0.014 & 0.000 & 0.031 & 0.000 & 0.273 \\
\hline UNPREDICT & 343 & 0.074 & 0.068 & 0.027 & 0.034 & 0.160 \\
\hline NOISE & 343 & 0.022 & 0.020 & 0.016 & 0.001 & 0.096 \\
\hline FIN & 343 & 0.132 & 0.147 & 0.164 & -0.560 & 0.517 \\
\hline$R O A$ & 343 & 0.082 & 0.071 & 0.077 & -0.191 & 0.567 \\
\hline MONITORING & 343 & 0.000 & -0.036 & 0.406 & -0.842 & 2.397 \\
\hline \%INDEPENDENT & 343 & 0.819 & 0.857 & 0.106 & 0.412 & 1.000 \\
\hline CEO_DUALITY & 343 & 0.076 & 0.000 & 0.265 & 0.000 & 1.000 \\
\hline$K L D \_R A T I N G$ & 343 & 3.157 & 3.000 & 3.301 & -3.000 & 15.000 \\
\hline$A B N \_A C C$ & 343 & 0.012 & 0.011 & 0.341 & -1.516 & 1.072 \\
\hline
\end{tabular}




\begin{tabular}{lcccccc}
\hline \multicolumn{7}{l}{ PANEL B: Mean comparisons of firms with and without CSR disclosures } \\
\hline & No Disclosure & No. & Disclosure $^{\mathbf{b}}$ & No. & t-value & p-value \\
D_CSRPM & 0.189 & 132 & 0.403 & 211 & -4.215 & 0.000 \\
CSRPM_SCOPE & 0.250 & 132 & 0.582 & 211 & -4.092 & 0.000 \\
CSRPM_IMP & 0.043 & 132 & 0.100 & 211 & -3.857 & 0.000 \\
LogAssets & 8.989 & 132 & 9.775 & 211 & -6.979 & 0.000 \\
MBR & 2.731 & 132 & 3.389 & 211 & -1.037 & 0.301 \\
LEVERAGE & 0.644 & 132 & 1.517 & 211 & -2.314 & 0.021 \\
RD & 0.051 & 132 & 0.029 & 211 & 2.903 & 0.004 \\
AD & 0.019 & 132 & 0.011 & 211 & 2.316 & 0.021 \\
UNPREDICT & 0.079 & 132 & 0.072 & 211 & 2.416 & 0.016 \\
NOISE & 0.026 & 132 & 0.020 & 211 & 2.980 & 0.003 \\
FIN & 0.121 & 132 & 0.138 & 211 & -0.933 & 0.352 \\
ROA & 0.095 & 132 & 0.074 & 211 & 2.430 & 0.016 \\
MONITORING & -0.080 & 132 & 0.050 & 211 & -2.922 & 0.004 \\
$\% I N D E P E N D E N T$ & 0.786 & 132 & 0.840 & 211 & -4.769 & 0.000 \\
CEO_DUALITY & 0.083 & 132 & 0.071 & 211 & 0.416 & 0.678 \\
KLD_RATING & 1.932 & 132 & 3.924 & 211 & -5.681 & 0.000 \\
ABN_ACC & 0.017 & 132 & 0.009 & 211 & 0.211 & 0.833 \\
\hline
\end{tabular}

\begin{tabular}{|c|c|c|c|c|c|c|}
\hline \multicolumn{7}{|c|}{ PANEL C: Mean comparisons of firms with and without CSR-based performance measures } \\
\hline & No CSR PMc & No. & CSR PM ${ }^{\mathrm{d}}$ & No. & t-value & p-value \\
\hline D_CSR_REPORTING & 0.541 & 233 & 0.773 & 110 & -4.215 & 0.000 \\
\hline lnPages & 1.957 & 233 & 2.764 & 110 & -3.741 & 0.000 \\
\hline $\ln W o r d s$ & 5.041 & 233 & 7.056 & 110 & -3.835 & 0.000 \\
\hline LogAssets & 9.310 & 233 & 9.817 & 110 & -4.139 & 0.000 \\
\hline$M B R$ & 3.546 & 233 & 2.265 & 110 & 1.945 & 0.053 \\
\hline LEVERAGE & 1.145 & 233 & 1.258 & 110 & -0.285 & 0.776 \\
\hline$R D$ & 0.051 & 132 & 0.029 & 211 & 2.903 & 0.004 \\
\hline$A D$ & 0.017 & 233 & 0.006 & 110 & 3.207 & 0.002 \\
\hline UNPREDICT & 0.076 & 233 & 0.071 & 110 & 1.353 & 0.177 \\
\hline NOISE & 0.025 & 233 & 0.018 & 110 & 3.648 & 0.000 \\
\hline FIN & 0.112 & 233 & 0.173 & 110 & -3.287 & 0.001 \\
\hline$R O A$ & 0.095 & 233 & 0.054 & 110 & 4.669 & 0.000 \\
\hline MONITORING & -0.030 & 233 & 0.063 & 110 & -1.998 & 0.047 \\
\hline$\% I N D E P E N D E N T$ & 0.805 & 233 & 0.849 & 110 & -3.688 & 0.000 \\
\hline CEO_DUALITY & 0.077 & 233 & 0.073 & 110 & 0.147 & 0.883 \\
\hline$K L D \_R A T I N G$ & 3.124 & 233 & 3.227 & 110 & -0.269 & 0.788 \\
\hline$A B N A C C$ & 0.022 & 233 & -0.010 & 110 & 0.815 & 0.416 \\
\hline
\end{tabular}

This table reports descriptives of CSR disclosure and CSR contracting for the full sample and four subsamples. Panel A shows descriptive statistics of the final sample. Panel B shows descriptive statistics for firms disclose and those that do not disclose a CSR report, respectively. Panel C shows descriptive statistics for firms with and without CSR contracting, respectively. Please see Appendix A for variable measurements and definitions.

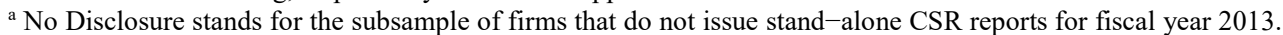

${ }^{\mathrm{b}}$ Disclosure stands for the subsample of firms that issue a stand-alone CSR report for fiscal year 2013.

${ }^{c}$ No CSR PM stands for the subsample of firms that do not use CSR contracting for fiscal year 2013.

${ }^{\mathrm{d}}$ CSR PM stands for the subsample of firms that use CSR contracting for fiscal year 2013. 


\subsubsection{Complementarity between CSR Disclosures and CSR Contracting (H1)}

Table 9 reports the regression results of Equations (1) and (2). Panel A of Table 9 reports the OLS regression results of the determinants of the two CSR strategies. As shown in the second column of Table 9, Panel A, the likelihood of issuing a CSR report increases with total assets, R\&D expenses, the percentage of independent directors, and claimed CSR orientation, while it decreases with noise in accounting measures, advertising expenses, and monitoring intensity. With respect to the use of CSR contracting, we observe a negative relationship with noise in accounting measures and a positive relationship with the percentage of independent directors. In line with our expectation, the regression residuals are positively correlated $(\mathrm{r}=$ $0.110, p=0.041$ ), indicating that CSR disclosures and CSR contracting are complements.

Panel B of Table 9 reports the OLS regression results of the determinants of CSR disclosure intensity and CSR contracting scope. The number of words disclosed in CSR reports increases with total assets, percentage of independent directors, monitoring intensity and claimed CSR orientation, while it decreases with advertising expenses. In line with the results of the number of words, we find that the number of pages also increases with total assets, percentage of independent directors and claimed CSR orientations, but decreases with advertising and R\&D expenses. CSRPM_SCOPE decreases with the market-to-book ratio and increases with leverage and the percentage of independent directors. In line with our expectation, the conditional correlations between the regression residuals are significantly positive. Specifically, the conditional correlation between the number of words disclosed in CSR reports and the scope of CSR contracting is 0.120 , with a p-value of 0.026 . We also observe a complementary relationship between the number of pages of CSR reports and the scope CSR contracting $(r=0.091 ; p=0.094)$. The conditional correlations show that the scope of CSR contracting complements CSR disclosure intensity.

Panel C of Table 9 reports the OLS regression results of the determinants of CSR disclosure intensity and the relative importance of CSR contracting. The conditional correlations of the residuals are again significantly positive. The conditional correlation between the number of words and the relative importance of CSR contracting is 0.107 ( $p=$ 0.048). Consistently, the number of pages complements the relative importance of the CSR contracting $(r=0.096, p=0.075)$. The conditional correlations show that the importance of CSR contracting complements CSR disclosure intensity. Overall, we find strong support for H1. 
TABLE 9: Analysis of Complementarity

PANEL A: Complementarity between CSR disclosures and CSR contracting

\begin{tabular}{|c|c|c|}
\hline & D_CSR_REPORTING & D_CSRPM \\
\hline \multirow[t]{2}{*}{ Constant } & -0.600 & -0.461 \\
\hline & $(0.564)$ & $(0.552)$ \\
\hline \multirow[t]{2}{*}{ LogAssets } & $0.110 * * *$ & 0.019 \\
\hline & $(0.0268)$ & $(0.0262)$ \\
\hline \multirow[t]{2}{*}{$M B R$} & 0.011 & -0.005 \\
\hline & $(0.00851)$ & $(0.00832)$ \\
\hline \multirow[t]{2}{*}{ LEVERAGE } & -0.009 & 0.003 \\
\hline & $(0.0140)$ & $(0.0137)$ \\
\hline \multirow[t]{2}{*}{$R D$} & $-1.526^{* * *}$ & -0.312 \\
\hline & $(0.410)$ & $(0.402)$ \\
\hline \multirow[t]{2}{*}{$A D$} & $-1.885^{* *}$ & $-1.389^{*}$ \\
\hline & $(0.815)$ & $(0.797)$ \\
\hline \multirow[t]{2}{*}{ UNPREDICT } & $1.769^{*}$ & -0.423 \\
\hline & $(1.042)$ & $(1.020)$ \\
\hline \multirow[t]{2}{*}{ NOISE } & $-3.493 * *$ & -2.811 \\
\hline & $(1.771)$ & $(1.733)$ \\
\hline \multirow{2}{*}{ FIN } & -0.152 & 0.045 \\
\hline & $(0.164)$ & $(0.161)$ \\
\hline \multirow[t]{2}{*}{$R O A$} & 0.153 & -0.396 \\
\hline & $(0.369)$ & $(0.361)$ \\
\hline \multirow[t]{2}{*}{ MONITORING } & 0.101 & 0.070 \\
\hline & $(0.0633)$ & $(0.0620)$ \\
\hline \multirow[t]{2}{*}{$\% I N D E P E N D E N T$} & $0.599 * *$ & $0.530 * *$ \\
\hline & $(0.237)$ & $(0.232)$ \\
\hline \multirow[t]{2}{*}{ CEO_DUALITY } & -0.065 & -0.068 \\
\hline & $(0.0926)$ & $(0.0906)$ \\
\hline \multirow[t]{2}{*}{ KLD_RATING } & $0.042 * * *$ & 0.0004 \\
\hline & $(0.00817)$ & $(0.00800)$ \\
\hline \multirow[t]{2}{*}{$A B N \_A C C$} & 0.059 & 0.0003 \\
\hline & $(0.0827)$ & $(0.0809)$ \\
\hline Industry fixed effects & Yes & Yes \\
\hline Prob $>F$ & 0.000 & 0.000 \\
\hline $\mathrm{N}$ & 343 & 343 \\
\hline Adj. R-sq & 0.2297 & 0.1863 \\
\hline & \multicolumn{2}{|c|}{ e_CSRPM } \\
\hline e_CSR_Reporting & \multicolumn{2}{|c|}{0.1103} \\
\hline $\mathrm{p}$-value & \multicolumn{2}{|c|}{$(0.0413)$} \\
\hline
\end{tabular}


Chapter 3

\begin{tabular}{|c|c|c|c|}
\hline \multicolumn{4}{|c|}{ PANEL B: Complementarity between CSR disclosure intensity and CSR contracting scope } \\
\hline & lnWords & lnPages & CSRPM_SCOPE \\
\hline \multirow[t]{2}{*}{ Constant } & $-9.982 *$ & $-3.912 *$ & -0.750 \\
\hline & $(5.209)$ & $(2.110)$ & $(0.875)$ \\
\hline \multirow[t]{2}{*}{ LogAssets } & $1.321 * * *$ & $0.521 * * *$ & 0.045 \\
\hline & $(0.248)$ & $(0.100)$ & $(0.0416)$ \\
\hline \multirow[t]{2}{*}{$M B R$} & $0.136^{*}$ & 0.048 & $-0.031 * *$ \\
\hline & $(0.0786)$ & $(0.0318)$ & $(0.0132)$ \\
\hline \multirow[t]{2}{*}{ LEVERAGE } & -0.176 & -0.042 & 0.035 \\
\hline & $(0.130)$ & $(0.0524)$ & $(0.0218)$ \\
\hline \multirow[t]{2}{*}{$R D$} & $-15.51^{* * *}$ & $-5.934 * * *$ & -0.465 \\
\hline & $(3.792)$ & $(1.536)$ & $(0.637)$ \\
\hline \multirow[t]{2}{*}{$A D$} & $-15.76^{* *}$ & $-6.008 * *$ & -1.399 \\
\hline & $(7.529)$ & (3.049) & $(1.265)$ \\
\hline \multirow[t]{2}{*}{ UNPREDICT } & $17.86^{*}$ & 5.961 & -0.684 \\
\hline & $(9.631)$ & $(3.901)$ & $(1.618)$ \\
\hline \multirow[t]{2}{*}{ NOISE } & -19.67 & -7.876 & -2.565 \\
\hline & (16.37) & $(6.628)$ & (2.749) \\
\hline \multirow[t]{2}{*}{ FIN } & -1.753 & -0.757 & 0.069 \\
\hline & (1.519) & $(0.615)$ & $(0.255)$ \\
\hline \multirow[t]{2}{*}{$R O A$} & 1.028 & 1.502 & -0.100 \\
\hline & (3.409) & $(1.381)$ & $(0.573)$ \\
\hline \multirow[t]{2}{*}{ MONITORING } & 0.964 & $0.438^{*}$ & 0.080 \\
\hline & $(0.585)$ & $(0.237)$ & $(0.0983)$ \\
\hline \multirow[t]{2}{*}{$\% I N D E P E N D E N T$} & $5.744 * * *$ & $1.824 * *$ & $0.661^{*}$ \\
\hline & (2.194) & $(0.888)$ & $(0.368)$ \\
\hline \multirow[t]{2}{*}{ CEO_DUALITY } & -0.309 & -0.145 & -0.001 \\
\hline & $(0.856)$ & $(0.347)$ & $(0.144)$ \\
\hline \multirow[t]{2}{*}{$K L D \_R A T I N G$} & $0.435^{* * *}$ & $0.204 * * *$ & 0.002 \\
\hline & $(0.0755)$ & $(0.0306)$ & $(0.0127)$ \\
\hline \multirow[t]{2}{*}{$A B N \_A C C$} & 0.738 & 0.411 & 0.030 \\
\hline & $(0.764)$ & $(0.310)$ & $(0.128)$ \\
\hline Industry fixed effects & Yes & Yes & Yes \\
\hline Prob $>F$ & 0.0000 & 0.0000 & 0.0000 \\
\hline $\mathrm{N}$ & 343 & 343 & 343 \\
\hline \multirow[t]{2}{*}{ Adj. R-sq } & 0.2723 & 0.2889 & 0.2020 \\
\hline & e_lnWords & e_lnPages & \\
\hline e_CSRPM_SCOPE & 0.1199 & 0.0906 & \\
\hline $\mathrm{p}$-value & 0.0264 & 0.0939 & \\
\hline
\end{tabular}




\begin{tabular}{|c|c|c|c|}
\hline $\begin{array}{l}\text { PANEL C: Compleme } \\
\text { contracting }\end{array}$ & ween CSR d & sity and rel & portance of CS \\
\hline & lnWords & InPages & CSRPM_IMP \\
\hline Constant & $-9.982 *$ & $-3.912 *$ & -0.0938 \\
\hline & (5.209) & $(2.110)$ & $(0.160)$ \\
\hline LogAssets & $1.321 * * *$ & $0.521 * * *$ & 0.00518 \\
\hline & $(0.248)$ & $(0.100)$ & $(0.00758)$ \\
\hline$M B R$ & $0.136^{*}$ & 0.0475 & -0.00117 \\
\hline & $(0.0786)$ & $(0.0318)$ & $(0.00241)$ \\
\hline LEVERAGE & -0.176 & -0.0423 & 0.000613 \\
\hline & $(0.130)$ & $(0.0524)$ & $(0.00397)$ \\
\hline$R D$ & $-15.51 * * *$ & $-5.934 * * *$ & -0.147 \\
\hline & (3.792) & $(1.536)$ & $(0.116)$ \\
\hline$A D$ & $-15.76^{* *}$ & $-6.008 * *$ & -0.343 \\
\hline & $(7.529)$ & $(3.049)$ & $(0.231)$ \\
\hline UNPREDICT & $17.86^{*}$ & 5.961 & 0.0324 \\
\hline & $(9.631)$ & $(3.901)$ & $(0.295)$ \\
\hline NOISE & -19.67 & -7.876 & -0.753 \\
\hline & (16.37) & $(6.628)$ & $(0.501)$ \\
\hline FIN & -1.753 & -0.757 & 0.0104 \\
\hline & (1.519) & $(0.615)$ & $(0.0466)$ \\
\hline$R O A$ & 1.028 & 1.502 & -0.0894 \\
\hline & (3.409) & $(1.381)$ & $(0.104)$ \\
\hline MONITORING & 0.964 & $0.438^{*}$ & 0.0253 \\
\hline & $(0.585)$ & $(0.237)$ & $(0.0179)$ \\
\hline \%INDEPENDENT & $5.744 * * *$ & $1.824 * *$ & 0.101 \\
\hline & (2.194) & $(0.888)$ & $(0.0672)$ \\
\hline CEO_DUALITY & -0.309 & -0.145 & -0.0157 \\
\hline & $(0.856)$ & $(0.347)$ & $(0.0262)$ \\
\hline$K L D \_R A T I N G$ & $0.435^{* * *}$ & $0.204 * * *$ & 0.000715 \\
\hline & $(0.0755)$ & $(0.0306)$ & $(0.00231)$ \\
\hline$A B N \_A C C$ & 0.738 & 0.411 & 0.0239 \\
\hline & $(0.764)$ & $(0.310)$ & $(0.0234)$ \\
\hline Industry fixed effects & Yes & Yes & Yes \\
\hline Prob $>F$ & 0.000 & 0.000 & 0.000 \\
\hline $\mathrm{N}$ & 343 & 343 & 343 \\
\hline Adj. R-sq & 0.2723 & 0.2889 & 0.1969 \\
\hline & e_lnWords & e_lnPages & \\
\hline e_CSRPM_IMP & 0.1069 & 0.0964 & \\
\hline $\mathrm{p}$-value & 0.0478 & 0.0745 & \\
\hline
\end{tabular}

$*^{* * *}, * * *$ indicate $\mathrm{p}<0.1, \mathrm{p}<0.05, \mathrm{p}<0.01$, respectively, two-tailed test. Standard errors are in parentheses. This table reports results of the complementarity analysis. Panel A reports the OLS regressions for CSR disclosures and CSR contracting for the full sample. Panel B reports the OLS regressions for the intensity of CSR disclosures and the scope of CSR contracting for the full sample. Panel C reports the OLS regressions for the intensity of CSR disclosures and the relative importance of CSR performance measures for the full sample. Please see Appendix A for variable definitions. 
Chapter 3

\subsubsection{Contextual Analysis (H2a and $\mathrm{H} 2 \mathrm{~b}$ )}

Table 10 shows the descriptive statistics for the high-scrutiny and low-scrutiny subsamples. Most notably, compared to firms in low-scrutiny industries, firms in high-scrutiny industries are more likely to use CSR contracting and to use it more intensively. In addition, these firms are more likely to use both CSR contracting and CSR disclosures, as well as use both strategies more intensively. 
The Complementarity between CSR Disclosures and the Use of CSR-based Performance Measures

TABLE 10: Descriptive Statistics for High-Scrutiny and Low-Scrutiny Industries

\begin{tabular}{|c|c|c|c|c|c|c|c|}
\hline \multirow[b]{2}{*}{ Variable } & \multicolumn{3}{|c|}{ High-Scrutiny $(n=91)$} & \multicolumn{3}{|c|}{ Low-Scrutiny $(n=252)$} & \multirow{2}{*}{$\begin{array}{c}\text { T test } \\
\text { Mean-Diff }\end{array}$} \\
\hline & Mean & Median & Std. Dev. & Mean & Median & Std. Dev. & \\
\hline D_CSRPM & 0.604 & 1.000 & 0.492 & 0.218 & 0.000 & 0.414 & $\begin{array}{c}0.386 * * * \\
{[7.25]}\end{array}$ \\
\hline CSRPM_SCOPE & 0.900 & 1.000 & 0.875 & 0.292 & 0.000 & 0.620 & $\begin{array}{c}0.608 * * * \\
{[7.11]}\end{array}$ \\
\hline CSRPM_IMP & 0.168 & 0.167 & 0.018 & 0.046 & 0.000 & 0.006 & $\begin{array}{c}0.122 * * * \\
{[8.03]}\end{array}$ \\
\hline D_CSR_REPORTING & 0.670 & 1.000 & 0.473 & 0.595 & 1.000 & 0.492 & $\begin{array}{l}0.075 \\
{[1.26]}\end{array}$ \\
\hline lnPages & 2.472 & 3.219 & 1.881 & 2.214 & 2.708 & 1.900 & $\begin{array}{l}0.348 \\
{[1.50]}\end{array}$ \\
\hline $\ln W o r d s$ & 6.205 & 8.927 & 4.566 & 5.500 & 8.195 & 4.652 & $\begin{array}{c}0.705 \\
{[1.25]}\end{array}$ \\
\hline HIHI & 0.473 & 0.000 & 0.502 & 0.167 & 0.000 & 0.373 & $\begin{array}{c}0.306 * * * \\
{[6.08]}\end{array}$ \\
\hline HIHI25_PAGE_SCOPE & 0.231 & 0.000 & 0.424 & 0.056 & 0.000 & 0.230 & $\begin{array}{c}0.175 * * * \\
{[4.88]}\end{array}$ \\
\hline HIHI25_WORD_SCOPE & 0.220 & 0.000 & 0.416 & 0.067 & 0.000 & 0.251 & $\begin{array}{c}0.152 * * * \\
{[4.10]}\end{array}$ \\
\hline HIHI25_PAGE_IMP & 0.220 & 0.000 & 0.416 & 0.032 & 0.000 & 0.176 & $\begin{array}{c}0.188 * * * \\
{[5.875]}\end{array}$ \\
\hline HIHI25_WORD_IMP & 0.209 & 0.000 & 0.409 & 0.044 & 0.000 & 0.204 & $\begin{array}{c}0.165 * * * \\
{[4.933]}\end{array}$ \\
\hline LogASSETS & 10.003 & 9.992 & 0.954 & 9.281 & 9.156 & 1.065 & $\begin{array}{c}0.722 * * * \\
{[5.70]}\end{array}$ \\
\hline$M B R$ & 2.128 & 1.590 & 2.000 & 3.500 & 3.150 & 6.527 & $\begin{array}{c}-1.372 * * \\
{[-1.97]}\end{array}$ \\
\hline$L E V E R A G E$ & 1.321 & 1.135 & 1.432 & 1.130 & 0.989 & 3.895 & $\begin{array}{c}0.191 \\
{[0.457]}\end{array}$ \\
\hline$R D$ & 0.001 & 0.000 & 0.004 & 0.050 & 0.015 & 0.077 & $\begin{array}{c}-0.049 * * * \\
{[6.123]}\end{array}$ \\
\hline$A D$ & 0.007 & 0.000 & 0.027 & 0.016 & 0.002 & 0.033 & $\begin{array}{c}-0.009 * * \\
{[-2.37]}\end{array}$ \\
\hline UNPREDICT & 0.071 & 0.066 & 0.024 & 0.075 & 0.069 & 0.028 & $\begin{array}{l}-0.004 \\
{[-1.32]}\end{array}$ \\
\hline NOISE & 0.016 & 0.014 & 0.017 & 0.025 & 0.021 & 0.015 & $\begin{array}{c}-0.009 * * * \\
{[-4.65]}\end{array}$ \\
\hline FIN & 0.216 & 0.229 & 0.138 & 0.101 & 0.114 & 0.163 & $\begin{array}{c}0.115^{* * *} \\
{[6.02]}\end{array}$ \\
\hline$R O A$ & 0.039 & 0.033 & 0.050 & 0.097 & 0.086 & 0.079 & $\begin{array}{c}-0.058 * * * \\
{[-6.55]}\end{array}$ \\
\hline MONITORING & 0.095 & -0.011 & 0.472 & -0.034 & -0.089 & 0.3 .74 & $\begin{array}{c}0.130 * * * \\
{[2.64]}\end{array}$ \\
\hline$\% I N D E P E N D E N T$ & 0.820 & 0.867 & 0.119 & 0.818 & 0.846 & 0.101 & $\begin{array}{l}0.002 \\
{[0.17]}\end{array}$ \\
\hline CEO_DUALITY & 0.121 & 0.000 & 0.328 & 0.060 & 0.000 & 0.237 & $\begin{array}{l}0.061^{*} \\
{[1.90]}\end{array}$ \\
\hline KLD_RATING & 2.637 & 2.000 & 3.068 & 3.345 & 3.000 & 3.368 & $\begin{array}{c}-0.708 * \\
{[-1.76]}\end{array}$ \\
\hline$A B N \_A C C$ & -0.149 & -0.021 & 0.464 & 0.070 & 0.030 & 0.262 & $\begin{array}{c}-0.219 * * * \\
{[-5.47]}\end{array}$ \\
\hline
\end{tabular}


Table 11 reports the analyses of whether firms in high-scrutiny industries are more likely to show complementarity of the two strategies. Panel A of Table 11 presents the regression results of Equation (1) and Equation (2) for the high-scrutiny and low-scrutiny subsamples, respectively. We find a significantly positive conditional correlation coefficient only in the low-scrutiny subsample $(\mathrm{r}=0.130, \mathrm{p}=0.039)$. In the high-scrutiny subsample, the conditional correlation coefficient is positive, but not significant $(r=0.093, p=0.382)$. The Fisher transformation test suggests that the two correlations do not differ from each other $(z=$ $-0.30, \mathrm{p}=0.7462)$.

Panel B reports industry differences with respect to the complementarity between CSR disclosure intensity and the scope of CSR contracting. Firms in the high-scrutiny subsample show a significantly positive conditional correlation between the scope of CSR contracting and the number of words $(r=0.190, p=0.067)$ and the number of pages $(r=$ 0.272, $\mathrm{p}=0.009$ ) used in CSR reports, respectively. We do not observe significant conditional correlations between disclosure intensity and the scope of CSR contracting for firms in low-scrutiny industries: The conditional correlation between the number of words and the scope of CSR contracting is $0.082(\mathrm{p}=0.192)$, and between the number of pages and the scope of CSR contracting is $0.011(\mathrm{p}=0.865)$.

Table 11, Panel $\mathrm{C}$ reports the differences in correlation coefficients between subsamples. In line with the expectations, the Fisher score for the difference in conditional correlation coefficients between the number of pages and the scope of CSR contracting is 2.16 , with a p-value of 0.031 . However, we do not find a significant difference when CSR disclosure intensity is measured via the number of words.

Panel D of Table 11 reports the results of the complementarity analysis between CSR disclosure intensity and the relative importance of CSR contracting of high-scrutiny versus low-scrutiny industries. In line with our expectations, for firms in high-scrutiny industries, the conditional correlation between the number of pages disclosed in CSR reports and the relative importance of CSR contracting is significantly positive $(r=0.275, p=0.008)$. We also find a complementarity relationship between the number of words disclosed in CSR reports and the relative importance of CSR contracting $(r=0.185, p=0.079)$. In contrast, we do not observe such complementarity for firms in low-scrutiny industries.

Panel E of Table 11 compares the differences in correlation coefficients of the two subsamples. We only observe a significant difference across the conditional correlation coefficients between the number of pages and the relative importance of CSR contracting ( $z=$ $2.19, \mathrm{p}=0.029)$.

In sum, we only find weak support for H2a. While we observe a complementarity of CSR disclosure intensity and CSR contracting intensity in the high-scrutiny sample (indicating a stronger complementarity in these firms), the conditional correlation coefficients are only significantly different between the subsamples when CSR disclosure intensity is measured with the number of pages, but not when measured with the number of words. Furthermore, we do not find significant differences between the conditional correlation coefficients for high-scrutiny and low-scrutiny industries when using indicator variables for CSR disclosures and CSR contracting. In fact, contrary to our expectations, we do not find a significant conditional correlation at all in the high-scrutiny sample. One reason might be that 
the indicator variables do not capture enough variation in the two choices in the high-scrutiny sample, given that almost $50 \%$ of these firms use both strategies (in line with $\mathrm{H} 2 \mathrm{~b}$ ).

TABLE 11:

Impact of HIGH-SCRUTINY on the Relation between CSR Disclosure and CSR Contracting PANEL A: Complementarity of CSR disclosures and CSR contracting

\begin{tabular}{|c|c|c|c|c|}
\hline & \multicolumn{2}{|c|}{ High-Scrutiny } & \multicolumn{2}{|c|}{ Low-Scrutiny } \\
\hline & D_CSR_REPORTING & D_CSRPM & D_CSR_REPORTING & D_CSRPM \\
\hline \multirow{2}{*}{ Constant } & -0.612 & $-1.866^{* *}$ & $-\overline{1} .211 * * *$ & 0.214 \\
\hline & $(0.831)$ & $(0.874)$ & $(0.369)$ & $(0.355)$ \\
\hline \multirow[t]{2}{*}{ LogAssets } & 0.101 & $0.192 * * *$ & $0.119 * * *$ & -0.019 \\
\hline & $(0.0671)$ & $(0.0706)$ & $(0.0293)$ & $(0.0282)$ \\
\hline \multirow[t]{2}{*}{$M B R$} & 0.047 & -0.041 & 0.006 & -0.004 \\
\hline & $(0.0290)$ & $(0.0305)$ & $(0.00883)$ & $(0.00851)$ \\
\hline \multirow{2}{*}{ LEVERAGE } & -0.042 & -0.003 & -0.004 & 0.003 \\
\hline & $(0.0444)$ & $(0.0467)$ & $(0.0146)$ & $(0.0141)$ \\
\hline \multirow[t]{2}{*}{$R D$} & 14.25 & -5.331 & $-1.535^{* * *}$ & -0.126 \\
\hline & $(13.46)$ & $(14.16)$ & $(0.395)$ & $(0.381)$ \\
\hline \multirow[t]{2}{*}{$A D$} & -1.607 & -2.131 & $-1.901 * *$ & -1.191 \\
\hline & $(2.111)$ & $(2.221)$ & $(0.863)$ & $(0.832)$ \\
\hline \multirow[t]{2}{*}{ UNPREDICT } & 0.558 & $5.360^{*}$ & 1.517 & -0.752 \\
\hline & $(2.683)$ & $(2.823)$ & (1.074) & $(1.035)$ \\
\hline \multirow[t]{2}{*}{ NOISE } & -2.975 & -0.243 & -2.556 & -1.637 \\
\hline & (3.577) & $(3.763)$ & $(1.956)$ & $(1.885)$ \\
\hline \multirow[t]{2}{*}{ FIN } & -0.230 & -0.600 & -0.058 & 0.161 \\
\hline & $(0.395)$ & $(0.415)$ & $(0.174)$ & $(0.167)$ \\
\hline \multirow[t]{2}{*}{$R O A$} & $-3.008 * *$ & -0.294 & $0.663^{*}$ & -0.315 \\
\hline & $(1.255)$ & $(1.320)$ & $(0.387)$ & $(0.373)$ \\
\hline \multirow[t]{2}{*}{ MONITORING } & -0.006 & -0.051 & 0.120 & $0.166^{* *}$ \\
\hline & $(0.117)$ & $(0.123)$ & $(0.0792)$ & $(0.0763)$ \\
\hline \multirow[t]{2}{*}{$\% I N D E P E N D E N T$} & 0.465 & 0.531 & $0.671 * *$ & 0.419 \\
\hline & $(0.506)$ & $(0.533)$ & $(0.272)$ & $(0.262)$ \\
\hline \multirow[t]{2}{*}{ CEO_DUALITY } & 0.052 & -0.166 & -0.094 & -0.075 \\
\hline & $(0.153)$ & $(0.161)$ & $(0.118)$ & $(0.113)$ \\
\hline \multirow[t]{2}{*}{ KLD_RATING } & 0.012 & 0.012 & $0.049 * * *$ & -0.004 \\
\hline & $(0.0197)$ & $(0.0207)$ & $(0.00883)$ & $(0.00852)$ \\
\hline \multirow{2}{*}{$A B N \_A C C$} & 0.116 & 0.213 & $-0.233 * *$ & -0.013 \\
\hline & $(0.131)$ & $(0.138)$ & $(0.110)$ & $(0.106)$ \\
\hline Industry fixed effects & No & No & No & No \\
\hline Prob $>F$ & 0.0072 & 0.0102 & 0.0000 & 0.0812 \\
\hline $\mathrm{N}$ & 91 & 91 & 252 & 252 \\
\hline \multirow[t]{2}{*}{ Adj. R-sq } & 0.1815 & 0.1702 & 0.2755 & 0.0232 \\
\hline & \multicolumn{2}{|c|}{ e CSR Reporting } & \multicolumn{2}{|c|}{ e CSR Reporting } \\
\hline \multirow{2}{*}{$\begin{array}{c}\text { e_CSRPM } \\
\text { p-value }\end{array}$} & \multicolumn{2}{|l|}{0.0927} & \multicolumn{2}{|l|}{0.1299} \\
\hline & \multicolumn{2}{|l|}{0.3820} & \multicolumn{2}{|l|}{0.0393} \\
\hline
\end{tabular}




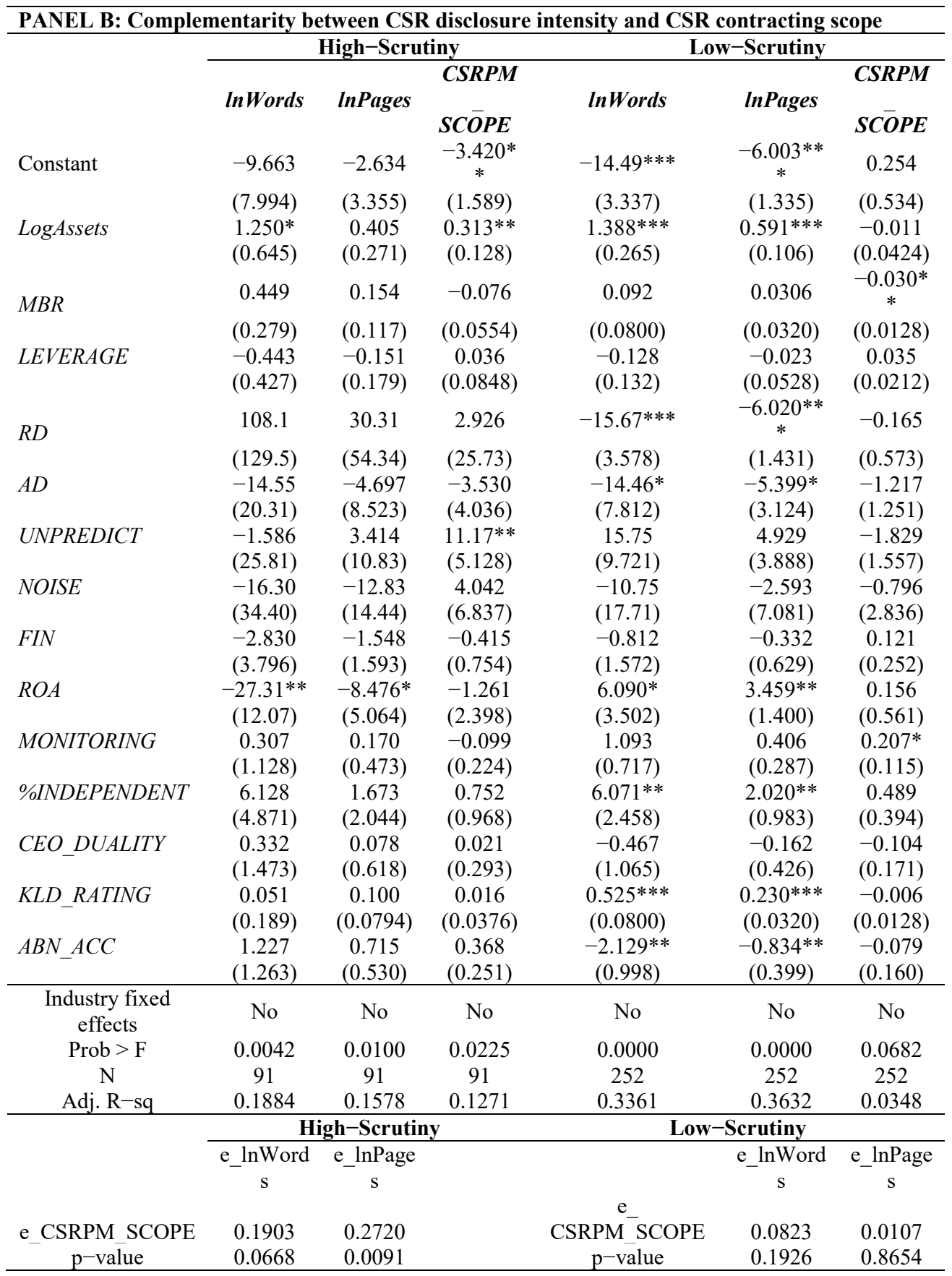


The Complementarity between CSR Disclosures and the Use of CSR-based Performance Measures

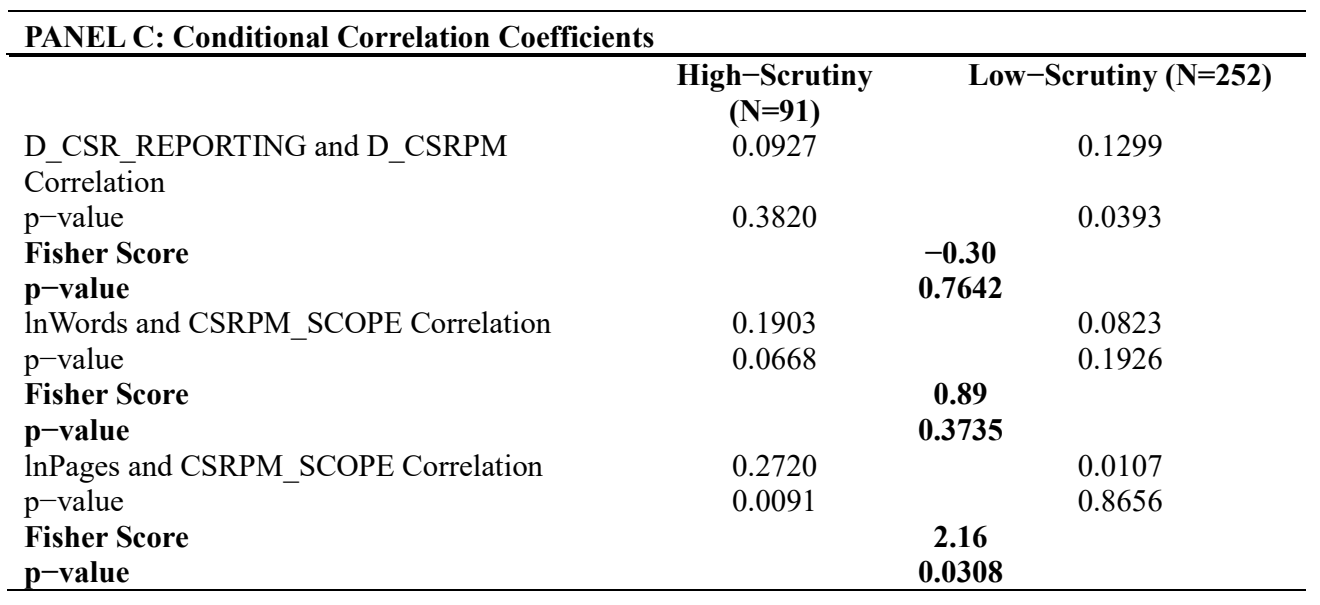




\begin{tabular}{|c|c|c|c|c|c|c|}
\hline \multicolumn{7}{|l|}{$\begin{array}{l}\text { PANEL D: Comple } \\
\text { contracting }\end{array}$} \\
\hline & \multicolumn{3}{|c|}{ High-Scrutiny } & \multicolumn{3}{|c|}{ Low-Scrutiny } \\
\hline & InWords & InPages & CSRPM_IMP & lnWords & InPages & $\begin{array}{c}\text { CSRPM_I } \\
M P\end{array}$ \\
\hline \multirow[t]{2}{*}{ Constant } & -9.663 & -2.634 & -0.360 & $-14.49 * * *$ & $\begin{array}{c}-6.003 * \\
* *\end{array}$ & 0.0552 \\
\hline & (7.994) & (3.355) & $(0.323)$ & (3.337) & $(1.335)$ & $(0.0894)$ \\
\hline \multirow[t]{2}{*}{ LogAssets } & $1.250^{*}$ & 0.405 & 0.0420 & $1.388 * * *$ & $0.591 * * *$ & -0.00291 \\
\hline & $(0.645)$ & $(0.271)$ & $(0.0261)$ & $(0.265)$ & $(0.106)$ & $(0.00710)$ \\
\hline \multirow[t]{2}{*}{$M B R$} & 0.449 & 0.154 & -0.0116 & 0.0922 & 0.0306 & -0.000927 \\
\hline & $(0.279)$ & $(0.117)$ & $(0.0113)$ & $(0.0800)$ & $(0.0320)$ & $(0.00214)$ \\
\hline \multirow[t]{2}{*}{ LEVERAGE } & -0.443 & -0.151 & -0.00485 & -0.128 & -0.0231 & 0.000938 \\
\hline & $(0.427)$ & $(0.179)$ & $(0.0173)$ & $(0.132)$ & $(0.0528)$ & $(0.00354)$ \\
\hline \multirow{2}{*}{$R D$} & 108.1 & 30.31 & -1.199 & $-15.67 * * *$ & $\begin{array}{c}-6.020 * \\
* *\end{array}$ & -0.111 \\
\hline & $(129.5)$ & $(54.34)$ & $(5.238)$ & (3.578) & $(1.431)$ & $(0.0959)$ \\
\hline \multirow[t]{2}{*}{$A D$} & -14.55 & -4.697 & -0.617 & $-14.46^{*}$ & $-5.399 *$ & -0.251 \\
\hline & $(20.31)$ & $(8.523)$ & $(0.822)$ & (7.812) & $(3.124)$ & $(0.209)$ \\
\hline \multirow[t]{2}{*}{ UNPREDICT } & -1.586 & 3.414 & 1.028 & 15.75 & 4.929 & -0.0108 \\
\hline & $(25.81)$ & $(10.83)$ & (1.044) & $(9.721)$ & (3.888) & $(0.261)$ \\
\hline \multirow[t]{2}{*}{ NOISE } & -16.30 & -12.83 & -0.191 & -10.75 & -2.593 & -0.201 \\
\hline & $(34.40)$ & $(14.44)$ & $(1.392)$ & (17.71) & $(7.081)$ & $(0.475)$ \\
\hline \multirow[t]{2}{*}{ FIN } & -2.830 & -1.548 & -0.116 & -0.812 & -0.332 & 0.0336 \\
\hline & $(3.796)$ & $(1.593)$ & $(0.154)$ & $(1.572)$ & $(0.629)$ & $(0.0421)$ \\
\hline \multirow[t]{2}{*}{$R O A$} & $-27.31 * *$ & $-8.476^{*}$ & -0.187 & $6.090^{*}$ & $3.459 * *$ & -0.0541 \\
\hline & (12.07) & $(5.064)$ & $(0.488)$ & $(3.502)$ & $(1.400)$ & $(0.0939)$ \\
\hline \multirow[t]{2}{*}{ MONITORING } & 0.307 & 0.170 & -0.0153 & 1.093 & 0.406 & $0.0541 * * *$ \\
\hline & $(1.128)$ & $(0.473)$ & $(0.0456)$ & $(0.717)$ & $(0.287)$ & $(0.0192)$ \\
\hline \multirow[t]{2}{*}{$\% I N D E P E N D E N T$} & 6.128 & 1.673 & 0.147 & $6.071 * *$ & $2.020 * *$ & 0.0508 \\
\hline & $(4.871)$ & $(2.044)$ & $(0.197)$ & $(2.458)$ & $(0.983)$ & $(0.0659)$ \\
\hline \multirow[t]{2}{*}{ CEO_DUALITY } & 0.332 & 0.0781 & -0.0445 & -0.467 & -0.162 & -0.0141 \\
\hline & $(1.473)$ & $(0.618)$ & $(0.0596)$ & $(1.065)$ & $(0.426)$ & $(0.0285)$ \\
\hline \multirow[t]{2}{*}{$K L D \_R A T I N G$} & 0.0509 & 0.0998 & 0.00162 & $0.525^{* * *}$ & $0.230 * * *$ & -0.000426 \\
\hline & $(0.189)$ & $(0.0794)$ & $(0.00765)$ & $(0.0800)$ & $(0.0320)$ & $(0.00214)$ \\
\hline \multirow{2}{*}{$A B N_{-} A C C$} & 1.227 & 0.715 & 0.0754 & $-2.129 * *$ & $\begin{array}{c}-0.834 * \\
*\end{array}$ & 0.000322 \\
\hline & $(1.263)$ & $(0.530)$ & $(0.0511)$ & $(0.998)$ & $(0.399)$ & $(0.0268)$ \\
\hline $\begin{array}{l}\text { Industry fixed } \\
\text { effects }\end{array}$ & No & No & No & No & No & No \\
\hline Prob $>F$ & 0.0058 & 0.0149 & 0.2291 & 0.0000 & 0.0000 & 0.1679 \\
\hline $\mathrm{N}$ & 91 & 91 & 91 & 252 & 252 & 252 \\
\hline \multirow[t]{3}{*}{ Adj. R-sq } & 0.1884 & 0.1578 & 0.0442 & 0.3361 & 0.3632 & 0.0203 \\
\hline & \multicolumn{3}{|c|}{ High-Scrutiny } & \multicolumn{3}{|c|}{ Low-Scrutiny } \\
\hline & $\begin{array}{c}\text { e_lnWor } \\
\text { ds }\end{array}$ & $\begin{array}{c}\text { e_lnPag } \\
\text { es }\end{array}$ & & & $\begin{array}{c}\text { e } \ln W o r \\
\text { ds }\end{array}$ & e_lnPages \\
\hline $\begin{array}{c}\text { e_CSRPM_IMP } \\
p-\text { value }\end{array}$ & $\begin{array}{l}0.1849 \\
0.0793\end{array}$ & $\begin{array}{l}0.2746 \\
0.0084\end{array}$ & & $\begin{array}{c}\text { e_CSRPM_ } \\
\text { IMP } \\
\text { p-value }\end{array}$ & $\begin{array}{l}0.0721 \\
0.2542\end{array}$ & $\begin{array}{l}0.0103 \\
0.8707\end{array}$ \\
\hline
\end{tabular}


TABLE 12: Probabilities of Choosing both CSR Disclosure and CSR-based performance measures

\begin{tabular}{|c|c|c|c|c|c|}
\hline & HIHI & $\begin{array}{c}\text { HIHI25 } \\
\text { PAGE SCOPE }\end{array}$ & $\begin{array}{c}\text { HIHI25 } \\
\text { WORD SCOPE }\end{array}$ & $\begin{array}{c}\text { HIHI } 25 \\
\text { WORD IMP }\end{array}$ & $\begin{array}{c}\text { HIHI25 } \\
\text { PAGE IMP }\end{array}$ \\
\hline Constant & $\begin{array}{c}-3.48 * * * \\
(1.216)\end{array}$ & $\begin{array}{c}-4.245^{* *} \\
(1.697)\end{array}$ & $\begin{array}{c}-6.035 * * * \\
(1.938)\end{array}$ & $\begin{array}{c}-6.37 \overline{8} * * * \\
(2.068)\end{array}$ & $\begin{array}{c}-4.385 * * \\
(1.795)\end{array}$ \\
\hline HIGH-SCRUTINY & $\begin{array}{c}0.486 * * \\
(0.220)\end{array}$ & $\begin{array}{c}0.787 * * * \\
(0.284)\end{array}$ & $\begin{array}{l}0.534^{*} \\
(0.295)\end{array}$ & $\begin{array}{c}0.698 * * \\
(0.314)\end{array}$ & $\begin{array}{c}0.972 * * * \\
(0.306)\end{array}$ \\
\hline LogAssets & $\begin{array}{c}0.105 \\
(0.095)\end{array}$ & $\begin{array}{c}0.094 \\
(0.131)\end{array}$ & $\begin{array}{l}0.105 \\
(0.133)\end{array}$ & $\begin{array}{l}0.113 \\
(0.143)\end{array}$ & $\begin{array}{c}0.101 \\
(0.142)\end{array}$ \\
\hline$M B R$ & $\begin{array}{l}0.0571 \\
(0.037)\end{array}$ & $\begin{array}{c}0.016 \\
(0.0522)\end{array}$ & $\begin{array}{c}0.011 \\
(0.0522)\end{array}$ & $\begin{array}{c}-0.00303 \\
(0.0528)\end{array}$ & $\begin{array}{l}0.00125 \\
(0.0543)\end{array}$ \\
\hline LEVERAGE & $\begin{array}{l}-0.089 \\
(0.057)\end{array}$ & $\begin{array}{c}-0.009 \\
(0.0802)\end{array}$ & $\begin{array}{c}-0.010 \\
(0.0840)\end{array}$ & $\begin{array}{c}0.0160 \\
(0.0900)\end{array}$ & $\begin{array}{c}0.0172 \\
(0.0863)\end{array}$ \\
\hline$R D$ & $\begin{array}{c}-3.535^{*} \\
(1.928)\end{array}$ & $\begin{array}{l}-2.698 \\
(2.772)\end{array}$ & $\begin{array}{l}-3.286 \\
(2.898)\end{array}$ & $\begin{array}{l}-4.025 \\
(3.478)\end{array}$ & $\begin{array}{l}-3.294 \\
(3.395)\end{array}$ \\
\hline$A D$ & $\begin{array}{c}-8.623 * \\
(4.600)\end{array}$ & $\begin{array}{l}-0.499 \\
(4.056)\end{array}$ & $\begin{array}{l}-0.758 \\
(4.379)\end{array}$ & $\begin{array}{l}-0.319 \\
(4.505)\end{array}$ & $\begin{array}{c}-0.0932 \\
(4.196)\end{array}$ \\
\hline UNPREDICT & $\begin{array}{l}1.513 \\
(3.637)\end{array}$ & $\begin{array}{c}5.302 \\
(4.899)\end{array}$ & $\begin{array}{c}4.425 \\
(5.049)\end{array}$ & $\begin{array}{c}5.347 \\
(5.312)\end{array}$ & $\begin{array}{c}6.371 \\
(5.181)\end{array}$ \\
\hline NOISE & $\begin{array}{l}-6.420 \\
(6.609)\end{array}$ & $\begin{array}{l}-5.208 \\
(8.606)\end{array}$ & $\begin{array}{l}-6.137 \\
(9.136)\end{array}$ & $\begin{array}{l}-6.029 \\
(9.907)\end{array}$ & $\begin{array}{l}-5.804 \\
(9.399)\end{array}$ \\
\hline FIN & $\begin{array}{l}0.126 \\
(0.603)\end{array}$ & $\begin{array}{c}-0.0006 \\
(0.850)\end{array}$ & $\begin{array}{c}0.065 \\
(0.876)\end{array}$ & $\begin{array}{c}-0.0431 \\
(0.929)\end{array}$ & $\begin{array}{l}-0.124 \\
(0.903)\end{array}$ \\
\hline$R O A$ & $\begin{array}{c}-3.021 * \\
(1.691)\end{array}$ & $\begin{array}{l}-0.584 \\
(2.291)\end{array}$ & $\begin{array}{l}-0.651 \\
(2.323)\end{array}$ & $\begin{array}{l}0.0736 \\
(2.425)\end{array}$ & $\begin{array}{c}0.122 \\
(2.431)\end{array}$ \\
\hline MONITORING & $\begin{array}{l}0.382^{*} \\
(0.225)\end{array}$ & $\begin{array}{l}0.466^{*} \\
(0.278)\end{array}$ & $\begin{array}{c}0.794 * * * \\
(0.290)\end{array}$ & $\begin{array}{c}0.829 * * * \\
(0.303)\end{array}$ & $\begin{array}{c}0.466 \\
(0.291)\end{array}$ \\
\hline$\% I N D E P E N D E N T$ & $\begin{array}{c}2.213^{* *} \\
(0.915)\end{array}$ & $\begin{array}{l}1.401 \\
(1.183)\end{array}$ & $\begin{array}{c}3.576^{* * *} \\
(1.428)\end{array}$ & $\begin{array}{c}3.642 * * \\
(1.529)\end{array}$ & $\begin{array}{l}1.220 \\
(1.246)\end{array}$ \\
\hline CEO_DUALITY & $\begin{array}{l}-0.131 \\
(0.328)\end{array}$ & $\begin{array}{l}-0.419 \\
(0.455)\end{array}$ & $\begin{array}{l}-0.173 \\
(0.404)\end{array}$ & $\begin{array}{l}-0.131 \\
(0.409)\end{array}$ & $\begin{array}{l}-0.385 \\
(0.463)\end{array}$ \\
\hline KLD_RATING & $\begin{array}{c}0.033 \\
(0.028)\end{array}$ & $\begin{array}{c}0.0870 * * \\
(0.0373)\end{array}$ & $\begin{array}{l}0.091 * * \\
(0.0378)\end{array}$ & $\begin{array}{l}0.0768 * \\
(0.0404)\end{array}$ & $\begin{array}{l}0.0733 * \\
(0.0403)\end{array}$ \\
\hline$A B N \_A C C$ & $\begin{array}{l}-0.121 \\
(0.269)\end{array}$ & $\begin{array}{l}-0.031 \\
(0.343)\end{array}$ & $\begin{array}{l}-0.144 \\
(0.353)\end{array}$ & $\begin{array}{l}-0.163 \\
(0.367)\end{array}$ & $\begin{array}{c}-0.0396 \\
(0.358)\end{array}$ \\
\hline Ind-fixed & No & No & No & No & No \\
\hline Prob > Chi (2) & 0.0000 & 0.0002 & 0.0000 & 0.0000 & 0.0004 \\
\hline $\mathbf{N}$ & 343 & 343 & 343 & 343 & 343 \\
\hline Pseudo R & 0.1740 & 0.1806 & 0.2182 & 0.2395 & 0.2096 \\
\hline
\end{tabular}

$*, * *, * * *$ Indicate $\mathrm{p}<0.1, \mathrm{p}<0.05, \mathrm{p}<0.01$ (two-tailed), respectively. Standard errors are in parentheses.

This table reports the Probit models estimating the probabilities of choosing the high use of both CSR reporting and CSR-based performance measures. Please see Appendix A for variable definitions. 


\subsection{Additional Tests}

\section{Relative Importance of CSR-based Performance Measures}

Our theory hinges on the assumption that CSR reports suffer from credibility concerns, partly due to a lack of systematic assurance by external parties (low percentage of assured CSR reports), and the difficulty to provide external assurance in the first place given data availability issues and measurement problems (low information value of assurance). In our main analysis, we do not distinguish between assured and non-assured CSR reports. In a next step, we therefore shed light on the role of CSR report assurance. As reported in Panel A of Table 13, in our sample, 40 out of 211 CSR reports (18.96\%) are (partly) assured by external parties. Only 5 reports $(2.37 \%)$ are fully assured; the majority only assures environmental (e.g., waste, energy, carbon emission) and safety dimensions. Further, the assurance providers acknowledge potential reliability issues. For example, in the Hewlett 2013 CSR report, the external assurer (Ernst \& Young LL) acknowledges:

"Information (in the assurance report) are subject to measurement uncertainties resulting from limitations inherent in the nature and the methods used for determining such data. The selection of different but acceptable measurement techniques can result in materially different measurements. The precision of different measurement techniques may also vary."

One could argue that choosing to seek assurance for a CSR report might be an alternative signal to CSR contracting (i.e., a substitute) to credibly communicate a true CSR orientation to the market. However, as the assurance itself lacks credibility, we expect that this is not the case. However, we still investigate the potential interrelation of CSR contracting and CSR report assurance, conditional on issuing a CSR report. In particular, we estimate the conditional correlations between CSR contracting (intensity) and CSR report assurance within the sample of CSR report issuers. The results, reported in Table 13 Panel B, indicate that the choice to seek assurance for a CSR report is not interrelated with the choice of CSR contracting. Thus, these strategies are not alternative ways of credibly signalling a true CSR orientation to the market. These results provide further substantiation for our expectation of CSR disclosures by themselves not providing sufficient signals, as only very few CSR reports are fully assured, and investment in CSR report assurance does not substitute for the investment in CSR contracting. 
TABLE 13: CSR Report Assurance and CSR Contracting

\begin{tabular}{cccccc}
\hline \multicolumn{2}{l}{ PANEL A: Assurance Distribution } & & & & \\
\hline $\begin{array}{c}\text { External } \\
\text { Assurance }\end{array}$ & CSRPM=0 & CSRPM=1 & $\begin{array}{c}\text { Fully } \\
\text { Assured }\end{array}$ & $\begin{array}{c}\text { Partially } \\
\text { Assured }\end{array}$ & Total \\
\hline 0 & 105 & 66 & & & 171 \\
1 & 24 & 16 & 5 & 35 & 40 \\
Total & 129 & 82 & & & 211 \\
\hline
\end{tabular}

PANEL B: Mean comparisons of firms with and without external assurance for CSR reports

\begin{tabular}{lcccccc}
\hline & No Assurance & No. & Assurance & No. & t-value & p-value \\
D_CSRPM & 0.397 & 171 & 0.425 & 40 & -0.316 & 0.752 \\
CSRPM_SCOPE & 0.579 & 171 & 0.55 & 40 & 0.203 & 0.839 \\
CSRPM_IMP & 0.105 & 171 & 0.078 & 40 & 1.040 & 0.299 \\
LogAssets & 9.969 & 171 & 10.111 & 40 & -2.231 & 0.027 \\
MBR & 3.247 & 171 & 3.996 & 40 & -0.891 & 0.374 \\
LEVERAGE & 1.477 & 171 & 1.685 & 40 & -0.403 & 0.687 \\
RD & 0.024 & 171 & 0.047 & 40 & -2.641 & 0.009 \\
AD & 0.011 & 171 & 0.011 & 40 & 0.050 & 0.960 \\
UNPREDICT & 0.072 & 171 & 0.069 & 40 & 0.431 & 0.667 \\
NOISE & 0.019 & 171 & 0.024 & 40 & -1.880 & 0.061 \\
FIN & 0.137 & 171 & 0.143 & 40 & -0.258 & 0.797 \\
ROA & 0.072 & 171 & 0.083 & 40 & -0.901 & 0.368 \\
MONITORING & 0.022 & 171 & 0.168 & 40 & -2.414 & 0.017 \\
\%INDEPENDENT & 0.838 & 171 & 0.850 & 40 & -0.781 & 0.436 \\
CEO_DUALITY & 0.061 & 171 & 0.100 & 40 & -0.788 & 0.432 \\
KLD_RATING & 3.585 & 171 & 5.375 & 40 & -3.098 & 0.002 \\
ABN_ACC & 0.005 & 171 & 0.023 & 40 & -0.324 & 0.746 \\
\hline
\end{tabular}




\begin{tabular}{|c|c|c|c|c|}
\hline \multicolumn{5}{|c|}{ PANEL C: The choice of external assurance of CSR reports and CSR contracting } \\
\hline & External_Assurance & D_CSRPM & CSRPM_SCOPE & CSRPM_IMP \\
\hline \multirow[t]{2}{*}{ Constant } & -0.903 & 0.103 & $0 . \overline{2} 62$ & 0.109 \\
\hline & $(0.579)$ & $(0.691)$ & $(1.128)$ & $(0.205)$ \\
\hline \multirow[t]{2}{*}{ LogAssets } & $0.0651 * *$ & -0.0178 & -0.0144 & -0.00939 \\
\hline & $(0.0296)$ & $(0.0353)$ & $(0.0577)$ & $(0.0105)$ \\
\hline \multirow[t]{2}{*}{$M B R$} & 0.0187 & 0.00814 & -0.00198 & -0.0000952 \\
\hline & $(0.0135)$ & $(0.0162)$ & $(0.0264)$ & $(0.00478)$ \\
\hline \multirow[t]{2}{*}{ LEVERAGE } & -0.0219 & -0.0249 & -0.0129 & -0.00344 \\
\hline & $(0.0215)$ & $(0.0257)$ & $(0.0419)$ & $(0.00760)$ \\
\hline \multirow[t]{2}{*}{$R D$} & 0.366 & -1.033 & -1.281 & -0.226 \\
\hline & $(0.649)$ & $(0.775)$ & $(1.265)$ & $(0.229)$ \\
\hline \multirow[t]{2}{*}{$A D$} & -2.138 & -2.260 & -1.885 & -0.311 \\
\hline & $(1.321)$ & $(1.577)$ & (2.574) & $(0.467)$ \\
\hline \multirow[t]{2}{*}{ UNPREDICT } & $2.246^{*}$ & -1.465 & -3.453 & -0.484 \\
\hline & (1.219) & $(1.455)$ & $(2.374)$ & $(0.431)$ \\
\hline \multirow[t]{2}{*}{ NOISE } & 2.167 & -2.842 & -0.688 & -0.783 \\
\hline & (2.293) & $(2.737)$ & $(4.467)$ & $(0.810)$ \\
\hline \multirow[t]{2}{*}{ FIN } & 0.0169 & 0.295 & 0.414 & 0.0696 \\
\hline & $(0.198)$ & $(0.236)$ & $(0.386)$ & $(0.0700)$ \\
\hline \multirow[t]{2}{*}{$R O A$} & 0.238 & -0.637 & -0.722 & -0.0633 \\
\hline & $(0.564)$ & $(0.673)$ & (1.098) & $(0.199)$ \\
\hline \multirow[t]{2}{*}{ MONITORING } & $0.142^{*}$ & 0.120 & 0.171 & $0.0503 *$ \\
\hline & $(0.0816)$ & $(0.0974)$ & $(0.159)$ & $(0.0288)$ \\
\hline \multirow[t]{2}{*}{ \%INDEPENDENT } & -0.0940 & 0.481 & 0.505 & 0.0935 \\
\hline & $(0.309)$ & $(0.369)$ & $(0.602)$ & $(0.109)$ \\
\hline \multirow[t]{2}{*}{ CEO_DUALITY } & 0.0163 & -0.0669 & 0.0723 & -0.0225 \\
\hline & $(0.108)$ & $(0.129)$ & $(0.211)$ & $(0.0383)$ \\
\hline \multirow[t]{2}{*}{$K L D \_R A T I N G$} & $0.0229 * *$ & 0.0105 & 0.00166 & 0.00152 \\
\hline & $(0.00917)$ & $(0.0109)$ & $(0.0179)$ & $(0.00324)$ \\
\hline \multirow[t]{2}{*}{$A B N \_A C C$} & 0.0725 & -0.0766 & -0.0988 & 0.00643 \\
\hline & $(0.0988)$ & $(0.118)$ & $(0.193)$ & $(0.0349)$ \\
\hline Industry fixed effects & Yes & Yes & Yes & Yes \\
\hline Prob $>$ F & 0.0038 & 0.0000 & 0.0000 & 0.0000 \\
\hline $\mathrm{N}$ & 211 & 211 & 211 & 211 \\
\hline \multirow[t]{2}{*}{ Adj. R-sq } & 0.1028 & 0.1835 & 0.1977 & 0.2126 \\
\hline & & e_D_CSRPM & e_CSRPM_SCOPE & $\begin{array}{c}\mathrm{e} \\
\text { CSRPM_IMP }\end{array}$ \\
\hline e_External_Assurance & & 0.0629 & 0.0184 & -0.0445 \\
\hline $\mathrm{p}$-value & & 0.3636 & 0.7908 & 0.5200 \\
\hline
\end{tabular}

$*, * *, * * *$ Indicate $\mathrm{p}<0.1, \mathrm{p}<0.05, \mathrm{p}<0.01$, respectively. Standard errors are in parentheses.

This table shows results of the relationship between the choice of using CSR contracting and seeking external assurance for CSR reports. Panel A presents assurance distributions of the disclosure subsample. Panel B shows descriptive statistics for firms with and without external assurance. Panel $\mathrm{C}$ shows the regression results and conditional correlation coefficients of CSR contracting and external assurance. 


\section{HIGH-SCRUTINY as a potential joint determinant of CSR strategies}

In line with our second hypothesis, we show that affiliation to "high-scrutiny" industries affects the interdependence of CSR strategies. It could also be the case that $H I G H$ SCRUTINY is not only a system-specific variable affecting the interdependence of CSR strategy choices, but also a potentially joint determinant of the individual CSR strategies. To rule out that the complementarity we observe in our tests for $\mathrm{H} 1$ is driven by $H I G H$ SCRUTINY being an omitted joint determinant driving both control choices (and thus the positive correlation of the residuals), we include HIGH-SCRUTINY as a determinant in our tests for H1. As reported in Table 14, while CSR disclosure is not associated with HIGHSCRUTINY, CSR contracting is significantly more likely used in firms in the "high-scrutiny" industries. Most importantly, the conditional correlations between (the intensity of) CSR disclosures and (the intensity of) CSR contracting remain significantly positive when $H I G H$ SCRUTINY is controlled for. 
TABLE 14: HIGH-SCRUTINY as joint determinant

\begin{tabular}{|c|c|c|}
\hline PANEL A: Complemen & etween CSR disclosures & cting \\
\hline & D_CSR_REPORTING & D_CSRPM \\
\hline Constant & $-1.150 * * *$ & -0.389 \\
\hline & $(0.332)$ & $(0.323)$ \\
\hline HIGH-SCRUTINY & -0.0395 & $0.317 * * *$ \\
\hline & $(0.0657)$ & $(0.0640)$ \\
\hline LogAssets & $0.123 * * *$ & 0.0208 \\
\hline & $(0.0270)$ & $(0.0263)$ \\
\hline$M B R$ & 0.00906 & -0.00557 \\
\hline & $(0.00850)$ & $(0.00829)$ \\
\hline LEVERAGE & -0.00423 & 0.00457 \\
\hline & $(0.0140)$ & $(0.0137)$ \\
\hline & $(9.819)$ & $(9.573)$ \\
\hline$A D$ & $-1.915^{* *}$ & $-1.311^{*}$ \\
\hline & $(0.807)$ & $(0.787)$ \\
\hline UNPREDICT & 1.110 & 0.271 \\
\hline & $(1.002)$ & $(0.977)$ \\
\hline NOISE & $-3.280 * *$ & -2.007 \\
\hline & $(1.663)$ & $(1.621)$ \\
\hline FIN & -0.151 & -0.000414 \\
\hline & $(0.162)$ & $(0.158)$ \\
\hline$R O A$ & -0.0510 & -0.377 \\
\hline & $(0.377)$ & $(0.367)$ \\
\hline MONITORING & $0.116^{*}$ & 0.0683 \\
\hline & $(0.0642)$ & $(0.0626)$ \\
\hline$\% I N D E P E N D E N T$ & $0.686^{* * *}$ & $0.633 * * *$ \\
\hline & $(0.238)$ & $(0.232)$ \\
\hline$C E O \_D U A L I T Y$ & -0.0827 & -0.0806 \\
\hline & $(0.0934)$ & $(0.0911)$ \\
\hline KLD_RATING & $0.0271 * * *$ & -0.00379 \\
\hline & $(0.00782)$ & $(0.00762)$ \\
\hline$A B N \_A C C$ & -0.0352 & 0.0537 \\
\hline & $(0.0790)$ & $(0.0770)$ \\
\hline Industry fixed effects & YES & YES \\
\hline Prob $>F$ & 0.000 & 0.000 \\
\hline $\mathrm{N}$ & 343 & 343 \\
\hline Adj. R-sq & 0.2048 & 0.1664 \\
\hline & & \\
\hline e_CSR_Reporting & & \\
\hline $\mathrm{p}$-value & & \\
\hline
\end{tabular}




\begin{tabular}{|c|c|c|c|c|}
\hline \multicolumn{5}{|c|}{ PANEL B: Complementarity between CSR disclosure intensity and CSR contracting intensity } \\
\hline & lnWords & lnPages & CSRPM_SCOPE & CSRPM_IMP \\
\hline \multirow[t]{2}{*}{ Constant } & $-14.51 * * *$ & $-5.654 * * *$ & $-0 . \overline{8} 11$ & $-0 . \overline{108}$ \\
\hline & $(3.029)$ & $(1.229)$ & $(0.523)$ & $(0.0936)$ \\
\hline \multirow[t]{2}{*}{ HIGH-SCRUTINY } & -0.558 & -0.0510 & $0.485 * * *$ & $0.102 * * *$ \\
\hline & $(0.603)$ & $(0.245)$ & $(0.104)$ & $(0.0186)$ \\
\hline \multirow[t]{2}{*}{ LogAssets } & $1.421 * * *$ & $0.566 * * *$ & 0.0512 & 0.00658 \\
\hline & $(0.246)$ & $(0.0999)$ & $(0.0426)$ & $(0.00761)$ \\
\hline \multirow[t]{2}{*}{$M B R$} & $0.149^{*}$ & $0.0537 *$ & $-0.0290 * *$ & -0.000840 \\
\hline & $(0.0781)$ & $(0.0317)$ & $(0.0135)$ & $(0.00241)$ \\
\hline \multirow[t]{2}{*}{ LEVERAGE } & -0.180 & -0.0458 & 0.0335 & 0.000517 \\
\hline & $(0.129)$ & $(0.0523)$ & $(0.0222)$ & $(0.00398)$ \\
\hline \multirow[t]{2}{*}{$R D$} & $-14.84 * * *$ & $-5.754 * * *$ & -0.389 & -0.118 \\
\hline & (3.647) & $(1.480)$ & $(0.629)$ & $(0.113)$ \\
\hline \multirow[t]{2}{*}{$A D$} & $-15.94 * *$ & $-6.300^{* *}$ & -1.568 & -0.358 \\
\hline & $(7.362)$ & $(2.987)$ & $(1.268)$ & $(0.228)$ \\
\hline \multirow[t]{2}{*}{ UNPREDICT } & $17.48^{*}$ & $6.393 *$ & 0.562 & 0.187 \\
\hline & $(9.237)$ & (3.749) & $(1.592)$ & $(0.285)$ \\
\hline \multirow[t]{2}{*}{ NOISE } & -10.13 & -3.758 & -0.596 & -0.335 \\
\hline & (15.38) & $(6.243)$ & $(2.651)$ & $(0.475)$ \\
\hline \multirow[t]{2}{*}{ FIN } & -1.155 & -0.524 & 0.0116 & 0.00601 \\
\hline & $(1.482)$ & $(0.602)$ & $(0.256)$ & $(0.0458)$ \\
\hline \multirow[t]{2}{*}{$R O A$} & 0.674 & 1.279 & -0.171 & -0.0966 \\
\hline & (3.412) & $(1.385)$ & $(0.587)$ & $(0.105)$ \\
\hline \multirow[t]{2}{*}{ MONITORING } & 0.936 & $0.421^{*}$ & 0.0675 & 0.0250 \\
\hline & $(0.584)$ & $(0.237)$ & $(0.101)$ & $(0.0181)$ \\
\hline \multirow[t]{2}{*}{ \%INDEPENDENT } & $6.321 * * *$ & $2.072 * *$ & $0.896^{* *}$ & $0.136^{* *}$ \\
\hline & $(2.162)$ & $(0.877)$ & $(0.373)$ & $(0.0668)$ \\
\hline \multirow[t]{2}{*}{ CEO_DUALITY } & -0.212 & -0.0921 & -0.0164 & -0.0172 \\
\hline & $(0.854)$ & $(0.347)$ & $(0.147)$ & $(0.0264)$ \\
\hline \multirow[t]{2}{*}{$K L D \_R A T I N G$} & $0.397 * * *$ & $0.187 * * *$ & -0.00324 & -0.000623 \\
\hline & $(0.0739)$ & $(0.0300)$ & $(0.0129)$ & $(0.00229)$ \\
\hline \multirow[t]{2}{*}{$A B N \_A C C$} & 0.379 & 0.273 & 0.0950 & 0.0308 \\
\hline & $(0.722)$ & $(0.293)$ & $(0.124)$ & $(0.0223)$ \\
\hline Industry fixed effects & No & No & No & No \\
\hline Prob $>F$ & 0.0000 & 0.0000 & 0.0000 & 0.0000 \\
\hline $\mathrm{N}$ & 343 & 343 & 343 & 343 \\
\hline \multirow[t]{2}{*}{ Adj. R-sq } & 0.269 & 0.283 & 0.163 & 0.179 \\
\hline & e_lnWords & $\mathrm{p}$-value & e_lnPages & p-value \\
\hline e_CSRPM_SCOPE & 0.1401 & 0.0097 & 0.1233 & 0.0230 \\
\hline e CSRPM IMP & 0.1261 & 0.0195 & 0.1288 & 0.0170 \\
\hline
\end{tabular}

$*^{*},{ }^{*}, * * *$ Indicate $\mathrm{p}<0.1, \mathrm{p}<0.05, \mathrm{p}<0.01$, respectively, two-tailed test. Standard errors are in parentheses. This table reports results of complementarity analysis. Panel A reports the OLS regressions for CSR disclosures and CSR contracting for the full sample. Panel B reports the OLS regressions for the intensity of CSR disclosures and scope and importance of CSR contracting for the full sample. Please see Appendix A for variable definitions. 


\section{Alternative measure of CSR contracting intensity}

In our main tests, the scope of CSR contracting is captured by the number of CSR dimensions covered by CSR-based performance measures. While in the majority of cases the total number of performance measures corresponds with the number of CSR dimensions covered, in around $30 \%$ of the observations there are multiple performance measures used in at least one of the dimensions. This most often occurs in the employee dimension as it comprises a broad array of measures. Thus, as a robustness test, we rerun all analyses using the total number of performance measures used (1) as an alternative measure for the scope of CSR contracting, and (2) as the nominator in measuring the relative importance of CSRbased performance measures. The results, untabulated, indicate that our inferences do not change when using these alternative measures.

\subsection{Conclusion}

Given the increasing attention that society pays to a more sustainable lifestyle, also businesses are pressured more into demonstrating socially responsible business conduct and feel the need to communicate their CSR-related efforts to their stakeholders. Firms can do so by voluntarily disclosing their CSR-related activities in CSR reports or by incorporating CSR-based performance measures in executives' incentive contracts. While these two alternative strategies have so far been investigated in isolation, we investigate their interrelation. We show that the intensity of CSR disclosures and CSR contracting are not independent strategies addressing different control problems, but a set of complementary choices that reinforce each other in achieving high credibility. We also show that this complementarity is not uniform, but especially observed in firms that face particular incentives to convince their stakeholders of their CSR commitment. Most interestingly, we show that firms in high scrutiny industries are more likely to incur the high cost of adopting both choices (intensively) than firms that face less public scrutiny.

Overall, our findings provide important insights into the cost and benefits of alternative CSR strategies and highlight the importance of aligning decisions with respect to external disclosure policies and internal contract design choices. We provide evidence that firms interactively use strategies to deal with internal and external stakeholders, which has important implications for practitioners as well. 





Adopting CSR Performance Measures into Executives' Compensation Contracts: Does Board Experience Matter? 


\begin{abstract}
This paper explores firms' motivations to adopt CSR performance measures by investigating whether they incorporate decision-relevant information when making this choice. Specifically, I investigate whether directors' recent experience of using CSR performance measures in other firms, as an important information source of designing and implementing these measures, explains the adoption in the focal firm. I argue that director experience only matters for true adopters who care about such decision-relevant information, but is not relevant for symbolic adopters. I find a positive association between director experience and firms' adoption decisions. In addition, firms' reliance on director experience increases with the uncertainty of adopting CSR performance measures. I further find that adopters with experienced directors do show higher substantiveness in the adoption than those adopters without experienced directors. This study contributes to management accounting literature on the debate of whether the adoption of complex performance measures such as CSR performance measures is symbolic or substantive, and highlights the role that director experience plays in designing performance measurement systems.
\end{abstract}




\subsection{Introduction}

A recently developed innovation in executives' compensation is the integration of corporate social responsibility (CSR) performance measures in their compensation contracts (Rickard 2014). In 2002, less than 10 percent of U.S. listed firms used CSR-related performance measures in their CEO contracts. This ratio increased to almost 40 percent in 2013 (Chapter 3). Practitioners commonly refer to this incentive mechanism as "CSR contracting", as opposed to the traditional "pay for (financial) performance" (Flammer et al. 2017). While the practice of adopting CSR performance measures in executive contracts becomes prevalent, whether such adoption reflects a substantial commitment or merely a symbolic attempt remains an unanswered question in the literature (e.g. Berrone and Gomez-Mejia 2009b).

Extant research has indicated that firms may take CSR-related symbolic actions with an attempt to maintain legitimacy from stakeholders (Meyer and Rowan 1977; Murillo et al., 2008). For instance, symbolic adopters of CSR performance measures may attach very low weight on CSR dimensions, set easily-achievable CSR targets, or do not induce significant changes in core CSR-related practices. While such symbolic policies are decoupled from core practices, firms send a positive signal to stakeholders or at least can announce that they are linking executive pay to CSR criteria. It allows firms to mislead public perceptions regarding their social legitimacy and enhance their social acceptance. Under certain circumstances, it may provide a cover for poor CSR performance by appearing to take observable actions in the right direction (Russo and Harrison 2005). However, as there are no uniform criteria to evaluate or monitor internal CSR practices, it is very difficult to detect firms' authentic intention to adopt CSR performance measures from the outside of a firm.

In this study, I approach this question by investigating whether firms incorporate decision-relevant information when they adopt CSR performance measures. Due to the complexity of CSR, adopters who care about the efficiency of CSR performance measures particularly need knowledge and expertise to handle risks associated with the adoption. I thus examine whether directors' recent experience of serving on the board of other firms that use CSR performance measures in executive compensation contract is incorporated into focal firms' adoption choices. Next, I test whether adopters with experienced directors do show higher substantiveness in CSR performance measure adoptions than the adopters without an experienced director. The substantiveness in CSR performance measure adoptions is captured by the number of CSR dimensions and the relative weights on CSR performance measures in the executives' incentive contracts. In the third step, I argue that the relevance of director experience is not uniform to all firms, but is dependent on specific firm-contexts. I thus further investigate under which circumstances focal firms are more likely to rely on this experience for adoption.

While choosing performance measures is a non-trivial exercise, deciding on CSR performance measures is a different sort of challenge and specifically needs information (e.g. Rickard 2014): First, unlike prior research that in general finds a positive relationship between non-financial performance measures (e.g. customer satisfaction) and future financial performance (Ittner and Larcker, 1998; Banker et al., 2000), neither the relationship between CSR and financial performance nor the underlying mechanism is conclusive (Margolis and Walsh 2003). This ambiguity imposes difficulties on firms to trade-off economic benefits and 
social benefits when designing CSR performance measures. Second, designing CSR performance measures is a process that responds to the demands of a plurality of internal and external stakeholders (Ioannou, et al., 2016). Rewarding certain actions that are beneficial for one group can cause discontent among other stakeholders (Berrone and Gomez-Mejia, 2009b). An important challenge of adoption is thus the balance of different stakeholder group interests. Third, given the short history of CSR performance measures, there is very limited information to assist firms with the adoption (Ioannou et al., 2016). In addition, as executives' CSR performance often requires discretionary judgments, external parties may not be very able to provide constructive advice regarding the assessment benchmarks. All in all, these ambiguities not only pose distinct challenges for potential adopters, but also hinder outsiders from understanding firms' authentic motivation of implementing such practice.

Given the complexity of CSR, substantive adopters thus may prudently gather information relevant to the adoption of these performance measures. One important information source is directors with recent experience of using CSR performance measures in other firms. As directors play a central role in executive contracts design and performance evaluation (e.g. Lipton and Lorsch 1992; Hayes and Schaefer 2000; Chhaochharia and Grinstein 2009; Hoppe and Moers 2011), those with the experience of using CSR performance measures in other firms are likely to obtain an information advantage to deal with potential uncertainties of the adoption (Bol and Moers, 2010; Schoorman et al., 1981; Cai et al., 2014). Thus, when a firm is confronted with difficulties of adoption, it may seek advice and information from experienced directors.

Nevertheless, director experience only matters for "true adopters" that are concerned about the effectiveness of CSR performance measures. For true adopters, this information is an important guidance for the design and assessment of CSR performance measures. In contrast, for symbolic adopters that do not commit to CSR performance measures, director experience is not relevant. ${ }^{20}$ As symbolic adopters are neither concerned about the underlying rationale of designing CSR performance measures, nor care about the evaluation of executive performance over CSR dimensions, they may not further allocate efforts to collect information that is relevant to the design and evaluation of CSR performance measures from experienced directors when adopt CSR performance measures. Therefore, a positive relationship between director experience and firms' adoption is only expected if potential adopters care about the efficacy of CSR performance measures. For symbolic adopters, the positive association is not expected.

Based on above arguments, the test of my research question is a joint test of both the effect of director experience on firms' CSR-related strategy and the assumption that the adopters are true adopters (i.e. firms incorporate relevant information for the adoption). It is noteworthy to mention that information can go both ways: a firm may adopt CSR

\footnotetext{
${ }^{20}$ Examples of symbolic adoption can be that firms write CSR performance measures in executive compensation contracts, but do not evaluate executives' performance over CSR dimensions; firms set easily achievable targets of CSR performance measures, while these targets do not necessarily trigger executives' efforts over CSR dimensions; firms attach trivial weight on CSR performance measures; firms say that they incorporate CSR criteria to evaluate executive performance, but do not actually do so. In all these cases, symbolic adopters do not care about the effectiveness of CSR performance measures in promoting executive efforts over CSR dimensions, nor do they care about the logic to evaluate executives' performance over CSR dimensions.
} 
performance measures because it has experienced directors, or a firm may intend to adopt and hence appoint experienced directors for information. There is information sharing in both cases.

While I argue that true adopters rely on director experience for the adoption choice, a related and important question is whether such reliance is uniform across firms and industries. Therefore, my second research question addresses the extent to which director experience influences firms' adoption with different contexts. I argue that the relative benefits that an experienced director can bring to a potential adopter depend on the relative difficulties that the potential adopter has. As mentioned previously, the trade-offs between CSR and economic profits, as well as the balance of different CSR stakeholder groups are important challenges to a potential adopter (e.g. Berrone and Gomez-Mejia 2009b). When environmental unpredictability increases, it becomes more difficult to estimate the consequences of CSR activities. Thus, potential adopters may rely more on director experience for advice. Similarly, stakeholders' expectations vary by firms and industry. For firms with more diversified CSR demands among stakeholders, it becomes more difficult to balance stakeholder interests with limited numbers of CSR performance measures. In this case, information from experienced directors is more valued. Hence, I expect that potential adopters' reliance on director experience is stronger for firms in high unpredictable environments and for firms with diversified CSR interests among their stakeholder groups.

I identify firms' initial years to adopt CSR performance measures from the ASSET4 database. ${ }^{21}$ Director experience is captured by two situations by merging the ASSET4 and the Boardex databases: (1) a director sits on the board of another firm that uses CSR performance measures (director interlock); and/or (2) a director has worked as a board member in another firm that uses CSR performance measures (working history). To capture variations in the substantiveness of CSR performance measure adoption, I manually collect executive compensation contract data from adopters' proxy statements (Def 14). I find that director experience increases the likelihood of CSR performance measure adoption. The positive association between director experience and adoption suggests that firms do incorporate information from experienced directors to make the adoption choice, which reflects their substantive intention. In addition, compared to adopters without experienced directors, adopters with experienced directors are more likely to disclose a link between CSR and executive compensation in proxy statements, use more CSR performance measure dimensions, and attach relatively higher weight on CSR performance measures. These findings suggest that adopters with experienced directors show higher substantiveness in CSR performance measure adoption than those without experienced directors. With respect to cross-sectional variations, consistent with my prediction, I find that the reliance on director experience is stronger for firms with more diversified CSR interests among stakeholder groups and for firms in more unpredictable environments.

\footnotetext{
${ }^{21}$ The Thomas Reuter ASSET4 database provides environmental, social and governance (ESG) information to enable socially responsible investment analysis based on $250+$ key performance indicators and $750+$ individual data points since 2002. Data is collected by analysts from publicly available sources including firm reports, newspapers, NGO reports, firm websites, journals and CSR reports. Until 2014, this database includes more than 4500 listed firms all over the world and covers major indexes: MSCI World, MSCI Europe, STOXX 600, NASDAQ 100, Russell 1000, S\&P 500, FTSE 100, ASX 300 and MSCI Emerging Markets, etc.
} 
This study contributes to the literature in several ways. First, the answer to my research question contributes to the debate of whether firms are symbolically adopting CSR performance measures in executive compensation contracts or not. Despite the prevalence of CSR performance measures in executive compensation contracts, firms' authentic motivation to do so is not clear. While prior studies approach this question by looking at CSR compensation and CSR performance, they find mixed evidence (Campbell et al. 2007; Berrone and Gomez-Mejia 2009a; Mahoney and Thorne 2005; Cordeiro and Sarkis 2008; Deckop et al. 2006; McGuire et al. 2003; Cai, Jo and Pan 2011). This study takes "one step back" by investigating whether firms incorporate relevant information to make the adoption decision. If the adoption is a symbolic attempt, firms can copy CSR terms directly from various sources and thus do not necessarily incorporate relevant information. I find that firms are incorporating information from experienced directors for the adoption, which reflects a serious commitment. In addition, I find that firms with experienced directors show more substantiveness in CSR performance measure adoption.

Second, I complement the literature by exploring the moderating role of uncertainties in the relationship between information sharing and performance measurement design in a CSR setting (e.g. Hwang, Erkens and Evan 2009). Prior studies have suggested that the uncertainty of performance-based incentive systems plays an important role in firms' adoption decisions (Bol and Moers 2010). Despite intensive discussions of the uncertainties associated with CSR performance measures, prior research has not investigated how firms respond to these uncertainties (e.g. Berrone and Gomez-Mejia 2009b). My research indicates that director experience is one important way to address these uncertainties. When uncertainties with CSR performance measure increase, information shared from experienced directors is more valued. These findings are not only limited to CSR, but can be generalized to the design of other long-term performance measures.

Third, this study contributes to literature on performance measurement systems by highlighting individual factors such as supervisors' background and experience in the distribution of performance measures across firms. By showing that director experience of using CSR performance measures in other firms increases the likelihood of focal firms' adoption, I suggest that individual information sharing is an important factor that influences the diffusion of performance measurement systems across firms and industries.

Fourth, this study supplements and extend current literature on firm connections and strategies (e.g. Schabus et al. 2018; Brown and Drake, 2013). For instance, prior literature finds that firms are more likely to manage earnings if they are connected with another firm who did earning management (Chiu et al. 2013). Compared to firms' decisions such as earning management or tax avoidance, the economic benefits of doing CSR are less obvious, at least in the short term. This study provides evidence that firms' CSR-related strategy can diffuse via interlocked directors as well.

The remainder of the paper is organized as follows. Section II discusses prior literature and develops hypotheses. Section III presents the sample selection procedure and empirical research design. Section IV present results for the main test of CSR performance measures adoption and director experience, and contextual factors that explain the crosssectional variations. Section V provides additional analysis, and section VI concludes. 


\subsection{Literature Review and Hypotheses Development}

\subsubsection{Prior Literature on Tying CSR to Executive Compensation Contracts}

Traditional principal-agent theory suggests that if the principal wants to motivate the agent to take actions that are desired by her, appropriate incentives should be in place to ensure that the agent allocates efforts on the desired dimensions (e.g. Banker and Datar 1989; Hölmstrom and Milgrom, 1991; Kaplan and Norton 1996). Following this argument, firms are encouraged by multiple stakeholder groups to incorporate CSR performance measures in their executives' compensation contracts. Glass Lewis, a leading provider of global governance services, found that about 40 percent of all global firms reviewed provided a link between executives' compensation and CSR in 2014, up from 29 percent in 2010 (Glass Lewis, 2016).

However, whether this trend indicates a serious commitment to CSR or it arises because of firms' symbolic impression management is not clear. A related stream of literature investigates firms' motivation for tying incentives to CSR by exploring the relationship between executives' compensation and CSR performance, but finds mixed evidence. For instance, Berrone and Gomez-Mejia (2009a) find a positive relationship between executive total compensation and firms' environmental performance. They argue that the positive link indicates firms' intention to reward good environmental performance. However, Cai et al. (2011) document that a positive relation may suggest insiders' over-investment in CSR for their private benefits, while a negative link reflects firms' intention to use CSR to resolve conflicts between managers and other stakeholders. Campbell et al. (2007) provide another explanation for linking CSR to CEO incentives. They show that firms with higher emission relative to the industry benchmark pay more to their executives to compensate them for bearing higher environmental risks.

The above discussion implies a lack of consensus in the existing literature of firms' motivation for tying incentives to CSR. Several reasons might explain why prior studies find mixed evidence: First, rather than capturing CSR-performance measures used in executives' contracts, prior studies focus on the achievement of executive compensation. They fail to capture the board's intention to incorporate CSR performance measures in executive compensation contracts (e.g. Cai et al., 2011; Campbell et al., 2007). Second, some studies use CSR ratings or indexes as a proxy for CSR performance, which are often open to manipulation (Edmans 2011; Russo and Harrison 2005). Firms can symbolically incorporate CSR into their executives' compensation contracts as a response to CSR rating criteria, which is called the "check the box" behaviour (Edmans 2011). In addition, as CSR is often longterm oriented, it takes time to realize CSR strategies (Berrone and Gomez-Mejia 2009a). ${ }^{22}$ Executives that put efforts on CSR dimensions may not see an immediate improvement in CSR performance. Therefore, simply examining executive CSR-related incentives and CSR consequences might not be very informative. Further, some studies focus on a limited number

22 "(Pollution reduction strategies) require production redesign, new equipment, and cross-functional employee coordination.......Good environmental performance takes time to come to fruition" --Berrone and Gomez-Mejia (2009a) 
of industries, which hinders the generalizability of their findings. In sum, firms' authentic motivation for incorporating CSR into executives' compensation contracts, or more specifically, CSR performance measures, remains an unsolved question in the literature.

\subsubsection{Uncertainties of CSR Performance Measures in Executives' Contracts}

This study is an attempt to fill the gap in our understanding of firms' motivation for adopting CSR performance measures in executive compensation contracts. I approach this question by investigating whether firms incorporate information that is relevant to CSR performance measure design and assessment when they make the adoption choices. Prior literature has extensively described that the design of performance measures is a complex task. It involves the balance of resource allocation over different aspects, the trade-offs between tasks with different time-horizons, and the evaluation of performance afterwards (e.g. Ittner and Larcker 1998; Holmstrom et al. 1979; Nagar and Rajan 2001). Managerial expertise and information is therefore highly valuable in the processes of designing performance measurement systems (e.g. Hwang, Erkens, Evan 2009).

Prior literature has indicated that the adoption of CSR performance measures is a different sort of challenge (e.g. Berrone and Gomez-Mejia 2009b; Rickard 2014; Ioannou et al. 2016; Soderstrom et al. 2017). Therefore, firms that care about the efficacy of CSR performance measures may gather information to deal with uncertainties associated with the adoption. However, the adoption may only be an impression management tool (Armstrong et al. 2010; Westphal and Zajic 1995). With this symbolic attempt, firms may neither care much about the underlying rationales to design CSR performance measures, nor embed CSR into their business strategies (Westphal and Zajac 1995). In this case, information relevant to CSR performance measure adoption is not relevant for symbolic adopters.

Uncertainties of CSR performance measure adoption can be reflected in several aspects. The first frequently discussed uncertainty is the link between CSR actions and financial performance (Bansal 2005; Sharma 2000; Berrone and Gomez-Mejia 2009b; Margolis and Walsh 2003; Lys et al. 2015). In a review of studies on CSR performance and financial results, Margolis and Walsh (2003) find that less than half of the reviewed papers exhibit a positive relationship, and that the majority show a neutral or negative link. In a recent study, Lys et al. (2015) find that CSR is not associated with positive cash flows or ROA. Although some studies show benefits of doing CSR (e.g. lower cost of capital, better access to finance, Dhaliwal et al., 2011; Cheng et al., 2014), it can take long time to realize these benefits and consequently increases uncertainties of the outcome (e.g. Aragon and Correa, 1998). The ambiguity to estimate financial consequences of doing CSR increases difficulties to estimate how much resources and weights to allocate to CSR dimensions when designing CSR performance measures.

In addition, the design of CSR performance measures involves the balance of different stakeholder interests (Ioannou et al. 2016). To deploy executives' efforts over CSR dimensions with limited resources, firms first need to identify important stakeholders. However, there are large differences across studies in defining relevant stakeholders (Van Marrewijk 2003; Soderstrom et al. 2017). Besides, the interests of different stakeholders may 
conflict with each other. Rewarding certain actions believed to be beneficial for one group can cause discontent among other stakeholders (Berrone and Gomez-Mejia 2009b). Therefore, how to balance various stakeholder interests with limited numbers of CSR performance measures is another challenge that potential adopters face with.

Further, the adoption of CSR performance measures is a recent trend, which means that firms have much less experience and much less available information that can be used in figuring out how to design these measures (Ioannou et al. 2016). As CSR performance is often long-term oriented, it does not necessarily have an immediate impact on short-term performance. For instance, some CSR strategies can be technologically complex because they require changes in systems, innovations and products (Berrone and Gomez-Mejia 2009a). Thus, it often needs discretionary judgements to evaluate executives' CSR-related efforts and decisions. While some external parties might provide general instructions related to CSR aspects, they may not be able to provide detailed guidance of how to design or implement specific CSR performance measures. These features pose distinct challenges for potential adopters.

\subsubsection{Hypotheses Development}

One important information source of adopting CSR performance measures is directors who have recent experience of using such performance measures in other firms. Directors, who have the fiduciary duty to monitor executives, play a pivotal role in resolving contracting problems (e.g. Hoppe and Moers 2011). For instance, Hayes and Schaefer (2000) show that boards of directors use both observable and unobservable (to outsiders) performance measures to reward top executives for actions that benefit the firm but that are not reflected in currently observable performance. Their findings suggest that boards provide useful oversight of top managers' contract design by collecting and evaluating performancerelated information that is not available to those outside the firm. Hoppe and Moers (2011) find that the board of directors exercises different forms of subjectivity when assessing the performance of the CEO to solve different contracting problems. These studies suggest that directors provide information regarding the design of performance measures, monitor the implementation process, make performance assessments, and also justify the underlying rationales to outsiders (e.g. Hayes and Schaefer 2000; Lipton and Lorsch 1992; Chhaochharia and Grinstein 2009). Accordingly, directors who use CSR performance measures in other firms are likely to obtain knowledge and expertise of these performance measures.

When an organization is confronted with uncertainties in implementing a new strategy such as CSR performance measure adoption, it may seek advice from others who have dealt with similar problems in the recent past (McDonald and Westphal 2008; Cai et al. 2014). Such experience can be of particular importance in valuating emerging strategies and reducing uncertainty with a novel practice when alternative information sources are weak or absent (Haunschild and Beckman 1998; Washington and Ventresca 2004). As CSR performance measures only arose recently, there is relatively less available information from other sources such as NGOs, compensation consultants and business schools (e.g. Ioannou et 
al. 2016). Thus, director experience becomes a precious information source that reduces potential uncertainty associated with CSR performance measure adoption.

Through the experience of using CSR performance measures in other firms, directors improve their understanding of potential cost-benefits of CSR performance measures adoption. It will not only enable them to better react to potential risks associated with the adoption, but also make them more efficient in handling the implementation afterwards. For instance, experienced directors can provide vivid, concrete examples and first-hand knowledge regarding the design and implementation of CSR performance measures. This information advantage assists potential adopters to better cope with risks and reduces outcome uncertainties of the innovative practice (Bol and Moers 2010; Schoorman et al. 1981). This reduction in uncertainty can be sufficient to change potential adopters' costbenefit trade-offs, and leads to adoption (Bol and Moers 2010). Therefore, I expect that director experience increases the likelihood of CSR performance measure adoption in the focal firm.

Based on the arguments above, I propose the first hypothesis:

\section{H1: Firms with directors who have experience of using CSR performance measures} in other firms are more likely to adopt CSR performance measures in executive compensation contracts.

Uncertainty is often associated with the implementation of a new strategy as firms may not have enough information or knowledge to effectively cope with potential risks. One important way that directors' experience affects the strategies that a firm undertakes is by providing information and experience to reduce uncertainty (Geletkanycz and Hambrick 1997). However, the extent to which a directors' experience can reduce the uncertainty may not be uniform, but dependent on focal firms' specific contexts. Drawing on prior studies that discuss potential uncertainties associated with CSR performance measures (e.g. Berrone and Gomez-Mejia 2009b), I focus on two contextual factors that may change potential adopters' cost-benefit trade-offs, namely, environmental unpredictability and diversified CSR interests among stakeholder groups.

As mentioned previously, one difficulty that firms face with when they consider the adoption of CSR performance measures is to trade-off between CSR performance and economic profits. Rewarding executives on CSR dimensions may not generate obvious economic benefits in the short term or perhaps involves hidden costs (Berrone and GomezMejia 2009b). However, a firm can only benefit shareholders and wider groups of stakeholders if it is profitable and remains in business (Eccles et al. 2012). To efficiently allocate resources between business activities and CSR initiatives, CSR performance measures must be carefully designed to incorporate economic considerations (Berrone and Gomez-Mejia 2009a). To do this, on the one hand a firm may have to estimate economic profits that it generates in order to determine how much resource can be allocated. On the other hand, the firm may estimate the consequences of future economic performance when deploying resources to CSR dimensions.

When environmental unpredictability is high, it is more difficult to establish the optimal course of actions ex-ante (Hoppe and Moers 2011). In terms of CSR performance 
measure adoption, the estimations of firm's financial performance and financial consequences associated with CSR are more uncertain if a firm is in high unpredictable environments. Under the increased uncertainty, both the determination of resource allocation to CSR and the evaluation of CSR performance become more difficult. In this case, input from experienced directors will be more valuable and informative for focal firms to make the adoption decision. Based on the above arguments, I propose my second hypothesis:

H2: The positive effect of directors' experience in another firm on focal firms' adoption decisions is stronger when focal firms are faced with more environmental unpredictability.

Given that different stakeholder groups may have conflicting considerations, another challenge for potential adopters is to balance the interests of stakeholders (Berrone and Gomez-Mejia 2009b). As firm resources are limited, stakeholder groups are therefore not assumed to be treated in an equal way. They may compete with each other for firms' resources to support their own concerns. Depending on the likelihood of interest conflicts, the levels of difficulties to balance these CSR interests vary across firms. Specifically, the likelihood of conflicts will be higher for firms with more diversified CSR interests among stakeholders. With specialized knowledge and expertise, experienced directors have the ability to help firms handle these conflicts. The relative benefits of director experience will be more obvious for firms with more diversified CSR interests among stakeholders. Based on the above arguments, I propose my third hypothesis:

H3: The positive effect of directors' experience in another firm on focal firms' adoption decisions is stronger when focal firms are faced with more diversified CSR interest among stakeholder groups.

\subsection{Sample Selection and Variable Definitions}

\subsubsection{Sample Selection}

I examine whether firms with directors who have experience of using CSR performance measures in other firms are more likely to adopt CSR performance measures. Therefore, I require data on whether a firm adopts CSR performance measures or not and information of its directors. The ASSET4 database provides information of whether a firm uses CSR performance measures in executive compensation contracts from 2002 to 2014. After dropping firm-year observations with missing CSR performance measure values, there are 8,413 firm-year observations left. Next, I merge the Asset4 database with the Boardex database to identify whether a director has experience of serving on the board of other firms that use CSR performance measures. As the focus of this paper is the adoption decision of CSR performance measures in executive compensation contracts, firm-year observations after the initial adoption year are dropped. This further reduces the sample to 3,962 firm-year observations. If a firm has never adopted CSR performance measures in the executive compensation contract, it will be kept for all years available in the sample. 
I collect control variables from various publicly available sources: Compustat and CRSP provide financial data as well as stock price information; KLD provides information on firms' CSR ratings; I identify corporate governance information from the Boardex and Execucomp databases; Compensation consultant data is hand-collected from firms' annual proxy statements (DEF 14). Firm-year observations with missing control variables are dropped from the sample. Financial institutions are also excluded because they are subject to different regulations. The final sample contains 1,520 firm-year observations from 2002 to 2014. Table 15 Panel A provides details of the final sample construction. Panel B and C of Table 15 show year and industry distributions of the final sample, respectively.

\section{Table 15: Sample Selection and Distribution}

\section{Panel A: Sample selection}

Full Sample from Asset4 database from 2002-2014

No. Obs.

14,196

Drop observations with missing values from Asset4 database

Drop observations after first-year adoption

Drop observations that are not covered by Boardex

database or not able to identify board's experience

Drop missing observations from merging Execucomp,

KLD, CRSP and Compustat Databases to generate control variables

Drop financial institutions

Final Sample

1,520

\section{Panel B: Year distribution}

$\begin{array}{cc}\underline{\text { Year }} & \text { Freq. } \\ 2002 & 122 \\ 2003 & 93 \\ 2004 & 147 \\ 2005 & 153 \\ 2006 & 139 \\ 2007 & 133 \\ 2008 & 165 \\ 2009 & 175 \\ 2010 & 165 \\ 2011 & 153 \\ 2012 & 75 \\ \text { Total } & 1,520\end{array}$

\begin{tabular}{cc} 
Percent & Cum. \\
\cline { 1 - 1 } 8.03 & 8.03 \\
6.12 & 14.14 \\
9.67 & 23.82 \\
10.07 & 33.88 \\
9.14 & 43.03 \\
8.75 & 51.78 \\
10.86 & 62.63 \\
11.51 & 74.14 \\
10.86 & 85.00 \\
10.07 & 95.07 \\
4.93 & 100 \\
100 &
\end{tabular}

Panel C: Industry distribution

\section{Industry Description}

Agricultural Production - Crops

Metal, Mining

Oil \& Gas Extraction

Nonmetallic Minerals, Except Fuels

General Building Contractors

Heavy Construction, Except Building

Food \& Kindred Products

Apparel \& Other Textile Products

Furniture \& Fixtures

\begin{tabular}{|c|c|c|c|}
\hline$\underline{\text { SIC Code }}$ & Freq. & $\underline{\text { Percent }}$ & Cum. \\
\hline 1 & 6 & 0.39 & 0.39 \\
\hline 10 & 3 & 0.20 & 0.59 \\
\hline 13 & 67 & 4.41 & 5.00 \\
\hline 14 & 4 & 0.26 & 5.26 \\
\hline 15 & 27 & 1.78 & 7.04 \\
\hline 16 & 11 & 0.72 & 7.76 \\
\hline 20 & 59 & 3.88 & 11.64 \\
\hline 23 & 20 & 1.32 & 12.96 \\
\hline 25 & 19 & 1.25 & 14.21 \\
\hline
\end{tabular}




\begin{tabular}{lcccc}
\hline & Table 15-Continued & & & \\
Paper \& Allied Products & 26 & 39 & 2.57 & 16.78 \\
Chemical \& Allied Products & 28 & 155 & 10.20 & 26.97 \\
Petroleum \& Coal Products & 29 & 3 & 0.2 & 27.17 \\
Rubber \& Miscellaneous Plastics Products & 30 & 21 & 1.38 & 28.55 \\
Primary Metal Industries & 33 & 20 & 1.32 & 29.87 \\
Fabricated Metal Products & 34 & 21 & 1.38 & 31.25 \\
Industrial Machinery \& Equipment & 35 & 156 & 10.26 & 41.51 \\
Electronic \& Other Electric Equipment & 36 & 167 & 10.99 & 52.50 \\
Transportation Equipment & 37 & 62 & 4.08 & 56.58 \\
Instruments \& Related Products & 38 & 124 & 8.16 & 64.74 \\
Transportation by Air & 45 & 5 & 0.33 & 65.07 \\
Communications & 48 & 68 & 447 & 69.54 \\
Electric, Gas, \& Sanitary Services & 49 & 81 & 5.33 & 74.87 \\
Wholesale Trade - Durable Goods & 50 & 42 & 2.76 & 77.63 \\
Wholesale Trade - Nondurable Goods & 51 & 15 & 0.99 & 78.62 \\
Building Materials \& Gardening Supplies & 52 & 11 & 0.72 & 79.34 \\
General Merchandise Stores & 53 & 41 & 2.70 & 82.04 \\
Furniture \&Homefurnishings Stores & 57 & 10 & 0.66 & 82.70 \\
Miscellaneous Retail & 59 & 37 & 2.43 & 85.13 \\
Hotels \& Other Lodging Places & 70 & 2 & 0.13 & 85.26 \\
Business Services & 73 & 212 & 13.59 & 99.21 \\
Health Services & 80 & 12 & 0.79 & 100 \\
Total & & 1,520 & 100 & \\
\hline Pal A of & 59 &
\end{tabular}

Panel A of this table shows the construction of my final sample. Panel B of this table shows year distributions of the sample, and Panel C presents the industry distribution.

\subsubsection{Variable Definition}

\section{Director Experience of Using CSR Performance Measures in another Firm}

The key independent variable CSR_EXP is an indicator that equals one if a firm has at least one director that has experience with CSR performance measures in another firm, and zero otherwise. Here directors' experience in other firms is captured by two situations: First, the director serves on the board of another firm that uses CSR performance measures (through director interlock). One director can sit on more than one board of other firms. As long as any of the connected firms use CSR performance measures in executive compensation contracts, the director is identified as an experienced director. Second, a director may not be an interlocked director, but has worked as a director in another firm when that firm uses CSR performance measures (working history).

\section{Firms'Adoption of CSR Performance Measures}

The dependent variable CSRPM_ADOPT is an indicator variable that captures whether the focal firm adopts CSR performance measures. It is equal to one for the first year that a firm adopts CSR performance measures in the executive compensation contract, and zero 
otherwise. If a firm has never adopted CSR performance measures in executive compensation contracts, CSRPM_ADOPT is zero for all available years of this firm.

\section{Environment Unpredictability}

Following Hoppe and Moers (2011), Demsetz and Lehn (1985) and Core and Guay (1999), I capture environment unpredictability with a measure of stock return volatility. Hoppe and Moers (2011) argue that stock prices reflect expectations. The more fluctuation in the stock returns, the less predictable the environment. As the expectations are specific to different firms' actions, I focus on idiosyncratic risk. For each firm, I regress the firm's monthly stock returns (holding period return) from the CRSP database on the value-weighted index estimated over a period of prior 12-60 months. Next, I capture the standard deviation of the residuals as the proxy for UNPREDICT. HIGH is an indicator variable that is equal to one if a firm's environmental unpredictability is above or equal to the median of the full sample, and zero otherwise. $^{23}$

\section{Diversified CSR Interests among Stakeholders}

I rely on the Sustainability Accounting Standards Board (SASB) Materiality Map to capture the diversified interests among stakeholders. ${ }^{24}$ The SASB Materiality Map is provided by a non-profit institution SASB, whose mission is to develop sustainability accounting standards to help listed firms to identify and disclose material CSR-related factors on an industry-byindustry basis. Material dimensions are dimensions with evidence of wide interest from different stakeholder groups (Khan et al. 2016). For some industries, material CSR issues cover only one dimension. While for others, material CSR issues can cover a maximum of all five dimensions, including environment, social capital, human capital, business model and innovation, leadership and governance. Variable SASB_DIMENSIONS captures how many CSR dimensions are identified as material for firms in the SASB Map. The variable DISPERSE is an indicator that is equal to one if the number of a firm's material CSR dimensions is above or equal to the median of my sample, and is zero otherwise. ${ }^{25}$ This variable captures whether or not a firm has relatively more material stakeholder groups than other firms in the sample.

\section{Other Control Variables}

\footnotetext{
${ }^{23}$ As the standard deviation of variable UNPREDICT is low in my sample (0.04), I use a dummy variable to categorize firms in high unpredictable environment and firms in low unpredictable environment, and compare the difference of director experience on firms' CSR performance adoption decision in these two categories by interacting CSR_EXP and $H I G H$.

${ }^{24} \mathrm{https}: / /$ www.sasb.org/materiality/sasb-materiality-map/

${ }^{25}$ As variable DIMENSIONS is not continuous, I use a dummy variable DISPERSE to categorize firms with more diversified CSR interests among their stakeholder groups and firms with concentrated CSR interests among their stakeholder groups. For instance, stakeholders of firms in transportation industry are interested in five CSR-related aspects including environment, social capital, human capital, business model and governance. In contrast, stakeholders for service industry mainly focus on two aspects: environment and social capital. The average number of CSR aspects that stakeholders focus is 3.78. Therefore, DISPERSE for the transportation industry is 1 (above the average number of CSR aspects concerned by stakeholders) while for service industry, DISPERSE is 0 (below the average number of CSR aspects concerned by stakeholders).
} 
I control for a number of other firm characteristics that may affect a firm's choice of adopting CSR performance measures. For example, Jin (2002) shows that firm size is a determinant of compensation contracts. Large firms are more likely to be subject to public pressure and regulations (Lang and Lundholm 1993), and therefore may be more likely to adopt. Hence, I include the natural logarithm of total assets (LogAssets) to control for firm size. In addition, I include the market-to-book ratio $(M B R)$ to control for growth opportunities, $R O A$ to control for firm performance, and leverage (Said et al. 2003; Dhaliwal et al. 2011) to control firms' debt situations. McWilliams and Siegel (2001) argue that research and development expenses and advertising expenditures can influence firms' CSR strategies. Therefore, I incorporate advertising expenses and research and development expenses scaled by total revenue as additional controls ( $A D$ and $R D$, respectively). Firms raising capital in public markets may care more about their CSR-related strategies (Dhaliwal et al., 2011). Following Dhaliwal et al. (2011), I control for a firm's financing activities (FIN) by assessing the amount of debt or equity capital raised by the firm during the year scaled by total assets at the beginning of the year.

Board level monitoring and CEO power are important factors in determining executive compensation contracts (e.g. Core and Guay. 1999). Following prior literature (e.g. Abernethy et al. 2015; Hoppe and Moers, 2011), I incorporate board size (BOARD_SIZE) and the percentage of independent directors (\%INDEPENDENT) to control for corporate governance. CEO power is captured by CEO_DUALITY that is equal to one if the CEO also serves as the chairman of the board of directors, and zero otherwise. Hoppe and Moers (2011) indicate that noise in performance measures determines incentive choice. Following their procedure, I measure noise in accounting numbers (NOISE) as the time-series variability in median 3-digit industry accounting returns over prior five years. INDUSTRY_USER captures how many firms in the same 2-digit industry already use CSR performance measures in year t. CONSULT_DUMMY is an indicator variable that is equal to one if the firm explicitly states the use of a compensation consultant, and is zero otherwise. ${ }^{26}$ In chapter two of this dissertation, I show that firms' claimed CSR orientation captured by KLD_RATING is reflected in firms' internal CSR practices such as employee dismissals. Therefore, in this study, I further control for KLD_RATING as it may influence some of firms' internal CSR decisions. The KLD database rates strengths and concerns of companies on different dimensions including environment, community relation, employee, and product (Kim et al. 2012; Dhaliwal et al. 2011). CSR scores (KLD_RATING) are constructed by deducting the total concern value from the total strength value over these five dimensions. ${ }^{27}$

\footnotetext{
${ }^{26}$ Firms that hire compensation consultant may have more exposure to new performance measures. Therefore, I control for this possibility by including CONSULT_DUMMY. However, as I mentioned in previous sections, CSR contracting is a complex design thus external consultants may not be able to provide a detailed instruction. Aligned with this argument, the use of compensation consultant does not seem to be correlated with higher substantive adoption of CSR performance measures (see Panel C of Table 18).

${ }^{27}$ Larcker et al. (2007) suggests that corporate governance is a mechanism that affects managers' decisions when firms' ownership and control are separated. It is considered as a different concept than social responsibility practices. Therefore, to distinguish corporate governance from other CSR dimensions, the corporate governance score is not included in the calculation of the total CSR performance score.
} 
Grabner and Moers (2013) suggest that if two organizational design choices are interdependent, not controlling for this interdependency may cause the same omitted variable problem as not controlling for other contextual factors. In the previous study of this dissertation, we argue that the choice of using CSR performance measures and issuing CSR reports complements each other, as the net benefits of using the two mechanisms simultaneously outweigh the benefits of using either of them separately (Chapter 3). To rule out that the effect of board experience on firms' adoption of CSR performance measures is driven by potential interdependencies between CSR incentives and CSR reporting, I further incorporate an indicator variable $D \_C S R \_R E P O R T I N G$ that is equal to one if a firm issues a stand-alone CSR report in year $\mathrm{t}$, and zero otherwise. Appendix A provides information of how each variable is measured. Industry and year fixed effects are included in all the regressions.

\subsubsection{Empirical Model}

In my setting, the event of interest (i.e., the adoption of CSR performance measures) occurs at discrete points in time, conditionally on this event not occurring before. Firm-year observations after the first adoption year are dropped.

Allison (1982) recommends the discrete-time logistic model as the most appropriate model for time-to-event settings like this one. This model has several advantages: besides dealing with censored and uncensored data appropriately, and incorporating time-varying information, the economic magnitude of the coefficients can be easily computed and interpreted. Shumway (2001) shows that the discrete-time logistic models provide consistent estimations. Therefore, discrete-time logistic models are frequently used to analyse time-toevent settings in prior literature (e.g. Bizjak et al. 2009; Chiu et al. 2013).

To test my first hypothesis of whether board members' previous experience of using CSR performance measures in another firm increases the probability of adoption, I rely on a discrete logistic model and regress $D_{-} C S R P M_{t+2}$ on the variable of interest, CSR_EXPt, and other controls. I choose a two-year interval because it takes time for directors' experience in another firm to transfer to the focal firm. For a director to be able to change the focal firms' executive compensation contract, two conditions must hold: First, the director has already been in place, and second, he is able to change the contract which was specified ex ante. For these two conditions to hold, the earliest possible time interval is two years. The model is shown in Equation (1) as follow:

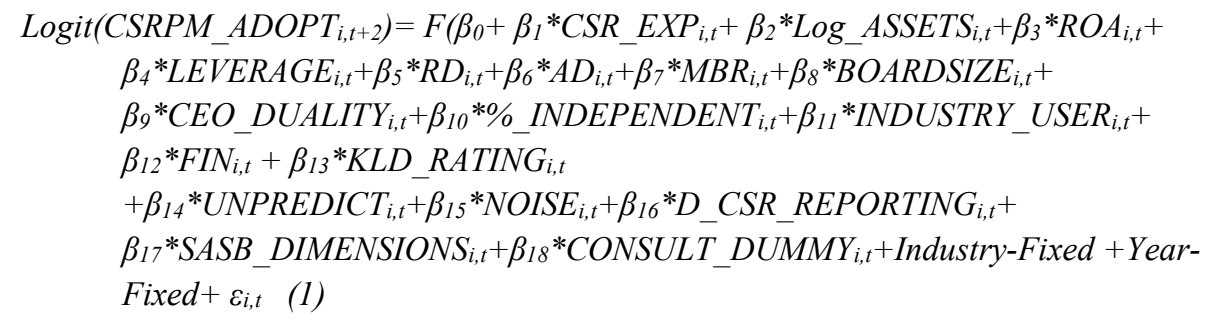


I estimate the discrete logit regression on a sample of firm-year observations using firm-clustered standard errors. To test the second and third hypotheses, I incorporate interaction terms of CSR_EXP*DISPERSE and CSR_EXP*HIGH in the regression model respectively. I also include the main terms (DISPERSE and $H I G H)$ to control for main term effects. I expect the coefficients both of the interaction terms to be positive. Marginal effects of the interaction terms are estimated according to the procedure based on Ai et al. (2004).

\subsection{Empirical Results}

\subsubsection{Descriptive Statistics}

Table 16 Panel A presents descriptive statistics on the variables for the full sample. Of the 1,520 firm-year observations, on average $40 \%$ have directors with the experience of using CSR performance measures in other firms. During the sample period, 176 firm-year observations have adopted CSR performance measures in the executive compensation contract. On average, my sample firms have 12,763.62 million dollars of total assets, with a market-to-book ratio of 3.64. The board has an average of ten directors, approximately $79 \%$ of whom are independent. The mean of CEO_DUALITY is $60 \%$, indicating that $60 \%$ of the CEOs in my sample also serve as the chairman of the board.

Panel B of Table 16 reports descriptive statistics separately for adopters versus nonadopters. Difference-in-means tests reveal that on average the adopters have a higher percentage of experienced directors $(52 \%)$ than the non-adopters $(38 \%)$. This univariate result provides preliminary support for my first hypothesis that firms with experienced directors are more likely to adopt CSR performance measures. Compared with non-adopters, adopters are larger, have more independent directors and are more likely to hire a compensation consultant. They are also more likely to issue CSR reports. In addition, adopters show lower environmental unpredictability, less noise in accounting measures and lower advertising expenses than the non-adopters. I do not find significant differences between the subsamples regarding leverage, market-to-book ratio, and KLD ratings. 
Table 16: Descriptive Statistics

\begin{tabular}{|c|c|c|c|c|c|c|}
\hline \multicolumn{7}{|c|}{ Panel A:Descriptive statistics for the full sample } \\
\hline Variable & $\underline{\text { Obs }}$ & Mean & $\frac{\text { Media }}{n}$ & $\underline{\text { Std. }}$ & $\underline{\text { Min }}$ & $\underline{\operatorname{Max}}$ \\
\hline CSRPM_ADOPT & 1,520 & 0.12 & $0 . \overline{0} 0$ & 0.32 & 0.00 & 1.00 \\
\hline CSR_EXP & 1,520 & 0.40 & 0.00 & 0.49 & 0.00 & 1.00 \\
\hline LOG_ASSETS & 1,520 & 8.73 & 8.60 & 1.09 & 6.45 & 11.70 \\
\hline$\overline{\mathrm{R}} \mathrm{OA}$ & 1,520 & 0.06 & 0.07 & 0.08 & -0.36 & 0.23 \\
\hline LEVERAGE & 1,520 & 0.22 & 0.20 & 0.16 & 0.00 & 0.74 \\
\hline $\mathrm{RD}$ & 1,520 & 0.03 & 0.01 & 0.05 & 0.00 & 0.21 \\
\hline $\mathrm{AD}$ & 1,520 & 0.01 & 0.00 & 0.03 & 0.00 & 0.18 \\
\hline MBR & 1,520 & 3.64 & 2.85 & 4.41 & -15.60 & 28.39 \\
\hline BOARDSIZE & 1,520 & 10.33 & 10.00 & 2.15 & 5.00 & 22.00 \\
\hline CEO_DUALITY & 1,520 & 0.60 & 1.00 & 0.49 & 0.00 & 1.00 \\
\hline$\%$ \%_INDEPENDENT & 1,520 & 0.79 & 0.82 & 0.12 & 0.25 & 1.00 \\
\hline INDUSTRY_USER & 1,520 & 5.62 & 3.00 & 7.33 & 0.00 & 40.00 \\
\hline FIN & 1,520 & -0.01 & -0.02 & 0.13 & -0.47 & 1.71 \\
\hline KLD_RATING & 1,520 & 0.68 & 0.00 & 3.28 & -9.00 & 15.00 \\
\hline UNPREDICT & 1,520 & 0.09 & 0.08 & 0.04 & 0.03 & 0.26 \\
\hline HIGH & 1,520 & 0.51 & 1.00 & 0.5 & 0.00 & 1.00 \\
\hline NOISE & 1,520 & 0.03 & 0.02 & 0.03 & 0.00 & 0.13 \\
\hline$\underset{G}{\text { D_CSR_REPORTIN }}$ & 1,520 & 0.19 & 0.00 & 0.39 & 0.00 & 1.00 \\
\hline SASB_DIMENSIONS & 1,520 & 3.78 & 4.00 & 0.81 & 2.00 & 5.00 \\
\hline DISPERSE & 1,520 & 0.61 & 1.00 & 0.49 & 0.00 & 1.00 \\
\hline CONSULT_DUMMY & 1,520 & 0.85 & 1.00 & 0.36 & 0.00 & 1.00 \\
\hline
\end{tabular}

Panel B: Mean-comparison of firm characteristics for adopters VS non-adopters

Adopters (176 Obs.)

Variable
CSR_EXP
LOG_ASSETS
ROA
LEVERAGE
RD
AD

BOARDSIZE

CEO DUALITY

\%_INDEPENDENT

INDUSTRY_USER FIN

KLD_RATING

UNPREDICT

NOISE

D_CSR_REPORTING SĀSB DIMENSIONS CONSULT DUMMY

\begin{tabular}{|c|c|}
\hline Mean & Media \\
\hline 0.52 & $\frac{\mathbf{n}}{0}$ \\
\hline 9.06 & 896 \\
\hline 0.07 & 0.06 \\
\hline 0.24 & 0.24 \\
\hline 0.03 & 0.01 \\
\hline 0.01 & 0.00 \\
\hline 3.32 & 2.62 \\
\hline 10.55 & 11.00 \\
\hline 0.62 & 1.00 \\
\hline 0.81 & 0.83 \\
\hline 6.17 & 4.00 \\
\hline 0.00 & -0.02 \\
\hline 0.40 & 0.00 \\
\hline 0.08 & 0.07 \\
\hline 0.02 & 0.02 \\
\hline 0.27 & 0.00 \\
\hline 3.85 & 4.00 \\
\hline
\end{tabular}

Std.

0.50

1.07

0.06

0.14

0.04

0.02

4.11

2.03

0.49

0.10

6.78

0.18

3.71

0.04

0.02

0.44

0.84

$1.00 \quad 0.23$

Non-Adopters (1344 Obs.)

\begin{tabular}{|c|c|c|c|}
\hline Mean & Median & Std. & $\underline{\text { T-test }}$ \\
\hline 0.38 & 0.00 & 0.49 & $3.42 * * *$ \\
\hline 8.69 & 8.55 & 1.09 & $4.32 * * *$ \\
\hline 0.06 & 0.07 & 0.08 & 0.80 \\
\hline 0.22 & 0.20 & 0.16 & 0.70 \\
\hline 0.03 & 0.01 & 0.05 & -1.58 \\
\hline 0.01 & 0.00 & 0.03 & $-1.99 * *$ \\
\hline 3.69 & 2.88 & 4.44 & -0.37 \\
\hline 10.30 & 10.00 & 2.16 & 1.42 \\
\hline 0.60 & 1.00 & 0.49 & 0.56 \\
\hline 0.79 & 0.82 & 0.12 & $2.02 * *$ \\
\hline 5.55 & 3.00 & 7.40 & 1.06 \\
\hline-0.01 & -0.02 & 0.12 & 0.70 \\
\hline 0.71 & 0.00 & 3.22 & -1.19 \\
\hline 0.09 & 0.08 & 0.04 & $-4.03 * * *$ \\
\hline 0.03 & 0.02 & 0.03 & $-4.31 * * *$ \\
\hline 0.18 & 0.02 & 0.38 & $2.80 * * *$ \\
\hline 0.60 & 3.76 & 0.80 & 1.29 \\
\hline 0.83 & 1.00 & 0.37 & $3.83 * * *$ \\
\hline
\end{tabular}

This table presents summary statistics of my sample. I report the full sample descriptive statistics in Panel A. Panel B compares the mean differences between CSR performance measure adopters and non-adopters. The $t$ statistics are reported in the last column of Panel B. *, **, *** indicate significance levels (two-tailed) at 10\%, $5 \%$ and $1 \%$, respectively. All continuous variables are winsorized at the $1^{\text {st }}$ and $99^{\text {th }}$ percentiles. See variable definitions in Appendix A. 


\subsubsection{Regression Results}

\section{The Likelihood of Adopting CSR Performance Measures}

Table 17 Panel A presents the coefficients and marginal effects from estimating model (1). Column one shows the regression results for the full sample of 1,520 firm-year observations. The regression coefficient of CSR_EXP is significant at less than $5 \%$ (coefficient $=0.467 ; \mathrm{z}=$ 2.31), indicating that firms with experienced directors are more likely to adopt CSR performance measures. The results are consistent with my first hypothesis that firms are more likely to adopt CSR performance measures if their directors serve or have served on the boards of other firms that use CSR performance measures.

Following Chiu et al. (2013), I further calculate the economic magnitude in two ways. First, the marginal effect of 0.041 implies that having an experienced director increases the likelihood of adoption with 4.1 percent. Given that only 11.6 percent of my sample firms adopt CSR performance measures, this marginal effect of 0.041 is not only statistically but also economically significant. It suggests that an experienced board has a marginal effect of 35.34 percent $(0.041 / 0.116)$ as large as the unconditional probability (11.6 percent). Alternatively, the odds ratio equals 1.59. This implies that directors' experience increases the likelihood of adoption in focal firms by 1.59 .

In the second and third hypotheses, I argue that firms rely more on director experience when they are in more unpredictable environments and when they have more diversified CSR interests among stakeholders. Panel B of Table 17 presents the results. The first column of Panel B shows that the coefficient of the interaction term HIGH ${ }^{*} C S R \_E X P$ is marginally significant (coefficient $=0.495 ; \mathrm{z}=1.32$ ). This provides marginal evidence that firms with higher unpredictability are more likely to rely on director experience for the adoption decision. Consistent with my third hypothesis, Column three shows that the coefficient of the interaction term DISPERSE*CSR_EXP is significantly positive at the $10 \%$ level (coefficient $=0.667 ; \mathrm{z}=1.74$ ). The marginal effect of 0.058 suggests that when stakeholder groups have more diversified CSR interests, firms with experienced directors are 5.8 percent more likely to adopt CSR performance measures.

When the two interactions terms are included in one regression, as shown in Column five of Panel B, results do not change much. Overall, I find that the influence of director experience on focal firms' adoption decisions is stronger for firms with more diversified interests among stakeholders. I find marginal evidence that the effect of director experience is amplified when focal firms have high environmental unpredictability. 
Table 17: Director Experience and Firms' Adoption Decision

\begin{tabular}{|c|c|c|}
\hline \multicolumn{3}{|c|}{ Panel A: Full sample analysis of director experience on focal firms' adoption decision } \\
\hline$\underline{\text { Variable }}$ & CSRPM ADOPT & Margins \\
\hline & $\underline{(1)}$ & $\underline{(2)}$ \\
\hline CONSTANT & $\begin{array}{c}-8.783 * * * \\
(-3.49)\end{array}$ & \\
\hline CSR_EXP & $\begin{array}{c}0.467 * * \\
(2.31)\end{array}$ & 0.041 \\
\hline LOG_ASSETS & $\begin{array}{c}0.338 * * * \\
(3.14)\end{array}$ & 0.030 \\
\hline ROA & $\begin{array}{l}2.446 \\
(1.61)\end{array}$ & 0.215 \\
\hline LEVERAGE & $\begin{array}{l}-0.765 \\
(-1.09)\end{array}$ & -0.067 \\
\hline $\mathrm{RD}$ & $\begin{array}{l}1.218 \\
(0.41)\end{array}$ & 0.107 \\
\hline $\mathrm{AD}$ & $\begin{array}{c}-7.927 * \\
(-1.94)\end{array}$ & -0.697 \\
\hline MBR & $\begin{array}{l}-0.015 \\
(-0.61)\end{array}$ & -0.001 \\
\hline BOARDSIZE & $\begin{array}{l}-0.017 \\
(-0.34)\end{array}$ & -0.001 \\
\hline CEO_DUALITY & $\begin{array}{l}-0.036 \\
(-0.17)\end{array}$ & -0.003 \\
\hline$\%$ INDEPENDENT & $\begin{array}{l}-0.492 \\
(-0.52)\end{array}$ & -0.043 \\
\hline INDUSTRY_USER & $\begin{array}{c}-0.057 * * \\
(-2.28)\end{array}$ & -0.005 \\
\hline FIN & $\begin{array}{l}0.165 \\
(0.23)\end{array}$ & 0.015 \\
\hline KLD_RATING & $\begin{array}{l}-0.015 \\
(-0.40)\end{array}$ & -0.001 \\
\hline UNPREDICT & $\begin{array}{l}0.885 \\
(0.26)\end{array}$ & 0.078 \\
\hline NOISE & $\begin{array}{c}-15.856 * * * \\
(-2.73)\end{array}$ & -1.393 \\
\hline D_CSR_REPORTING & $\begin{array}{l}-0.084 \\
(-0.32)\end{array}$ & -0.007 \\
\hline SASB_DIMENSIONS & $\begin{array}{l}0.357 \\
(0.86)\end{array}$ & 0.031 \\
\hline CONSULT_DUMMY & $\begin{array}{c}1.145^{* *} \\
(2.54)\end{array}$ & 0.101 \\
\hline Industry_Fixed & YES & \\
\hline Year_Fixed & YES & \\
\hline Cluster (Firm) & YES & \\
\hline Pseudo $\mathrm{R}^{2}$ & 0.1727 & \\
\hline $\mathrm{N}$ & 1520 & \\
\hline
\end{tabular}




\begin{tabular}{|c|c|c|c|c|c|c|}
\hline \multicolumn{7}{|c|}{$\begin{array}{l}\text { Panel B: The moderating effects of diversified CSR interests and environmental unpredictability on } \\
\text { firms' adoption decision }\end{array}$} \\
\hline Variable & CSRPM S & Margin & CSRPM S & Margin & CSRPM S & Margin \\
\hline _CONS & $\begin{array}{c}\frac{(\mathbf{1})}{-7.741 * * *} \\
(-4.11)\end{array}$ & (2) & $\begin{array}{c}\frac{(\mathbf{3})}{-7.471 * * *} \\
(-3.93)\end{array}$ & (4) & $\begin{array}{c}\frac{(\mathbf{5})}{-7.406 * * *} \\
(-3.92)\end{array}$ & (6) \\
\hline CSR_EXP & $\begin{array}{l}0.289 \\
(1.18)\end{array}$ & 0.025 & $\begin{array}{l}0.059 \\
(0.20)\end{array}$ & 0.005 & $\begin{array}{l}-0.130 \\
(-0.33)\end{array}$ & -0.011 \\
\hline CSR_EXP*HIGH & $\begin{array}{l}0.495 \\
(1.32)\end{array}$ & 0.044 & & & 0.501 & 0.044 \\
\hline CSR_EXP*DISPERSE & & & $\begin{array}{r}0.667^{*} \\
(1.74)\end{array}$ & 0.058 & $\begin{array}{l}0.669^{*} \\
(1.76)\end{array}$ & 0.059 \\
\hline $\mathrm{HIGH}$ & $\begin{array}{l}-0.376 \\
(-1.39)\end{array}$ & -0.033 & -0.126 & -0.011 & -0.378 & -0.033 \\
\hline DISPERSE & $\begin{array}{l}1.057 \\
(0.85)\end{array}$ & 0.093 & $\begin{array}{l}0.822 \\
(0.67)\end{array}$ & 0.072 & $\begin{array}{l}0.777 \\
(0.64)\end{array}$ & 0.068 \\
\hline LOG_ASSETS & $\begin{array}{l}0.338 * * * \\
(3.15)\end{array}$ & 0.030 & $\begin{array}{l}0.334 * * * \\
(3.12)\end{array}$ & 0.029 & $\begin{array}{l}0.336^{* * *} \\
(3.13)\end{array}$ & 0.029 \\
\hline ROA & $\begin{array}{l}2.316 \\
(1.53)\end{array}$ & 0.204 & $\begin{array}{l}2.299 \\
(1.55)\end{array}$ & 0.201 & $\begin{array}{l}2.317 \\
(1.54)\end{array}$ & 0.203 \\
\hline LEVERAGE & $\begin{array}{l}-0.747 \\
(-1.07)\end{array}$ & -0.066 & $\begin{array}{l}-0.859 \\
(-1.20)\end{array}$ & -0.075 & $\begin{array}{l}-0.838 \\
(-1.18)\end{array}$ & -0.073 \\
\hline$R \& D$ & $\begin{array}{l}1.643 \\
(0.57)\end{array}$ & 0.144 & $\begin{array}{l}1.044 \\
(0.37)\end{array}$ & 0.091 & $\begin{array}{l}1.226 \\
(0.43)\end{array}$ & 0.107 \\
\hline$A \& D$ & $\begin{array}{c}-7.422 * \\
(-1.82)\end{array}$ & -0.652 & $\begin{array}{c}-8.070 * * \\
(-1.98)\end{array}$ & -0.707 & $\begin{array}{c}-7.740 * \\
(-1.90)\end{array}$ & -0.678 \\
\hline MBR & $\begin{array}{l}-0.015 \\
(-0.58)\end{array}$ & -0.001 & $\begin{array}{l}-0.016 \\
(-0.61)\end{array}$ & -0.001 & $\begin{array}{l}-0.016 \\
(-0.60)\end{array}$ & -0.001 \\
\hline BOARDSIZE & $\begin{array}{l}-0.028 \\
(-0.57)\end{array}$ & -0.002 & $\begin{array}{l}-0.025 \\
(-0.52)\end{array}$ & -0.002 & $\begin{array}{l}-0.027 \\
(-0.55)\end{array}$ & -0.002 \\
\hline CEO_DUALITY & $\begin{array}{l}-0.054 \\
(-0.26)\end{array}$ & -0.005 & $\begin{array}{l}-0.063 \\
(-0.31)\end{array}$ & -0.006 & $\begin{array}{l}-0.061 \\
(-0.30)\end{array}$ & -0.005 \\
\hline \%_INDEPENDENT & $\begin{array}{l}-0.434 \\
(-0.47)\end{array}$ & -0.038 & $\begin{array}{l}-0.591 \\
(-0.63)\end{array}$ & -0.052 & $\begin{array}{l}-0.490 \\
(-0.52)\end{array}$ & -0.043 \\
\hline INDUSTRY_USER & $\begin{array}{c}-0.059^{* *} \\
(-2.37)\end{array}$ & -0.005 & $\begin{array}{c}-0.057 * * \\
(-2.28)\end{array}$ & -0.005 & $\begin{array}{c}-0.057 * * \\
(-2.31)\end{array}$ & -0.005 \\
\hline FIN & $\begin{array}{l}0.281 \\
(0.38)\end{array}$ & 0.025 & $\begin{array}{l}0.171 \\
(0.24)\end{array}$ & 0.015 & $\begin{array}{l}0.248 \\
(0.35)\end{array}$ & 0.022 \\
\hline KLDSCORE & $\begin{array}{l}-0.015 \\
(-0.40)\end{array}$ & -0.001 & $\begin{array}{l}-0.014 \\
(-0.37)\end{array}$ & -0.001 & $\begin{array}{l}-0.013 \\
(-0.35)\end{array}$ & -0.001 \\
\hline NOISE & $\begin{array}{c}-15.41 * * * \\
(-2.61)\end{array}$ & -1.355 & $\begin{array}{c}-15.97^{* * * *} \\
(-2.74)\end{array}$ & -1.399 & $\begin{array}{c}-16.11 * * * \\
(-2.72)\end{array}$ & -1.411 \\
\hline REPORTING & $\begin{array}{l}-0.106 \\
(-0.40)\end{array}$ & -0.009 & $\begin{array}{l}-0.090 \\
(-0.34)\end{array}$ & -0.008 & $\begin{array}{l}-0.103 \\
(-0.39)\end{array}$ & -0.009 \\
\hline CONSULT_DUMMY & $\begin{array}{c}1.176^{* * *} * \\
(2.82)\end{array}$ & 0.103 & $\begin{array}{c}1.198 * * * \\
(2.85)\end{array}$ & 0.105 & $\begin{array}{c}1.215^{* * *} \\
(2.86)\end{array}$ & 0.106 \\
\hline Industry_Fixed & YES & & YES & & YES & \\
\hline Year_Fixed & YES & & YES & & YES & \\
\hline Cluster (Firm) & YES & & YES & & YES & \\
\hline Pseudo $\mathrm{R}^{2}$ & 0.1746 & & 0.1757 & & 0.1774 & \\
\hline $\mathrm{N}$ & 1520 & & 1520 & & 1520 & \\
\hline
\end{tabular}

This table presents the effect of director experience on firms' CSR performance measure adoption choices. Panel A reports coefficients and marginal effects of logit regression for the full sample. Panel B include interaction terms of CSR_EXP*HIGH and CSR_EXP*DISPERSE in regressions. The $z$-statistics are reported in parentheses. $*, * *, * * *$ indicate significance levels (two-tailed) at $10 \%, 5 \%$ and $1 \%$. All continuous variables are winsorized at the $1^{\text {st }}$ and $99^{\text {th }}$ percentiles. All other variables are defined in Appendix A. 


\section{Do adopters with experienced directors show higher substantiveness in CSR performance measures?}

To further analyse whether adopters with experienced directors show higher substantiveness in CSR performance measures than those without experienced directors, I manually collect executive compensation contract data from the compensation section of proxy statements (Def 14). In the Compensation Discussion and Analysis session, firms are required by the SEC to disclose detailed performance metrics that they use to evaluate executives' performance. I manually search through the description of executives' annual incentives to identify CSR-related performance metrics. ${ }^{28}$ These metrics include: safety, injury rate, incident rate, diversity (diverse), environment, environmental footprint, greenhouse gas emission, carbon emission, health, ethics (ethical), ethical business practice, renewable energy, community, equality, social responsibility, product safety, customer safety/security, customer health. If any of these terms are identified, it indicates that the firm explicitly disclose the link of specific CSR performance measures to executive compensation in its proxy statement ( $\left.E X \_L I N K \_A D O P T\right)$. I further capture how many CSR performance measure dimensions are disclosed (CSRPM_DIMENSIONS). ${ }^{29} \mathrm{I}$ capture the relative weights (INTENSITY) attached on CSR performance measures by dividing total dimensions of CSR performance measures by the total number of performance measures in executives' incentive contracts. ${ }^{30}$ I measure the overall substantiveness of CSR performance measure adoption by computing a factor score (SUBSTANTIVENESS) that includes EX_LINK_ADOPT, CSRPM_DIMENSIONS and INTENSITY.

Of the 176 adopters, I manage to find 172 proxy statements from the Edgar database. Panel A of Table 18 shows that 49 percent of the adopters explicitly disclose a link between executive compensation contract to CSR performance measures in their proxy statements. On average, $0.72 \mathrm{CSR}$ performance measure dimensions are disclosed in firms' proxy statements. The most frequently disclosed dimension in proxy statements for the adopters is employee dimension. Only one of the adopters discloses CSR performance measure over human right dimension in its proxy statement.

Panel B of Table 18 exhibits mean-comparison tests for the adopters with experienced directors and without experienced directors. Overall, adopters with experienced directors are more likely to disclose a link between CSR performance measures and executive compensation in proxy statements $(\mathrm{t}=2.01 ; \mathrm{p}=0.046)$. They also integrate more CSR performance measure dimensions in proxy statements than those without experienced directors $(\mathrm{t}=2.59 ; \mathrm{p}=0.010)$. I further find that compared to adopters without an experienced director, adopters with experienced directors are more likely to integrate CSR performance measures over customer and society dimensions in proxy statements. With

\footnotetext{
${ }^{28}$ I focus on CSR-related performance measures in executives' annual incentives as most firms only use financial performance measures (e.g. shareholder return) in long-term incentives.

${ }^{29}$ CSR performance measures can be allocated into five dimensions: employee, environment, customer, society and human rights.

${ }^{30}$ Most firms do not determine specific weights on CSR performance measures in executive compensation contracts. CSR performance is often evaluated together with other non-financial performance measures in a subjective manner. Therefore, I calculate the relative weight to capture the relative concentration of performance measures on CSR dimensions in executive compensation contracts.
} 
respect to the relative weights of CSR performance measures, I find marginal evidence that adopters with experienced directors attach higher weights $(t=1.59 ; \mathrm{p}=0.113)$. Adopters with experienced directors also exhibit higher overall substantiveness in CSR performance measure adoption than adopters without experienced directors $(t=2.19 ; \mathrm{p}=0.03)$. In general, these findings support the argument that director experience is associated with higher substantiveness in CSR performance measure adoption.

Panel C of Table 18 reports the OLS regression results. Consistent with my expectation, I that find adopters with experienced directors adopt more CSR performance measure dimensions (coefficient $=0.517 ; \mathrm{t}=3.02$ ), are more likely to disclose a link between CSR performance measures and executive compensation in proxy statements (coefficient $=$ $0.205 ; \mathrm{t}=2.33$ ), and attach higher weights on CSR performance measures (coefficient $=0.047$; $\mathrm{t}=2.18)$. The last column shows the results of regressing the factor score SUBSTANTIVENESS on CSR_EXP and other controls. I find the coefficient of CSR_EXP significantly positive (coefficient $=0.485 ; \mathrm{t}=2.72$ ), which indicates that adopters with experienced directors show higher substantiveness in CSR performance measures.

Table 18: Substantiveness of CSR Performance Measures Adoption

\begin{tabular}{|c|c|c|c|c|c|}
\hline \multicolumn{6}{|c|}{ Panel A: Proxy statement information for CSR performance measure adopters } \\
\hline Variable & Obs & Mean & Std. Dev. & Min & $\operatorname{Max}$ \\
\hline Employee dimension & $\overline{172}$ & 0.41 & 0.49 & 0 & 1 \\
\hline Environmental & & & & & \\
\hline dimension & 172 & 0.10 & 0.30 & 0 & 1 \\
\hline Customer dimension & 172 & 0.08 & 0.27 & 0 & 1 \\
\hline Social dimension & 172 & 0.13 & 0.33 & 0 & 1 \\
\hline Human rights & & & & & \\
\hline dimension & 172 & 0.01 & 0.08 & 0 & 1 \\
\hline CSR total dimensions & 172 & 0.72 & 0.893 & 0 & 4 \\
\hline Explicit Link & 172 & 0.49 & 0.50 & 0 & 1 \\
\hline Intensity & 172 & 0.10 & 0.12 & 0 & 0.6 \\
\hline
\end{tabular}

Panel B: Comparison between adopters with and without experienced directors

\begin{tabular}{ccccc}
\hline & $\begin{array}{c}\text { Adopters with } \\
\text { Experienced } \\
\text { Directors } \\
\mathbf{N = 8 9 )}\end{array}$ & $\begin{array}{c}\text { Adopters without } \\
\text { Experienced } \\
\text { Directors } \\
\mathbf{( N = 8 3 )}\end{array}$ & $\begin{array}{c}\text { T-value } \\
\text { Mean }\end{array}$ & $\frac{\text { P-value }}{0.314}$ \\
$\begin{array}{c}\text { Variable } \\
\text { Employee dimension } \\
\text { Environmental } \\
\text { dimension }\end{array}$ & 0.45 & 0.37 & 0.61 & 0.541 \\
$\begin{array}{c}\text { Customer dimension } \\
\text { Social dimension }\end{array}$ & 0.11 & 0.08 & 3.29 & 0.001 \\
$\quad \begin{array}{c}\text { Human rights } \\
\text { dimension }\end{array}$ & 0.19 & 0.01 & 2.60 & 0.010 \\
$\begin{array}{c}\text { CSR total dimensions } \\
\text { (CSRPM_Dimensions) }\end{array}$ & 0.00 & 0.06 & 1.04 & 0.302 \\
$\quad \begin{array}{l}\text { Explicit Link } \\
\text { (Ex_Link_Adopt) }\end{array}$ & 0.89 & 0.01 & 2.59 & 0.010 \\
$\quad \begin{array}{c}\text { Relative Weight } \\
\text { (Intensity) }\end{array}$ & 0.11 & 0.54 & 2.01 & 0.046 \\
Substantiveness & 0.16 & 0.41 & 1.59 & 0.113 \\
\hline
\end{tabular}




\begin{tabular}{|c|c|c|c|c|}
\hline \multicolumn{5}{|c|}{ Panel C: Director experience on the substantiveness of CSR performance measure adoption } \\
\hline Variable & CSRPM_Dimensions & $\underset{\text { (2) }}{\text { Ex_Link }}$ & $\begin{array}{l}\text { Intensity } \\
\text { (3) }\end{array}$ & $\begin{array}{c}\text { Substantiveness } \\
\text { (4) }\end{array}$ \\
\hline \multirow[t]{2}{*}{ CONSTANT } & -1.139 & $-1.416^{* *}$ & -0.0874 & -2.351 \\
\hline & $(-0.85)$ & $(-2.24)$ & $(-0.40)$ & $(-1.61)$ \\
\hline \multirow[t]{2}{*}{ CSR_EXP } & $0.517 * * *$ & $0.205^{* *}$ & $0.0470 * *$ & $0.485 * * *$ \\
\hline & $(3.02)$ & $(2.33)$ & $(2.18)$ & $(2.72)$ \\
\hline \multirow{2}{*}{ LOG_ASSETS } & $0.236^{* *}$ & $0.190 * * *$ & $0.0365 * *$ & $0.33 * * *$ \\
\hline & (2.19) & (3.14) & (2.48) & (2.77) \\
\hline \multirow[t]{2}{*}{ ROA } & 1.849 & $1.518^{*}$ & 0.242 & 2.495 \\
\hline & $(1.33)$ & (1.69) & $(0.98)$ & (1.39) \\
\hline \multirow[t]{2}{*}{ LEVERAGE } & -0.588 & 0.0146 & -0.0700 & -0.427 \\
\hline & $(-1.01)$ & $(0.05)$ & $(-0.96)$ & $(-0.67)$ \\
\hline \multirow[t]{2}{*}{$\mathrm{RD}$} & -3.023 & $-2.585^{*}$ & -0.429 & -4.245 \\
\hline & $(-1.22)$ & $(-1.93)$ & $(-1.27)$ & $(-1.52)$ \\
\hline \multirow[t]{2}{*}{$\mathrm{AD}$} & -4.766 & $-3.730 *$ & $-0.867 * *$ & $-7.000 *$ \\
\hline & $(-1.39)$ & $(-1.69)$ & $(-2.02)$ & $(-1.84)$ \\
\hline \multirow[t]{2}{*}{ MBR } & 0.00556 & 0.00301 & 0.000577 & 0.006 \\
\hline & $(0.31)$ & $(0.24)$ & $(0.28)$ & $(0.29)$ \\
\hline \multirow[t]{2}{*}{ BOARDSIZE } & 0.0235 & -0.0177 & -0.000365 & -0.004 \\
\hline & $(0.41)$ & $(-0.56)$ & $(-0.05)$ & $(-0.06)$ \\
\hline \multirow[t]{2}{*}{ CEO_DUALITY } & 0.0851 & 0.00926 & -0.00799 & 0.018 \\
\hline & $(0.51)$ & $(0.09)$ & $(-0.34)$ & $(0.09)$ \\
\hline \multirow[t]{2}{*}{ \%_INDEPENDENT } & -0.465 & -0.214 & -0.0304 & -0.422 \\
\hline & $(-0.64)$ & $(-0.45)$ & $(-0.30)$ & $(-0.49)$ \\
\hline \multirow[t]{2}{*}{ INDUSTRY_USER } & 0.0104 & -0.0109 & -0.000586 & -0.005 \\
\hline & $(0.37)$ & $(-0.89)$ & $(-0.18)$ & $(-0.19)$ \\
\hline \multirow[t]{2}{*}{ FIN } & 0.324 & $0.448^{*}$ & 0.0680 & 0.637 \\
\hline & $(0.65)$ & $(1.85)$ & (1.16) & $(1.27)$ \\
\hline \multirow[t]{2}{*}{ KLD_RATING } & -0.0257 & 0.000659 & -0.00464 & -0.023 \\
\hline & $(-0.95)$ & $(0.04)$ & $(-1.19)$ & $(-0.79)$ \\
\hline \multirow[t]{2}{*}{ UNPREDICTBILTY } & -2.509 & -0.979 & -0.395 & -2.821 \\
\hline & $(-1.05)$ & $(-0.72)$ & $(-1.14)$ & $(-1.04)$ \\
\hline \multirow[t]{2}{*}{ NOISE } & 0.617 & 0.228 & 0.0640 & 0.590 \\
\hline & $(0.13)$ & $(0.08)$ & $(0.09)$ & $(0.10)$ \\
\hline \multirow[t]{2}{*}{ D_CSR_REPORTING } & $-0.490 * *$ & $-0.298^{* *}$ & $-0.0549 * *$ & $-0.562 * *$ \\
\hline & $(-2.26)$ & $(-2.57)$ & $(-2.06)$ & $(-2.43)$ \\
\hline \multirow[t]{2}{*}{ SASB_DIMENSIONS } & -0.181 & 0.210 & 0.000349 & 0.075 \\
\hline & $(-0.32)$ & $(0.63)$ & $(0.00)$ & $(0.11)$ \\
\hline \multirow[t]{2}{*}{ CONSULT_DUMMY } & -0.389 & -0.0996 & -0.0272 & -0.304 \\
\hline & $(-1.38)$ & $(-0.59)$ & $(-0.67)$ & $(-0.94)$ \\
\hline Industry_Fixed & YES & YES & YES & YES \\
\hline Year_Fixed & YES & YES & YES & YES \\
\hline Cluster (Firm) & YES & YES & YES & YES \\
\hline $\mathrm{R}$-Square & 0.4092 & 0.4261 & 0.4481 & 0.4386 \\
\hline $\mathrm{N}$ & 172 & 172 & 172 & 172 \\
\hline
\end{tabular}

This table reports analysis of director experience on the substantiveness of CSR performance measures adoption. Panel A and Panel B report descriptives. Panel C reports coefficients of OLS regressions for the adopter sample. The dependent variables, CSRPM_Dimensions, Ex_Link_Adopt and Intensity capture three aspects of the substantiveness of the adoption. The dependent variable in the last regression is a factor score that is formed by the three substantiveness variables. The $t$-statistics are reported in parentheses. *, **, *** indicate significance levels (two-tailed) at $10 \%, 5 \%$ and $1 \%$. All continuous variables are winsorized at the $1^{\text {st }}$ and $99^{\text {th }}$ percentiles. Other variables are defined in Appendix A. 


\section{Do firms rely more on director experience when alternative information sources are scarcer?}

In my hypotheses development section, I argue that director experience is an important information source of designing and implementing CSR performance measures. However, it is likely that firms still obtain some information from alternative sources. Director experience will be valued more by potential adopters when there are fewer alternative information sources. I hereby investigate focal firms' reliance on director experience in situations where less alternative information is available. Specifically, I compare the effect of director experience on firms' adoption decision before and after 2007.

I choose the year 2007 as a critical point for the following reasons: First, the Global Reporting Initiatives (GRI), a non-profit organization, launched the G3 Guidelines as an instruction for sustainability disclosure in 2006. Although there are other guidelines provided by GRI before 2006, such as G1 and G2, these guidelines only provide a reporting framework. The abstract information that guided CSR reporting may not be helpful to CSR performance measurement design. Second, in December 2006, a new disclosure rule that requires firms to provide information on the role of compensation consultants in SEC filings came into force. Before the rule was implemented, there were fewer firms disclosing of hiring compensation consultants. Third, in early years, not many firms have implemented CSR performance measures. Thus consulting firms and social media may not approach many clients or cases regarding the design of CSR performance measures.

The first column of Table 19 presents the results of director experience on CSR performance measure adoption decisions for firm-year observations before 2007. The regression coefficient of CSR_EXP is significantly positive at $5 \%$ (coefficient $=0.918 ; \mathrm{z}=$ 2.02). The marginal effect is 0.060 . This suggests that for a firm with an experienced director, the likelihood of adopting CSR performance measures in executive compensation contracts is 6 percent higher than for firms without an experienced director before year 2007. The third column shows the effect of director experience on CSR performance measure adoption for firm-year observations after 2007. I do not find significant results (coefficient $=0.020 ; \mathrm{z}=$ $0.07)$.

To compare the effect of director experience on focal firms' adoption choice before and after 2007, I create a dummy variable $P R E$ that is equal to 1 if a firm-year is before 2007. If a firm-year is after 2007, the variable $P R E$ is equal to 0 . Next, I interact $P R E$ and $C S R_{-} E X P$. If firms' reliance on director experience is stronger in early years when there is not much alternative information, I expect the coefficient of the interaction term to be significantly positive. The fifth column shows the regression results. In line with my prediction, one-tailed test suggests that the coefficient of the interaction between CSR_EXP and PRE is significantly positive (coefficient $=0.706, \mathrm{z}=1.65$ ). A marginal effect of 0.058 indicates that compared to firm-year observations after 2007, firm-year observations before 2007 are 5.8 percent more likely to rely on director experience to adopt CSR performance measures.

One potential concern of using year 2007 as a split criterion is, before 2007, there were still a lot of director interlocks which makes information transfer more likely. In contrast, due to the passage of SOX, director interlocks are less likely to arise after 2007. 
Thus, one alternative explanation to my findings is that director experience before and after 2007 coincides with other corporate governance changes simultaneously. To address this concern, I include total interlocked directors as a control variable. Untabulated results show that controlling for the number of interlocked directors, firms in early years are more likely to adopt CSR performance measures when they have experienced directors. Alternatively, to find a cleaner situation, I focus on a smaller subsample of firm-year observations before year 2007. In this subsample, I still find that firms are more likely to rely on director experience for adoption in early years than in later years. 


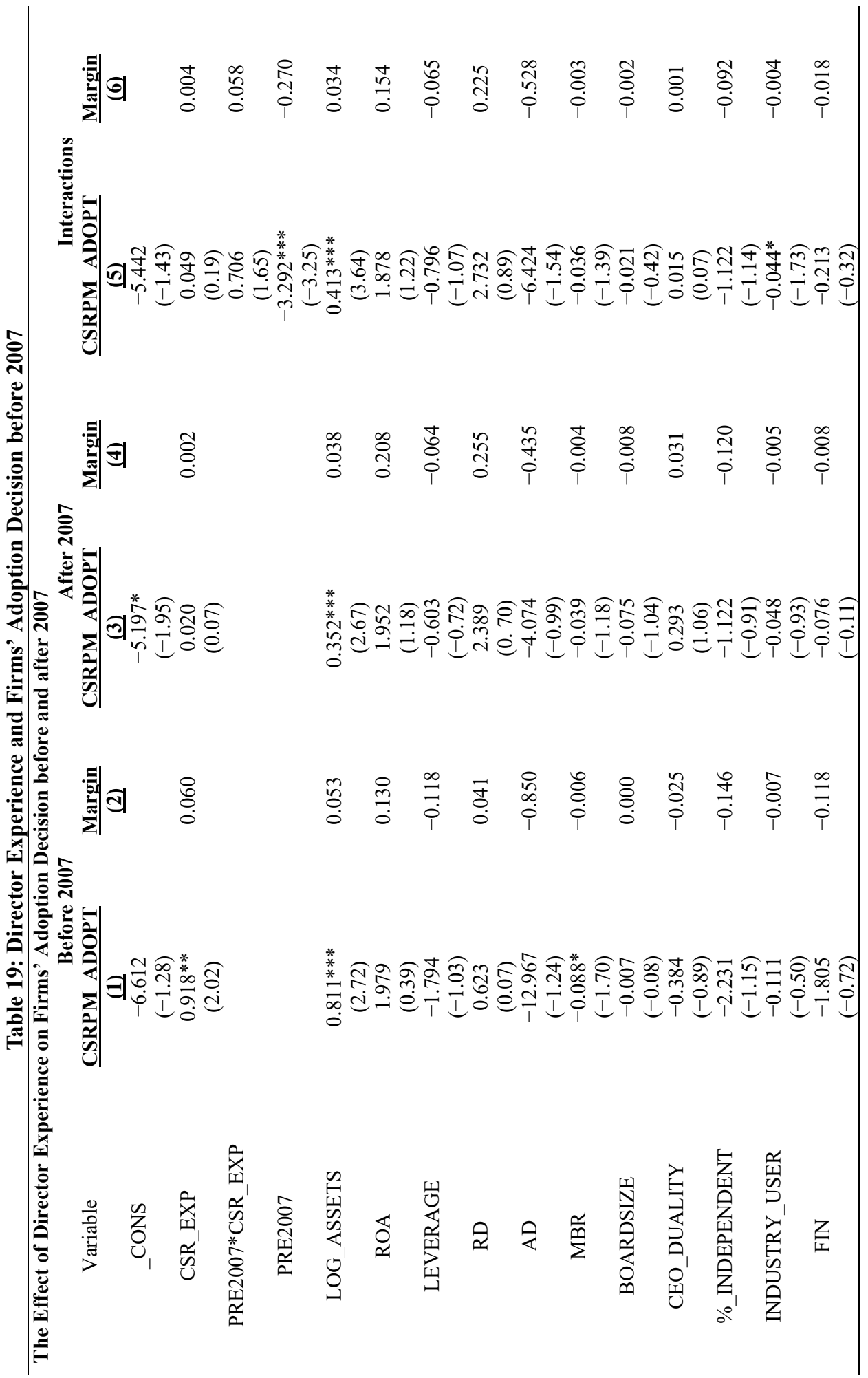


Chapter 4

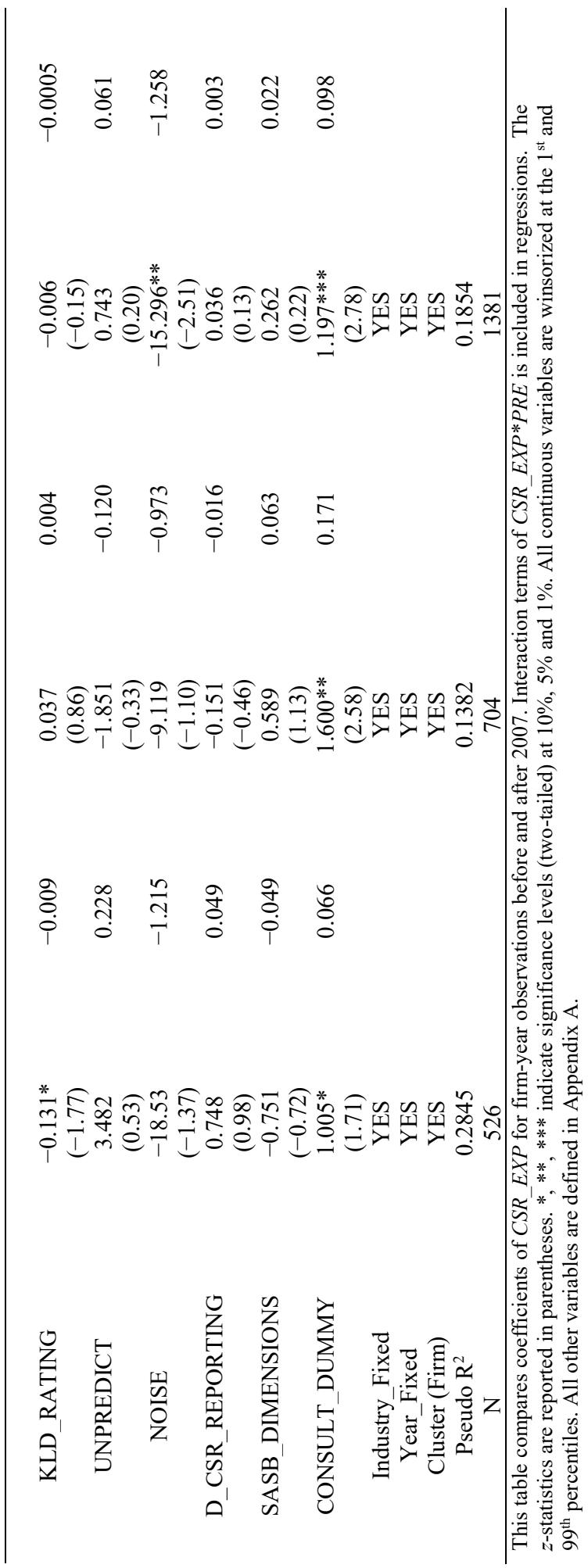




\section{The Intensity of Director Experience}

In my sample, there are cases that one firm has multiple experienced directors. In order to examine whether the intensity of director experience has any incremental impact on the likelihood of CSR performance measure adoption, I create a variable that is equal to the number of total experienced directors scaled by board size. Table 20 presents the results. I find no evidence that the intensity of director experience is associated with higher possibility of CSR performance measure adoption (coefficient $=-0.150 ; \mathrm{z}=-0.27$ ). This indicates that it is the presence, rather than the intensity, of director experience that matters for the decision to adopt CSR performance measures in executive compensation contracts. 
Table 20: Intensity of Experienced Directors

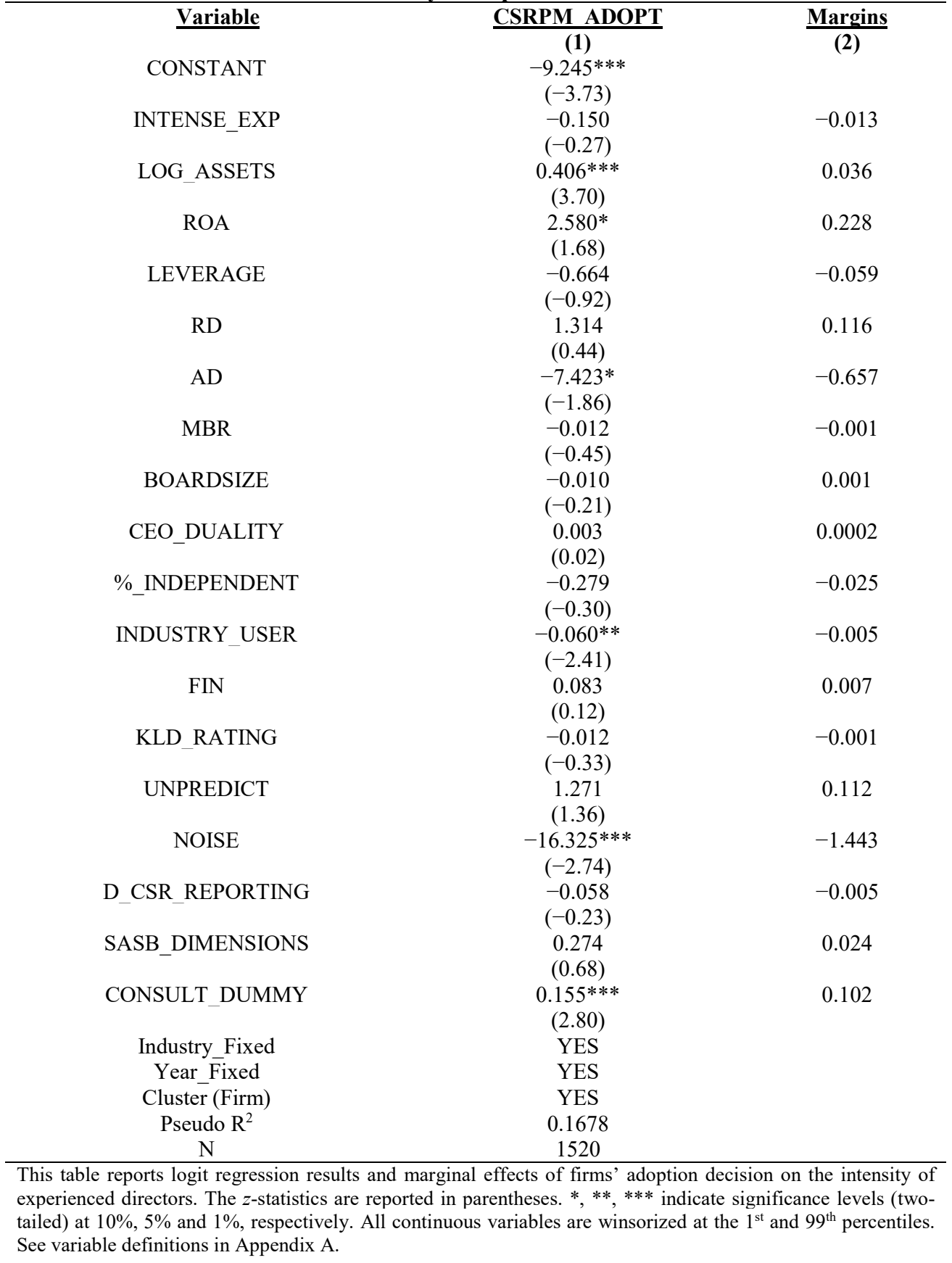




\subsection{Robustness Tests}

\subsubsection{A Change Analysis}

Although I control for variables that affect firms' decisions of adopting CSR performance measures in executive compensation contracts, one concern is that unobservable characteristics can be correlated with both director experience and firms' adoption choice. To address this potential omitted-variable problem, I capture one year before and the year when CSR-experience comes to the firm, and investigate whether there is a change in firm's adoption decision. The sample of the change analysis consists of 283 firm-year observations. I control for industry fixed effect by using one-digit sic code due to the small sample size.

Panel A of Table 21 shows that the coefficient of CSR_EXP is significantly positive at the $1 \%$ level (coefficient $=2.830 ; z=3.28$ ). A marginal effect of 0.14 suggests that a change of CSR experience from 0 to 1 increases the likelihood of adopting CSR performance measures in the focal firm by 14 percent. Panel B shows cross-sectional analysis of firms' adoption decision when CSR_EXP changes from 0 to 1 . Aligned with my hypotheses, both of the coefficients of the interaction terms CSR_EXP*HIGH and DISPERSE*CSR_EXP are significantly positive, suggesting that when director experience changes from 0 to 1 , firms with more diversified stakeholder interests and firms in more unpredictable environmental are more likely to adopt. 
Table 21: A Change Analysis

\begin{tabular}{|c|c|c|}
\hline \multirow{2}{*}{\multicolumn{3}{|c|}{ Panel A: Firms' adoption choice when CSR_EXP changes from zero to one }} \\
\hline & & \\
\hline Variables & $\underline{P T}$ & $\underline{\text { Margins }}$ \\
\hline & $\overline{(1)}$ & $\underline{(2)}$ \\
\hline _cons & $\begin{array}{c}-13 . \overline{902} * * \\
(-2.55)\end{array}$ & \\
\hline CSR_EXP & $\begin{array}{c}2.830 * * * \\
(3.28)\end{array}$ & 0.142 \\
\hline LOG_ASSETS & $\begin{array}{l}0.724 \\
(1.50)\end{array}$ & 0.036 \\
\hline ROA & $\begin{array}{l}16.377 * * * \\
(2.53)\end{array}$ & 0.822 \\
\hline LEVERAGE & $\begin{array}{l}-0.107 \\
(-0.04)\end{array}$ & -0.005 \\
\hline $\mathrm{RD}$ & $\begin{array}{l}1.871 \\
(0.23)\end{array}$ & 0.093 \\
\hline $\mathrm{AD}$ & $\begin{array}{l}-12.720 \\
(-1.63)\end{array}$ & -0.639 \\
\hline MBR & $\begin{array}{l}0.033 \\
(0.61)\end{array}$ & 0.002 \\
\hline BOARDSIZE & $\begin{array}{l}-0.094 \\
(-0.47)\end{array}$ & -0.005 \\
\hline CEO_DUALITY & $\begin{array}{c}-1.911 * * * \\
(-3.02)\end{array}$ & -0.096 \\
\hline$\%$ INDEPENDT & $\begin{array}{l}3.183 \\
(1.05)\end{array}$ & 0.160 \\
\hline INDUSTRY_USER & $\begin{array}{l}-0.070 \\
(-1.37)\end{array}$ & -0.004 \\
\hline FIN & $\begin{array}{l}-1.769 \\
(-0.83)\end{array}$ & -0.089 \\
\hline KLD_RATING & $\begin{array}{l}-0.134 \\
(-1.31)\end{array}$ & -0.007 \\
\hline UNPREDICT & $\begin{array}{l}0.497 \\
(0.05)\end{array}$ & 0.025 \\
\hline NOISE & $\begin{array}{l}-22.340 \\
(-0.98)\end{array}$ & -1.222 \\
\hline 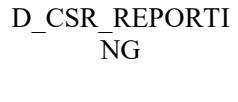 & $\begin{array}{l}0.900 \\
(1.18)\end{array}$ & 0.045 \\
\hline $\begin{array}{c}\text { SASB_DIMENSIO } \\
\text { NS }\end{array}$ & $\begin{array}{l}0.107 \\
(0.19)\end{array}$ & 0.005 \\
\hline $\begin{array}{c}\text { CONSULT_DUM } \\
\text { MY }^{\text {Con }}\end{array}$ & $\begin{array}{l}1.719 \\
(1.28)\end{array}$ & 0.086 \\
\hline Industry Fixed & YES & \\
\hline Year Fixed & YES & \\
\hline Cluster (Firm) & YES & \\
\hline Pseudo $\mathrm{R}^{2}$ & 0.3715 & \\
\hline $\mathrm{N}$ & 283 & \\
\hline
\end{tabular}




\begin{tabular}{|c|c|c|c|c|c|c|}
\hline \multicolumn{7}{|c|}{$\begin{array}{l}\text { Panel B: The effects of diversified CSR interests and environmental unpredictability on firms' adoption } \\
\text { decision when } C S R \_E X P \text { changes from zero to one }\end{array}$} \\
\hline Vorioblo & CSRPM ADO & Margin & CSRPM ADO & Margin & CSRPM ADO & Margin \\
\hline variable & $\frac{\text { PT }}{(1)}$ & $\underline{s}$ & $\frac{\mathrm{PT}}{(3)}$ & $\frac{\mathrm{s}}{(4)}$ & $\frac{\text { PT }}{(5)}$ & $\frac{s}{(6)}$ \\
\hline CONS & $-12 . \overline{763} * * *$ & & $-11.887 * * *$ & & $-12 . \overline{402} * * *$ & \\
\hline & $(-2.85)$ & & $(-2.78)$ & & $(-2.76)$ & \\
\hline CSR_EXP & $\begin{array}{l}2.385 * * * \\
(3.61)\end{array}$ & 0.115 & $\begin{array}{l}1.159 \\
(1.13)\end{array}$ & 0.054 & $\begin{array}{l}0.212 \\
(0.19)\end{array}$ & 0.010 \\
\hline CSR_EXP*HIGH & $\begin{array}{l}15.246 * * * \\
(11.38)\end{array}$ & 0.738 & & & $\begin{array}{l}17.430 * * * \\
(6.07)\end{array}$ & 0.802 \\
\hline $\begin{array}{c}\text { CSR_EXP*DISPER } \\
\text { SE }\end{array}$ & & & $17.595 * * *$ & 0.826 & $18.395 * * *$ & 0.846 \\
\hline & & & $(11.81)$ & & (10.49) & \\
\hline HIGH & $\begin{array}{c}-16.083 * * * \\
(-12.80)\end{array}$ & -0.778 & $\begin{array}{l}-0.875 \\
(-1.02)\end{array}$ & -0.041 & $\begin{array}{c}-18.039 * * * \\
(-6.76)\end{array}$ & -0.830 \\
\hline DISPERSE & $\begin{array}{l}0.771 \\
(0.93)\end{array}$ & 0.037 & $\begin{array}{c}-16.219^{* * *} \\
(-12.84)\end{array}$ & -0.076 & $\begin{array}{c}-16.901 * * * \\
(-10.84)\end{array}$ & -0.778 \\
\hline LOG_ASSETS & $\begin{array}{l}0.712 \\
(1.46)\end{array}$ & 0.034 & $\begin{array}{l}0.762 * \\
(1.87)\end{array}$ & 0.036 & $\begin{array}{l}0.705 * \\
(1.82)\end{array}$ & 0.032 \\
\hline ROA & $\begin{array}{l}18.677 * * \\
(2.45)\end{array}$ & 0.904 & $\begin{array}{c}17.236^{* *} \\
(2.55)\end{array}$ & 0.809 & $\begin{array}{c}18.281 * * * \\
(2.57)\end{array}$ & 0.841 \\
\hline LEVERAGE & $\begin{array}{l}-0.886 \\
(-0.33)\end{array}$ & -0.043 & $\begin{array}{l}-0.983 \\
(-0.39)\end{array}$ & -0.046 & $\begin{array}{l}-1.284 \\
(-0.46)\end{array}$ & -0.059 \\
\hline $\mathrm{RD}$ & $\begin{array}{l}2.659 \\
(0.31)\end{array}$ & 0.129 & $\begin{array}{l}3.326 \\
(0.42)\end{array}$ & 0.156 & $\begin{array}{l}4.250 \\
(0.51)\end{array}$ & 0.196 \\
\hline $\mathrm{AD}$ & $\begin{array}{l}-8.607 \\
(-1.13)\end{array}$ & -0.416 & $\begin{array}{r}-12.611 \\
(-1.50)\end{array}$ & -0.592 & $\begin{array}{l}-7.229 \\
(-0.87)\end{array}$ & -0.332 \\
\hline MBR & $\begin{array}{l}0.063 \\
(1.18)\end{array}$ & -0.003 & $\begin{array}{l}0.062 \\
(1.23)\end{array}$ & -0.002 & $\begin{array}{l}0.091 \\
(1.49)\end{array}$ & 0.004 \\
\hline BOARDSIZE & $\begin{array}{l}-0.178 \\
(-0.71)\end{array}$ & -0.009 & $\begin{array}{l}-0.137 \\
(-0.64)\end{array}$ & -0.006 & $\begin{array}{l}-0.098 \\
(-0.44)\end{array}$ & -0.005 \\
\hline CEO_DUALITY & $\begin{array}{l}-2.130 * * * \\
(-2.87)\end{array}$ & -0.103 & $\begin{array}{c}-2.145 * * * \\
(-3.06)\end{array}$ & -0.101 & $\begin{array}{c}-2.092 * * * \\
(-2.97)\end{array}$ & -0.096 \\
\hline \%_INDEPENDENT & $\begin{array}{l}3.556 \\
(1.06)\end{array}$ & 0.172 & $\begin{array}{l}3.015 \\
(0.90)\end{array}$ & 0.142 & $\begin{array}{l}3.410 \\
(0.95)\end{array}$ & 0.157 \\
\hline INDUSTRY_USER & $\begin{array}{c}-0.098^{*} \\
(-1.76)\end{array}$ & -0.004 & $\begin{array}{c}-0.098 * \\
(-1.74)\end{array}$ & -0.004 & $\begin{array}{c}-0.092 * \\
(-1.73)\end{array}$ & -0.004 \\
\hline FIN & $\begin{array}{l}-1.278 \\
(-0.49)\end{array}$ & -0.062 & $\begin{array}{l}-1.447 \\
(-0.54)\end{array}$ & -0.067 & $\begin{array}{l}-1.301 \\
(-0.47)\end{array}$ & -0.060 \\
\hline KLD_RATING & $\begin{array}{l}-0.137 \\
(-1.17)\end{array}$ & -0.007 & $\begin{array}{l}-0.160 \\
(-1.28)\end{array}$ & -0.008 & $\begin{array}{l}-0.168 \\
(-1.28)\end{array}$ & -0.008 \\
\hline NOISE & $\begin{array}{c}-16.861 \\
(-0.71)\end{array}$ & -0.816 & $\begin{array}{c}-17.487 \\
(-0.91)\end{array}$ & -0.821 & $\begin{array}{c}-16.386 \\
(-0.73)\end{array}$ & -0.754 \\
\hline$\underset{\text { DG }}{\text { D_CSR_REPORTI }}$ & 0.877 & 0.042 & 1.068 & 0.050 & 1.142 & 0.053 \\
\hline & $(1.08)$ & & $(1.24)$ & & $(1.36)$ & \\
\hline $\begin{array}{c}\text { CONSULT_DUM } \\
\text { MY }\end{array}$ & 2.117 & 0.102 & 2.126 & 0.100 & $2.451 *$ & 0.113 \\
\hline & $(1.55)$ & & $(1.40)$ & & $(1.70)$ & \\
\hline Industry_Fixed & YES & & YES & & YES & \\
\hline Year_Fixed & YES & & YES & & YES & \\
\hline Cluster (Firm). & YES & & YES & & YES & \\
\hline Pseudo $\mathrm{R}^{2}$ & 0.4044 & & 0.4268 & & 0.4435 & \\
\hline $\mathrm{N}$ & 283 & & 283 & & 283 & \\
\hline
\end{tabular}

This table presents the comparison of focal firms' adoption of CSR performance measures when CSR_EXP changes from zero to one. Panel B shows the results of incorporating interaction terms of CSR_EXP* $\bar{H} I G H$ and $C S R \_E X P * D I S P E R S E$ in the regressions. The $z$-statistics are reported in parentheses. *,**,*** indicate significance levels (two-tailed) at $10 \%, 5 \%$ and $1 \%$, respectively. All continuous variables are winsorized at the $1^{\text {st }}$ and $99^{\text {th }}$ percentiles. Industry fixed effect is control by one-digit SIC code. 


\subsubsection{Propensity Score Matching}

Although I control for firm characteristic, the descriptive statistics in Table 2 Panel B show that there are mean differences of observed variables between adopters and non-adopters. If the relationship between the dependent and independent variables is mis-specified, the regression models can lead to biased estimations (Shipman et al., 2017). Propensity score matching (PSM) analysis is one way to alleviate this bias (Rosenbaum and Rubin 1983; Shipman et al., 2017). I thus follow a one-to-one propensity score matching procedure without replacement to match each firm-year observation with experienced directors with another observation without experienced directors based on firm-level characteristics in Model (1). The calliper distance is 0.001 .

Table 22 presents the mean difference tests of the treatment and control groups. Covariates are not statistically different between the two groups. Covariate imbalance testing suggests that I cannot reject the null hypothesis of equality of means in the treated and control groups, indicating a successful match. As can be seen from the bottom row in Table 22, the treatment group is more likely to adopt than the control group $(\mathrm{t}=1.814)$. Untabulated results show that my inferences are unaffected when I relax the calliper distance to $0.01,0.03$ and 0.1. Overall, the PSM analysis supports my hypothesis that director experience increases the likelihood of adopting CSR performance measures.

Table 22: Propensity Score Matching

\begin{tabular}{|c|c|c|c|c|}
\hline Variable & $\frac{\text { CSR EXP }=1}{\frac{(297)}{\text { Mean }}}$ & $\frac{\text { CSR EXP }=0}{\frac{(297)}{\frac{\text { Mean }}{(2)}}}$ & $\frac{\text { Difference in Mean }}{\frac{\text { t-value }}{(3)}}$ & $\frac{p-\text { value }}{(4)}$ \\
\hline LOG_ASSETS & 8.858 & 8.788 & 0.77 & 0.444 \\
\hline ROA & 0.062 & 0.064 & -0.24 & 0.814 \\
\hline LEVERAGE & 0.224 & 0.219 & 0.36 & 0.719 \\
\hline $\mathrm{RD}$ & 0.032 & 0.028 & 1.04 & 0.298 \\
\hline $\mathrm{AD}$ & 0.013 & 0.014 & -0.55 & 0.585 \\
\hline MBR & 3.824 & 3.791 & 0.09 & 0.926 \\
\hline BOARDSIZE & 10.451 & 10.455 & -0.02 & 0.985 \\
\hline CEO DUALITY & 0.640 & 0.622 & 0.42 & 0.671 \\
\hline$\%$ INDEPENDT & 0.807 & 0.798 & 0.93 & 0.355 \\
\hline INDUSTRY USER & 5.428 & 5.525 & -0.17 & 0.864 \\
\hline UNPREDICT & 0.089 & 0.087 & 0.59 & 0.557 \\
\hline KLDSCORE & 0.630 & 0.572 & 0.21 & 0.831 \\
\hline DISPERSE & 0.553 & 0.578 & -0.41 & 0.679 \\
\hline CONSULT_DUMMY & 0.862 & 0.862 & 0.00 & 1.000 \\
\hline NOISE & 0.027 & 0.027 & -0.25 & 0.800 \\
\hline FIN & -0.016 & -0.017 & 0.17 & 0.869 \\
\hline D_CSR_REPORTING & 0.195 & 0.195 & 0.00 & 1.000 \\
\hline CSRPM ADOPT & 0.158 & 0.108 & 1.814 & 0.070 \\
\hline
\end{tabular}

This table presents covariate mean comparisons between firm-year observations with experienced directors and propensity score matched observations without experienced directors. ${ }^{*}, * *, * * *$ indicate significance levels (two-tailed) at $10 \%, 5 \%$ and $1 \%$, respectively. All continuous variables are winsorized at the $1^{\text {st }}$ and $99^{\text {th }}$ percentiles. See variable definitions in Appendix A. 


\subsection{Conclusion and Discussion}

Over the last decade, we have witnessed a shift from the traditional view of the firm-where firm financial performance was the only indicator of success - towards a broader view that considers firms' impact on society at large (Berrone and Goemz-Mejia, 2009b). In this new competitive landscape, firms begin to change CEO compensation contract to incorporate CSR performance measures (Coombs and Gilley, 2005). However, one concern of this practice is that firms may take a symbolic approach of copying CSR-related terms in CEO contracts.

In this study, I argue that director experience of using CSR performance measures is an important information source for potential adopters. As such information is valuable to reduce uncertainties associated with the adoption, true adopters that are concerned with these uncertainties are expected to rely on such information for adoption. However, if firms symbolically write CSR terms into CEO contracts, they do not need to wait until someone with experience in place to adopt. This study provides evidence that on average firms with experienced directors are more likely to adopt CSR performance measures in the executive compensation contract, which suggests a substantive intention. I further compare the substantiveness of CSR performance measure between adopters with and without experienced directors. Using hand-collected data from proxy statements, I show that the substantiveness of CSR performance measure adoption is stronger for adopters with experienced directors.

I further look into contextual factors that drive the difference in the reliance of director experience. Specifically, I show that the positive association between adoption and director experience is stronger when focal firms are in more uncertain environments and when their stakeholder groups have more diversified CSR interests. While literature argues that uncertainty in CSR performance measures is an important concern of CSR contracting, research failed to provide empirical evidence of how these uncertainties influence CSRrelated contracting choices. My findings suggest that one way to deal with these challenges is to rely on director experience.

One concern of this study is that an experienced director may symbolically use CSR performance measures in other firms, and adopt these measures symbolically in the focal firm (the "symbolic-symbolic" story). If this story holds, I would expect that director experience is associated with less substantive adoption. In contrast, analysis of contract data from proxy statements shows that adopters with experienced directors are more likely to substantively adopt CSR performance measures than adopters without experienced directors. Another concern of this study is that the association between director experience and firms' adoption decision might be driven by concurrent events. In all the analysis, I carefully control for industry-peer effect as well as compensation consultants. In addition, I find that the positive association holds in situations where alternative information sources are scarcer. Overall, the findings are consistent with my hypothesis that firms incorporate information from experienced directors for the adoption decision.

As with any empirical studies, this study has several limitations. One limitation is that I do not distinguish whether a focal firm actively approaches experienced director for adoption, or an experienced director leads to the adoption decision. As the aim of this study is to see whether firms incorporate information for adoption, and there is information sharing in 
both situations, my argument holds in both cases. Another limitation is that I cannot identify the different impact of directors' good or bad experience on focal firms' adoption. Directors may accumulate experience from both. On average, the results suggest firms rely on director experience for the adoption. Not examining the type of experience is unlikely to drive my findings, but future research can explore this area to broaden our understanding.

Notwithstanding these limitations, this study contributes to the literature on CSR as well as to the accounting literature in general. By demonstrating that firms do rely on information content from director experience for the adoption decision, I contribute to literature in debate of "symbolic adoption" versus "substantive commitment" in terms of CSR performance measures. This study also advances management accounting literature by showing that individual factors such as directors' background and experience play a role in firms' choices of designing performance measurements. Such experience may explain why performance measurement systems diffuse across firms. 
Chapter

Conclusions 



\section{Conclusions}

In this dissertation, I investigate firms' choices of incorporating CSR-related strategies. Over the last decade, there has been an increasing emphasis on socially responsible corporate activities around the world. In addition to economic profit creation, firms are expected to incorporate the needs of the environment and society into their business operations (KPMG 2013). Although firms' claimed commitment to CSR has increased over time, investors often feel skeptical towards the disclosed CSR activities. As there are no uniform criteria to evaluate and monitor firms' CSR performance, CSR strategies are often criticized to be a marketing tool, instead of being rooted in firms' internal decisions (e.g. Gray et al. 1995; Laufer 2003; Simnett et al. 2009; Eccles and Krzus 2010; KPMG 2011; Casey and Grenier 2014). The inconsistency between firms' internal and external CSR activities can lead to conflicts and ultimately weakens the credibility and the effectiveness of CSR strategies' outcomes (Weaver et al. 1999; Basu and Palazzo 2008; Yuan, Bao and Verbeke 2011).

I investigate three aspects related to firms' internal CSR strategies. In my first study, I investigate whether firms "practice what they preach" in terms of their employee dismissal decisions. Specifically, I investigate whether firms with a stronger claimed CSR orientation fire fewer employees when sales decrease than firms with a weaker claimed CSR orientation. I further investigate firms' dismissal decisions in more extreme situations where firms are pressured to meet earnings benchmarks. In my second study, I focus on how firms combine different CSR-related strategies, i.e. whether these CSR-related choices are made simultaneously, or whether they are determined independently from each other. I examine the interdependence between the choices of CSR disclosures and CSR contracting. In my third study, I investigate whether firms incorporate director experience with using CSR contracting in other firms when the focal firm adopts CSR-based performance measures in executives' incentive contracts. The section that follows discusses the findings of each of these three studies, followed by the main contributions, limitations and potential avenues for future research.

\subsection{Summary}

This dissertation analyses firms' internal and external CSR-related choices including CSR disclosure, CSR contracting and employee dismissal decisions. In chapter two, I investigate whether firms practice what they preach in terms of their declared CSR orientation. Specifically, I investigate whether firms with a stronger claimed CSR orientation fire fewer employees in response to a sales decrease. KLD ratings collect information from firms' disclosed CSR reports, websites and media disclosures. Therefore, the KLD database is often considered as capturing firms' words. I thus use KLD ratings to proxy for firms' claimed CSR orientation. As employees are often considered as the most important stakeholder of the firm, the way in which the firm treats its employees is thus an important signal of the firm's internal CSR practices (Pfeffer 2010; Shen and Benson 2016). I use firms' employee firing decisions when sales decrease to proxy for firms' internal CSR practices. I find that compared to those with a weaker claimed CSR orientation, firms with a stronger claimed 
CSR orientation fire fewer employees when sales decrease. Furthermore, the differences regarding firing decisions between firms with a stronger and weaker claimed CSR orientation are amplified in myopic situations where firms are to meet earnings targets. My findings suggest that on average, firms practice what they preach in terms of CSR decisions. These findings are consistent with behaviour integrity theory (e.g. Simons 2002) and suggest the validity of KLD data as a proxy for firms' internal CSR decisions.

Despite increasing disclosure on CSR aspects, firms are frequently suggested to incorporate CSR-based performance measures in executive compensation contracts. However, there is little understanding of how firms adopt CSR contracting in CEO annual incentives. In chapter four, I examine the effect of director experience on the focal firms' adoption of CSRbased performance measures. I argue that CSR-based performance measure adoption imposes a distinct challenge on potential adopters. One important information channel is experienced directors who have used such performance measures in other firms. However, this information is only valuable for true adopters who care about the efficiency of CSR performance measures. I find a positive association between director experience and the likelihood of CSR performance measure adoption. I further show that the reliance on director experience is stronger when focal firms are in more information demand. This indicates that in general, firms are incorporating information from experienced directors when adopting CSR contracting. My findings suggest that director experience is one way to cope with uncertainties in innovative performance measurement systems.

While chapter two and chapter four look into firms' CSR-related disclosure and CSR contracting separately, in chapter three, I take one step back and investigate whether a relationship between external and internal CSR actions exists and which form this relationship takes. I find that CSR disclosures and CSR contracting are complements, as they both demonstrate a strong CSR orientation of the firm to the market. Further, firms that have a strong CSR orientation but face higher credibility concerns show stronger complementarity between the two strategies and are more likely to use both strategies intensively. This study is linked to and extend the other two chapters by showing that firms interactively use strategies to deal with internal and external stakeholders.

\subsection{Contribution and Implications}

I have discussed the contributions of each individual study separately in the corresponding chapters. However, I would like to highlight some of the key contributions of this dissertation overall. First, this dissertation contributes to the debate of credibility issues regarding CSR practices. The CSR literature has long discussed the difficulty to monitor and verify firms' CSR practices (Simnett et al. 2009; Cohen and Simnett 2014). Due to the fact that CSR activities are often voluntarily implemented, and there is a lack of uniform criteria to evaluate CSR declarations, firms' announced CSR practices are often criticized for being symbolic or greenwashing (e.g. Laufer 2003; Lydenberg 2002). In contrast to this argument, my findings suggest that in general firms' CSR-related practices are not symbolic. In chapter two, I provide large-sample evidence that firms' claimed CSR orientations are reflected in their internal CSR decisions. In chapter four, I show that firms are incorporating relevant 
information from experienced directors when adopting CSR performance measures, which suggests that the trend of CSR contracting adoption does not arise due to firms' symbolic attempts. In chapter three, I find a complementarity between CSR disclosures and the use of CSR-based performance measures in executives' incentive contracts. I further find that firms in industries facing high credibility issues show stronger complementarity between the two mechanisms. These findings again testify that credibility is an important issue related to CSR and that firms interactively use internal and external CSR strategies to address this concern.

Second, from the perspective of internal coherence (defined in Chapter one), firms are expected to incorporate announced CSR strategies into their internal business operations. However, very few studies explore whether and how CSR is integrated into firms' internal practices (Yuan, Bao and Verbeke 2011). My studies show that firms do achieve an internal coherence with respect to their CSR decisions. First, I show that firms' internal CSR practices are aligned with their externally claimed CSR orientation. My finding suggests that when firms are considering their CSR strategies, they not only communicate their CSR orientation to outside stakeholders, but also factor these orientations into their internal decisions. This therefore indicates an internal consistency between firms' internal business operation and firms' claimed CSR orientation. Second, in contrast to most research that investigates internal and external CSR choices separately, my studies view the choices of CSR strategies from a perspective of systematic coherence. I show that firms are incorporating the interdependencies that exist between CSR practices when making CSR-related decisions. This indicates the achievement of internal fit with respect to CSR-related choices.

Third, this dissertation contributes to the growing stream of management accounting literature on innovative performance measures. While this dissertation shows the incorporation of CSR performance measures in executive compensation contracts, my findings are not limited to CSR, but can be generalized to complex and innovative performance measures as well. For instance, my findings highlight the importance of individual experience in reducing uncertainties associated with innovations in performance measurement systems. My findings also provide evidence on the effectiveness of performance measurement systems in communicating firms' orientations and strategies.

\subsection{Limitations and Future Research}

As with any study, this dissertation is subject to certain limitations that provide avenues for future research. While I have discussed limitations of each study in the previous chapters, I would like to discuss common limitations of all chapters here. First, in all the three studies, I focus on CSR-related internal practices and strategies. For instance, in chapter two, I examine firms' firing decision in response to a sales decrease, which can be viewed as a reflection of firms' attitudes towards internal stakeholders. In chapter three and four, a common variable I use is the incorporation of CSR-based performance measures in executives' incentive contracts. Grabner and Moers (2013) demonstrate that the relative benefits of one organizational choice can be influenced by the use of another organizational choice. While my current studies focus on CSR-related choices, it might be that firms' non-CSR-related strategies are adjusted as well when CSR-related strategies are in place. Examining how firms 
adapt strategies with different orientations and related consequences could be an interesting avenue to follow. Future research can explore how firms combine long-term and short-term oriented tasks. This process might not be achieved at once but progresses dynamically.

Furthermore, my dissertation shows the effectiveness of performance measurement systems in communicating firms' orientations and strategies. For instance, the use of CSR performance measures can be viewed as a signal that the firm is incorporating CSR orientation into its internal business operations. Future research may investigate whether and how performance measurement systems can change outsiders' perception about the firm, and what the consequences are of this change of perception. 
References 



\section{References}

Abbott, W. F., and Monsen, R. J. (1979). On the measurement of corporate social responsibility: Self-reported disclosures as a method of measuring corporate social involvement. Academy of Management Journal, 22(3), 501-515.

Abernethy, M. A., Kuang, Y. F., \& Qin, B. (2015). The influence of CEO power on compensation contract design. The Accounting Review, 90(4), 1265-1306.

Adams, C. A. (2002). Internal organisational factors influencing corporate social and ethical reporting: Beyond current theorising. Accounting, Auditing \& Accountability Journal, 15(2), 223-250.

Allison, P. D. (1982). Discrete-time methods for the analysis of event histories. Sociological Methodology, 13(1), 61-98.

Anderson, J. C., \& Frankle, A. W. (1980). Voluntary social reporting: an iso-beta portfolio analysis. The Accounting Review, 55(3), 467-479.

Anderson, M. C., Banker, R. D., \& Janakiraman, S. N. (2003). Are selling, general, and administrative costs "sticky"? Journal of Accounting Research, 41(1), 47-63.

Anderson, S. W., and W. Lanen. (2007). Understanding Cost Management: What Can We Learn From theEvidence on "Sticky" Costs. Working Paper, Rice University and the University of Michigan.

Aragón-Correa, J. A. (1998). Strategic proactivity and firm approach to the natural environment. Academy of Management Journal, 41(5), 556-567.

Armstrong, C. S., Guay, W. R., \& Weber, J. P. (2010). The role of information and financial reporting in corporate governance and debt contracting. Journal of Accounting and Economics, 50(2), 179-234.

Baber, W. R., Fairfield, P. M., \& Haggard, J. A. (1991). The effect of concern about reported income on discretionary spending decisions: The case of research and development. The Accounting Review, 66(4), 818-829.

Balakrishnan, R., Sprinkle, G. B., and Williamson, M. G. (2011). Contracting benefits of corporate giving: An experimental investigation. The Accounting Review, 86(6), 18871907

Banker, R. D., \&Datar, S. M. (1989). Sensitivity, precision, and linear aggregation of signals for performance evaluation. Journal of Accounting Research, 27(1), 21-39.

Banker, R. D., Byzalov, D., \& Chen, L. T. (2013). Employment protection legislation, adjustment costs and cross-country differences in cost behavior. Journal of Accounting and Economics, 55(1), 111-127.

Banker, R. D., Byzalov, D., Ciftci, M., \& Mashruwala, R. (2014). The moderating effect of prior sales changes on asymmetric cost behavior. Journal of Management Accounting Research, 26(2), 221-242.

Banker, R. D., Potter, G., \& Srinivasan, D. (2000). An empirical investigation of an incentive plan that includes nonfinancial performance measures. The Accounting Review, 75(1), 65-92.

Bansal, P. (2005). Evolving sustainably: A longitudinal study of corporate sustainable development. Strategic Management Journal, 26(3), 197-218.

Barth, M. E., Elliott, J. A., \& Finn, M. W. (1999). Market rewards associated with patterns of increasing earnings. Journal of Accounting Research, 37(2), 387-413.

Bartov, E., Givoly, D., \& Hayn, C. (2002). The rewards to meeting or beating earnings expectations. Journal of Accounting and Economics, 33(2), 173-204.

Basu, K., \& Palazzo, G. (2008). Corporate social responsibility: A process model of sensemaking. Academy of Management Review, 33(1), 122-136. 
Berrone, P., \& Gomez-Mejia, L. R. (2009). Environmental performance and executive compensation: An integrated agency-institutional perspective. Academy of Management Journal, 52(1), 103-126.

Berrone, P., \& Gomez-Mejia, L. R. (2009). The pros and cons of rewarding social responsibility at the top. Human Resource Management, 48(6), 959-971.

Bizjak, J., Lemmon, M., \& Whitby, R. (2009). Option backdating and board interlocks. Review of Financial Studies, 22(11), 4821-4847

Blacconiere, W. G., and Patten, D. M. (1994). Environmental disclosures, regulatory costs, and changes in firm value. Journal of Accounting and Economics, 18(3), 357-377.

Bol, J. C., \& Moers, F. (2010). The dynamics of incentive contracting: The role of learning in the diffusion process. Accounting, Organizations and Society,35(8), 721-736.

Brammer, S., \& Millington, A. (2008). Does it pay to be different? An analysis of the relationship between corporate social and financial performance. Strategic Management Journal, 29(12), 1325-1343.

Brown, J. L., \& Drake, K. D. (2013). Network ties among low-tax firms. The Accounting Review, 89(2), 483-510.

Brown, L. D., \& Higgins, H. N. (2002). Managing earnings surprises in the US versus 12 other countries. Journal of Accounting and Public Policy, 20(4), 373-398.

Brundtland, G. H. (1987). Report of the World Commission on environment and development:" our common future.". United Nations.

Burgstahler, D., \& Dichev, I. (1997). Earnings management to avoid earnings decreases and losses. Journal of Accounting and Economics, 24(1), 99-126.

Burgstahler, D., \& Eames, M. (2006). Management of earnings and analysts' forecasts to achieve zero and small positive earnings surprises. Journal of Business Finance \& Accounting, 33(5-6), 633-652.

Cai, Y., Dhaliwal, D. S., Kim, Y., \& Pan, C. (2014). Board interlocks and the diffusion of disclosure policy. Review of Accounting Studies, 19(3), 1086-1119.

Cai, Y., Jo, H., and Pan, C. (2011). Vice or virtue? The impact of corporate social responsibility on executive compensation. Journal of Business Ethics, 104(2), 159173.

Campbell, K., Johnston, D., Sefcik, S. E., and Soderstrom, N. S. (2007). Executive compensation and non-financial risk: An empirical examination. Journal of Accounting and Public Policy, 26(4), 436-462

Carmeli, A., Gilat, G., \& Waldman, D. A. (2007). The role of perceived organizational performance in organizational identification, adjustment and job performance. Journal of Management Studies, 44(6), 972-992.

Casey, R. J., \& Grenier, J. H. (2014). Understanding and contributing to the enigma of corporate social responsibility (CSR) assurance in the United States. Auditing: A Journal of Practice \& Theory, 34(1), 97-130.

Chatterji, A. K., Levine, D. I., \& Toffel, M. W. (2009). How well do social ratings actually measure corporate social responsibility? Journal of Economics \& Management Strategy, 18(1), 125-169.

Chen, C. X., Lu, H., \& Sougiannis, T. (2012). The Agency Problem, Corporate Governance, and the Asymmetrical Behavior of Selling, General, and Administrative Costs.

Contemporary Accounting Research, 29(1), 252-282.

Cheng, B., Ioannou, I., \& Serafeim, G. (2014). Corporate social responsibility and access to finance. Strategic Management Journal, 35(1), 1-23.

Chhaochharia, V., and Y. Grinstein. 2009. CEO compensation and board structure. Journal of Finance, 64 (1), 231-261. 
Chiu, P. C., Teoh, S. H., \& Tian, F. (2013). Board interlocks and earnings management contagion. The Accounting Review, 88(3), 915-944.

Cho, C. H., \& Patten, D. M. (2007). The role of environmental disclosures as tools of legitimacy: A research note. Accounting, Organizations and Society, 32(7), 639-647.

Clark, A. E., \& Oswald, A. J. (1994). Unhappiness and unemployment. The Economic Journal, 104(424), 648-659.

Clarkson, M. E. (1995). A stakeholder framework for analyzing and evaluating corporate social performance. Academy of Management Review, 20(1), 92-117.

Clarkson, P. M., Li, Y., Richardson, G. D., \& Vasvari, F. P. (2008). Revisiting the relation between environmental performance and environmental disclosure: An empirical analysis. Accounting, Organizations and Society, 33(4), 303-327.

Cohen, J. R., and Simnett, R. (2014). CSR and assurance services: A research agenda. Auditing: A Journal of Practice \& Theory, 34(1), 59-74.

Coombs, J. E., and Gilley, K. M. (2005). Stakeholder management as a predictor of CEO compensation: Main effects and interactions with financial performance. Strategic Management Journal, 26(9), 827-840

Cordeiro, J. J., \& Sarkis, J. (2008). Does explicit contracting effectively link CEO compensation to environmental performance? Business Strategy and the Environment, 17(5), 304-317.

Core, J., \&Guay, W. (1999). The use of equity grants to manage optimal equity incentive levels. Journal of Accounting and Economics, 28(2), 151-184.

Cornelius, N., Todres, M., Janjuha-Jivraj, S., Woods, A., \& Wallace, J. (2008). Corporate social responsibility and the social enterprise. Journal of Business Ethics, 81(2), 355370.

Cornett, M. M., Marcus, A. J., \& Tehranian, H. (2008). Corporate governance and pay-forperformance: The impact of earnings management. Journal of Financial Economics, 87(2), 357-373.

DeAngelo, H., DeAngelo, L., \& Skinner, D. J. (1996). Reversal of fortune dividend signaling and the disappearance of sustained earnings growth. Journal of Financial Economics, 40(3), 341-371.

Dechow, P. M., \& Sloan, R. G. (1991). Executive incentives and the horizon problem: An empirical investigation. Journal of Accounting and Economics, 14(1), 51-89.

Dechow, P. M., Sloan, R. G., and Sweeney, A. P. (1995). Detecting earnings management. The Accounting Review, 70(2), 193-225.

Deckop, J. R., Merriman, K. K., \& Gupta, S. (2006). The effects of CEO pay structure on corporate social performance. Journal of Management, 32(3), 329-342.

Degeorge, F., Patel, J., \& Zeckhauser, R. (1999). Earnings management to exceed thresholds. The Journal of Business, 72(1), 1-33.

Delmas, M. A., \& Burbano, V. C. (2011). The drivers of greenwashing.California Management Review, 54(1), 64-87.

Demsetz, H., \& Lehn, K. (1985). The structure of corporate ownership: Causes and consequences. Journal of Political Economy, 93(6), 1155-1177.

Dhaliwal, D. S., Li, O. Z., Tsang, A., \& Yang, Y. G. (2011). Voluntary nonfinancial disclosure and the cost of equity capital: The initiation of corporate social responsibility reporting. The Accounting Review, 86(1), 59-100.

Dhaliwal, D., Li, O. Z., Tsang, A., \& Yang, Y. G. (2014). Corporate social responsibility disclosure and the cost of equity capital: The roles of stakeholder orientation and financial transparency. Journal of Accounting and Public Policy, 33(4), 328-355. 
Dierynck, B., Landsman, W. R., \& Renders, A. (2012). Do managerial incentives drive cost behavior? Evidence about the role of the zero earnings benchmark for labor cost behavior in private Belgian firms. The Accounting Review, 87(4), 1219-1246.

Ditillo, A., \& Lisi, I. E. (2016). Exploring sustainability control systems' integration: The relevance of sustainability orientation. Journal of Management Accounting Research, 28(2), 125-148.

Eccles, R. G., \& Krzus, M. P. (2010). One report: Integrated reporting for a sustainable strategy. John Wiley \& Sons.

Eccles, R. G., Ioannou, I., \& Serafeim, G. (2012). The impact of a corporate culture of sustainability on corporate behavior and performance (No. W17950). Cambridge, MA, USA: National Bureau of Economic Research.

Edmans, A. (2011). Does the stock market fully value intangibles? Employee satisfaction and equity prices. Journal of Financial Economics, 101(3), 621-640.

Eger, T. (2003). Opportunistic termination of employment contracts and legal protection against dismissal in Germany and the USA. International Review of Law and Economics, 23(4), 381-403.

Fagerberg, J., Verspagen, B., \& Caniels, M. (1997). Technology, growth and unemployment across European regions. Regional Studies, 31(5), 457-466.

Fama, E. F., \& Jensen, M. C. (1983). Separation of ownership and control. The Journal of Law \& Economics, 26(2), 301-325.

Feltham, G. A., and Xie, J. (1994). Performance measure congruity and diversity in multi-task principal/agent relations, The Accounting Review, 69(3), 429-453.

Fisher, R. A. (1915). Frequency distribution of the values of the correlation coefficient in samples from an indefinitely large population. Biometrika, 10(4), 507-521.

Flammer, C., Hong, B., \& Minor, D. (2017, January). Corporate Governance and the Rise of Integrating CSR Criteria in Executive Compensation. In Academy of Management Proceedings (Vol. 2017, No. 1, p. 11206). Academy of Management.

Frankel, R., McNichols, M., and Wilson, G. P. (1995). Discretionary disclosure and external financing. The Accounting Review, 70(1), 135-150.

Geletkanycz, M. A., \&Hambrick, D. C. (1997). The external ties of top executives: Implications for strategic choice and performance. Administrative Science Quarterly, 42(4), 654-681.

Gibbons, R., \& Katz, L. F. (1991). Layoffs and lemons. Journal of Labor Economics, 9(4), 351-380.

Gond, J. P., Grubnic, S., Herzig, C., \& Moon, J. (2012). Configuring management control systems: Theorizing the integration of strategy and sustainability. Management Accounting Research, 23(3), 205-223.

Grabner, I. (2014). Incentive system design in creativity-dependent firms. The Accounting Review, 89(5), 1729-1750.

Grabner, I., \& Moers, F. (2013). Management control as a system or a package? Conceptual and empirical issues. Accounting, Organizations and Society, 38(6), 407-419.

Grabner, I., Moers, F., and Vorst, P. (2016). Organizational design and voluntary disclosure: the effect of target-setting quality on the provision and nature of management guidance, Working paper, Maastricht University.

Grabner, I., Renders, A., \& Yang, L. (2018). The Complementarity between CSR Disclosures and the Use of CSR-Based Performance Measures in CEO Annual Incentive Contracts. Working paper, Maastricht University.

Gray, R., Kouhy, R., \& Lavers, S. (1995). Constructing a research database of social and environmental reporting by UK companies. Accounting, Auditing \& Accountability Journal 8(2), 78-101. 
Greenwood, M. R.: 2002, 'Ethics and Human Resource Management: A Review and Conceptual Analysis', Journal of Business Ethics, 36(3), 279-290.

Gunny, K. A. (2010). The Relation Between Earnings Management Using Real Activities Manipulation and Future Performance: Evidence from Meeting Earnings Benchmarks*. Contemporary Accounting Research, 27(3), 855-888.

Harcourt, M., Hannay, M., \& Lam, H. (2013). Distributive justice, employment-at-will and just-cause dismissal. Journal of Business Ethics, 115(2), 311-325.

Haunschild, P. R., \& Beckman, C. M. (1998). When do interlocks matter? Alternate sources of information and interlock influence. Administrative Science Quarterly, 43(4), 815844.

Hawn, O., \& Ioannou, I. (2016). Mind the gap: The interplay between external and internal actions in the case of corporate social responsibility. Strategic Management Journal, 37(13), 2569-2588.

Hayes, R. M., and S. Schaefer. 2000. Implicit contracts and the explanatory power of top executive compensation for future performance. RAND Journal of Economics, 31(2), 279-293.

Hemmer, T., and E. Labro. 2008. On the Optimal Relation Between the Properties of Managerial and Financial Reporting Systems. Journal of Accounting Research, 46(5), 1209-1240.

Hobson, J. L., and Kachelmeier, S. J. (2005). Strategic disclosure of risky prospects: A laboratory experiment. The Accounting Review 80(3), 825-846.

Hölmstrom, B. (1979). Moral hazard and observability. The Bell Journal of Economics 10(1), 74-91.

Hölmstrom, B., and Milgrom, P. (1991). Multitask principal-agent analyses: Incentive contracts, asset ownership, and job design. Journal of Law, Economics, \& Organization 7, 24-52.

Hope, O. K. (2003). Accounting policy disclosures and analysts' forecasts. Contemporary Accounting Research, 20(2), 295-321.

Hopkins, M. (2003). The business case for CSR: where are we? International Journal of Business Performance Management, 5(2-3), 125-140.

Höppe, F., \& Moers, F. (2011). The choice of different types of subjectivity in CEO annual bonus contracts. The Accounting Review, 86(6), 2023-2046.

Hwang, Y., Erkens, D. H., \& Evans III, J. H. (2009). Knowledge sharing and incentive design in production environments: Theory and evidence. The Accounting Review, 84(4), 1145-1170.

Husted, B. W., \& Allen, D. B. (2000). Is it ethical to use ethics as strategy? In Business Challenging Business Ethics: New Instruments for Coping with Diversity in International Business (pp. 21-31). Springer, Dordrecht.

Indjejikian, R. J., and Matějka, M. (2011). Accounting decentralization and performance evaluation of business unit managers. The Accounting Review 87(1), 261-290.

Ingram, R. W., and Frazier, K. B. (1980). Environmental performance and corporate disclosure. Journal of Accounting Research, 18(2), 614-622.

Ioannou, I., Li, S. X., \&Serafeim, G. (2016). The effect of target difficulty on target completion: the case of reducing carbon emissions. The Accounting Review, 91(5), 1467-1492.

Ittner, C. D., \& Larcker, D. F. (1998). Are nonfinancial measures leading indicators of financial performance? An analysis of customer satisfaction. Journal of Accounting Research, 36, 1-35. 
Jiang, K., Lepak, D. P., Han, K., Hong, Y., Kim, A., \& Winkler, A. L. (2012). Clarifying the construct of human resource systems: Relating human resource management to employee performance. Human Resource Management Review, 22(2), 73-85.

Jin, L. (2002). CEO compensation, diversification, and incentives. Journal of Financial Economics, 66(1), 29-63.

Kalil, A., \& Ziol-Guest, K. M. (2008). Parental employment circumstances and children's academic progress. Social Science Research, 37(2), 500-515.

Kama, I. (2009). On the market reaction to revenue and earnings surprises. Journal of Business Finance \& Accounting, 36(1-2), 31-50.

Kama, I., \& Weiss, D. (2013). Do earnings targets and managerial incentives affect sticky costs? Journal of Accounting Research, 51(1), 201-224.

Kaplan, R. S., \& Norton, D. P. (1996). Linking the balanced scorecard to strategy. California Management Review, 39(1), 53-79.

Khan, M., Serafeim, G., \& Yoon, A. (2016). Corporate sustainability: First evidence on materiality. The Accounting Review, 91(6), 1697-1724.

Kim, Y., Park, M. S., \& Wier, B. (2012). Is earnings quality associated with corporate social responsibility? The Accounting Review, 87(3), 761-796.

Kitzmueller, M., \& Shimshack, J. (2012). Economic perspectives on corporate social responsibility. Journal of Economic Literature, 50(1), 51-84.

Kothari, S. P., Leone, A. J., and Wasley, C. E. (2005). Performance matched discretionary accrual measures. Journal of Accounting and Economics, 39(1), 163-197.

KPMG (2013), The KPMG Survey of Corporate Responsibility Reporting 2013

KPMG, Currents of Change, The KPMG Survey of Corporate Responsibility Reporting 2015.https://home.kpmg.com/content/dam/kpmg/pdf/2015/12/KPMG-survey-of-CRreporting-2015.pdf

KPMG, T. "KPMG International survey of corporate responsibility reporting 2011." Amsterdam, The Netherlands: KPMG (2011).

Labro, E. 2015. Hobby Horses Ridden. Journal of Management Accounting Research, 27(1), 133-138.

Lado, A. A., \& Wilson, M. C. (1994). Human resource systems and sustained competitive advantage: A competency-based perspective. Academy of Management Review, 19(4), 699-727.

Lambert, R. A. (2001). Contracting theory and accounting. Journal of Accounting and Economics, 32(1), 3-87.

Lang, M., and Lundholm, R. (1993). Cross-sectional determinants of analyst ratings of corporate disclosures. Journal of Accounting Research, 31(2), 246-271.

Larcker, D. F., Richardson, S. A., and Tuna, I. (2007). Corporate governance, accounting outcomes, and organizational performance. The Accounting Review, 82(4), 963-1008.

Laufer, W. S. (2003). Social accountability and corporate greenwashing. Journal of Business Ethics, 43(3), 253-261.

Leroy, H., Palanski, M. E., \& Simons, T. (2012). Authentic leadership and behavioral integrity as drivers of follower commitment and performance. Journal of Business Ethics, 107(3), 255-264.

Li, F. (2008). Annual report readability, current earnings, and earnings persistence. Journal of Accounting and Economics, 45(2), 221-247.

Lipton, M., and J. W. Lorsch. 1992. A modest proposal for improved corporate governance. The Business Lawyer, 48 (1): 59-77.

Loughran, T., and McDonald, B. (2014). Measuring readability in financial disclosures. The Journal of Finance, 69(4), 1643-1671. 
Lydenberg, S. D. (2002). Envisioning socially responsible investing. Domini Social Investments.

Lys, T., Naughton, J. P., and Wang, C. (2015). Signaling through corporate accountability reporting. Journal of Accounting and Economics, 60(1), 56-72.

Mahoney, L. S., and Thorne, L. (2005). Corporate social responsibility and long-term compensation: Evidence from Canada. Journal of Business Ethics, 57(3), 241-253.

Maignan, I., Ferrell, O. C., and Hult, G. T. M. (1999). Corporate citizenship: cultural antecedents and business benefits. Journal of the Academy of Marketing Science, 27(4), 455-469.

Margolis, J. D., \& Walsh, J. P. (2003). Misery loves companies: Rethinking social initiatives by business. Administrative Science Quarterly, 48(2), 268-305.

McDonald, M. L., Westphal, J. D., \& Graebner, M. E. (2008). What do they know? The effects of outside director acquisition experience on firm acquisition performance. Strategic Management Journal, 29(11), 1155-1177.

McGuire, J., Dow, S., and Argheyd, K. (2003). CEO incentives and corporate social performance. Journal of Business Ethics, 45(4), 341-359

McKee-Ryan, F., Song, Z., Wanberg, C. R., \& Kinicki, A. J. (2005). Psychological and physical well-being during unemployment: a meta-analytic study. Journal of applied psychology, 90(1), 53.

McWilliams, A., and Siegel, D. (2001). Corporate social responsibility: A theory of the firm perspective. Academy of Management Review, 26(1), 117-127.

Merchant, K., and Van der Stede, W. (2012). Management control system: Performance measurement evaluation and incentives, Prentice Hall.

Meyer, J. W., \& Rowan, B. (1977). Institutionalized organizations: Formal structure as myth and ceremony. American Journal of Sociology, 83(2), 340-363.

Meyer, M., Milgrom, P., and Roberts, J. (1992). Organizational prospects, influence costs, and ownership changes. Journal of Economics \& Management Strategy, 1(1), 9-35.

Milgrom, P. and Roberts, J. (1995). Complementarities and fit strategy, structure, and organizational change in manufacturing. Journal of Accounting and Economics, 19(23), 179-208.

Murillo-Luna, J. L., Garcés-Ayerbe, C., \& Rivera-Torres, P. (2008). Why do patterns of environmental response differ? A stakeholders' pressure approach. Strategic Management Journal, 29(11), 1225-1240.

Murphy, R. O., \& Ackermann, K. A. (2014). Social value orientation: Theoretical and measurement issues in the study of social preferences. Personality and Social Psychology Review, 18(1), 13-41.

Nagar, V., \&Rajan, M. V. (2001). The revenue implications of financial and operational measures of product quality. The Accounting Review, 76(4), 495-513.

Noreen, E. (1991). Conditions under which activity-based cost systems provide relevant costs. Journal of Management Accounting Research, 3(4), 159-168.

Norton, E. C., Wang, H., \& Ai, C. (2004). Computing interaction effects and standard errors in logit and probit models. Stata Journal, 4, 154-167.

O’Keefe, D. J (1990) Persuasion Theory and Research. Sage, Newbury Park, CA.

Perrini, F., Russo, A., \& Tencati, A. (2007). CSR strategies of SMEs and large firms. Evidence from Italy. Journal of Business Ethics, 74(3), 285-300.

Pfeffer, J. (2010). Building sustainable organizations: The human factor. The Academy of Management Perspectives, 24(1), 34-45.

Rees, L., \& Sivaramakrishnan, K. (2007). The effect of meeting or beating revenue forecasts on the association between quarterly returns and earnings forecast errors. Contemporary Accounting Research, 24(1), 259-290. 
Rege, M., Telle, K., \& Votruba, M. (2011). Parental job loss and children's school performance. The Review of Economic Studies, 78(4), 1462-1489.

Richardson, S., Teoh, S. H., and Wysocki, P. D. (2004). The walk-down to beatable analyst forecasts: The role of equity issuance and insider trading incentives. Contemporary Accounting Research, 21(4), 885-924.

Rickard, G. 2014. Setting yourself up for failure? The challenges of environmental target setting. Carbon Trust (October 20)

Rosenbaum, P. R., \& Rubin, D. B. (1983). The central role of the propensity score in observational studies for causal effects. Biometrika, 70(1), 41-55.

Rousseau, D. M., \& McLean Parks, J. (1993). The contracts of individuals and organizations. Research in Organizational Behavior, 15, 1-1.

Roychowdhury, S. (2006). Earnings management through real activities manipulation. Journal of Accounting and Economics, 42(3), 335-370.

Ruhm, C. J. (1991). Are workers permanently scarred by job displacements? The American Economic Review, 81(1), 319-324.

Russo, A., \& Perrini, F. (2010). Investigating stakeholder theory and social capital: CSR in large firms and SMEs. Journal of Business Ethics, 91(2), 207-221.

Russo, M. V., \& Harrison, N. S. (2005). Organizational design and environmental performance: Clues from the electronics industry. Academy of Management Journal, 48(4), 582-593.

Samuelson, P. A. (1938). A note on the pure theory of consumer's behaviour. Economica, 5(17), 61-71.

Schabus, M. (2018). Do Director Networks Help Managers Plan and Forecast Better?

Schoorman, F. D., Bazerman, M. H., \& Atkin, R. S. (1981). Interlocking directorates: A Strategy for reducing environmental uncertainty. Academy of Management Review, 6(2), 243-251.

Scalet, S., \& Kelly, T. F. (2010). CSR rating agencies: What is their global impact? Journal of Business Ethics, 94(1), 69-88.

Schuler, R. S., \& Jackson, S. E. (1987). Linking competitive strategies with human resource management practices. The Academy of Management Executive, 1(3), 207-219.

Servaes, H., \& Tamayo, A. (2013). The impact of corporate social responsibility on firm value: The role of customer awareness. Management Science, 59(5), 1045-1061.

Sethi, S. P. (1975). Dimensions of corporate social performance: An analytical framework. California management review, 17(3), 58-64.

Sharfman, M. (1996). The construct validity of the Kinder, Lydenberg \& Domini social performance ratings data. Journal of Business Ethics, 15(3), 287-296.

Sharma, S. (2000). Managerial interpretations and organizational context as predictors of corporate choice of environmental strategy. Academy of Management journal, 43(4), 681-697.

Sharratt, D., Brigham, B. H., and Brigham, M. (2007). The utility of social obligations in the UK energy industry. Journal of Management Studies, 44(8), 1503-1522.

Shen, J., \& Benson, J. (2016). When CSR is a social norm how socially responsible human resource management affects employee work behavior. Journal of Management, 42(6), 1723-1746.

Shipman, J. E., Q. T. Swanquist, and R. L. Whited. 2017. Propensity Score Matching in Accounting Research. The Accounting Review, 92 (1),213-244.

Shumway, T. (2001). Forecasting bankruptcy more accurately: A simple hazard model*. The Journal of Business, 74(1), 101-124.

Simnett, R., Vanstraelen, A., \& Chua, W. F. (2009). Assurance on sustainability reports: An international comparison. The Accounting Review, 84(3), 937-967. 
Simons, T. (2002). Behavioral integrity: The perceived alignment between managers' words and deeds as a research focus. Organization Science, 13(1), 18-35.

Singer, T. (2012). Director Notes.

Soderstrom, K. M., Soderstrom, N. S., \& Stewart, C. R. (2017). Sustainability/CSR research in management accounting: A review of the literature. In Advances in Management Accounting 28, (pp. 59-85). Emerald Publishing Limited.

Van Marrewijk, M. (2003) Concepts and definitions of CSR and corporate sustainability: between agency and communion. Journal of Business Ethics 44: 95-105.

Varian, Hal R. (1992). Microeconomic Analysis (Third ed.). New York: Norton. ISBN 0393-95735-7. Section 8.7

Washington, M., \&Ventresca, M. J. (2004). How organizations change: The role of institutional support mechanisms in the incorporation of higher education visibility strategies, 1874-1995. Organization Science, 15(1), 82-97.

Weaver, G. R., Trevino, L. K., \& Cochran, P. L. (1999). Integrated and decoupled corporate social performance: Management commitments, external pressures, and corporate ethics practices. Academy of Management Journal 42(5), 539-552.

Welford, R.: 2005, 'Corporate Social Responsibility in Europe and Asia: Critical Elements and Best Practice', Corporate Social Review 13, 31-47.

Westphal, J. D., \& Zajac, E. J. (1995). Who shall govern? CEO/board power, demographic similarity, and new director selection. Administrative science quarterly, 40(1), 60-83.

Winkelmann, L., \& Winkelmann, R. (1998). Why are the unemployed so unhappy? Evidence from panel data. Economica, 65(257), 1-15.

Wood, D. J., and Jones, R. E. (1995). Stakeholder mismatching: A theoretical problem in empirical research on corporate social performance. The International Journal of Organizational Analysis 3(3), 229-267.

Wright, P., Ferris, S. P., Hiller, J. S., \& Kroll, M. (1995). Competitiveness through management of diversity: Effects on stock price valuation. Academy of Management Journal, 38(1), 272-287.

Yuan, W., Bao, Y., \& Verbeke, A. (2011). Integrating CSR initiatives in business: An organizing framework. Journal of Business Ethics 101(1), 75-92.

Zang, A. Y. (2011). Evidence on the trade-off between real activities manipulation and accrual-based earnings management. The Accounting Review, 87(2), 675-703. 

Appendices 



\section{Appendix A: Variable Definitions}

\begin{tabular}{|c|c|}
\hline Variable & Definition \\
\hline Employee & The actual number of people employed by the company; \\
\hline \multirow[t]{2}{*}{ Changes in employee } & (Employee Et $\left._{i t}\right)$ \\
\hline & $\log \left(\overline{\text { Employee }_{i t-1}}\right)$ \\
\hline \multirow[t]{4}{*}{ KLD_Ratings } & Measured as an overall score over five KLD rating dimensions: \\
\hline & Environment, Community, Employee Relation, Diversity and \\
\hline & Product. $K L D \_R A T I N G$ equals the total strengths minus total \\
\hline & concerns over these five dimensions. It captures the overall \\
\hline \multirow{3}{*}{ CSR } & This variable is obtained by transferring the discrete random \\
\hline & variable KLD ratings into a continuous variable whose \\
\hline & distribution follows a Cumulative Distribution Function (CDF). \\
\hline \multirow[t]{4}{*}{$E M P$} & This variable is obtained by transferring the discrete random \\
\hline & variable KLD ratings over employee dimensions into a \\
\hline & continuous variable whose distribution follows a Cumulative \\
\hline & Distribution Function (CDF). \\
\hline DCSR & $\begin{array}{l}\text { Dummy variable that is equal to one when CSR score of } \\
\text { previous year is higher than or equal to zero, and zero otherwise. }\end{array}$ \\
\hline \multirow[t]{2}{*}{ Changes in sales } & $\log \left(\frac{\text { Sales }_{i t}}{\text { Sd }^{2}}\right)$ \\
\hline & Indicator $\left(\right.$ sales $\left._{i t-1}\right)$ \\
\hline Decrease & $\begin{array}{l}\text { Indicator variable equal to one when sales revenue in year } t \text { is } \\
\text { lower than that in year } t-1 \text {, and zero otherwise }\end{array}$ \\
\hline \multirow[t]{2}{*}{ D_CSR_REPORTING } & Indicator variable that equals one if a firm issues a stand-alone \\
\hline & CSR report for fiscal year 2013, and zero otherwise. \\
\hline \multirow[t]{2}{*}{ D_CSRPM } & Indicator variable that equals one if a firm uses CSR-based \\
\hline & $\begin{array}{l}\text { performance measures in its CEO incentive contract for fiscal } \\
\text { year } 2013 \text {, and zero otherwise. }\end{array}$ \\
\hline \multirow[t]{2}{*}{ RATE } & Total dimensions of CSR-based performance measures divided \\
\hline & $\begin{array}{l}\text { by total number of performance measures used in CEO incentive } \\
\text { contracts. }\end{array}$ \\
\hline LnWords & Natural logarithm of total number of words of CSR report. \\
\hline LnPage & Natural logarithm of total number of pages of CSR report. \\
\hline \multirow[t]{8}{*}{ CSRPM_SCOPE } & Following GRI criteria, we identify five dimensions of CSR \\
\hline & activity: Environment, society, employee, human rights, and \\
\hline & product. We capture whether there are performance measures on \\
\hline & each of these five dimensions. If yes, the corresponding \\
\hline & dimension is set to one, and zero otherwise. We sum the values \\
\hline & over the five dimensions to create CSRPM_SCOPE, which \\
\hline & captures how many dimensions of CSR-based performance \\
\hline & measures are used in CEO contracts. \\
\hline HIHI & Indicator variable that equals one if both $D \_C S R P M$ and \\
\hline
\end{tabular}


$D \_C S R \_R E P O R T I N G$ is one, and zero otherwise.

\begin{tabular}{cl}
\hline HIHI25_PAGES_SCOPE & D_CSR_REPORTING is one, and zero otherwise. \\
& $\begin{array}{l}\text { Indicator variable that equals one if both CSRPM_SCOPE and } \\
\text { LnPage are in the top quartile, and zero otherwise }\end{array}$ \\
\hline HIHI25_WORDS_SCOPE & $\begin{array}{l}\text { Indicator variable that equals one if both CSRPM_SCOPE and } \\
\text { LnWords are in the top quartile, and zero otherwise }\end{array}$ \\
\hline HIHI25_WORD_IMP & $\begin{array}{l}\text { Indicator variable that equals one if both RATE and LnWords are } \\
\text { in the top quartile, and zero otherwise }\end{array}$ \\
\hline HIHI25_PAGE_IMP & $\begin{array}{l}\text { Indicator variable that equals one if both RATE and LnPage are } \\
\text { in the top quartile, and zero otherwise }\end{array}$ \\
\hline HIGH-SCRUTINY & $\begin{array}{l}\text { Indicator variable that equals one if a firm is in the Mining and } \\
\text { Construction (SIC 10-17) or Transportation and Public Utilities } \\
\text { (SIC 40-49) industries, and zero otherwise. }\end{array}$ \\
\hline
\end{tabular}

\section{Control variables}

\begin{tabular}{|c|c|}
\hline Average_Sales_Growth & $\log \left[\left(\frac{\text { Sales }_{i t}}{\text { Sales }_{i t-1}}+\frac{\text { Sales }_{i t-1}}{\text { Sales }_{i t-2}}+\frac{\text { Sales }_{i t-2}}{\text { Sales }_{i t-3}}\right) / 3\right]$ \\
\hline Success_D & $\begin{array}{l}\text { Indicator variable equal to one when there is a decrease in sales } \\
\text { in previous year, and zero otherwise }\end{array}$ \\
\hline$R O A$ & Net income scaled by total assets \\
\hline$\triangle R E C T$ & $\begin{array}{l}\text { Changes in account receivables in two subsequent years scaled } \\
\text { by total sales }\end{array}$ \\
\hline Asset_Intensity & Total assets/ sales \\
\hline Employee_Intensity & Total employee number/ total assets \\
\hline$F C F$ & $\begin{array}{l}\text { [Cash flow from operating-common and preferred dividends]/ } \\
\text { assets total }\end{array}$ \\
\hline$A B N \_A C C$ & Performance-adjusted abnormal accrual ((Kothari et al. 2005) \\
\hline Change_CEO & Indicator equals to 1 when the $\mathrm{CEO}$ changes and 0 otherwise \\
\hline$\triangle G N P$ & $\begin{array}{l}\text { Economic growth is calculated as the logarithm of GNP annual } \\
\text { increase ratio }\end{array}$ \\
\hline LogASSETS & $\log$ (total assets). \\
\hline DEBT_TO_EQUITY & Total debt/total common equity. \\
\hline$M B R$ & Total market value/ total value of book equity. \\
\hline FIN & $\begin{array}{l}\text { Following Richardson et al. (2004), financing activity is } \\
\text { measured as the sale of common and preferred shares minus the } \\
\text { purchase of common and preferred shares, plus long-term debt } \\
\text { issuance and minus long-term debt reduction, scaled by total } \\
\text { assets at the beginning of the year. }\end{array}$ \\
\hline$R D$ & R\&D expenses scaled by total sales. \\
\hline$A D$ & Advertising expenses scaled by total sales. \\
\hline MONITORING & $\begin{array}{l}\text { Factor score that includes board size, percentage of busy } \\
\text { outsiders (directors with three or more directorships) and } \\
\text { percentage of busy insiders (directors with two or more } \\
\text { directorships). }\end{array}$ \\
\hline \%INDEPENDENT & Percentage of independent board members. \\
\hline
\end{tabular}




\begin{tabular}{|c|c|}
\hline CEO_DUALITY & $\begin{array}{l}\text { An indicator variable that equals one if the CEO serves as the } \\
\text { chairman of the board of directors, and zero otherwise. }\end{array}$ \\
\hline NOISE & $\begin{array}{l}\text { Measured as the time-series variability in median 3-digit } \\
\text { industry accounting returns over five years prior to the proxy } \\
\text { data (Hoppe and Moers 2011). }\end{array}$ \\
\hline UNPREDICT & $\begin{array}{l}\text { We first regress stock holding period monthly returns on CRSP } \\
\text { value-weighted index over the prior } 12 \text { to } 60 \text { months. Next, } \\
\text { UNPREDICT is calculated as the standard deviation of the } \\
\text { residuals (Hoppe and Moers 2011). }\end{array}$ \\
\hline CSRPM_ADOPT & $\begin{array}{l}\text { A dummy variable that captures whether the focal firm adopts } \\
\text { CSR performance measures or not. }\end{array}$ \\
\hline$C S R \_E X P$ & $\begin{array}{l}\text { equals } 1 \text { if a director had experience of using CSR performance } \\
\text { measures in executive compensation contract in another firm in } \\
\text { year } t \text {, otherwise } 0\end{array}$ \\
\hline HIGH & $\begin{array}{l}\text { An indicator that is equal to one if a firm's environmental } \\
\text { unpredictability is above or equal to the median of the full } \\
\text { sample, and zero otherwise. }\end{array}$ \\
\hline SASB_DIMENSIONS & $\begin{array}{l}\text { The number of dimensions identified by the SASB Map as } \\
\text { material for firms in different industries. }\end{array}$ \\
\hline DISPERSE & $\begin{array}{l}\text { An indicator that is equal to one if the number of a firm's } \\
\text { material CSR dimensions is above or equal to the median of my } \\
\text { sample, and is zero otherwise. }\end{array}$ \\
\hline LEVERAGE & Total debt divided by total assets. \\
\hline$\% I N D E P E N D E N T$ & Percentage of independent directors \\
\hline CEO_DUALITY & CEO serves as both the CEO and chairman of the board \\
\hline INDUSTRY_USER & $\begin{array}{l}\text { Number of firms in 2-digit industry that have already used CSR } \\
\text { performance measures. }\end{array}$ \\
\hline FIN & $\begin{array}{l}\text { (Sales of common and preferred shares- the purchase of common } \\
\text { and preferred shares +long-term debt issuance- long-term debt } \\
\text { reduction)/total assets of the beginning of the year }\end{array}$ \\
\hline CONSULT_DUMMY & $\begin{array}{l}\text { An indicator variable that equals } 1 \text { if the firm uses a } \\
\text { compensation consultant, otherwise } 0 \text {. }\end{array}$ \\
\hline INTENSE_EXP & the number of total experienced directors scaled by board size \\
\hline CSRPM_DIMENSIONS & $\begin{array}{l}\text { The total number of CSR performance measure dimensions } \\
\text { disclosed in an adopter's proxy statement. }\end{array}$ \\
\hline$E X \_L I N K \_A D O P T$ & $\begin{array}{l}\text { An indicator that captures if a firm explicit discloses a link } \\
\text { between CSR performance and executive compensation }\end{array}$ \\
\hline INTENSITY & $\begin{array}{l}\text { The relative weights attached on CSR performance measures, } \\
\text { which is equal to the total number of dimensions of CSR } \\
\text { performance measures adopted divided by the total number of } \\
\text { performance measures in executives' incentive contracts. }\end{array}$ \\
\hline SUBSTANTIVENESS & $\begin{array}{l}\text { A factor score that includes EX_LINK, CSRPM_DIMENSIONS } \\
\text { and INTENSITY }\end{array}$ \\
\hline
\end{tabular}





\section{Appendix B}

\section{Examples of CSR-based Performance Measures in CEO Contracts:} Nobel Energy Inc.

Our short-term incentive plan ("STIP") is available to all of our full-time employees, including our Named Executive Officers. The target STIP bonus for an employee is the employee's base salary at year-end multiplied by the percentage factor assigned to the employee's salary classification. The target bonus percentage factors for our Named Executive Officers for 2013 were as follows:......CEO (110\%). Our Compensation Committee considered the Company's 2013 results against targets in the following four areas in arriving at the quantitative nondiscretionary STIP component: Production, Relative Controllable Unit Costs, Discretionary Cash Flow, and Relative Total Shareholder Return (each 15\%). The Compensation Committee also considered the Company's 2013 results in the following operational financial and other areas in arriving at the qualitative discretionary STIP component (40\%): Additions to proven oil and natural gas reserves, Safety and environmental performance, Financial controls, Exploration success, Strategic initiatives, Divestiture program and Relative total stockholder return.

\section{Northrop Grumman Inc.}

For the annual incentive plan, we use a mix of financial and non-financial metrics to measure our performance. The following financial metrics were selected for 2013: Pension-adjusted OM Rate, Free Cash Flow Conversion, Awards (Book-to-bill), and Pension-adjusted Net Income. In addition to the financial goals, non-financial goals have been established to align our objectives with customers, shareholders and employees. Performance against nonfinancial metrics can result only in downward adjustment to the financial metric score. The following non-financial metrics were selected: Customer Satisfaction, engagement, diversity, safety, quality environmental sustainability. (Quality: measured using program-specific objectives within each of our sectors, including defect rates, process quality, supplier quality, planning quality and other appropriate criteria for program type and phase. Diversity: measured in terms of improving representation of females and People of Color in mid-level and senior-level management positions with respect to peer and broader benchmarks. Safety: measured by Total Case Rate, defined as the number of Occupational Safety \& Health Administrator recordable injuries as well as by Lost Work Day Rate associated with those injuries. Environmental Sustainability: measured in terms of the reduction, in metric tons per sales, of greenhouse gas emissions, and reduction of solid waste and water utilization.

\section{PG\&E Corp.}

For 2013, the Committee adopted a STIP structure that enhanced PG\&E Corporation's and the Utility's focus on improving public and customer safety and customer satisfaction. Achievement of safety goals remained at a 40 percent weighting. The extent to which goals relating to customer satisfaction were met had a 35 percent weighting, an increase from 30 percent in the prior year, and the achievement of corporate financial performance targets represented 25 percent of the total STIP score, a decrease from 30 percent in the prior year.

The safety component was structured to provide a strong focus on the safety of 
employees, customers, and communities. It was made up of four subcomponents: (1) Nuclear Operations Safety, (2) Electric Operations Safety, (3) Gas Operations Safety, and (4) Employee Safety. The customer satisfaction measures were designed to incent employees to be more responsive to our customers' needs. As in prior years, corporate financial performance was measured by PG\&E Corporation's actual earnings from operations compared to budget.

\section{Philip Morris International Inc.}

Incentive Compensation (IC) Award: Performance is assessed against annual operating targets, progress towards strategic initiatives and the executive's individual performance. With regard to its quantitative assessment, the following table shows the performance target ranges pre-established by the Committee for 2013 incentive compensation awards and the Company's results. The percentages indicated for cigarette volume, net revenues, adjusted OCI and adjusted diluted EPS represent targeted and actual growth versus 2012 results.

In addition to these six quantitative performance measures, the Committee also evaluated our performance qualitatively on the following key strategic initiatives:.......our efforts and results in improving our health and safety record, with a record improvement in our lost-time injury rate; our continued efforts and results in improving our environmental record, particularly noting that we were one of only five Global 500Consumer Staples companies to qualify for the Carbon Performance Leadership Index and that our score increased six points over 2012 to 97\%, the highest rating in the tobacco sector; our continued progress in addressing child and migrant labor issues associated with tobacco farming;our continued progress in nurturing and developing our talent pool and future leadership and increasing our diversity; and our robust control, compliance and integrity programs.

\section{QEP Resources Inc.}

Our AIP is based on key one-year financial and operational metrics, the achievement of strategic goals that drive long-term shareholder value, as well as individual performance. For 2013, AIP-Adjusted EBITDA and strategic goals remained key metrics, together comprising $70 \%$ of the total plan results (each at $35 \%$ weighting). Strategic Objectives achievement (35\%) overall assessment: Form an MLP for Wyoming and North Dakota gathering assets; Grow crude oil reserves and production at reasonable and profitable finding and development costs; optimize corporate financial health; replace corporate system to enable timely and robust financial reporting; complete accounting group restructuring and ensure all processes are accurate and timely; work safety and respect the environment. 


\section{Appendix C: Valorization-addendum}

Corporate social responsibility has attracted a growing attention from various stakeholder groups, including investors, customers, top executives of firms as well as regulators of industries. As mentioned by the latest KPMG Survey of Corporate Social Responsibility Reporting, there are an increasing number of firms that voluntarily disclose their CSR-related strategies in stand-alone CSR reports. CSR issues covered by these reports varies from concerns of environmental protection to the wellbeing of labors, and from an emphasis of customer health and safety to a welfare creation of broader community and civil society. While increasing CSR disclosure improves transparency of firms' long-term oriented strategies, investors often hold a skeptical opinion towards such unregulated information. More importantly, it seems difficult for investors and other stakeholders outside a firm to understand whether and how firms integrate CSR initiatives in decision making.

The three studies in this dissertation investigate firms' internal choices of CSR related strategies, i.e. employee dismissal decision and CSR contracting in executives' annual incentives. As indicated by previous chapters, for a firm to successfully implements its CSR orientation, merely focusing on CSR-related disclosure or simply viewing CSR issues isolate from business operations might not be sufficient. It is equally important for the firm to integrate its CSR orientation when making decisions. However, despite numerous papers on CSR topic, most of prior research focuses on CSR disclosure or CSR assurance (e.g. Dhaliwal et al. 2011; Simnett et al. 2009). Therefore, it is very hard for outsiders such as practitioners, regulators and investors to understand whether firms' internal practice is aligned with their CSR orientation. In this dissertation, I focus on two important internal choices, employee dismissal and CSR contracting, and find that in general, firms' external disclosure is consistent with internal choices. Specifically, when firms are under pressure of meeting earnings benchmarks, firms with stronger claimed CSR orientation are less likely to fire employees to boost profits. In addition, rather than treating CSR disclosure and CSR contracting separately, I show that firms are more likely to consider these two choices from a systematically consistent perspective. The findings of my studies provide important insights of what firms are doing with respect to internal and external CSR decisions. Recognizing patterns of firms' CSR-related choices can not only depict a more complete picture to wide stakeholders outside the firm, but also bring a better understanding of a firm's CSR impact.

Further, with increasing recognition of the importance of CSR, firms are suggested to incorporate CSR performance measures in their executives' annual incentive contracts. As the saying goes, "what gets measured gets done". By using CSR performance measures in CEO compensation contracts, CEOs are expected to allocate resources and efforts to improve performance on CSR dimensions. However, as indicated in previous chapters, the design of CSR contracting may impose distinct challenges on the board. I show that firms may rely on directors' experience of using CSR performance measures in other firms to make the decision of adopting CSR contracting. Moreover, this reliance becomes stronger when firms are in situations where they demand more information related to CSR contracting. These findings have important practical implications on several aspects: First, the practice of CSR contracting can be influenced by firms' financial environment and stakeholder diversity. In other words, firms with different contexts may have different cost-benefit trade-offs of CSR 
contracting. Simply adopting CSR performance measures without analysing firms' contextual characteristics may lead to symbolic adoption. Second, while firms are encouraged by investors, regulators and active NGOs to integrate CSR criteria into executive performance evaluation, creating a better information environment regarding how pioneer adopters cope with uncertainties associated with CSR contracting may enhance the effectiveness of CSR contracting, for instance, increasing firms' awareness of potential challenges and thus mitigating these issues.

Furthermore, the findings of my dissertation may help firms to improve the efficiency of CSR-related decisions. Specifically, as indicated in previous chapters, I find that firms' CSR disclosure and CSR contracting complement each other, jointly serving the purpose of sending a credible signal of CSR strategies. I argue that the costs and benefits of one CSRrelated choice such as disclosure may influence the costs and benefits of another such as CSR contracting. Designing CSR-related strategies systematically may help firms simultaneously respond to inside and outside stakeholders and thus enhance legitimacy with respect to CSR.

To sum up, the three studies of my dissertation respond to the call of investigating the integration of CSR-related choices in firms' decision. Overall, my findings can improve the understanding of the consequences and interrelationship of firms' internal and external CSR decisions. My studies have direct practical implications for firms, investors and regulators. By publishing the findings in academic and practitioner oriented journals or by presenting the findings at various workshops, this dissertation can provide a more complete picture of firms' CSR-related decisions to both academics and practitioners, and improve firms' effectiveness of designing CSR-related strategies. 


\section{Curriculum Vitae}

Lu Yang was born on October 7th, 1988 in the beautiful city of Qingdao, China. From 20072011 she studied to obtain her undergraduate degree in Finance at the School of Economics, Shandong University (China). She then continued to pursue her Research Master degree in Finance in the same university from 2011 to 2013. During this period, she went to Tilburg University in the Netherlands to obtain both an MSc in Accounting and a Research Master in Accounting. In 2014, she became a Ph.D. Candidate at Maastricht University in the Department of Accounting and Information Management, focusing on research in Management Accounting. During her doctoral studies, she has been a visiting scholar at the University of Melbourne (Australia). Her work has been presented at various accounting conferences such as the midyear Meeting of the Management Accounting Section of the AAA, the European Accounting Association Doctoral Colloquium and workshops at the Maastricht University, and Accounting and Finance Association in Australia and New Zealand Annual Conference, and workshops at the Maastricht University, University of Melbourne, Groningen University, Tilburg University, Tongji University, and Shanghai University of Finance and Economics, University of Western Australia and Monash University. Since July 2018, she works as a Lecturer in the Department of Accounting at Monash University, Australia. 